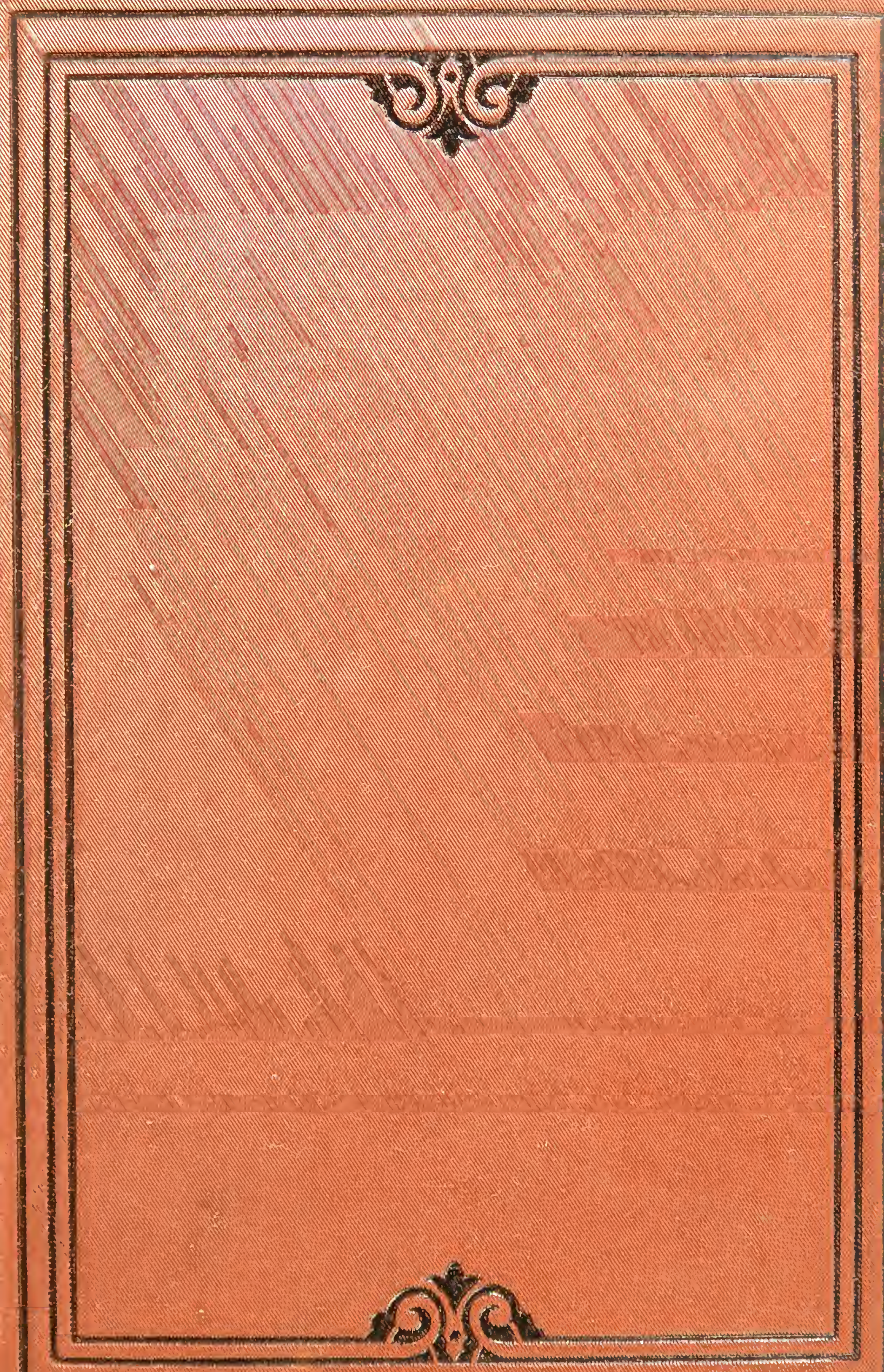



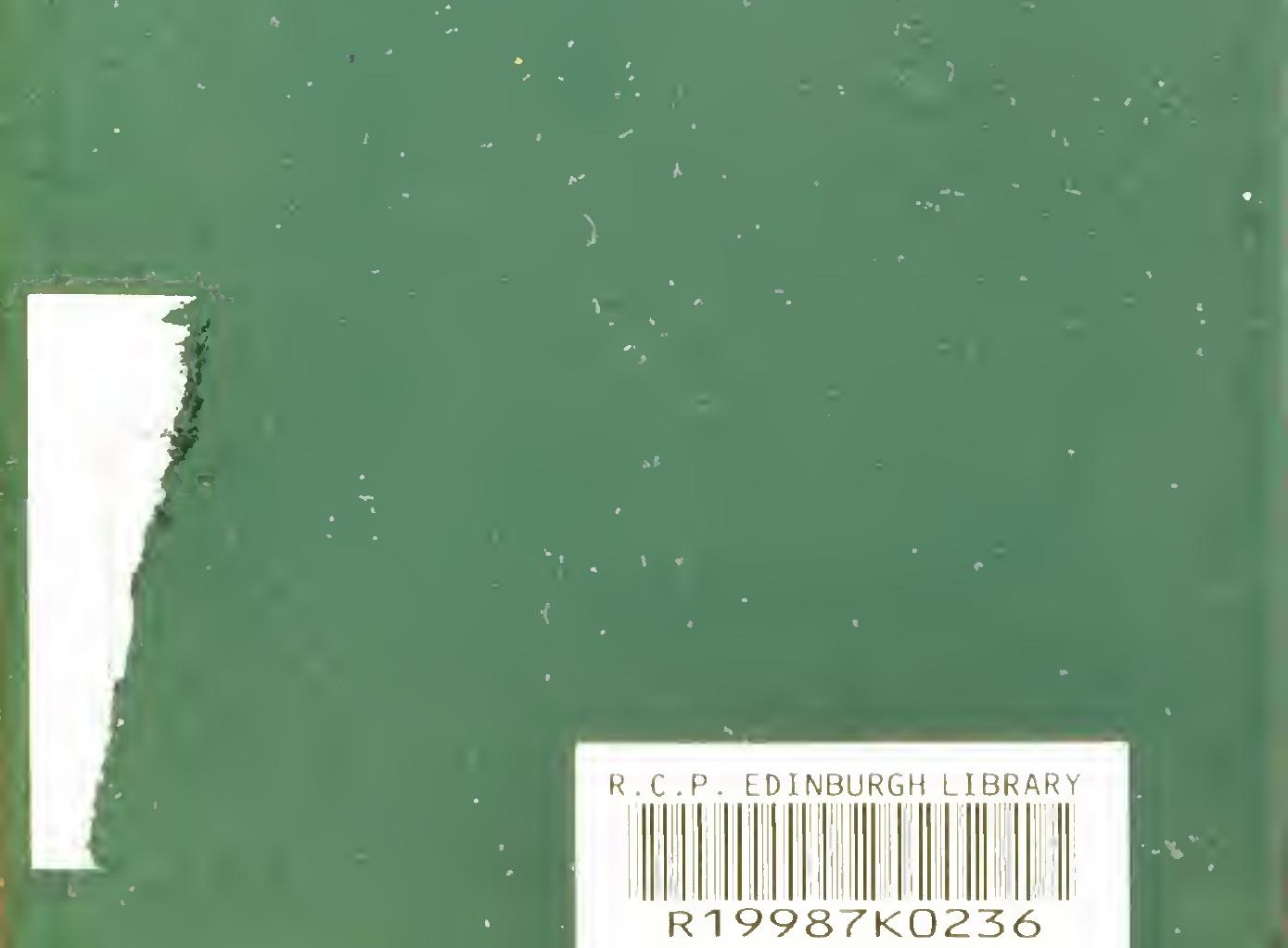

02.5 
ZOOLOGY FOR STUDENTS 
Digitized by the Internet Archive in 2015

https://archive.org/details/b21996945 


\title{
ZOOLOGY FOR STUDENTS
}

\author{
A 7Gandbook
}

By C. CARTER BLAKE, Doct. Sci.

LECTURER ON COMPARATIVE ANATOMY AND ZOOLOGY, WESTMINSTER HOSPITAL SCHOOL OF MEDICINE, AND HON. FOR. SEC. LONDON ANTHROPOLOGICAL SOCIETY

\section{$\because \cdots$ WITH A PREFACE}

BY RICHARD OWEN, C.B., F.R.S.

SURERINTENUENT OF THE NATURAL HISTORY DEPARTMENT, BRITISH MUSEUM

\section{LONDON}

DALDY, ISBISTER, \& CO.

56, LUDGATE HILL 
LONDON:

PRINTED BY VIRTUE AND CO,, CITY ROAD. 


\section{PREFACE.}

THE substance of this little work has been, year by year, delivered to the students of Comparative Anatomy at Westminster Hospital since the year 1869.

In these lectures it was my chief object to impart to others the teaching which I had received from the great master of the science in England, in order that younger comparative anatomists,

"Quasi cursores, vitaï lampada tradunt,"

might be able to transmit to a future generation, in the days of a retrograde anatomy, somewhat of the traditions of Hunter and Owen.

I have been careful to exclude from a manual intended for the student all unproven facts or problematical classifications. I trust that a reverence for what is exact, and a neglect of what is uncertain, may be duly appraised by students, to whose hands alone I commend this volume.

Having asked Professor Owen to give his imprimatur to the work, I have the Professor's permission to premise the following "Notes," taken from a "Course of Lectures" delivered in the theatre of the Royal College of Surgeons of England.

C. C. B. 
If parts of the frame of animals are taken as guides to classification according to the importance of the actions such parts subserve, the organ relating to the rise of volitional above automatic or "reflex" actions is the best guide; and the characters of that organ will denote the groups or divisions of highest value.

A condition of the nervous system is the primary and essential character of the Myelencephalous* subkingdom of animals. Vascular, respiratory, locomotive, tegumentary, developmental, structures are subordinately related to the nervous system. Such relation of the skeleton, or passive leverage of the strings of motion worked by the nerves, is indicated, e.g., by the synonym "vertebrate," also applied to the highest primary group of the Animal Kingdom.

The rise of the nerrous system, and especially of that part the actions of which are indicated by the terms "will," "intention," "choice," "craft" —in sum, "thought-necessitates corresponding rise in the rest of the framework, more especially of the systems more immediately concerned in carrying out the behests of the "will." Every vibration, or whatever may be the mode of motion, of a brain-thread occasions waste of such fibre, whether the result of the tremor be the "sensation" which, in the foxhound, follows the

* Mrelon = spinal chord or marrow ; Encephalon = brain. 
application of the lash of the whipper-in, or whether it be the "volition" which carries the yelper suddenly into the right course of the pack. Every contraction of a flesh-thread by which the will issued by the brain-thread is obeyed, is attended with waste of such muscular fibre.

When, therefore, the brain attains a larger size in proportion to the myelon and body generally, and when such increase of an important and specially vascular part of the brain is attained by folds, as, e.g., in the many-folded cerebellum of Birds, the accelerated waste of the subordinate instruments, e.g., muscles, bones, necessitates corresponding improvements in the machinery for renovation. The heart is adapted to the more vigorous and definite propulsion of the blood. The blood itself is made, by the greater number of its coloured discs, fitter for the renewal of the waste. And as the blood not only supplies the new but receives the old particles, the heart of the higher-brained class has risen in mechanical conditions to a power of circulating at one and the same "beat" pure blood to the entire body and "impure blood" to that organ of the body whose function it is to purify such blood; and this double action, without any admixture of the "arterial" and "venous" streams, also goes on more vigorously and frequently, with concomitant rapidity and perfection of the respiratory movements. 
One consequence of this correlation of brain-actions, muscle-actions, circulatory and respiratory functions, is a rise of the temperature of the body, and the degree to which it is elevated is as unintermitting as are the modes of motion occasioning it. Vertebrates with inferior brains to Birds rise and fall in temperature with their atmosphere, whether air or water, within a certain range, and they have no "wraps." But an unchanging higher temperature is associated with a non-conducting corering or garment, which in Birds consists of down and feathers, in Mammals of fur and hair. The rise in the faculty of forming ideas and enjoying sensations evokes the faculty of expression, such as is exemplified in the varied song of Birds and in the manifold cackle or vocal utterances of the poultry-yard.

The contrast which the Crocodile, highest of existing "cold-blooded" vertebrates, presents in its poor brain, mixed circulation, slow breathing, low dependent temperature, hard naked tegument, habitual muteness, rarely broken by hoarse monotonous bellowing, opposes its association in the same class with the bird. Eagles and Crocodiles are both, indeed, oviparous: but Spiders and Slugs also lay eggs. Man has a double occipital condyle, and so likewise has the Frog.

The warm-blooded Mammal, burrowing like the Worm in the earth, or cleaving the waters like a Fish, 
and limited to the element in which such mode of locomotion can be practised, seems degraded to a lower scale of life than the Bird. And it is not because the Mole or the Porpoise is viviparous that it is of higher grade; for certain Sharks bring forth their young alive, and nourish them while in the womb by a temporary structure called "placenta."

The brain here becomes the taxonomist's unexceptional guide. The lowest Mammal, though its cerebrum may be as smooth as in the Bird, has definite structurebands associating together the hemispheres or halves of the cerebrum, which are wanting in Birds, and the rise of Mammals in their class is indicated by the growth of such " commissures."

The hair-clad group which shows most structural resemblances to Reptiles has the superadded or " hippocampal commissure" at its lowest stage, uniting the least proportion of the hemispheres; and as these accordingly have least departed from their loose condition in Birds, the primary group of Mammals so indicated are called "loose-brained" (Lyencephala).

When the hippocampal commissure receives added bundles to its transverse fibres, interlacing with the vertically radiating fibres of the hemispheres, and associating those in action by a commissural mass, called by the old anthropotomists "corpus callosum," overarching the cerebral hollows or "ventricles," a 
higher condition of the mammalian organization is established. But to that condition are superadded other marked steps of cerebral development. The cerebrum may retain its primitive position anterior to the cerebellum, and with such character is commonly associated few or no folds of the surface of the cerebrum. This associated condition, being here the rule, suggested the term Lissencephala (smooth-brained) for the primary group of Mammals in which a "corpus callosum," with an anterior position of the cerebrum, is the constant brain-character. The Elephant, notwithstanding its many-folded cerebrum, has that part of the brain as distinct from and in advance of the cerebellum as have the Beaver, the Mole, the Bat, and the Anteater.

On the other hand, a diminutive Monkey (IIidas) may have a cerebrum of such relative magnitude as to overlap the cerebellum, and yet show as few cerebral fissures or folds as the Beaver. But the primary group of Mammals, characterized by the gift of an enlarged cerebrum expanding the brain-case, and extending from its former anterior position backward so as to overarch more or less of the cerebellum, shows, as a rule, an augmentation of the groy vascular superficies of the cerebrum by "convolutions;" hence the term Gyrencephala (wave-brained). The orders or subdivisions of this sub-class include Mammals characterized by brain- 
functions which we recognise in results defined to be more volitional, less instinctive, than in the lowerbrained sub-classes.

The most abrupt and marked rise in brain-development is presented by Man, and again more especially in the cerebrum, outswelling vertically, laterally, antero-posteriorly, extending forward above and beyond the olfactory lobes, overarching and extending backward beyond the cerebellum, with concomitant growth of the great commissure or corpus callosum within, and multiplication and deepening of the convolutions without. Hence the term Archencephala, applied to the highest group of the highest class of the Animal Kingdom: a sub-class which vindicates the value of its taxonomical character by its numerical superiority, its cosmopolitan relations to its globe, and its mastery over all the lower forms of life on that planet.

With the predominant thinking organ has been given an instrument to do its bidding withheld from every lower Mammal, to wit, a "hand" wielded by a limb liberated from all share in station and locomotion.

Thus the Archencephala are bimanous, and the only Nammals rightly so called. The fact that Man's hand includes five digits, homologous with those of every other pentadactyle Mammal, will influence but few, and for a brief period, in the appreciation of the true 
characteristics of great and well-marked natural groups of beings.

As to the temporary deciduous structures concerned in the uterine period of mammalian life, they vary in the degree of their importance or unimportance to the whole life-period. In the Lissencephala, e.g., are found annular, discoid, cotyledonal, \&c., placentr; in the Gyrencephala are found annular, discoid, cotyledonal, diffused placentæ. The placenta in Archencephala is discoid, as in many inferior groups of warm-blooded Vivipara. Better taxonomic characters than "placental" for ordinal divisions of mammalian sub classes are afforded by limbs and teeth.

\section{RICHARD OWEN.}




\section{CONTENTS.}

Sub-KIngdon.-VERTEBRATA . . . . . . . 1

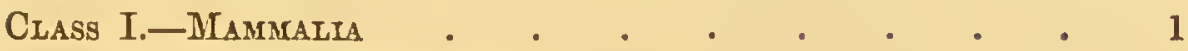

Sub-Class.-Archencephala $\quad . \quad$. ${ }^{\circ}$. $\quad$. 8

Order 1.-Bimana . . . . . . . . 10

Sub-Class.-Gyrencephala . . . . . . 14

Order 2.-Quadrumana • • • . . . • . 16

"3.-Carnivora . . . . . . . 21

$"$ 4.-Artiodactyla . . . . . . . 25

" 5.-Perissodactyla . . . . . . . . $\quad$. 32

"6.-Proboscidea . . . . . . . . . 38

"7.-Toxodontia . . . . . . . 43

" 8.-Sirenia . . . . . + . . 44

" 9.-Cetacea . . . . . . . . 47

Sub-Class.-Lissencephala $\quad . \quad$. $\quad . \quad$. $\quad 51$

Order 10.-Cheiroptera . . . . . . . 53

"11.-Insectivora . . . . . . . 56

" 12.-Rodentia . . . . . . . . 61

" 13.-Bruta . . . . . . . . . 70

Sub-Class.-Lyencephala . . . . . . . 77

Order 14.-Marsupialia . • . . . . . . . 77

"15.-Monotremata . . . . . . . 83

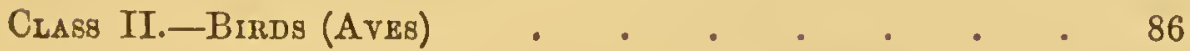

Order 1.-Raptores • . . . . . . 97

"2,-Scansores . . . . . . . 103 


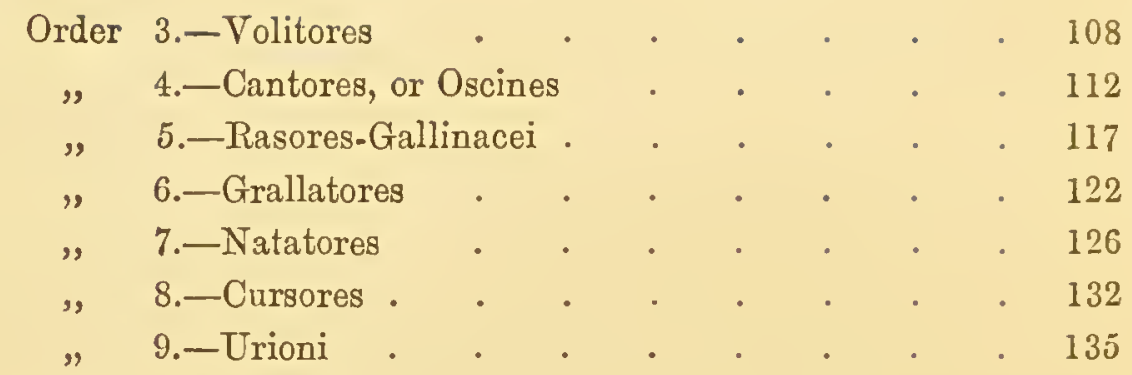

Class III.-Reptilia $\quad \cdot \quad \cdot \quad \cdot \quad \cdot \quad \cdot \quad \cdot \quad \cdot \quad \cdot 138$

Order 1.-Pterosauria (Extinct) . . . . . 111

" 2.-Dinosauria (Extinct) . . . . . . 142

" 3.-Crocudilia . . . . . . . 147

" 4.-Ophidia . . . . . . . . . 149

" 5.-Lacertilia . . . . . . . 154

" 6.-Chelonia . . . . . . . . 157

" 7.-Anomodontia (Extinct) . . . . . 161

" 8.-Sauropterygia (Extinct) . . . . . 164

" 9.-Ichthyopterygia (Extinct) . . . . 168

" 10.-Batrachia . . . . . . . 171

"11.-Labyrinthodontia (Extinct) . . . . 176

"12.-Ganocephala (Extinct) . . . . . 181

Class IV.-Fishes • . . . . . . . . 184

Order 1.-Protopteri . . . . . . . 195

" 2.-Plagiostomi . . . . . . . 198

" 3.-Holocephali . . . . . . . . 202

" 4.-Ganoidei • . • . . . . . 204

" 5.-Lophobranchii • . . . . . 208

"6.-Plectognathi . . . . . . . 210

"7.-Acanthopteri . . . . . . . 212

" 8.-Anacanthini . . . . . . . . 219

" 9.-Malacopteri . , . . . . . 222

" 10.-Cyclostomi . . . . . . . . 226

" 11.-Cirrostomi . . . . . . . 228

Sur-Kingdom.-MOLLUSCA . . • . . . . 231

Clags I.-Cephalotoda • • • • • • • . 248 
PAOR

Class II.-GASTEROPOdA • • . • . • • 243

Class III.-PTERopoda • . . . • • . . • 264

Class IV.-Lamellibranchiata

Class V.-Brachiopoda . . . . . . . . 273

Class VI.-Tunicata $•$ • • . • • • • 276

SUb-KINGdom.-ARTICULATA • • • • • • 278

Class I.-Insecta • • . • . • . • . 280

Order 1.-Aptera (Fleas and Lice) . _ . . • • . 282

" 2.-Diptera (Gnats, Flies) . . . . . . 283

" 3.-Hemiptora (Bugs) . . . . . . . 284

" 4.-Lepidoptera (Moths, Butterflies) . . . 285

" 5.-Orthoptera (Grasshoppers, Crickets) . . 287

" 6.-Hymenoptera (Bees, Wasps) . . . . 288

" 7.-Thysanoptera (Thrips) • . . . • . 289

" 8.-Neuroptera (Dragon-flies, May-flies) . 289

" 9.-Coleoptera . . . . . . . 291

Cliass II.-Arachnina . . . . . . . . 293

Class III.-Cirripedia . . . . . . . . 312

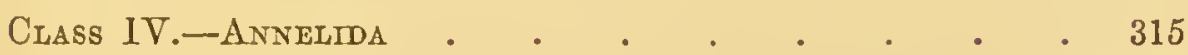

Class V.-ENTOZOA . • . . . . . • . 322

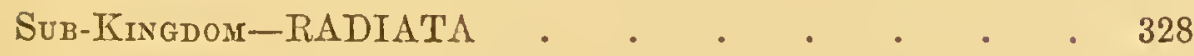

Class I.-Echinodermata . . . . . . 335

Class II.-ACalephe • . . . . . • . 342

Class III.-Anthozoa • • • • • • • . 356

Class IV.-HYdROZOA . . . . . . . . 367

KINGDOM.-ACRITA $. \quad . \quad . \quad . \quad . \quad . \quad . \quad 374$ 



\section{ZOOLOGY.}

\section{Sub-Kingdom-VERTEBRATA.}

\section{Ciass I.-MAMMALIA.}

WAMMALS are always entirely or partially covered with hair, and with two exceptions, the Ornithorhynchus and Echidna, have teats whereby the young are nourished. Mammary glands are always present; the fœtus is developed in the womb; the lungs are minutely cellular, and are suspended freely in a thoracic cavity, which is separated by a musculo-tendinous partition from the abdomen. The heart has two ventricles and two auricles; the respiration is rapid; inspiration is performed chiefly by the aid of the diaphragm; the blood corpuscles are smaller than in reptiles, and are usually circular. The right auriculo-ventricular valve is membranous; the aorta bends over the left bronchial tube. The abdominal aorta terminates by dividing beyond the kidneys into the iliac arteries; if continued beyond, it is as a caudal artery. The kidneys are relatively smaller than in other Vertebrata, and their secretion is derived from the arterial system alone; they never anastomose with the intestinal veins. The liver is generally divided into a greater number of lobes than in birds; the venous portal system is 
entirely formed of veins derived from the spleen and other viscera. When the cystic duct exists it always joins the hepatic duct, and never enters the duodenum separately. The pancreatic duct is commonly single. The mouth is closed by soft flexible muscular lips. The upper jaw is composed of three elements, palatine, maxillary, and premaxillary. The lower jaw is formed by two branches, each of which forms but one piece, and articulates by a convex or flat condyle to the squamosal, but never to the tympanic bone. In nearly all mammals teeth exist in a single row on the premaxillary, maxillary, and mandibular bones, where they are lodged in sockets, and not anchylosed with the substance of the jaw. The molar teeth are usually implanted by two or more fangs. Some Mammalia have but one set of teeth, and are termed "monophyodont," but the greater portion are "diphyodont," and have two sets of teeth, which vertically succeed each other. The tongue is large and fleshy, its apex being more or less free. The œsophagus is directly continued to the stomach, which varies according to the nature of the foor.

The centra of the vertebræ are ossified from three

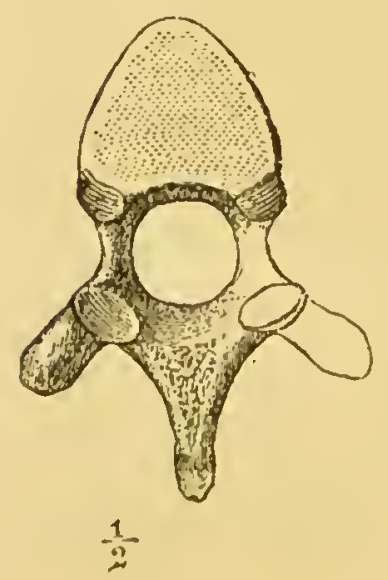
centres, and epiphyses are always developed at each extremity during early life; the cervicals (with two exceptions) are seren in number. The atlas is articulated by concave zygapophyses to two convex condyles. The scapula is an expanded plate of bone, and the coracoid, with two exceptious, is a small process of the scapula. The sternum (usu- 
ally narrow) consists of a simple longitudinal series of bones; and the sternal ribs are cartilaginous.

In the brain the cerebellum has large lateral lobes, and the grey surface is much folded; the optic lobes are medial, and divided by a transverse furrow. The cerebral lobes are not only united by a round, but by a "lyra" and hippocampal commissure, which in the majority of the class develops a corpus callosum, or great commissure, but which is virtually absent in the lowest subdivision of the class. The pelvic arch girdle is fixed on each side to the sacrum, and consists of ilium, ischium, and pubis. The ilium alone is attached to the transverse processes of the sacrum; the ischium and pubes form the lower part of the arch, the pubes

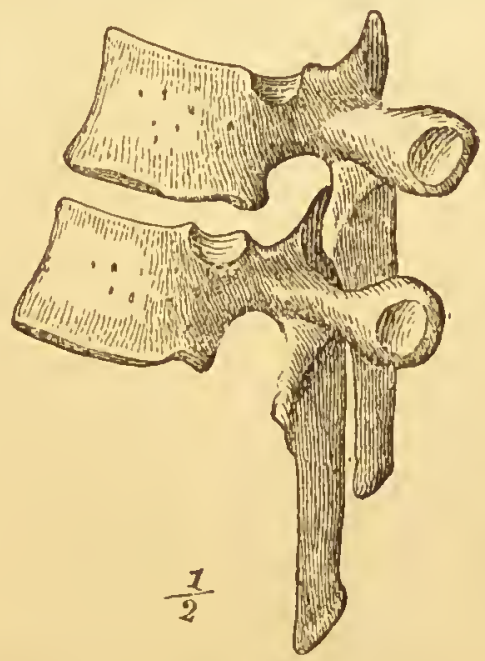

Dorsal Vertebræ. meeting across at the symphysis, and the ischia bending forward to join them at each side without meeting at the median line, like cartilages of false ribs, and so including the obturator foramen. The ilium is equivalent to the scapula, the ischium to the coracoid, and the pubes to the clavicle. All three elements enter into the acetabulum, or cavity into which the femur fits.

The teeth in Nammalia have various names given to them according to their position in the jaw, e.g. those which are implanted in the premaxillary bone and the part of the mandible which is immediately opposite to it in the jaws are termed "incisors." The "canine" is 
the single tooth implanted on each side of the upper jaw at or close to the suture between the maxillary and premaxillary; the single tooth in the lower jaw which corresponds to it in the series being always in front of its upper representative. Those teeth which replace

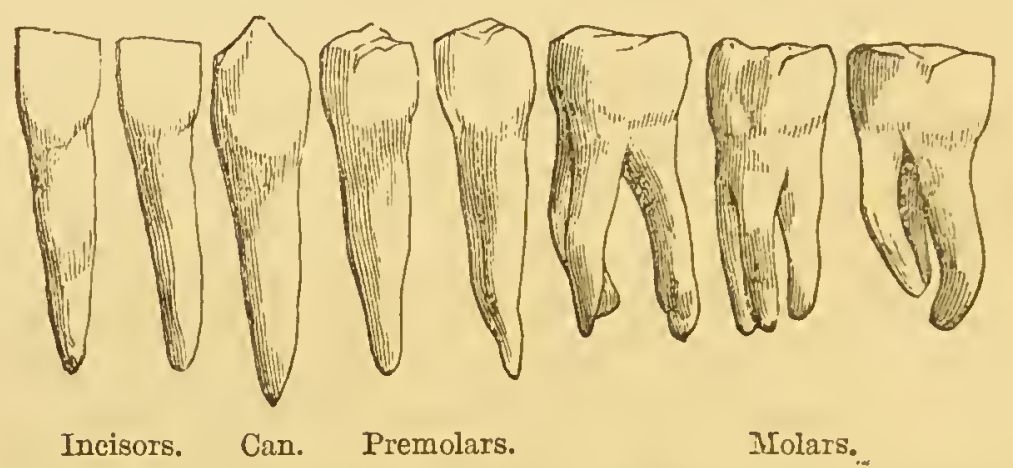

the deciduous molars of the milk dentition are termed premolars, and those which are farther back and do not replace any other teeth are termed true molars.

The tongue is bulky and soft, and usually covered with gustatory papillæ.

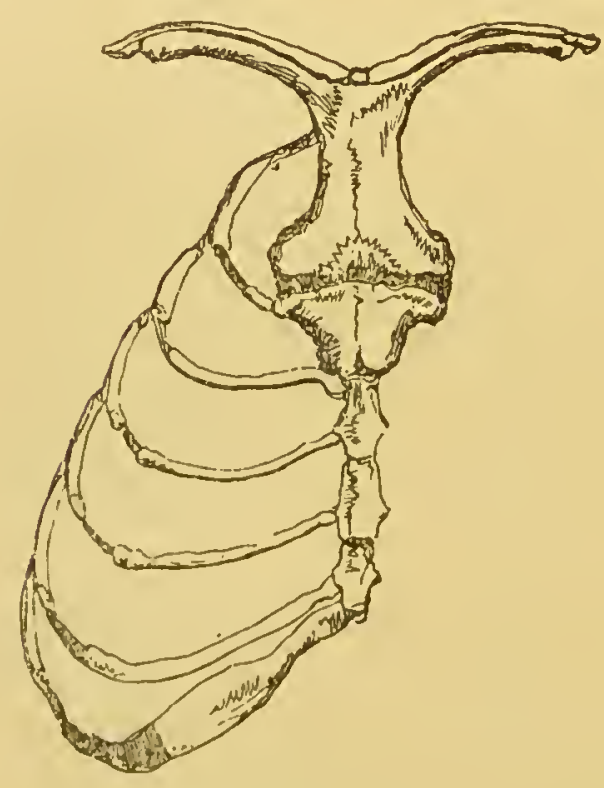

Stзmum of MIan.

The salivary glands are mostly arranged as in Man, but are wariting or imperfect in Cetacea and some Edentata.

There is an epiglottis and a hanging veil to the palate.

The following diagram expresses the history of the mammalian class in geological time. It will be seen that the MLarsu- 
pials, Rodents, Insectivora, Cheiroptera, Cetacea, Sirenia, Artiodactyla, Quadrumana, and Bimana have increased in numbers; the Bruta, Proboscidea, Perissodactyla, and Carnivora have been reduced; while the group Toxodontia have wholly and entirely disappeared.

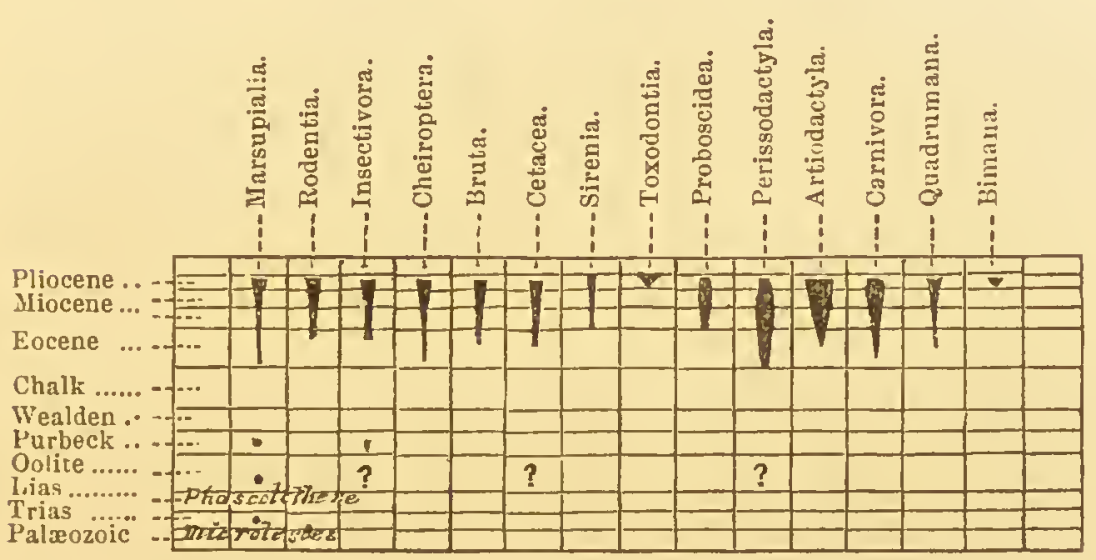

The following notes from Pictet may be of use to the student who seeks to find out the nature of any bone of a mammal, bird, or reptile which may fall into his hands. He will either have long bones or vertebræ to examine.

\section{1st. Long Bones.}

1. Bones presenting at one of their extremities one single artieular surfaee, in the form of a head, more or less rounded, and lateral to the axis

Bones terminated at both extremities by plane facets or by protuberances, artieular or not, situated nearly in the axis, or symmetric in relation to the axis...

2. Head detached, and bone on a rather long neck; the other extremity terminated by two eondyles, or rounded articular protuberanees, separated behind by a deep cavity

Head slightly detaehed from the shaft, neck short and broad, often none; the other extremity tcrminated by an articular fucct like a pulley, ordinarily presenting ono part 
cylindrical and onc part a little rounded; but these two parts are always continuous, or separated by a calient erest, and never by a eavity

$$
=\text { Humerus. }
$$

3. Une of the articulations notably distant from the extremity, and excavated in a half eylinder on one of the lateral crests of the bone

$$
=\text { Ulna. }
$$

The two articulations formed by terminal or subter minal facets

4. One of the articulations having its principal face lateral and parallel to the axis of the shafi.

The two articulations having their frincipal faces formed by one or many facets entirely at the end and perpendicular to the axis of the shaft.

5. Bones curved like an $S$, with one of the articulations terminal, the other lateral.$=$ Clavicle.

Straight bones, with two lateral articulations $=$ Fibula.

6. One of the extremities deprived of articulation = Ungual phalanx. Both extremities with articular facets . . 7 .

T. Large bones; the articulations of both extremities forming a cavity . . . .

Small bones, with one of the articulations convex

8. One (the broadest) of the two articulations formed of two rounded and not very deep cavities, separated by it median crest; the other extremity in the form of a concave half-eylinder, and terminated on one side by a point perpendicular to the artieular face

$$
\text { = 'Tibia. }
$$

8.

9.

The two articulations formed each of a single spherical or eylindrieal cavity, without any lateral point

$$
\text { = Radius. }
$$

9. One of the articulations formed by a plane facet, more or less iriangular, with trices of

smaller facets on the sides.
One of the articulations presenting a rery marked cavity

$$
=\left\{\begin{array}{c}
\text { Metatarsal or } \\
\text { metaearpal. }
\end{array}\right.
$$

10. Cavity simple, and uniformly rounded . $=\left\{\begin{array}{l}\text { 1st phalanx of } \\ \text { hands or feet. }\end{array}\right.$

Cavity divided into two parts $. . \quad=\left\{\begin{array}{l}2 \text { nd phalanx of } \\ \text { hunds or fcet. }\end{array}\right.$

\section{2nd. VERTEBR木.}

1. Transverso process, picrced with a longi-

tudinal hole Transversc process, not picreed with any hole = Cervical.

2. Transverse process, flattencd at the catremity, 
and showing evident traces of union with a neighbouring bone (the pelvis); the bodies of many vertebra often soldered together, and, in this case, the intertransversal spaces are reduced to mere holes . . = Sacral.

Transverse process, free and without union .

3. Vertebra almost reduced to its body; canal nearly always imperfect; no articular processes.

$$
\text { = Coccygian. }
$$

Vertebra of normal form

4. Transverse process, bearing at its extremity or on its lower face one articular facet; one similar cavity on the sides of the body. Spinous process broad = Dorsal.

Transverse process long and broad, without articular facets; spinous process broad; body large

. = Lumbar.

The homologies of the teeth will also receive attention. Teeth of each of the kinds arbitrarily termed " incisors," "canines," "false molars," and "molars," have received other special names, having reference to certain peculiarities of form or other property. The premolars in the human subject have been called "bicuspids." The last upper premolar and the first true molar in the Carnivora are termed "sectorials," or "molaires carnassières." Teeth of an elongated conical form, projecting considerably beyond the rest, and of uninterrupted growth, are called "tusks ;" such, for example, are the incisors of the Elephant, Narwhal, Dinotherium, and Dugong, the canines of the Boar, Walrus, and Hippopotamus. The long and large incisors of the rodent have been termed, from the shape and structure of their cutting edge, scalpriform teeth, chisel teeth, "dentes scalprarii." The lower incisors of the Colugos (Galeopithecus), with the crown deeply notched like a comb, are termed "dentes pectinati." The canines of the Baboon, which are deeply grooved. in front like the poison-fangs of some snakes, are "dentes canaliculati." The compressed crowns of the 
teeth of short-clawed Seals (Stenorhynchus), and of the extinct Zeuglodon, being divided into points like a saw, are "dentes serrati," \&c.

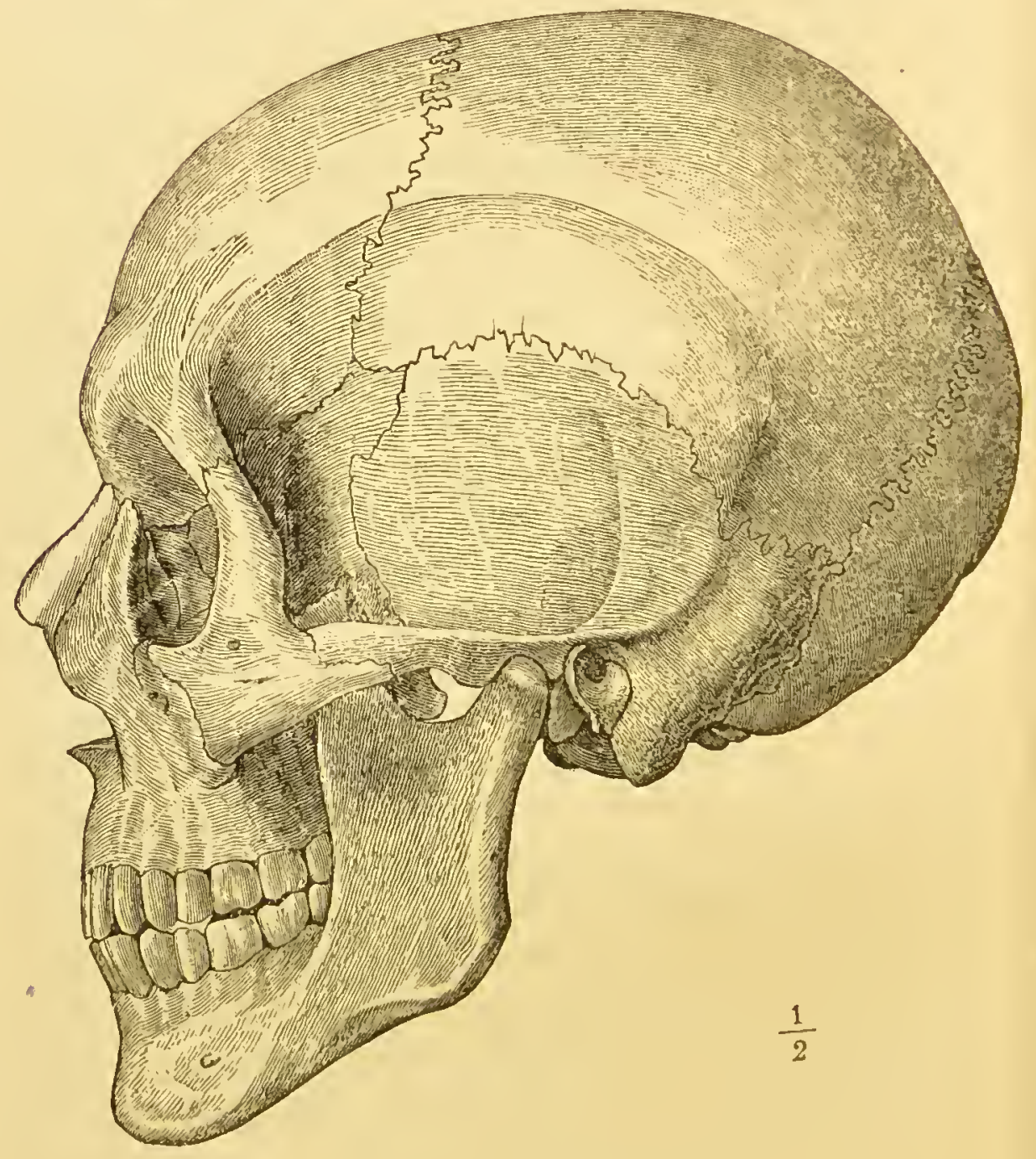

$$
\text { Sub-Class-ArchencephataA. }
$$

This is distinguished from the lower and all other groups of animals by the greater development of the 
cerebral matter. In Man, the cerebrum not only overlaps the olfactory lobes and cerebellum, but extends in advance of the one and further back than the other. Some of the structures contained within the posterior portion of such extension of the cerebrum have been termed pusterior cornu and hippocampus minor. In the anterior portion of the brain, the ventricle is produced into a hornlike form, in advance of the corpus striatum. The relative and absolute proportions of the brain to the cerebral nerves and to the spinal chord in Man, and the absence of the external perpendicular fissure, are also characters in which the human brain may be said to differ markedly from that of all animals

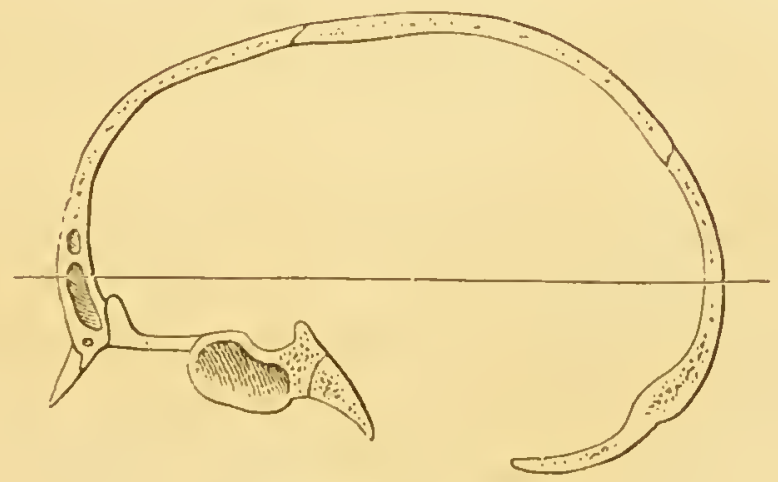

Section of Human Skull.

beneath him in the series. The absence of thumbs on the feet, a character produced by the flattened surface (for the hallux) of the entocuneiform bone, the shortness of the foot as compared with the length of the pelvic limb minus the foot, necessitates the erect position of Man, who also possesses a curvature of the spine and a form of the pelvis on a plan entirely different from that of any known Ape.

Turning to the skull, the fact that the maxillo-premaxillary suture is not visible on the face of the skull 
even at birth, and the presence of a nasal spine, show prominent marks of contrast, which development according to the operation of no known law could have changed. Unlike other Mammalia, hair is very little developed on the surface of the body, and is deficient on the back, though ordinarily abundant on the head and at the junction of the four limbs with the trunk. The muscular system affords structures which no other animal possesses, as, e.g., an extensor primi internodii pollicis, and a peroneus tertius. There is in normal Man no interspace between the small canines and the teeth before or behind them in the series. The permanent canine is cut before the second true molar teeth.

There is in the sub-class Archencephala only one order, one genus, but possibly two species of Man.

\section{Order 1.-Bimana. Genus-Homo.}

The geographical distribution of Man is almost universal over the globe. Spots in Siberia and in the American Arctic regions, however, exist where Man has not been able to survive, the lack of regetable or animal products, and not the climate, preventing him. Under certain limits Man appears to possess the power of perpetuating his species and maintaining life in all tempcrate and subtropical zones. Spots, however, exist in the tropics where the pure white race appear to be unablc to be acclimatised, and in which Europeans are unablc to maintain a footing. Here the second or dark race (Knox) of Man cxists, though rapidly decreasing in numbers. The two species brecd freely together (as in the casc of the Fringillide), although the off- 
spring, termed mulatto (white and black), mestizo (white and red), and zambo (red and black), and other names, does not perpetuate its breed after a few generations.

\section{Homo Sapiens.}

Third lower molars generally smaller than the second; alisphenoid and parietal bones usually united by suture. Divided into four races, the Malay, American, Mongolian, and European, by Blumenbach, this classification is perhaps more convenient than any other one yet proposed. The terms Aryan, Indo-European, Turanian, Hamitic, Shemitic, Japhetic, Allophylian, and others, have been used to denote various bodies of European and Western Asiatic men. None of these possess anatomical, linguistic, or historical characters which clearly define their distinction from each other. The American race appears to be divisible into two great sections, those on the eastern and those on the western shores, the physical characters and traditions of which differ extremely. The Malay is perhaps the least defined division, as, while it contrasts distinctly with the Australians and Papuas of the East, it has many points of cranial analogy with the Burmese and other races of South-Eastern Asia of indisputable Mongoloid origin. The Mongols appear to have had a wider distribution in past times than at present, and to have existed in Western Europe before the Celtic race was found there. The western races of Europe are disappearing before the eastern and northern races, and the Celts (occupying the western), the Latins (occupying the southern), are decreasing in numbers; while the Teuton (north) is in its turn disappearing before the Sclavonic (eastern) race. 
The most ancient, though uncertain, evidences of Man are in the Miocene period, where sharks' teeth apparently bored through for use or ornament have been found. Other proofs are afforded from the Post-Pliocene deposits, where there have been found chipped flints employed for use by early Man contemporary with the fossil Elephant and Rhinoceros of the Post-Pliocene age. The antiquity of these deposits cannot be precisely estimated in time, though they probably indicate an

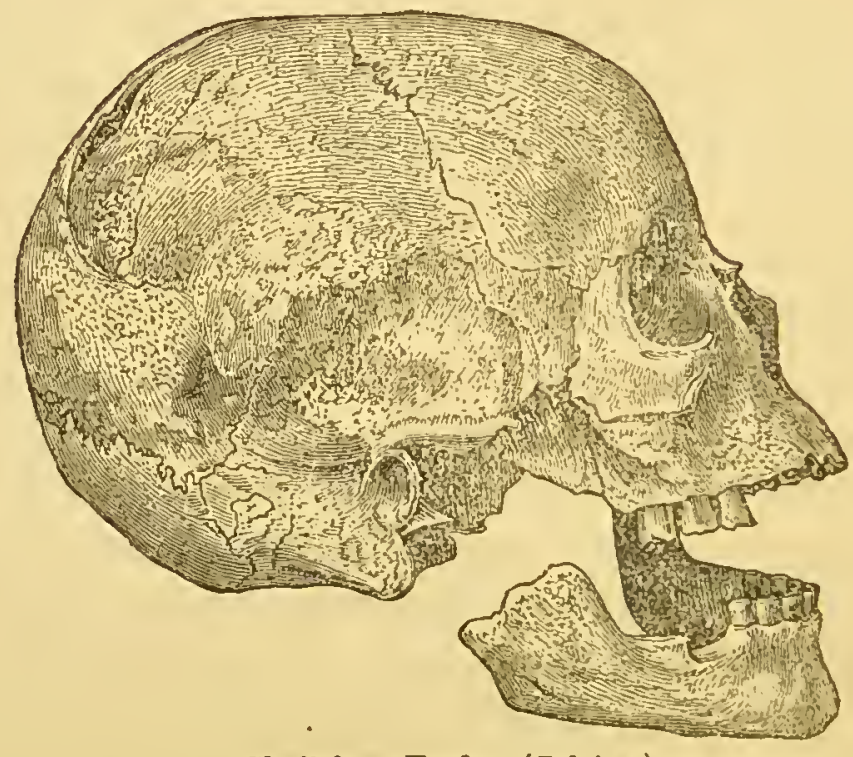

Skull from Furfooz (Belgium).

existence of Man at a period far more remote than the known historical tradition would lead us to infer. Evidence of associating this race of Man with that nuw living in Europe and Asia is afforded by bone-caves in Belgium, where at La Naulette was discovered the lower jaw of Man of a more simious character than the existing inhabitants, but presenting a mere exaggeration of the Sclavonic type. At Engis, near Liège, a human skull, presenting the ordinary Celtic characters, was found in juxtaposition with an extinct fauna. No 
other evidences of Post-Pliocene Man have been discovered worthy of consideration in this place, and it may be safely said that the oldest known Men were not in any way inferior to those of the present day, or more simious.

\section{Homo Afer.}

This comprises the Australian, Tasmanian, and the Negro races of Man, excluding the Kaffirs and the Northern Africans.

Characters. - Third lower molars usually larger than the second; squamosal and frontal bones generally united by suture.

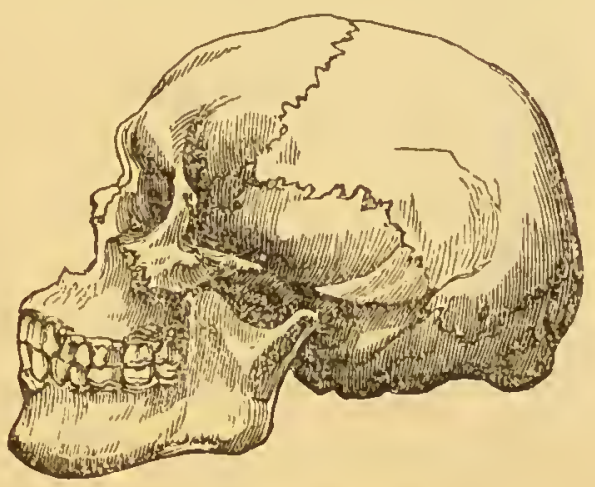

Skull of Australian.

This species, or sub-species, has appeared to merit separation by Broc, Knox, Virey, and the majority of foreign anthropologists. The breed produced with any of the so-called higher races becornes extinct in a very few generations, and the species itself seems doomed to extinction. The attempts to transplant the Negroes to America have failed, and the race, removed from its primitive habitat, and exposed to social influences foreign to its natural instincts, is rapidly decreasing in. numbers. The Tasmanians have become entirely extinct during the last ten years, and the Australians, who have never to any great extent bred successfully with the whites, are diminishing before the white settlers. There exists no reasonable grounds to infer that the lower or dark races of Man have had either 
any other descent than that of the rest of the genus, that they ever were distributed ovcr wider areas than that which they now occupy in the Old World, or that they originated in timc at a different or prior period to that of the genesis of mankind. Still less does there appear to exist any affinity between the Australians, the inhabitants of the Dekhan, or the Egyptians. Other dark races exist-the Semangs of Malacca, the Mincopies of the Andaman Islands, and certain tribes in Ceylon (Veddahs), the Philippine Islands, and Borneo. The connection of these with the great dark racc of man has not been demonstrated, and they appear to differ by reason of the shortness of the skull, as opposed to the great length which is characteristic of the Australians. These latter appear to be divided into several races of probably distinct origin.

A few terms will be convenient to the student. All skulls of which the proportions of the transverse to the longitudinal diameter is grcater than $80 \%$ are termed short-headed, or brachycephalic; all in which it is less than $80 \%$, long-headed, or dolichocephalic. There are many intermediate steps between these two extremes, to which various names have been given. The mean internal capacity of the skull is, in the European races, 92.3 ; in the Oceanic, 89.4 ; in the Amcrican, 87.5 ; in the Asiatic, 86.1 ; in the African, 86.0 ; and in the Australian, 81.9.

\section{Sub-Class-Gyrencephata.}

In this sub-class the incrcase of the size of the cerebrum is such, that it extends over half or more of the ccrebellum and of the olfactory lobcs. In a few of the 
smaller species the surface of the hemispheres is smooth, or with few and simple folds; but it is usually disposed in many gyri or convolutions, all of which are arranged according to a definite pattern, which can be traced from the most simple to the most complex members of the sub-class. The majority of those Mammalia whose services are functional to Man are comprised amongst the Gyrencephala. The blood from the head and anterior limbs is returned to the right auricle by a single precaval trunk.

Three great divisions of Gyrencephala are known,

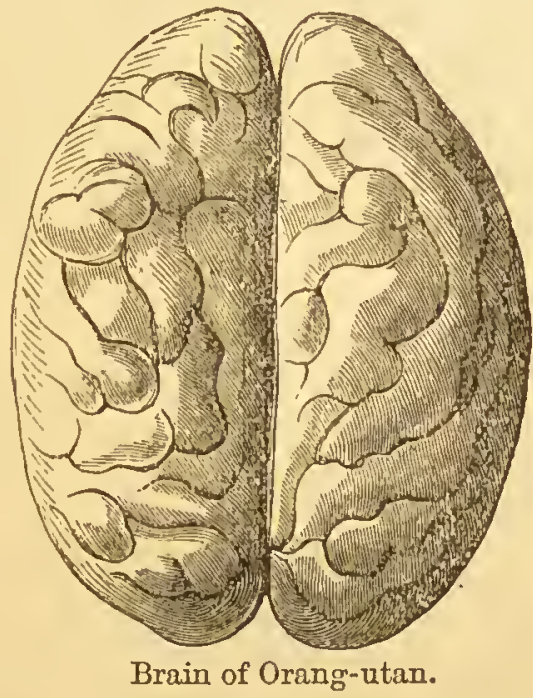

Brain of Orang-utan. respectively termed Unguiculata (clawed); Ungulata (hoofed); and Mrutilata, in which the posterior extre-

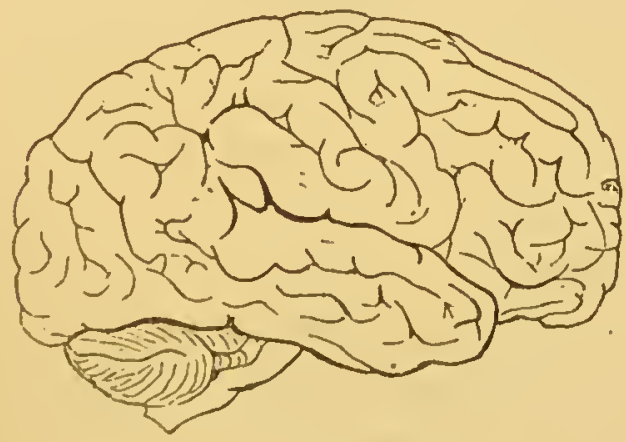

Brain of Minn.

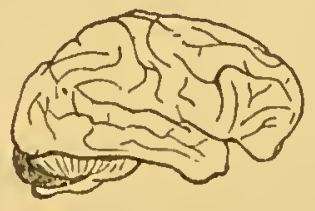

Brrin of Chimpanzcc.

mities may be modified, as in the case of the Whales and Manatees, into a resemblance of the tail fins of true fishes (but transverse).

The orders of gyrencephalous (or wave-brained) 
Mammals are the Quadrumana, Carnivora, Artiodactyla, Perissodactyla, Proboscidea, Toxodontia, Sirenia, and Cetacea.

\section{Order 2.-Quadrumana.}

In this order the innermost digit is so modified, that, with few exceptions, it can be opposed to the other fingers, unlike some of the following orders.

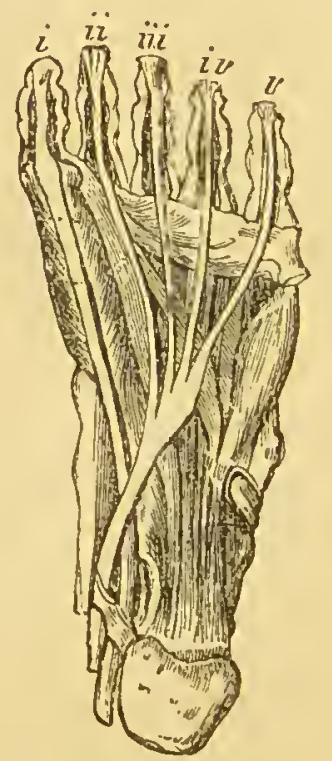

Foot of Man.

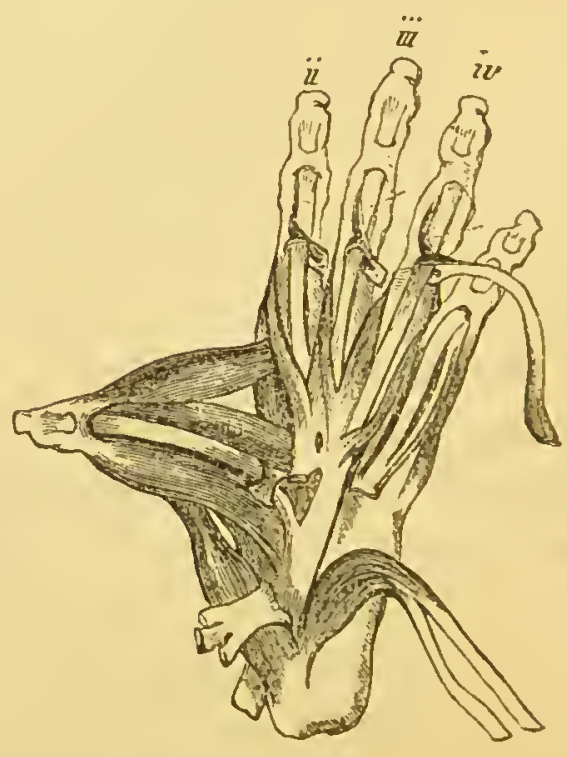

Foot of Gorilla.

There are two incisors only on each side of the jaw ; a varying number of premolars, perfect clavicles, and pectoral mamme. In all these points they agree with Man and differ from lower animals. But all except the higher members of the order differ from Man in the considerable breadth of the sternum, the little development of the metapophysial and anapophysial processes, and the absence of a vermiform appendix to the cæecum. 
Three broad divisions of this order exist, founded (as was supposed) on the construction of the nostrils, which were imagined, as a general rule, to be oblique, approximating below, and opening behind the muzzle in the Catarrini, or Monkeys of the Old World; wide apart, and not opening at the end of the snout, in the Platyrrhini, or New World Monkeys; and in the Strepsirhini, or Lemurs, where the muzzle is long and pointed, the termination of the nostrils has a peculiar oblique curvature.

Though these characters are not precisely accurate, there can be no doubt of the nature and value of the three family groups into which the Quadrumana are divisible. The premolar teeth in the Catarrhini agree in number with those of Man, but in the New World Monkeys an extra premolar is developed, raising the total number of teeth to thirty-four. The Catarrhini fall naturally into three groups. One (Latisterni) comprises the true Apes, Troglodytes (Gorilla and Chimpanzee), Pithecus (Orang-utan), and Hylobates (Gibbon, or long-armed Ape). The latter section agrees with those beneath it in possessing ischial callosities, which are absent in the members of the order nearest to Man. They are termed by Kühl Scleropyga, as opposed to the Dasypyga or true Apes. They form, in fact, the transitional links between the higher dasypygal or anthropoid Apes, and the Guenons immediately beneath them in the series. The following diagram best shows the general classification of catarrhine and platyrrhine Quadrumana. 
Family.

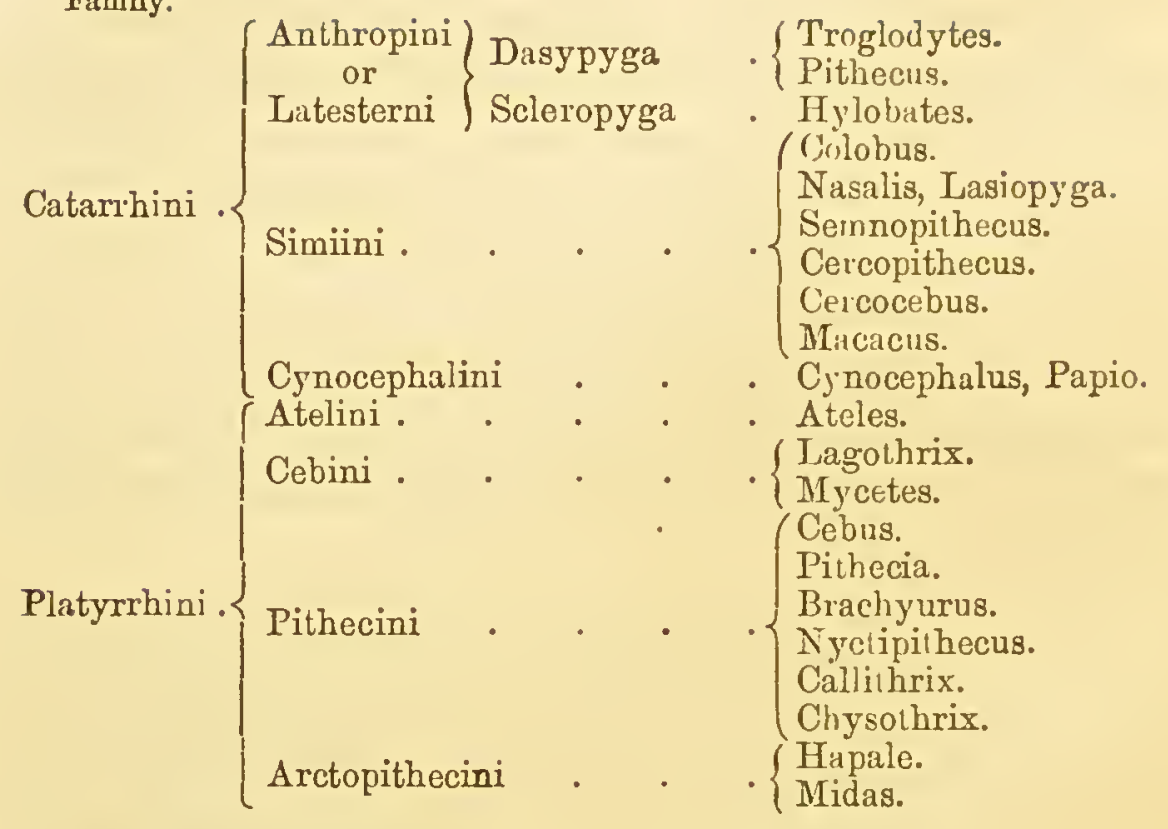

The Hylobates are chiefly Indian; the Cercopitheci and Cercocebi are found in India and Africa; while the Macaci and Cynocephali are the African types of the division. They are the commonest and best known Monkeys. The lower we reach the series of Baboons, we find a greater diversion from the human form of the lumbar vertebræ. Here, in the lower forms, they are tightly locked together with metapophysial articulations, which lock the whole loins together.

In the lower Baboons (Cynocephali) no trace can be found of any annectant link with such higher forms as the Gorilla, which may be regarded as a development from the higher and truly anthropoid Apes, such as Hylobates or Pithecus. Between the long-armed Gibbon and the highest tailed Guenon (Semnopithecus) is a gap which is not filled up by any intervening form, and which science is as impotent to grasp as it is unable to point out intervening links between Gorilla and Man.

If we turn to the fossil distribution of the quadru- 
manous order, we find that we have evidence in America alone of the type of platyrrhine Monkeys in the geological period immediately preceding the arrival of Man and the existing Sapajous. In Europe we have proof of the existence of fossil Apes (Dryopithecus) which were closely allied to the Gibbons (Hylobates) of Northern India, and a few Greek forms at Pikermi, connected mainly with such African types as Macacus, or such Indian ones as Semnopithecus. Africa and India, where fossil Apes probably exist, only afford us in the Sewalik hills types closely allied to the existing Indian Apes. Borneo and Western Equatorial Africa, where species of Troglodytes and Pithecus (the Gorilla and Orang-utan) may be supposed to be found fossil, are as yet unexplored; whilst Australia, where no existing Apes are found at the present day, does not afford us any fossil form superior either in organization or in affinity to Man to the existing Gorilla of the West Coast of Africa, which up to the present time, proximo sed longo intervallo, appears to be the highest known gyrencephalous form.

The family Platyrrhini, or New World Apes, exhibits some curious modifications. The thumb, which in all the species is aborted, is in some (Ateles) entirely absent. A like character was shown by the scansorial Ape (Colobus) of the Old World. Between the two there can be no generic link is sufficiently shown by the dental formula.

The great divisions of the Platyrrhini exist, in which the dental formula is entirely different. The Catar $\%$ ini possess in the molar series p. $\frac{2-2}{2-2} \mathrm{~m} \cdot \frac{3-3}{3-3}=20$. The ordinary Platyrrhini possess p. $\frac{3-3}{3-3}$ and $\mathrm{m} \cdot \frac{3-3}{3-3}=24$. But the Marmozets, or Arctopithecini, apparently accord 
with the Old World Apes in having p. $\frac{3-3}{3-3} \mathrm{~m} \cdot \frac{2-2}{2-2}=20$. It will be seen, however, that the agreement in the total number is based on the composition of wholly different factors, and that, as Owen has pointed out, they, instead of resembling the Old World Apes in dentition, differ from them to a greater extent than do the other New World Simiæ; they have not only one premolar more but one molar less in the dental formula. In their deciduous dentition, however, the Marmozets correspond with the American Quadrumana. They are found throughout the tropical parts of America from Texas to Buenos Ayres, and afford that division of the order which is nearest akin to the Lemuridæ and to the Carnivora, while, by analogical relations based on their food and habits, they possess an adaptive relationship to the Carnivora and to the far-removed insectivorous family of lissencephalous Mammalia. The other divisions of the Platyrrini, composed of the prehensiletailed (Cebus) and non-prehensile-tailed (Pithecia, Callithrix, and Chrysothrix) are also essentially of tropical or sub-tropical distribution; they exhibit no upward affinity to the Catarrhini, from whom they are separated by the Atlantic, nor downwards to the other Arctopithecini, or to any other form. No catarrhine Monkey has ever been found fossil in the New, no Platyrrhini in the Old World.

The Strepsirlina (Lemurs) inhabit Madagascar, Africa, and parts of the Indian Archipelago. But Madagasear may be said to be their metropolis, as the species found in other localities are all aberrant from the common type of the Lemurida. This is highly complicated, and affords marks of internal as well as apparent distinction from the other quadrumanous types. In nearly the whole of this family there exists 
a peculiarity of the arrangements of the fingers on the anterior and posterior extremities. In the Aye Aye (Cheiromys) the median digit is singularly atrophied, while in the Potto (Perodicticus) and some allied forms of Lemur (Lemurida) the second or index digit is very much shorter than the others, and has but two rudimentary phalanges; whilst in some species the fingers reach a degree of slenderness not attained by any other mammalian form, in others they appear as if abruptly truncated. - In the Potto there is also an additional bone on the palmar side of the carpus.

\section{Order 3.-CARNIVORA.}

This order comprises those wave-brained mammals in which the clavicle is rudimental or absent; the innermost digit is often stunted or absent; there are no vesiculæ seminales; the teats are abdominal, and the placenta zonular. In the vertebræ there is an enormous development of the transverse processes of the atlas and of the spine of the axis, for attachment of muscles moving the head and neck in the destruction of prey. The dorsal vertebræ, which are thirteen to sixteen in number, have long spines, which in the anterior part of the dorsal region are directed backwards; but in the posterior and part of the lumbar series are forwardly directed. There are four to seven lumbars, and usually four sacral vertebræ, though in the white Bear, which forms an apparent exception to the rule, there are seven. The caudal vertebræ range from six in the stunted tail of the Bear to twentythree in the Lion. In Seals, the coracoid as a process is hardly developed. The conformation of the skulls 


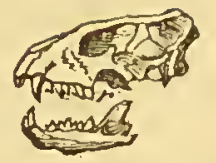

should be carefully compared by all students with that of the next order of Mammalia. In the annexed diagrams the skulls and fore-limbs of the Lion and the Ox are shown. We perceive in the Lion large pointed canine teeth, which seize on the prey, and a series of sectorial teeth behind them, playing like scissor-blades as the lower jaw moves upon the upper. The mandible is short and strong, articulating to the skull by a transversely extended condyle received into a glenoid cavity, forming a closefitting joint, which gives a firm attachment to the jaw, but almost. restricts its movements to one plan, as in opening or shutting the mouth. The plate which is called the

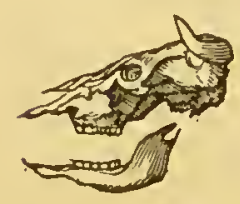

coronoid process, and gives attachment to the chief biting muscle (temporal), is broad and high. It may be generally noticed in the mammalian series that the breadth and height of the coronoid process in the jaw of a Carnivore or Insectivore is in ratio to the carnivorous nature of the animal. This will be more clearly seen when we compare the jars of some of the herbivorous and carnivorous Marsupials; on the side and top of the skull where the temporal muscles arise are strong pitted ridges, which afford ex- 
tensive attachment to powerful muscles which raise the head.

In the fore-limb the paw consists of five digits, the innermost and shortest answering to our thumb, and having two bones; the other four digits having each three bones or phalanges. The terminal phalanx is so modified as to project from a forward peg, forming a retractile claw, fixed on the pointed termination of the phalanx. The paw can be rotated by the freedom of motion of the joint which articulates the ulna and radius with the humerus; carrying with it the whole paw, which is thus endowed with the power of pronation or supination, applying it as a weapon for seizing and tearing.

Ridges for the attachment of the supinator, pronator, flexor and extensor muscles, cover the humerus; but, to defend the main artery and nerve of the fore-leg from compression during the action of these muscles, they are covered by a bridge of bone. The scapula is of great breadth, the spinous, acromion, and coracoid processes being well developed, and a small clavicle gives force to and divides the muscles of the head from those of the arm. With the exception of a few Seals, the incisors are $\frac{3-3}{3-3}$ in number; the canines are always longer than the other teeth, and the molar's graduate from the tuberculate form presented in the Bears and Badgers to the trenchant and sectorial type which we have seen in the Lion.

Three great divisions were made by Cuvier, and the arrangement has since been in the main adbered to. One group, the Pinnigrada, in which both the fore and hind limb are short and expanded into paddles for swimming, the hinder limbs being confined by an 
extension of the skin to the tail, comprises the Walruses and Seals. These are placed at the lowest grade of the order.

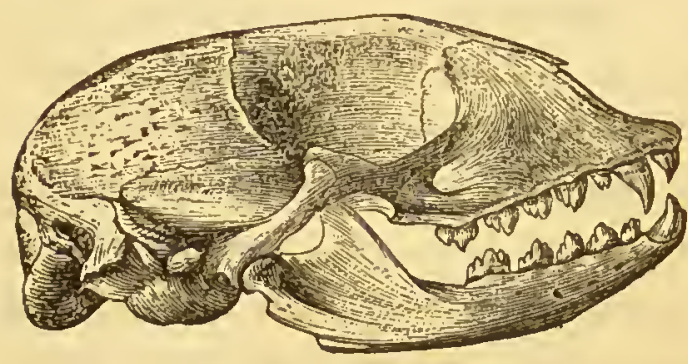

Skull of Seal.

In another group nearly the whole of the hind foot forms a sole which rests on the ground, and the name Plantigrada was accordingly given to it.

In the renal, genital, and other organs, great affinity is shown by the Bears to the Seals. The oldest known examples of the carnivorous order (Amphicyon, Hyce. nodon) show the dentition of forty-four teeth characteristic of the elder Eocene Mammalia.

The third division of the order termed Digitigrada, where the toes only touch the ground, the heel being

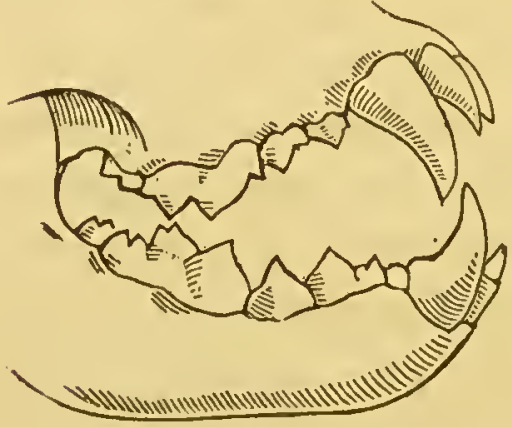

Jaws of Lion. much raised, comprises such forms as the Cat (Felis), Dog (Canis), Weasel (Mustela), Genet ( $V_{i}$ verra). These are found to blend with the Plantigrada by a series of connecting forms which chiefly existed in a fossil state, though the gap between the two families is at present large. Yet there were a number of examples in Eocene and Miocene times of which the palæontologist who examines the bones cannot now definitely predict whether they appertained to the Digitigrade or the Plantigrade division.

The origin of our domestic Cats and Dogs is, and has 
been since the time of Buffon, unknown to zoologists. It is probable that these species have been domesticated by man for so long a period that the original wild stock has become extinct. The domestic Cat (Felis domestica), which was undoubtedly introduced into Europe from the East, shows no affinity with the wild Cat (Felis catus) of our forests, but rather with the Manul or Gloved Cat (Felis maniculata) of Egypt and Nubia.

The European Dog at least does not exhibit any trace of connection with the Wolves or Jackals, but rather with some forms of Asiatic Dog, one of which from Nepal was named Cuon primcevus by its discoverer, $\mathrm{Mr}$. B. H. Hodgson. In what way these Dogs were first domesticated by Man we are ignorant, as we also are of the origin of every other form of tame animal. Distinction must always be drawn between animals truly wild, whose ancestors have never been subject to the dominion of Man, and the descendants of originally tame animals, who in a feral state are loose and savage apart from human subjection. It will be seen that this remark will equally apply to the Hog and to the Horse.

\section{Order 4.-Artiodactyla.}

As the preceding order comprised the domestic animals who are Man's closest companions, so the present one and the following includes those forms which are most useful to him. The hoofs are always of even number, whence the name is given. They may be either two, as in the Giraffe, four, as in the Hippopotamus, or two functional and two rudimental, as in the greatest number of ruminant types. The distinction between this form of typical herbivorous ungulate 
animal and the preceding, affords to the comparative anatomist an opportunity of estimating the adaptive distinctions between carnivorous and herbivorous forms of skull and limb. If we take the cranium and forelimb of an $\mathrm{Ox}$, we find that the teeth which answer to the great canines are absent, and it is only in a few examples of the order (e.g. Musk Deer) that they are developed. The lower canines are reduced in size and altered in shape so as to form the outer teeth in the series of incisors which terminate the lower jaw. The molar teeth, in place of being sharp, cutting, are furnished with broad and flat crowns roughened with hard edges, ridges produced by islands of enamel, and opposing each other by a grinding action like millstones. This triturating process is aided by the construction of the condyle, which is flat and admits of rotary movements on a flattened articular surface of the skull, the glenoid cavity being so obliterated as to limit the extent of opening and shutting the mouth. The coronoid process, unlike that of the typical Carnivore, is weak, while the pterygoid plates, which attach the rotatory muscles of the jaw and the angular part of the jaw to which they are attached, are large and broad.

The fore-foot of the $\mathrm{Ox}$ is composed of two principal toes, with two unfunctional and rudimentary ones dangling behind. Each of these is enveloped in a separate horny case, or hoof; the radius and ulna are so joined together, that reciprocal action or movement of these bones on each other is impossible. Another joint restricts the movement of the fore-arm (antibrachium) upon the arm to one plane; the scapula is long and narrow, with a stunted coracoid and no clavicle. Such modifications adapt the limb to perform 
the movements required for locomotion alone. No pronation or supination of the anterior (or posterior) extremity is possible in the ungulate quadruped.

The group Artiodactyla falls naturally into two divisions, the Omnirora (Hog) and the Ruminantia (Sheep).

But while these types are the two leading ones upon which all our modern ideas of classification fasten, they were linked together in the Eocene period by a series of annectant forms, such as the Anoplotherium, which entirely bridged over the chasm which now separates the Hogs and Hippopotami from the Ruminants. These, like the ancient Carnivora, preserved the full complement, inc. $\frac{3}{3}$ c. $\frac{1}{1} p \cdot \frac{4}{4} \mathrm{~m} \cdot \frac{3}{3}=44$, which indicates the typical dentition of the primitive mammal. Of the omnivorous family, the Pigs (Sus), the Wart Hogs (Phascocharus and Chceropotamus), and the Pecaris (Dicotyles), are the chief existing representatives. This family, Suina, have usually four toes to each foot, though the hind-feet are sometimes supported on three toes alone. All the toes are incased in a horny covering, but only the two lower are in functional contact with the ground. The molar teeth are usually tuberculate, as in the Bears and Monkeys, in relation to the omnivorous character of the diet.

The Hippopotamus, which inhabits the eastern and central districts of Africa, and the elevated highlands which form the watershed between the Nilotic rivers and those of south-eastern Africa, may be considered essentially as a magnified Hog. Unlike the true Suina, its molars present a trefoil-shaped arrangement of the enamel on the crown which distinguishes it from all other animals of the order. 
Though now restricted in its geographical distribution, it ranged over India, where the representative species (Hexaprotodon) had six incisors, and Europe, where it appears during the Post-Pliocene period to have been contemporary with Man.

The true ruminant form of artiodactyle Mammals are a clearly defined group, which fall naturally into four divisions, Camelina, Moschina, Ceraticomia, and Cavicornia, respectively. The first is comprised of two genera alone, the Camels and the Llamas. In neither of these do canine teeth or horns exist. Confined to tropical regions, the Llamas of the New World, two species in number, represent and replace the Camels and Dromedaries of the Old World. The toes in the Camel are united until near the point by a common hoof; the neck is very long, and the upper lip split. The large development of fat which exists on the back of the Camel has no relationship to any modification of the inferior vertebræ. There are callosities on the breast and on the front of the fore-legs and the knees of the hind-legs ; four ventral mammæ.

In the Llamas there are two hoofs, furnished with small and separate nails; the neck is proportionately longer than in the Camel; there is no hump. The callosities are small or none, and the two mammæ are inguinal.

The next division, Moschina, comprises two groups, one of which, the Tragulina, is raised by some zoologists to the dignity of separate classification. Excluding, however, theoretical considerations, the Musk Deer are distinguished from other Ruminants, in the first place, by their long canines projecting from the upper jaw, and, in the second, by retaining the phalanges and metacarpals of the lateral digits separate, whilst 
the metaearpals representing the third and fourth digits, instead of being soldered together as in the "cannon-bone" of ordinary Ruminants, always show the traee of division along the internal surfaee. In the extinet Anoplotherium, Dichodon, and Nicrotherium the metacarpals were entirely separate. The Musk Deer are Asiatie and African in their distribution. No speeies is known in the New World. The Afriean form (Hyomoschus aquaticus) most resembles the Eocene and Miocene fossil Ruminants.

The other ruminant forms fall into two well-marked divisions - those with persistent hollow horns, the Cavicornia, and those in which the horns are deeiduous, i.e. shed annually. The latter, or Ceraticornia, are divisible into two sub-sections, those to whieh the Giraffe and Deer respectively appertain. In the Giraffe both sexes have a pair of short horns, carried on the forehead, whieh are persistent, and covered by skin. Its general affinities, however, are so distinctly with the Deer, that it is grouped with them in the same division of the order. The neck is extremely long, and the fore-legs exeeed the hind legs in length. The Giraffe is eonfined at present to the Afriean continent, but the Plioeene and Post-Pliocene strata of France and India indicate the existenee of closely allied genera and species. The true Deer (Cervidce) are found in every quarter of the globe except Australia. After the horns have been worn and used for some months, they lose all vaseular conneetion with the skull, and are slowly undermined and shed, the growth of a suceeeding pair of horns eommeneing soon afterwards. The shedding of the antlers coincides annually with that of the hair in mammals and the feathers in birds. In Deer, with a few exceptions, the horns are branched, and the degree 
of bifurcation, or complex division, coincides with that of the Deer or Stag.

The Reindeer, an extreme northern form, is almost the solitary exception in which antlers are developed by the female. As in the male, they are shed and renewed, but are much smaller in size. Castration produces diminution in size of the horns. In some aberrant forms of Deer (MIuntjac), the pedicels which support the horns are long and slender.

Cavicorn or hollow-horned Ruminants exist (Prong Buck-Antilocapra Americana) in which the full-sized horns are acquired by progressive growth of the persistent core, and by annual shedding and renewal of the extra vascular sheath. Such form only a small proportion of the family. The origin of the hollow horns from various parts of the frontal bone of the skull aftiords a means of classification of the family. In the $\mathrm{Ox}(B o s)$, the horns arise from the hinder angles of the frontals; in the Bisons, from a spot a littie in advance of these angles; in the Buffalos (Bubalus buffelus), B. Caffer, the Musk Buffalo, B. muschatus, and the Gnu, broad extended bases extend over the frontal bone, and meet at its median line. In Antelopes they are more in adrance. The horns in most hollow-horned Ruminants are developed in both sexes, but in a few of the Antelopes in the male alone.

The Goats (Capra) and the Sheep (Ovis) differ in the formation of the forehead in the former genus, which is concave, but in the Sheep convex. The horns have a tendency to become arcuate in the Goat, but in the Sheep spiral. The Goats are bearded, and the Sheep not. The origin of the domestic Sheep is unknown, though it has many points of affinity with the Argali (Ovis argali), which is found in all the lofty mountainous 
regions of Asia and Northern Africa. In Sardinia and Corsica, and formerly in Spain, exists a species, the Mouflon, or Muffione (Ovis musimon), which has also been alleged to bear a genetic relationship with our domestic Sheep.

The domestic Oxen also afford us trace of the primitive original whence our domestic breeds have been derived. The closest relationship of the domestic Ox of England is with the Bos longifrons of the Post-Pliocene strata, which exhibits a close connection with the stunted Galloway and Highland Kyloe Oxen, and of which it was possibly the ancestor. These breed freely with the ordinary English Ox, which is descended from the cattle which the Romans brought into England, and which was, in its turn, probably derived from the Egyptian and some of the Indian cattle. Three other species, at least, of fossil Ox existed in Fingland (Bos primigenius, frontosus, and trochoceros), which do not appear to be represented in our existing breeds of cattle. The direction of the horn-cores, and two or three features observable in the dentition, are enough amply to demonstrate the fact. The "wild" cattle of Chillingham Park are the descendants of feral Roman cattle, and show no connection with any of the previously existing European types of oxen. The digestive organs of the Ruminants are complicated to a greater extent than in any other mammalian order. The stomach consists of four compartments - the paunch, the "honeycomb" or reticulum, the psalterium, and the abomasus or rennet. The first, or paunch, is internally lined with villi. It is larger than the others, and forms the first receptacle of the food. The second, reticulum, has its inner surface extended by hexagonal cells or compartments. This forms in the $\mathrm{Ox}$ an edible substance, which is termed 
honeycomb, and which, with the tripe, which is the lining of the next compartment, or psalterium, is consumed for food. In this third division the lining membrane is arranged in laminæ, like the leaves of a book. In the fourth division, abomasus, or rennet, the lining membrane is filled with gastric tubular glands, and is apparently the representative of the

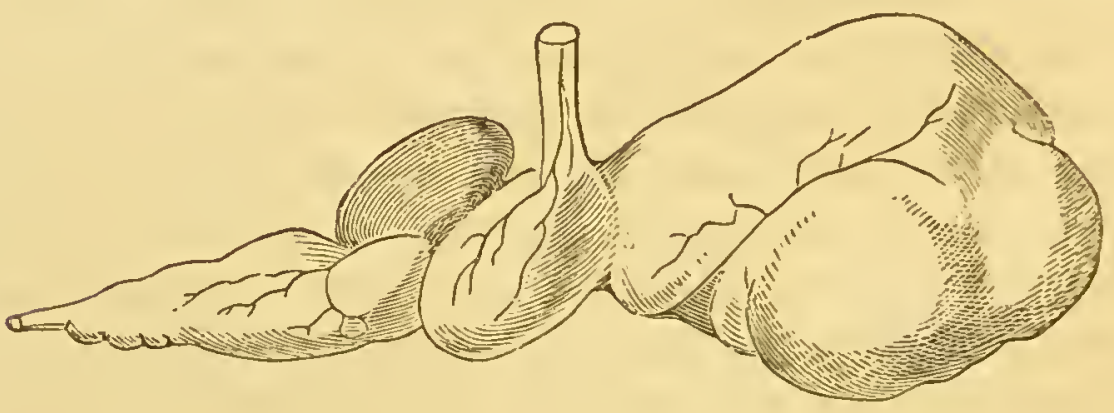

simple stomach of other Ruminantia. After being swallowed, the food is subject to a rotary movement in the paunch, where it is moistened by the fluid in the reticulum, and can at will be regurgitated into the mouth for a longer and better process of mastication before it has to pass into the third and fourth carities, to pass in its turn through the abdominal canal.

\section{Order 5.-Perissodactyla.}

The odd-toed division of ungulate Mammalia comprises fewer living species in number than is possessed by the even-toed orders, though in a fossil state the Artiodactyla were probably of far exceeding numbers. The dorsolumbar vertebral series is never fewer than twenty-two (in Artiodactyla nineteen). The femur bas a third trochanter for the attachment of mscules, and the medullary artery, which in the even-toed ungu- 
lates penetrates the fore and upper parts of the shaft enters the back part. The fore part of the astragalus, which in the preceding order was equally divided, here exhibits two very unequal facets. The os magnum, which was not larger than the other carpal bones, is here excessively large to support the median digit. If the species be horned the horn is single, or if two horns are developed they are placed on the median line of the head. The crowns of the hinder premolars are as complex as those of the true molars; and the last lower milk-molar develops two, instead of three, lobes. The stomach is simple, and the cæcum capacious and sacculated. The placenta is diffused in all species except Hyrax, where it is annular.

Three great divisions of Perissodactyla exist, of which the Rhinoceros, the Tapir, and the Horse form the existing types.

The Rhinoceri are found in Asia and Africa, where several species exist, some with one horn, some with two. The skin, except in one of the newly discovered species ( $R$. lasiotis), is uncovered with hair. In the fossil forms of the genus, whose distribution appears to have extended over the whole of Europe and Northern Asia, from the west of England to China, fossil animals closely allied to the Rhinoceros, if not indeed of the same genus, are found in the Western States of America.

The Tapirs (Tapirus) form a group of odd-toed ungulates, which represent more closely than do any other the forms of the Eocene Mammalia. The existing Tapirs are only four species; one inhabiting the Malay Archipelago, one Brazil, another the Isthmus of Darien, and a fourth Nicaragua and Costa Rica. The Malayan Tapir preserves the pattern of broad trans- 
verse bands across the body, which is characteristic of the young in most Ungulata. The molars exhibit on their crown before they have been worn two transverse and straight eminences. The nose is terminated by a small trunk, which is movable in all directions, but is not terminated by a tactile organ as in the Elephant. The neck is rather long; the skin is thick and covered with coarse hair. There are two inguinal mammæ. In the Brazilian Tapir, the male bears a small mane, which is absent in the Malayan form. The Pinchaque (Tapirus villosus) is covere with thick woolly hair. The habits of these animais are nocturnal, and their flesh resembles that of the Hog. Numerous fossil animals allied to the Tapirs (Lophiodon, Coryphodon, Palcootherium, Pliolophus, Hyracotherium, \&c.), existed during the deposition of the Eocene tertiary strata in England and France. These were generally of larger size than the existing Tapirs.

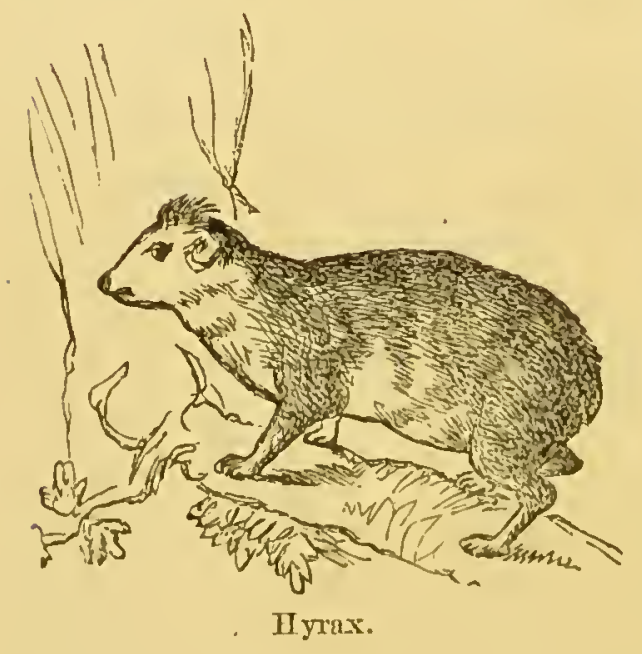

The little Shaphan or "Coney" of Scripture, (Hyrax) though of small dimensions, is nevertheless of sufficient importance to merit a separate and detailed notice. It mar be defined as a miniature bairy Rhinoceros, with which the pattern of its molar teeth is found closely to accord. In the twenty-two pair of ribs, the simple stomach and complex cxcal structures, the four toes on the fore-feet, and three toes on the hind-feet as in the hornless Rhinoceros (Acerotherium) of the Mio- 
cene, and in many other small but definite characters, Hyrax seems to find a place amongst the Perissodactyla. At the same time the placenta is annular, instead of being diffused as in the rest of the order.

The Horses (Equidce) have been considered to form a separate family, but are connected with the Lophiodon division of the Tapirs by a series of links by which a perfect gradation seems to have existed from the Mid-Tertiary period to the present day. The Miocene deposits of Eppelsheim, Vaucluse, and India exhibit remains of a true Horse differing from all existing types, inasmuch as in it the small digits and hoofs representing the second and fourth toes, which in the

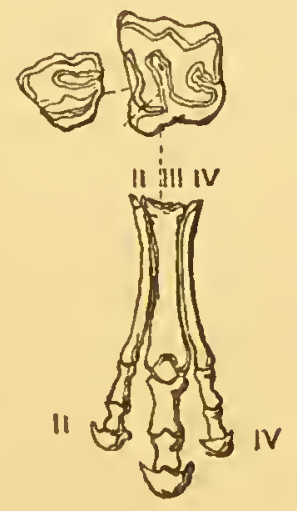

Palæotherium.

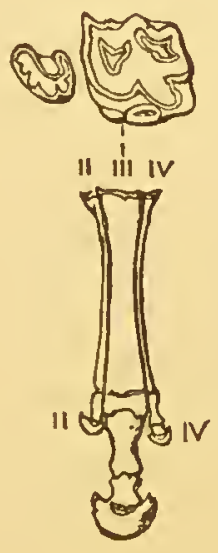

Hipparion.

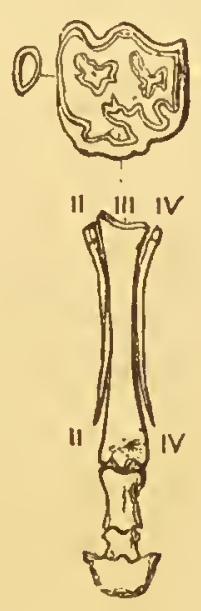

Horse.

living Horse are terined splint bones, were developed. These small hoofs hung by the side of the large and functional hoof developed from the third digit, like the small rudimental hoofs behind those which form the cloven foot in the Ox. A link was thus formed between Hipparion and the Tapirs on one side and the Horse on the other, and a scheme exhibited showing by what means a process of gradual development might arise 
which would convert one generic form into the other. The canines in Equus are separated from the molars by a large diastema or intermediary vacancy; the molars are of square form, marked with numerous folds of enamel: two inguinal mammæ. The Equidce are exclusively confined to the Old World, but in the Pliocene period were found in America. The Ass and Horse form the leading examples of the group, which has been separated into two genera. The tail of the Horses is flowing throughout with hairs from its base the whole of its length. In the Asses it is tufted; there is a dark cross on the shoulders. The feral Horses of the Pampas in America are merely the descendants of the wild Horses which the Spanish brought into America, and have since increased and spread over the whole of the continent, where they repeat the characters of their Arab ancestors. The coat in the Horses is of a uniform colour.

In the Asses (Asinus) the height is less, the legs are shorter, there is a dark cross on the shoulders, and the ears are long and frequently tufted. The Dsiggetai or Kiang (E. hemionus) is of one uniform colour, the tail is naked to the extremity, where it is tufted, and the cross on the back is relatively smaller than in the domestic Ass. It has been imagined to be the original stock of the domestic Ass, from whom, however, it differs in the dentition. The Quaggas and Zebras form a group of Asses separate from the brown types of Asia. 'They have all a tendency, which in the Quagga is slightly, but in the Zebra and Daauw (Equus Burchellii) highly developed, to be covered with stripes which extend over the whole of the body. There are several other species of Equida-the Onager, or so-called wild Ass or Koulan; the Yo-to-tze (E. cquuleus); the E. hip- 
pagrus, hamar, antiquorum, and isabellinus-some of which may show an affinity with existing stocks. The historic documents relative to the antiquity of the utilisation of the Horse by the Iranians or Aryo Persians, Hindoos, Greeks, Assyrians, Phœnicians, Egyptians, Hebrews, Arabs, Chinese, and Turanians, prove that some of these people who were farthest separated from Central Asia did not originally possess Horses. Zoology shows us that Central Asia has been the cradle of an important race of Horses, and that the Ass is originally from the south-east of Asia and the north of Africa. The Shemites primarily domesticated the Ass, and the Aryans conquered and utilised the Horse in Central Asia. The study of the ancient Egyptian monuments proves that there were no Horses in Egypt at a period entirely historical. Sesostris (B.c. 3433 - 3395) had no Horses in his army when he invaded Asia. In Egypt the Horse was introduced and naturalised by the invasion and occupation of this country by the Hyksos or Shepherd Kings (2898-1945 B.c.). There existed a large number of Horses in the armies which were conducted into Asia by Séti I. and his son Rameses II. the Great, sovereigns whose acts have been often confounded with those of the celebrated Sesostris. The reign of Rameses the Great (sixteenth century B.c.) ought to be considered as the minimum date which one can assign to the introduction of Horses into Nubia, where they have preserved their principal characters up to the present day. The Hebrews had not been accustomed to the use of the Horse at the time of the high priest Heli, and its use was contrary to the Mosaic law. The books of Samuel, Kings, and Chronicles, prove that it was David who introduced and Solomon who generalised the use of the Horse amongst the Israclites. This 
usage was reproached by the prophets of Israel for a long period after this epoch. The Horse which was domesticated in Britain and Gaul before the appearance of Latin civilisation, was, no doubt, a small, wiry, fleet animal, existing in large numbers, and docile to its master. It probably had some genetic relations of descent with the Equus fossilis of the English bonecaves, if indeed it was not an identical species.

\section{Order 6.-Proboscidea.}

In this order, which has now almost become extinct, the nose is prolonged into a cylindrical trunk, flexible in all directions, highly sensitive, and terminated by a prehensile appendix like a finger. The feet are fivetoed; the testes abdominal ; the placenta annular; and the mammæ pectoral. Three groups of Proboscideans may be defined. In one form, entirely extinct (Dinotherium), the incisors project in the form of long tusks from the upper jaw ; in the existing Elephants, from the lower jaw ; and in most species of the extinct Mastodon from both jaws. There are no canines; the molars are few, large, and transversely edged, the ridges sometimes few ; in Mastodon mammillate, often numerous, and with every intermediate gradation. There are never more than one molar wholly or two partially in place and use on each side at any time, the series being continually in progress of formation and destruction, or of shedding and replacement; and all the grinders succeed each other like true molars, horizontally from behind forwards. The total number of teeth developed in the Elephant is i. $\frac{2}{0} \mathrm{~m} . \frac{6}{6}$; the two large permanent tusks are preceded by two small deciduous 
ones, and the number of molar teeth which succeed each other on each side the jaws are not less than six, of which the last three answer to the true molars of other Mammalia. The surface of the crown of the molars in the Elephant is folded into a number of long laminar edges running at right angles to the axis of the jaw ; each ridge consists of a cone of dentine invested by enamel, and the intervals between the ridges are filled up with cement. As the surface is worn, it becomes regularly broken into ridges of different degrees of hardness, and therefore of different degrees of projection. The molars descend in succession from behind forward, and in a sort of arc, the anterior part of the grinding surface of each projecting first.

Two species of Elephants are known to exist at present, the Asiatic and African types. The first is distinguished by its elongated head, concave forehead, and comparatively small ears; there are four nails on the hinder toes; the molar teeth exhibit parallel ridges which are nearly equidistant; the tusks

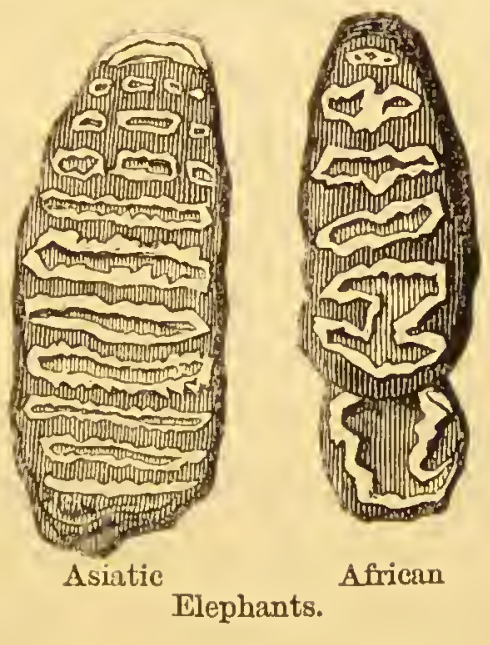
are usually short. In the African species the tusks are large; the external ear is enormous; there are three loose nails on the hinder toes; the bead is short, and the forehead convex. The grinding surface of each molar tooth presents a lozenge-shaped or rhomboidal figure, with a large median expansion. The Elephants are divided into three divisions-the Stegodont (fossil), the Loxodont (African), and the Euelephine (Indian) types. 
The Dinotherium, like the Tapirs, exhibited a series of molar teeth with broad transverse ridges, so closely resembling those of the Tapirs that Cuvier considered it to belong to that genus, and named it Tapir gigantesque. The lower jaw had two large tusks turned downwards, and the animal was apparently of aquatic habits. The general form of the skull and aspect of the nostrils places Dinotherium in an intermediate series between Manatus

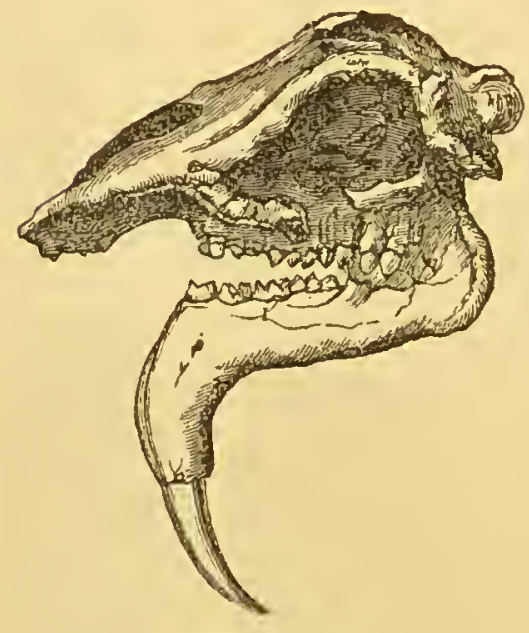

Dinotherium. and Elephas; but limb bones have been found so associated with teeth as to prove that the Dinotherium was a hoofed quadruped of aquatic habits, apparently transitional between the large Lophiodons and the Proboscideans. The Dinotherium is found in the Miocene deposits of Germany,

France, Spain, Switzerland, and India. Bones have been found associated with the pelvis of Dinotherium in such shape and juxtaposition, as to lead the discoverer to the conclusion that the Dinotherium displayed the character hitherto unknown in all wavebrained mammals, of possessing true marsupial bones like those of the Opossums and Kangaroos.

The second type of Proboscidea, that of the Mastodons, presents the large incisor teeth in the lower jaw, which however, unlike Dinotherium, are only slightly defected from the line of the grinding teeth. This species of Mastodon (MI. longirostris or arremensis) exhibited the teeth as in the annexed figure. The Mastodons 
were Elephants with the grinding teeth less complex in structure, and adapted for bruising coarser vegetable substances. The grinding surface of the molars was divided into numerous wedge-shaped transverse ridges, the summits of which were subdivided into smaller coves, which more or less resemble the teats of a cow, whence the name was given. Transitional links exist between these extinct Mastodons and the existing Elephants. Wear reduces the turned mammillated molars of Mastodon to show trefoil-shaped markings unlike those of the Hippopotamus.

The Elephants which are revealed to us in a fossil state exhibit a much greater diversity of form than is presented by the existing forms. The Elephas primigenius, or Mammoth, occurs throughout the Post-Pliocene period, and has ever been found in deposits where Man appears to have been contemporaneous with it. The grinders of the Mammoth are relatively broader, with narrower, more numerous and close-set transverse plates and ridges than in the existing Elephants. The Elephas priscus and the E. Melitensis, which latter was of the size of a small calf, belonged to the present African type. The tusks of the Elephant exhibit a pattern in the transverse section which accords with that of the "engineturning" of the outside of a watch, and affords a mark of easy distinction from the other ivories (Walrus and Hippopotamus) which are employed in commerce. The ivory found attached to the Mammoth remains is frequently so little altered as to be fit for the purposes of inanufacture, while the turquoise is produced from ivory tusks of the Mastodon highly charged with copper. The tusks of extinct Elephants 
often reach a far greater length than existing Indian Elephants.

The Elephas ganesa had tusks ten feet six inches in length, and curving so slightly that they projected eight feet five inches in front of the head. The Mammoth, as well as its contemporary the tichorhine Rhinoceros, lived in Siberia down to a period so close upon the advent of Man, that its flesh and hair, ligaments and skin, have been preserved to us. Unlike the existing Elephants, the genus enjoyed in palæontological times far wider distribution than at present. No form of Elephant is now known in the Old World but in the Post-Pliocene period; the Mammoth of species identical with that of England and Siberia ranged over the whole of the North American continent, co-existing with the true gigantic Mastodon, and with a second species of true Elephant (E. texianus mihi, seu Columbi, Falc.), the teeth of which showed molar plates wider apart, with broader cement valleys, and more alike in form to the existing Asiatic Elephant than was the old Mammoth, whose teeth were adapted to browse on the branches of the northern pines, birches, and willows. The Mammoth and the tichorhine Rhinoceros have passed away. The gigantic bovine animal which was their contemporary (Bubalus moschatus), and which was like them covered with a thick hairy coat, the better to adapt its essentially tropical organisation to the cold climate of Siberia, still exists up to the seventieth degree north latitude, and affords in northern regions almost the only gigantic representative of the Post-Pliocene fauna.

There are, as Cuvier has pointed out, some affinities between the largest and the smallest forms of mammalian life. The Elephants and the Rodentia 
have some points in common, which are, however, purely anatomical, and which do not indicate any real affinity between the Proboscidea and any form of smooth-brain mammal. The true line of affinity, or descent, as it might be termed, has been through the Sirenia to the Cetacea, which are the lowest known form of Gyrencephala. The order Proboscidea commenced at the beginning of the Miocene period; it reached its maximum in the later Pliocene and in the Post-Pliocene period. Though many of the species seem to have lived down to a time contemporaneous with that of Man, its development in species is now alike geologically and geographically restricted as well as in number.

\section{Order 7.-Toxodon'tia.}

This order only rests on two genera of large ungulate animals, with ever-growing incisor teeth like those of the Rodentia, the Toxodon and Nesodon being the two separate generic forms.

They were found in the Pliocene period of South America. Their classification as yet as a separate order is extremely doubtful, as they exhibit affinities to the Rodentia, the Sirenia, and the Proboscidea. No other forms are known of this gigantic rodent form, which appear to have been confined to the southern division of the New World.

In the two following orders of the gyrencephalate sub-class the hind limbs appear at first sight to have been amputated. They only possess the pectoral pair of limbs which are modified into the form of fins; the hind end of the body is expanded into a broad, hori- 
zontally flattened, tegumentary caudal fin. They have large brains, with many and deep convolutions, are devoid of hair, and have neither neck, scrotum, nor external ears.

\section{Order 8.-Sirenta.}

In this group both incisor and molar teeth exist, with flattened crowns, adapted for vegetable food. They form the link between the entirely aquatic Cetacea and the ungulate quadrupeds. The nostrils are two, situate on the upper part of the snout; the lips are covered with thick bristles; the mammæ are pectoral. The habits of the Sirenia are like those of the Hippopotamus, but, unlike it, they are found on the sea-coast as well as in rivers, which they ascend in the rainy season

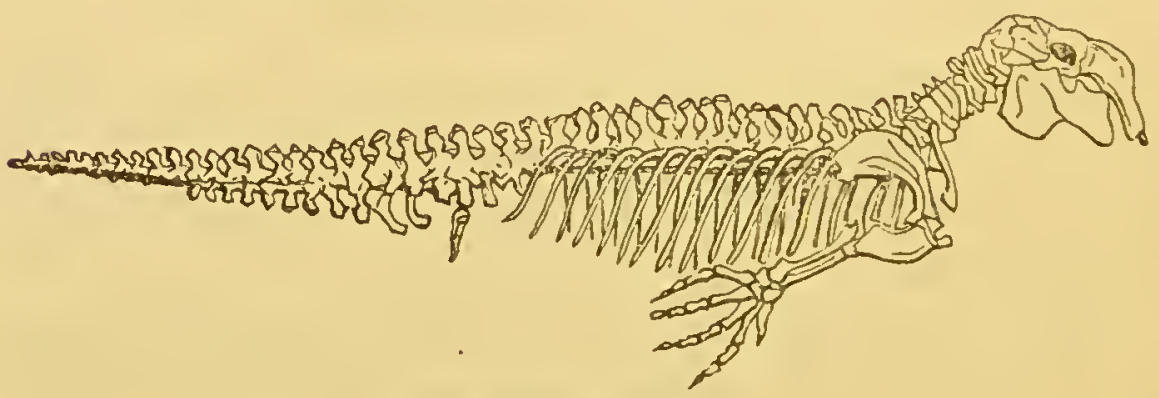

Skeleton of Dugong.

to browse on the fuci, water-plants, or shore-grass. The oldest known sirenian, Halitherium, is of Miocene age. Since that time the order has scarcely increased or decreased in numbers. 'The body is less fish-like than that of the Cetacea, the head is divided from the body by a short neck, the thoracic vertebræ are numerous and the lumbar very few; thus the Dugong (Halicore) has nineteen thoracic and four lumbar, and the Manati seventeen thoracic and two lumbar. The bodies of the vertebræ are rather triangular, being compressed and 
keeled below, and in the young state have no distinctly ossified terminal epiphyses. The bodies of all the thoracic vertebræ bear articular facets for the heads of the ribs. The neural spines are not very high, but the zygapophyses are well developed throughout the sexes. The metapophyses are rudimentary, and there are no distinct anapophyses. "The skull of the African Manati (Manatus Senegalensis), which may be taken as a type of the order, is remarkable for the massiveness and density of structure of the bones of which it is formed. There are no air sinuses in any part, and most of the bones when cut through appear as hard and solid as ivory. This character is not peculiar to the skull, but shared with it by the ribs and other bones, and must add much to the general specific gravity of this slowmoving animal, and aid in keeping it at the bottom of the shallow water in which it dwells while feeding on fuci and other aquatic vegetables. One of the most peculiar features of the upper surface of the face is derived from the position of the anterior nares, which is a further modification of that met with in the Tapirs among the Ungulata, and presents some approach to that so characteristic of the Cetacea. Taken together they form a large lozenge-shaped aperture, which extends backwards considerably behind the orbits. Their sides are formed by the ascending processes of the premaxillx below, and by the supraorbital processes of the frontals above, no trace of nasals being found in most skulls, though these bones are occasionally found in a most rudimentary condition attached to the edge of the frontals, far away from the middle line, a condition quite unique among the Mammalia, or only approached in some of the Dolphins. In the floor of the great narial opening is sem the vomer 
of very delicate structure, and posteriorly the ossified portion of the mesethmoid of considerable vertical extent. The olfactory chamber of the nasal cavity is greatly compressed from side to side, and contains a series of simple, longitudinally-placed ethmoturbinals, of which the upper one is very much the largest. There are no maxilloturbinals in any skulls which $I$ have examined. In front of the narial opening the face is prolonged into a narrow rostrum, formed by the premaxillæ, supported below and at the sides by the maxillæ. The under surface of this is very rugose, and in life supports a horny plate. There is a large, oval, single median anterior palatine foramen. The palate is long and narrow between the two parallel rows of numerous molar teeth. It does not extend beyond the last of these, and is formed almost entirely by the maxillæ, the horizontal plates of the palate bones being very narrow. Behind each row of teeth is a massive descending rough process, formed by the union of the palatine pterygoid plate of the alisphenoid and true pterygoid. Posteriorly this has a longitudinal groove, corresponding to the pterygoid fossa. Behind these the base of the skull contracts in width, leaving a large opening on each side of the basioccipital, between the alisphenoid in front and the exoccipital behind, and only partially filled by the tympanic and periotic." * The left carotid subclavian and vertebral arteries all arise separately from the aor'ta ; the heart shows external signs of the division into a right and left side, and its apex is deeply notched.

There are two long cæcal appendages attached to the stomach. They show some analogy to the structure of fishes, in which there are many separate cxcal ap- 
pendages; these open into the commencement of the intestine, and not into the stomach proper. Three sirenian iypes are known-one, the Manatis, which are found in Central America, Senegal, and the Red Sea; the Halicore or Dugongs, which are common in the Indian Archipelago; and the Rytina, a gigantic Sirenian form which was observed by Steller near the Kurile Islands in the middle of the last century, but was extirpated by the whalers.

\section{Order 9.-Cetacea.}

This order comprises the Whales, Dolphins, Porpoises, \&c., and is composed of entirely aquatic animals. The body is entirely fish-like in form, the fore-limbs are converted into fins, and the tail is transverse to the body. They are either toothless or monophyodont. In the latter case the teeth reach the maximum number known in the class Mammalia, reaching in some of the Dolphins to 190 teeth in all. The teeth are of one kind, and are of semi-conical shape. More than three phalanges are developed in the hand. The external nostrils are on the top of the head, and are termed spiracles or blow-holes. The skin is naked, except a few vibrissæ near the mouth; and there is a thick coat of blubber underneath the skin. The cervical vertebræ are partly soldered together; they are reduced to six. The sternum only supports a few ribs, and in some cases is almost rudimentary. The form of the sternum in those genera where it exists is a convenient test of the species. The lumbar vertebræ have the upper transverse process much developed. There is no sacrum. The stomach is often complex. There are large arterial plexuses in the 
thorax, towards the base of the skull, and around the spinal chord, storing arterial blood during the submersion of the Whale; and in the posterior part of the body are venous plexuses of great capacity, reserving blood for the lungs. The structure of the jaw and mouth are very peculiar. Large plates of horny substance, termed "baleen," or whalebone, are found on either side of the upper jaw ; of these plates, which are termed "fanons," there are in the right Whale 700 in all. These are arranged in a single longitudinal series on each side of the upper jaw, situated close to each other, depending vertically from the maxillary bones. The base of each of the whalebone plates is hollow, and is fixed upon a pulp developed from a vascular gum. Each plate develops a fringe of

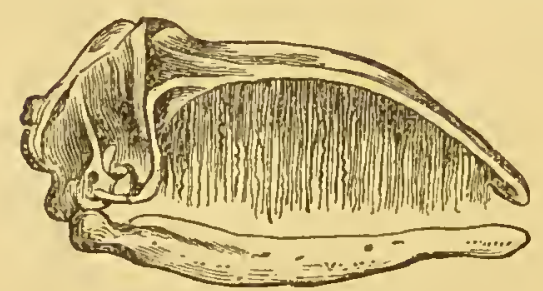

Slsull of Whale.

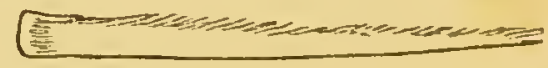

Whalebone.

moderately stiff hairs, which project into the mouth, and form an obstacle to the escape of the small marine animals (Clio, Limacina) and minute crustacea on which the Whale feeds. In Balona mysticetus there are about two hundred large marginal plates on each side, from ten to fourteen, and rarely fifteen feet, in length, and about one foot in breadth at their base; these plates are overlapped and concealed by the underlip when the mouth is shut. In the Finner Whales (Batonoptera) the baleen processes are fewer and smaller than in the "right" Whales: the marginal plates, on the other hand, are more numerous, and exceed three 
hundred on each side; the are broader in proportion to their length, and much smaller in proportion to the size of the entire animal. For this reason the Finner Whales are held in less estimation, and produce inferior commercial results.

Before the Whales acquire their series of baleen plates, they manifest in the fœtus a true dental system, which accords with that of the earliest stage of tooth development in the other Mammalia. In the fœtus of a Balcenoptera there were twenty-eight minute teeth in the upper and forty-two in the lower jaw. These disappear before birth, and are subservient to no practical use, but merely illustrate the morphological law which governs organs in an arrested state of development. The bottle-nosed Whales form a transitional link between the true Whales and the Dolphins, as the fotal denticles do not perish, but the anterior ones, answering to the lower incisors in other Mammalia, are developed to a large extent, though they remain during life hidden by the gum.

In the Narwhals (Monodon monoceros) the matrix of the tooth in the left premaxillary is enlarged, and this solitary tooth is often developed to the length of nine or ten feet, with a basal diameter of four inches. The tusk is outside marked with spiral ridges. The right premaxillary in a few instances has been known to develop a similar tusk. In the grey Dolphins there are at least six pairs of teeth which arise above the gum. In the spermaceti Whales (Physeter macrocephalus) the outward dentition is confined to the lower jaw. There are twenty-seven teeth on each side. In the young they are conical and pointed, but are more obtuse in the aged. They are lodged in a wide and moderately deep groove, imperfectly divided into 
sockets, the septa of which reach only about half-way from the bottom of the groove. These sockets are too wide and too shallow to retain the teeth independently of the soft parts. The dental system of the lower jaw enters depressions in the opposite gum when the mouth is closed. This gum, however, contains specimens of the primitive fotal series of teeth, which are always much smaller and more curved than those of the lower jaw. The most formidable dentition in the order is that of the carnivorous Grampus (Phoccena orca), whose canine teeth are as large in proportion to the length of the jaws as in the Crocodile; they are fifty in number, all fixed in deep and distinct sockets separated by interspaces which allow of the close interlocking of the upper and lower teeth when the mouth is closed; the longest and largest teeth are at the middle of the series, and they gradually decrease in size as they approach the ends. In the common Dolphin the teeth are one hundred and fifty. Aberrant forms of dentition are also presented in Platanista and Ziphius. In nearly all of these types the skull is uneven and asymmetrical. The foramina for the passage of nerves are more unequally arranged than even in Man. The fuce is stretched out into an elongated depressed pointed beak or rostrum, "formed by the premaxillæ and maxillæ surrounding the vomer and prefrontal bones." * The cerebral cavity is of peculiar shape, short and broad, but excessively high and contracted above. The ear-bones of the Whales and Dolphins are distinct from the rest of the skull, and only connected by ligament with the other

* This elomentary fract is accented, as the vomor has hecn said to show on the upper facc of the rostrum in Belemoziplins (Quart. Jour. Geol. Soc. vol. xx. 1. 392), and even to occupy" "lully a third of tho width of 'its ' upper' face." 
cranial bones. It is easily separated from the rest of the skull by maceration, and consists chiefly of the tympanic bone, which is large and inflated. A cavity is usually developed on the top of the skull of the Sperm Whale, which contains the fatty excretion known by the name of "spermaceti" in commerce. This substance is also produced from the blubber, which is only fourteen inches deep on the breast and eleven on the other parts of the body, and is therefore not so abundant in proportion to the size of the animal as that which is obtained from the Greenland Whale. Its superior quality, however, compensates fully for its deficiency in quantity. It is much used for burning in lamps. The spermaceti from the head is very valuable as an ointment and for burning in candles.

Several otber species of Whales besides the "right" Whale (Balcena mysticetus) are employed in commerce. The white Whale (Beluga catodon), the hump-backed Whale (Megaptera longimana), and the Pike, or finned Whale (Balcenoptera rostrata), are found in the Arctic seas neighbouring and west of Greenland.

The skull in the true Whale is usually more symmetrical than in the Odontocete or Dolphin family. The Porpoise (Delphinus phocana), the Dolphin (D. delphis), and the Grampus (D. orca), attain less dimensions than do the larger or baleen Whales.

\section{Sub-Class.-Lissenchiphala.}

These mammals are separated by a wide chasm from the forms hitherto described. The corpus callosum is present connecting semispheres as little advanced in relative bulk or outward character as in the succeeding 
sub-class. The surface of the hemispheres is usually smooth, or with very slight folds, whence the name of

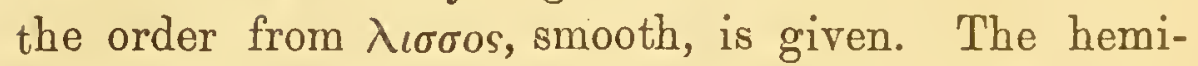
spheres leave the cerebellum and part of the olfactory

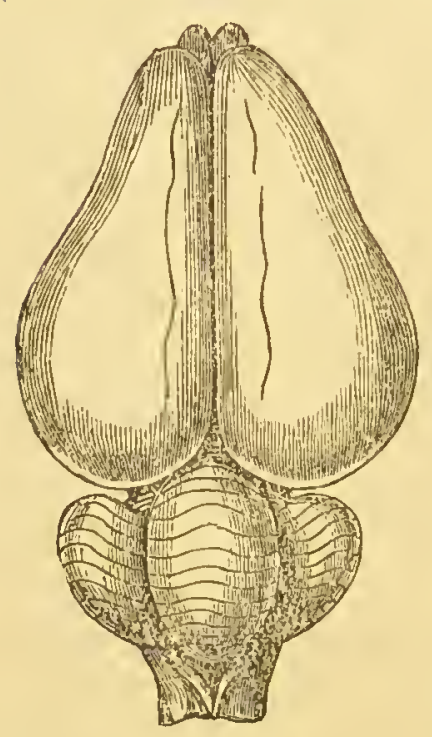

Brain, Agouti.

lobes exposed. There are two precaval veins. The squamosal in most and the tympanic in some retain their primitive character of distinct bones. The orbits have never an entire rim of bone. It has been well said by Owen that besides these general characters of affinity to birds and reptiles, there are other striking indications of the same low position in particular orders or genera of the sub-class. Such, e.g., are the cloaca, convoluted trachea, supernumerary cervical vertebræ, and their floating ribs, in the three-toed Sloth: the irritability of the muscular fibre, and persistence of contractile power in the Sloths and some of the Bruta; the long, slender, beak-like edentulous jaws and gizzard of the Anteater; the imbricated scales of the equally edentulous Pangolins, which have both gizzard and gastric glands like the proventricular ones in birds; the dermal bony armour of the Armadillos like that of loricated Saurians; the quills of the Porcupine and Hedgehog; the proventriculus of the Dormouse and Beaver; the prevalence of disproportionate development of the hind limbs in the Rodentia, coupled in the Jerboa with confluence of the three chief metatarsals into one hone, as in birds; the keeled sternum and wings of the Bats; the aptitudes of the Cheiroptera, 
Insectivora, and certain Rodentia to fall, like reptiles, into a state of torpidity, associated with a corresponding faculty of the heart to circulate carbonised or black blood;--these, and the like indications of co-affinity with the Lyencephala to the oviparous air-breathing Vertebrata, concur with the cerebral character in demonstrating the low position of the Lissencephala in the mammalian class. The lissencephalous or smoothbrained mammals fall naturally into four well-defined orders-the Cheiroptera, Insectivora, Rodentia, and Bruta. As the Cheiroptera afford perhaps one of the most aberrant types in the whole class Mammalia, classed by Linnæus with the Primates highly organized or Quadrumana on account of their pectoral mammæ, associated by Cuvier with Carnivora, and considered by later zoologists almost as a mere branch of the Insectivora, they demand separate investigation, in order that their claims to ordinal distinction should be investigated.

\section{Order 10.-CheIroptera.}

This order of Mammalia is characterised by having the anterior extremities, and especially the hands, so modified as to serve the office of wings, the fingers being extremely lengthened and connected together by a thin membrane. Of this order the common Bat (Vespertilio pipistrellus) may be regarded as the type. The order includes very numerous and diversified species, which have been grouped by De Blainville, who has devoted an especial study to them, into three principal divisions. Of these the first includes the largest species, called "Flying Foxes" (Pteropus). 
They are, however, vegetable-feeders, and are characterised by having the ears and nose of a simple form; the two innermost fingers of the hand armed with

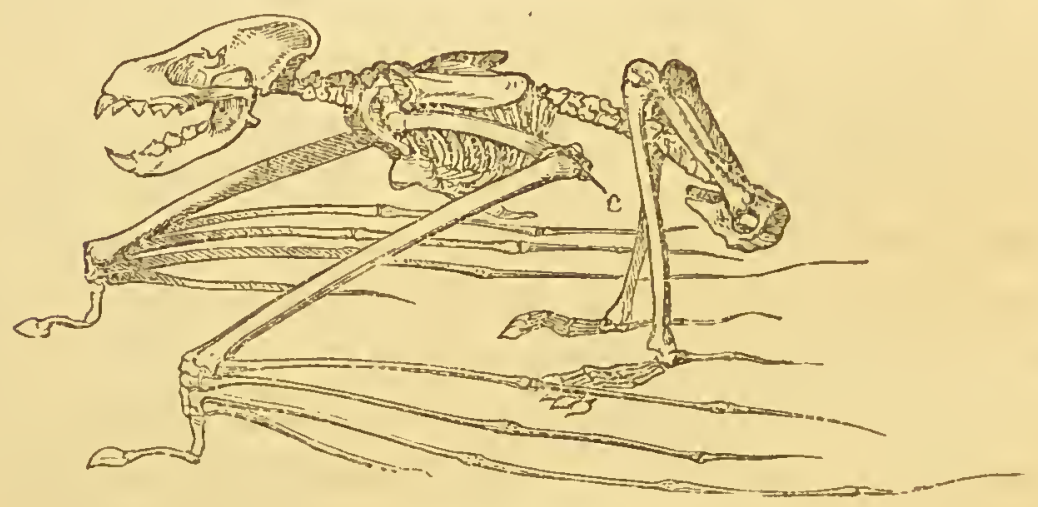

Skeleton of̂ Bat.

claws, and of the ordinary structure; the tail and the web-skin connecting the hind-legs, and called the "interfemoral" web, very short or wanting; and

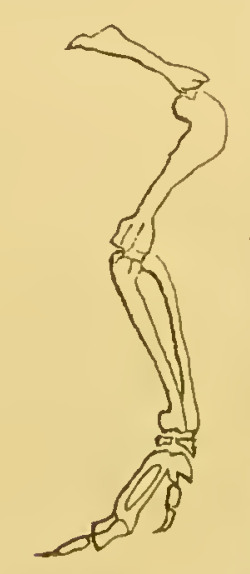

Fore-limb of Bird.

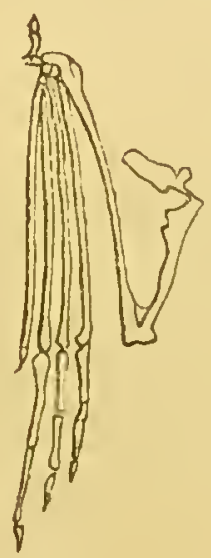

Fore-limb of d3at.

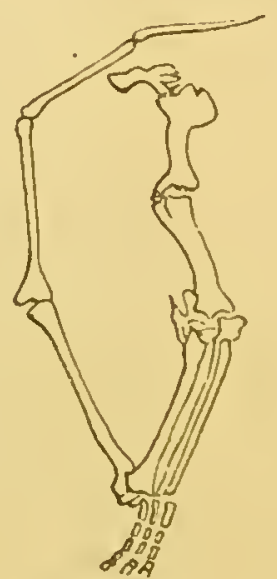

Fore-limb of P'terodactsle.

lastly, by having the molar teeth separated by intervals, and of simple structure. These Bats are distributed over the warmer latitudes of the old continents, and extend to the islands of the Pacific Ocean. Tho 
second division has the nose complicated by variously shaped and grotesque membranous foliations; the first or innermost digit alone retains its ordinary structure and armature; the molar teeth are beset with sharp tubercles; and the food of these species consists of insects, or the blood of higher organised and larger animals. The vampire Bats of South America belong to this group, which also includes the horse-shoe Bats (Rhinolophi) and other genera distributed over all parts of the Old World. The third division of Cheiroptera has the nose constantly simple; the other characters as in the second. It includes the Bats properly so-called (Vespertilio), which are uniformly insectivorous and of small size. A fourth division of true Cheiroptera, that which includes the Colugos (Galeopitheci), is more difficult to classify, inasmuch as they afford steps which link them closely on to the Lemurs in the quadrumanous series. Their teeth are almost unique in the mammalian class, the first two lower incisors presenting the form of a comb, which is procumbent, and extends in front of the lower series of in-
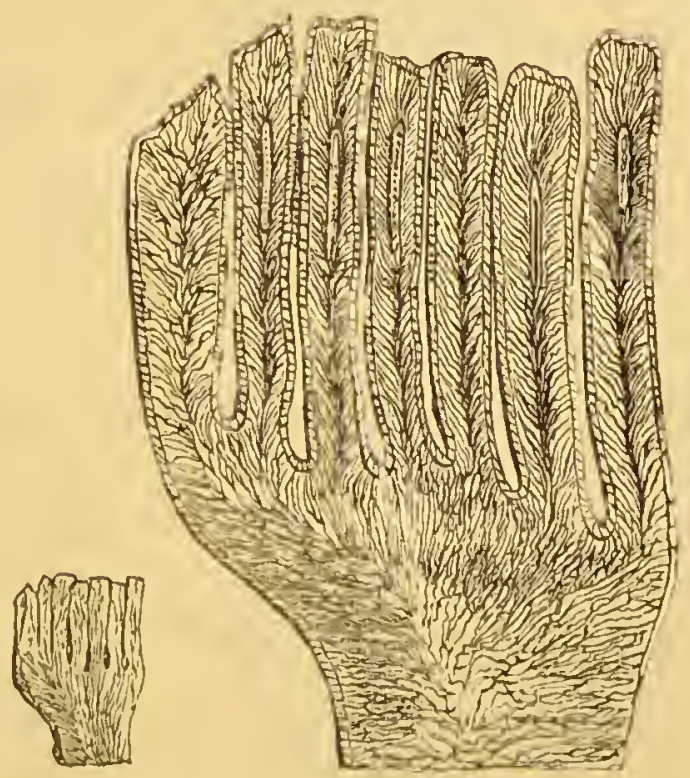

Teeth of Colygo. cisor teeth. The two anterior incisors of the upper jaw are separated by a wide space. The section of the lower incisor of Galeopithecus is shown in the accom- 
panying diagram. In these Mammals the cæcum is large and long; there are two nipples in each armpit. The Colugos are found in the Philippine Islands and Malacca. Bats of the genera Phyllostoma, Plecotus, and Megaderma exhibit modification of the nose membrane drawn in the accompanying figures, such dilation of the muscles and membranes surrounding the nasal and mouth cavities in other mammalian forms.

\section{Order 11.-Insectivora.}

In the order of small smooth-brained mammals

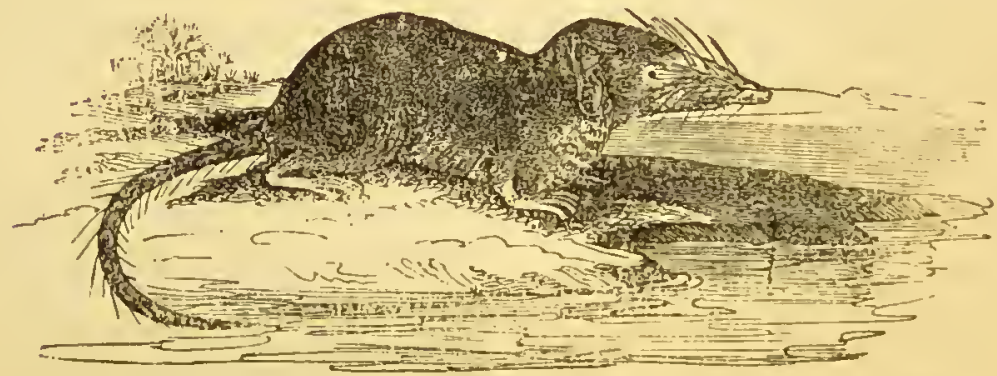

Shrew.

the molar teeth bristle with cusps, and are associated

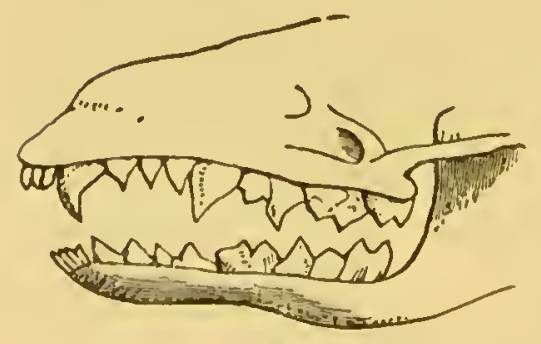

Teeth of Shrew. with true canines and incisors; they are unguiculate, plantigrade and pentadactyle, and they have complete clavicles. In South America and Australia they are absent, but their place is filled up by marsupial Insectivores. One genus, Solenodon, is found in Cuba and St. Domingo. The earliest known Mammalia contain many types which 
accord with the form of the Insectivora order. In the Purbeck beds Spalacotherium tricuspidens appears to resemble the Cape Mole (Chrysochlora aurea) in most of its characters, at the same time that it affords a relationship to Amphitherium, a marsupial form from the Stonesfield slate or Middle Oolitic series.

Four divisions of Insectivora are known, those to which the Mole, the Shrew, the Tupaia, and the Hedgehog respectively belong. The Moles are distributed over the whole Northern Hemisphere. A genus of them is also found in South Africa; none have ever been met with in the intertropical parts of the world, nor in South America, nor Australia. Three types of form exist amongst the Moles-one Talpa, peculiar to Europe and Asia; one Scalops, to North America; and the third Chrysochloris, to South Africa-all very limited in number of species. The European Mole extends eastward in the temperate latitudes from Treland to the Altai Mountains. A species of Urotrichus is found in Japan, and another closely allied one in California; these, although separated from each other by the whole width of the Pacific Ocean, are apparently so closely related as to be nearly identical. The true Mole is not found in North America, the representative genus Scalops, in which there are four lower incisor teeth instead of six or eight, taking its place. The star-nosed Mole, Condylura, in which the point of the nose is produced into a slender proboscis, furnished at the apex with caruncles arranged radiately, was thought formerly to possess a knotted structure of the tail, whence the name was given. This, however, arises through a mistake. The Condylura is found in the whole northern part of the United States, from the Atlantic to the Pacific. The Cape Mole (Chrysochloris 
aurea) is wholly South African, and in the fure-paws there are only three fingers developed instead of five.

The second division of Insectivora, or Shrews, may be divided into three great sections-the long-tailed Shrews (Sorex, Amphisorex, and Crossopus), which are found in the northern part of both hemispheres; the short-tailed Shrews (Blarina), found in North America; and Crocidura, which is essentially an Old World tropical form. The Sorex etruscus is the smallest Mammal known, scarcely more than two and a half inches long, of which the tail makes about one inch. In Russia is f'ound another genus of Shrew (Myogale), with a naked, more or less compressed tail, of which one species is found on the banks of the streams at the foot of the Pyrenees. An allied species is found fossil in the Miocene at Sansan, in France. In Solenodon, a West Indian genus, the middle lower incisors are small and narrow, placed between two long conical ones, hollowed on the inner surface by a deep groove, and possibly linking the true Shrews with the Tanrecs (Centetes) and Ericulus. These Madagascar forms resemble the Hedgehog, but, unlike it, do not possess the power of rolling themselves up in a ball. The snout is elongated, and the nose proboscidean. The back is covered with bristles and hairs mixed alternately. The Hedgehogs are found over the whole of Europe and the northern half of Asia. A species exists at the Cape, but none are yet known from Western or Central Africa. The body is densely covered above with spines, and at the sides and below with bristles and hair.

The skeleton of Insectivora exhibits a singular and remarkable modification of the whole structure, which in Hedgehogs is adapted for ordinary progression, in 
other forms for leaping and swimming, but in a more special degree for burrowing. In the Mole the first sternal bone, or manubrium, is of unusual length, being much produced forward and its under surface downward in the shape of a deep keel, for extending the origin of the pectoral muscles. Seven pair of ribs join the sternum. In the lumbar vertebræ a wedge-shaped hypapophysis is fixed into the lower interspace of the bodies of the vertebræ. The scapula is extended, the clavicle is strong and well developed, the humerus square and massive, and the hand broad and rake-like. The long and carinated sternum attaches pectoral muscles which govern these forms, which indicate how well the Mole may cleave its way through the earth. The soft and silky fur, from its being inserted in the skin perpendicularly to the surface, will lie indifferently in any direction, affords no obstacle to the retrograde retreat of the Mole when it meets with any

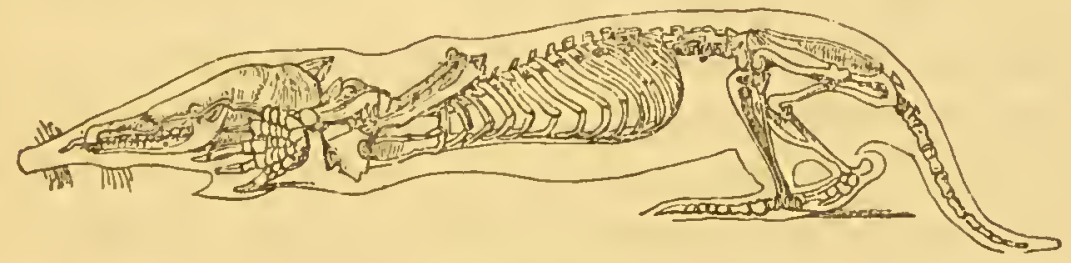

Skeleton of Mole.

opposition to its progress. The anterior extremities exhibit the most admirable conformation for the purpose of excavating its way through the soil. The strength and peculiar structure of the bones of the shoulder and of the fore-arm are in harmony with the remarkable form and direction of the hand. The joints of the fingers are extremely short, with the exception of the terminal ones, which are almost as long as the rest of the hand; these are convex above, grooved beneath, taper at the extremities, at which part they 
approximate to each other, and each is furnished with a long acute nail. The palms are directed outwards; the hand is only susceptible of being partially closed, which is effected by the inclination of the terminal joint alone. The Hedgehog, on the other hand, affords a dentition and a general physiognomy entirely diverse from that of the Mole.

Bell has said there has existed in France for a long period an opinion that there are two species of Hedgehog indigenous to that country, one of which is said. to have the snout of a hog, the other the muzzle of a dog. Renault, who has given the only existing figure of the latter form, appears to have held this opinion, and to have supported it, at least to his own satisfaction, by dissections. Ray declares that one of them certainly does not exist in England, and seems to doubt its reality. Daubenton also states that he examined two males, said by the country people to belong to the two sorts above named, and that although he found considerable diversity in the dimensions of the various parts, as well as in the size and weight of the individuals, he comes to the conclusion that these distinctions constitute them varieties only of the same species. The body of this animal is oblong, regularly convex above; the head very conical; the ears short, broad, and rounded; the eyes prominent. The teeth are thirty-six in number. The central incisor teeth in the upper jaw are long and robust, separated to a great extent above, slightly approximating towards the points, at which part, however, they are still distant; the second and third on each side are small, particularly the second, and conical, resembling false molars. There is a small space between the third incisor and the next tooth, which has two roots. There are two 
other false molars, smaller than the former, each having an internal tubercle. The first three true molars are large, nearly quadrate, and furnished with strong, acute tubercles; the second of these is the largest; the last molar is a small tooth placed obliquely, and having in some measure a cutting edge. In the lower jaw the central incisive teeth stand nearly forwards, and much resemble those of the upper jaw. The two anterior false molars stand forwards, and are very similar to the lateral incisive teeth of the upper jaw; the third is nearly perpendicular. The first true molar is an oblique tooth, with two principal tubercles; the second and third are broad, strong teeth, having five and four tubercles; and the fourth is very small.

The common Shrew in England is the Sorex araneus, the Water Shrew (Sorex fodiens) and the Oared Shrew (Sorex remifer) being also known. The latter species is more rare than the others, and is the largest known species in England. The fossil Shrews extend throughout the Pliocene, Miocene, and Eocene strata; and in fact Spalacotherium and Triconodon of the Purbeck beds can be considered true placental smooth-brained Insectivora. The larger types, such as the Desman, appear to have been well represented in geological time, and to have had a wider distribution than the existing forms now have.

\section{Order 12.-Ronentia.}

These are characterised by the large and longcurved incisors in each jaw, separated by a wide interval from the molars, and the teeth are so constructed and the jaw so articulated as to reduce the food to 
small particles by acts of rapid and continual gnawing,

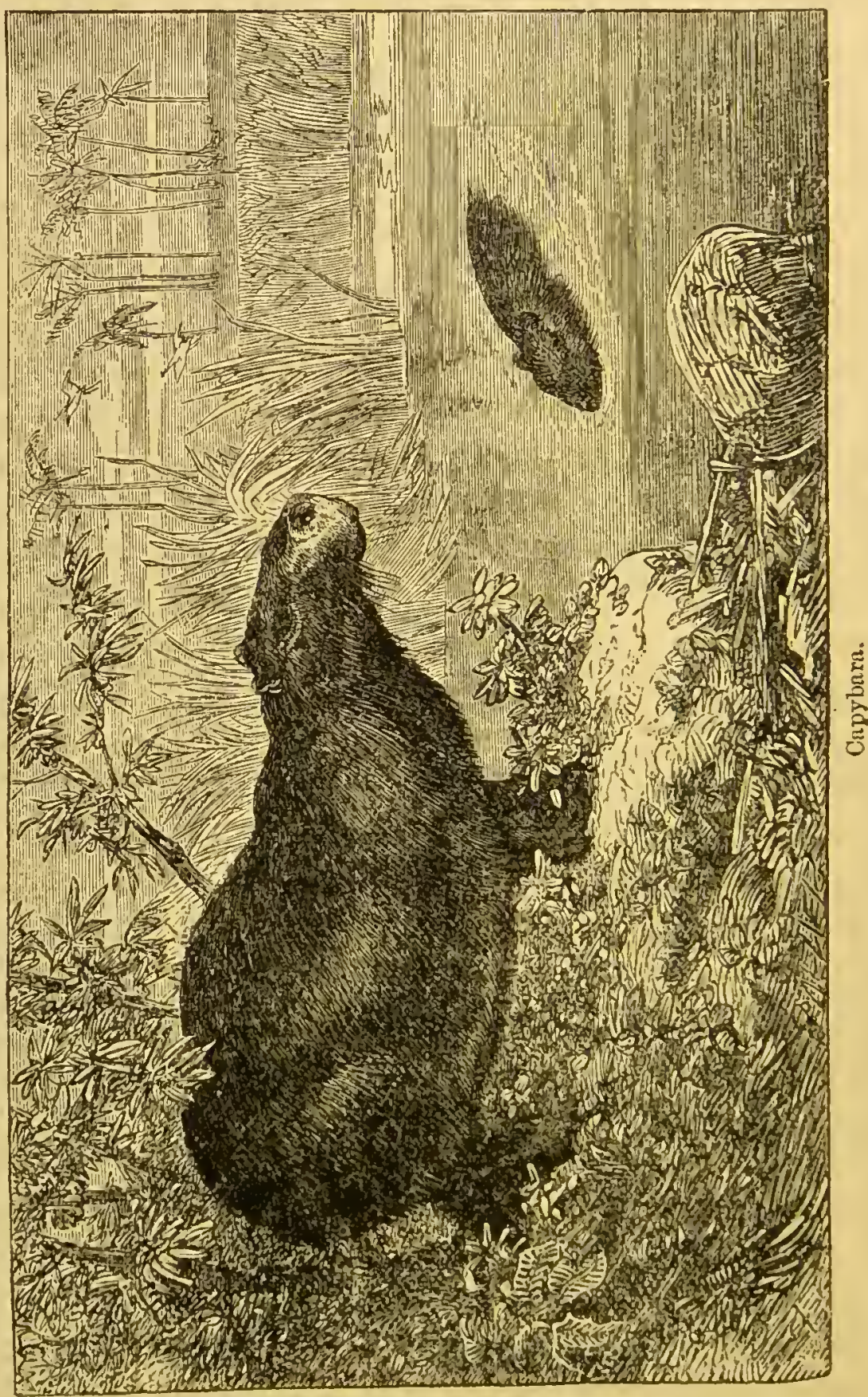

whence the name of the order. The orbits are not separated from the temporal fossæ. The placenta is 
asually discoid, but is sometimes a circular mass, or flattened and divided into three or more lobes (Lepus). The Beaver and Capybara are now the giants of the order, which, like the Ducks amongst birds, is distributed over every continent. They chiefly consist of small, numerous, prolific, and various unguiculate genera, subsisting wholly or in part upon vegetable food. Some Squirrels (Pteromys) have an expansicn of skin between the fore and hind limbs, which subserves the purpose of taking short flights like the Bats and Galeopitheci. Some Lemmings perform remarkable migrations, to which the impulse, unchecked by danger or any obstacles, appears to be mechanical. Thus the Lemmings of Lapland cross rivers and wide sea estuaries, where they are often drowned, and traverse deserts where no food exists for their sustenance. Many Rodents build artificial nests, and a few, as the Beaver, build these in association. In these inferior mental phenomena we are reminded of birds. Hiberuation is performed by

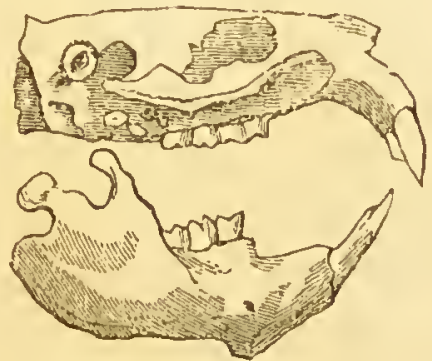

Skill of Rodent. Rodentia as in the Reptilia. There is no evidence of fossil Rodentia in the secondary strata, and the oldest forms appear in the lowest tertiary beds. 'The Rodentia have seven cervicial and as a rule nimeteen dorso-lumbar vertebra. In this order, as in the Dinotheres, Toxodonts, Mastodons, Ilephants, Dugongs, amongst the Gyrencephala, and the Wombat umongst the Marsupials, the ordinary number of incisors is diminished, and their growing power trausferred to a single number of tusks projecting from the fore part of the upper or lower juw, or of both. A 
single pair of large-curved, ever-growing incisors, in each jaw, is confined with so many peculiarities of structure as to have led to their association in one order, called by Linnæus Glires (from the word Glis, a Dormouse), and by Cuvier Rongeurs, from the gnawing power arising from this dental peculiarity.

The incisors are separated by a wide interval from the molars; the upper pair form a larger segment of a small circle, the lower ones a small segment of a large circle; these are usually the longest, and these sockets extend below or on the inner side of those of the molars to the back.

The first family amongst the Rodentia is that of the Porcupines (Hystricidce), which also includes the Cavies or Guinea-pigs, Chinchillas, Chilian Squirrels or Octodons, Spiny Rats or Echimyina, and Pacas or Agoutis, or Dasyproctince. These are almost entirely South American forms, with the exception of the Porcupines themselves. Only two species belonging to them are found anywhere else than in the Old World, and only five or six out of South America. Of the Porcupines, two wellmarked groups exist; one confined to the Old and one to the New World. The first family of the Rodents is that in which the Cavies (Cavia) are comprised. The Capybara may be taken, as it is the largest individual amongst all Rodentia, as the first for consideration. In this form there is more absolute resemblance to the Pachydermata than at first appears from its essential rodent affinities. It had been pointed out by Cuvier that the Proboscidea had many relations with certain Rodentia. Firstly, their large incisor teath; secondly, their molar teeth, often formed of parallel plates; thirdly, the form of many of their bones, in which a great analogy can be traced between the Proboscidea and the 
Caviini. Here the body of the molar teeth are completely traversed by nine or ten plates of enamel, reminding us of the plates of which the teeth in Elephants are composed and united by parallel folds of cement. The analogies with the Pachyderms are stated by Mr. A. Murray to extend also to their babits. The largest species of the order Rodentia are the most aquatic. The Beaver, the Coypú, and the Capybara are all semi-aquatic, and attain larger dimensions than other genera of the order. The Capybara is an essentially South American form; and remains of an animal closely resembling it have been found in the Pliocene Brazilian bone-caves. The other Cavies illustrate a remarkable restriction to the southern part of the American continent. The Patagonian Cavy (Dolichotis Patagonica), and the common Cavy or Guinea-pig (Cavia aperea), are perhaps the best-known types. The latter was commonly called "Guinea-pig" because imported in the ships which had traded to Guinea, and, on their return royage, often brought Brazilian produce from the opposite side of the Atlantic. All Cavies are entirely unknown in the Old World. The next family of Rodents is that of the Chinchillide, which, also confined to South America, are usually found at the highest elevation in the Andes. The close woolly hair of these animals adapts them for a colder climate than is the case in the Cavies, whose glossy, and often bristly, coat is more suited for a warmer locality. One exception, however, to this rule exists in the Viscacha of the Pampas, which is the only burrowing form amongst the Chinchillidx. It does not, like the Dolichotis, subsist on the desert gravel of Patagonia, but prefers a clayey or sandy soil, and a different or more abundant vegetation. Near Mendoza it occurs in close 
neighbourhood with the allied Alpine species; but, according to Darwin, the river Uruguay forms an impenetrable obstacle to its eastward migration. Unlike the Lemmings, the Viscachas have never traversed this apparently impossible barrier.

The other Chinchillas, the fur of some of which used to be highly prized in commerce, are confined to the higher regions of Peru, Bolivia, and Chili. The next family, the Octodontina, are closely allied to the Chinchillas, and their habitat is on the whole similar. The republic of Chili appears to be their metropolis. They are found on both sides of the Andes. Fossil species are also known from Bahia Blauca, where they were contemporaneous with the Mastodon, Mylodon, and other extinct forms.

The Echimyina are Rats, practically spinous and partially hairy. They are found in South America generally; one species inhabiting the Cape of Good Hope, and another both in Western and Southern Africa. The great metropolis, however, of the family is Brazil ; one genus, Carterodon, has been found in the bone-caves in a fossil state, which has been since proved by Reinhardt to exist in a living state, affording us thus a link between the ancient and the existing faunæ of the New World.

The Agoutis (Dasyproctina) are almost peculiar to Brazil and to the neighbouring countries; they also exist in the West Indies and New Granada. The Pacas and Agoutis bear a superficial resemblance to the Cavies. The true Porcupines, some of which are terrestrial and some arboreal, some burrowing, some diurnal and some nocturnal, are found both in the New and the Old World. All the arboreal and prehensile-tailed forms are habitants of $\Lambda$ merica. 
The Hares (Leporini) are found in nearly all regions above the tropic of Capricorn, as well as in the Cape Colony. The Pikas (Lagomys) appear to have been the predecessors of Hares in the Pliocene and PostPliocene periods. They are found throughout what may be termed the "Mongolian" Asiatic zone, from the Caucasus eastward. The true Hares (Lepus) comprise about thirty species. The common English Hare is not indigenous in Ireland nor in the highlands of Scotland, where the Celtic or variable Hare, which in winter turns white, replaces it. Hares are rarest in South America, where their place is occupied by the Cavies and dasyproctine Rodents above described. The range of the common Rabbit is very much the same as that of the Hare; but, unlike it, extends into North Africa.

The family of Dormice (Myoxini) is entirely confined to the Old World, where three species are familiar to French, and one, the Myoxus avellanarius, to English zoologists. The family appears to have been in existence since the Miocene epoch.

The Squirrels (Sciuridce) are divisible into two great divisions; those which are arboreal- the Squirrels properly so called-and those which are terrestrial, the latiter being termed Marmots. The African bristly Squirrel (Xerus) forms a slightly diverse section of the first division. The hundred and eighty species into which the restricted genus (Sciurus) is divided are widely distributed over the whole globe. Some of them (Sciuropterus and Pteromys) have a peculiar formation of the membranes of the side, which are dilated so as to form a wing-like expansion, the better to aid the animal in its leaps from tree to tree. Another form - the Ground Squirrels (Tamia) and the Sousliks (Sper- 
mophitus) - link the Squirrels with the Narmots, as they, unlike the Squirrels, possess the cheek pouches, which are so characteristic of the latter type of Rodent. Between the Missouri River and the Rocky Mountains is found another form of Marmot, the "Prairie Dog" $(C y n n$ mys $)$, which burrows in the plains of the western United States. The family Murini may be grouped under six heads - the Beavers (Custor), the Voles (Arvicolu), the Jerboas (Dipus), the Molerats (Spalux), the Gophers (Saccomys), and the true Rats and Mice (Mus and Hesperomys).

The Beavers are confined to northern temperate zones, the Old and New World species being of distinct origin. In the Post-Pliocene period Beavers of allied species to the existing ones (Trogontherium) were frequent. While they formerly inhabited the whole of Europe and northerly Asia they were extirpated by Man, and, in a few scattered examples, now only exist where they are carefully preserved. The constructive instincts of the Beavers, though they have been much exaggerated, are truly remarkable.

The Arvicole comprise both the Musk Rats and the Field Mice or Voles. Unlike the Beaver, the tail is vertically disposed in all the species. They occups

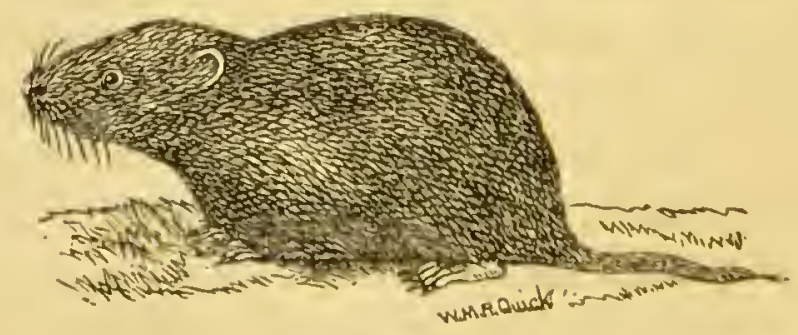

Field Vole.

generally colder and more northern districts than the true Mice. In the Lemmings (Myodes) the feet bave 
hairy soles, and the claws are sickle-shaped, and adapted for digging. Whether the Isernming exists in Iceland or not is an open question, but five species of the genus Myodes are known from the New World and three from the Old. In the Spalacini, or Molerats, the eyes are aborted in the slightest possible developrient, and there appears to be no functional developraent of the sense of sight. The Pouched Rats (Geomys) and the Gophers (Saccomys) are absent in South America. In these species the cheek pourhes are enormously developed.

The division of true Mice falls very naturally into two groups, those of the Old and those of the New World. 'The old World Mice have large and broad molars, eacin with tubercles placed transversely, and those in the upper jaw have their tubercles in each transverse series. The New World species have the molars narrower, and only two tubercles in each transverse (or slightly oblique) series. The Mice are the only Rodents, and nearly the only placental mammals, in Australia. 'They are the largest distributed of all mammals. The only places where they are almost absent is the Arctic regions and in Central Asia. The size varies, the largest species, the Pandicnot of India, being more than two feet in length. The old English black Pat is becoming almost extinct before the brown (erroneously termed the Norway) Rat, which species has spread itself over nearly the whole world, and of which descendants more or less modified are found in the Galapagos and Ascension Islands.

The Jumping Mice (Meriones) are found in Africa. or the continental parts of Asia, including India and China. In the northern portion of the United States they are replaced by the Jaculi, or true Jerboas, or by the Irapalotes, a placental Rodent, which in Australia 
leaps across the plains. Another form (Pedetes) is found at the Cape of Good Hope, and appears to present a considerable superficial resemblance to the marsupial Kangaroo Rats.

\section{Order 13.-BRUTA.}

Two genera exist in this order which are devoid of teeth; the rest possess these organs, which are destitute of true enamel, are never displaced by a second series, and are very rarely implanted in the premaxillary bones. All the species have very long and strong claws. The ischium as well as the ilium unites with the sacrum. The orbits are not divided from the temporal fossæ. The three-toed Sloth shows analogy to the oviparous Vertebrata by having supernumerary cervical vertebræ, which support false ribs, and by a convoluted wind-pipe, as in birds. The dorsal region is excessively elongated, being composed of twentythree pairs of ribs, and the lumbar region is proportionately abbreviated, as in the Lizard. The same tendency to repeat characters, only exhibited in inferior types, is shown by the abdominal testes, the single cloacal outlet, the lower cerebral development in all Bruta, the bony scales of the Armadillo and the horny scales of the Pangolins, the solidity of the bones produced by the absence of medullary canals in the Sloths, and the great tenacity of life and long-enduring irritability of the muscular fibre in both the Sloths and Anteaters. In the present geological period we find that the order Bruta is scantily represented, and that it was in a fossil state where its past greatest development both of number and species has taken place. One form 
represented by the Manis, or Pangolin, is found in Asia and Africa; the Orycteropus is peculiar to Central and South Africa ; the rest of the order, consisting of the true

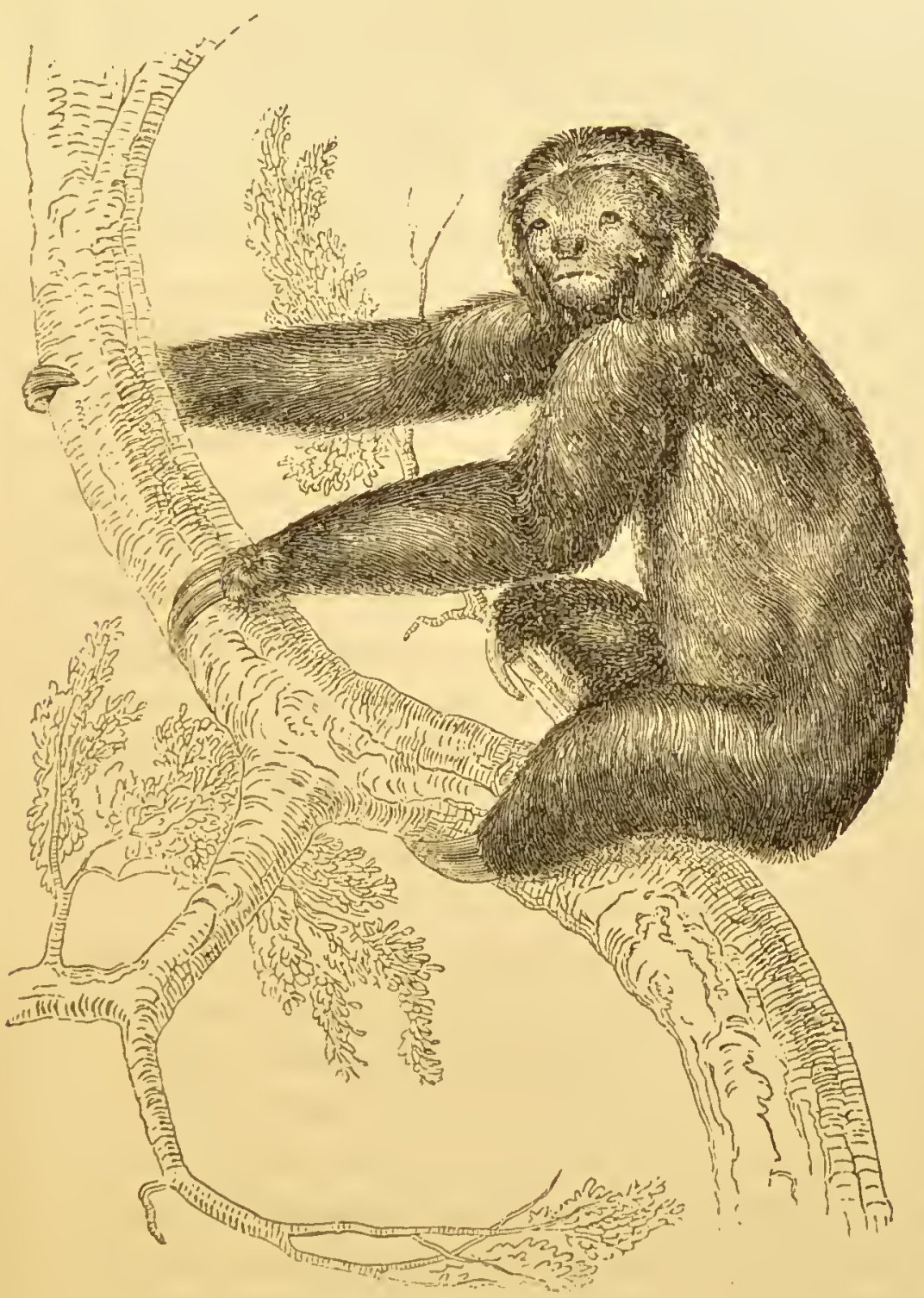

Three-toed Sloth (Achcus ai).

Anteaters (Myrmecophaga), the Armadillos (Dasypus), and the Sloth (Bradypus), are truly South American. The earliest-known fossil of this order, the Macrotherium, be- 
longs to the Miocene age. The distribution of fossil Edentata was far less vast than at present, while the species were probably far greater in number. They formerly existed in North America, throughout the whole United States and Nebraska, where no existing type of Edentata animal is now found. Existing Bruta are absent throughout the Andean region, though present in all parts of America south of Texas. A far wider distribution existed in Pliocene times, where we have evidence of a true sloth-like animal, the IIylodon, in Oregon. But while the distribution was wider in America than at present in the Old World, the converse relations seem to have subsisted; for whilst existing forms are found along the whole coast of Southern Africa and Eastern India and the Archipelago in the Old World, the Bruta seem only to have existed in two localities in France and Germany, and no trace of them appears in Africa or Asia. In Australia, where the mammalian fauna is generally low, no edentate type has yet been discovered. The Edentata fall into three great divisions -those of the Sloths, the Anteaters, and the Armadillos.

The first family, Tardigrada, or Sloths, comprises animals in which the head is truncated anteriorly and flat. The legs, especially the anterior ones, are long, the claws are incurved and compressed. They live in South America, principally in the large forests; feed on leaves of trees; the females bear only a single little one, and carry it as long as it continues to be such on their backs. In them the body is hairy, and the molar teeth separate and cylindric. The ears are very short, concealed under the hair' the fore-feet are three-toed or two-toed, with the toes conjoined as far as the claws. There are two pectoral mammæ, and the tail is short or 
absent. They naturally fall into two divisions, of which the Ais, or three-toed Sloths (Acheus), and the Unaus, or two-toed Sloths (Cholcepus), form the two types. In the former form the first molar tooth is small, the whole series forming $\frac{5-5}{4-4}$; in the latter the first molar, which resembles a canine in all respects save that the lower tooth is placed behind the upper, the whole molar series being $\frac{5-5}{3-3}$. In the former type the tail is short, and there are three toes; in the latter there is no tail, and the animal is didactylate. In the three-toed Sloths there are usually nine cervical vertebræ instead of seven; in one of the two-toed species (Cholcepus Hoffimani) found in Costa Rica there are six cervicals instead of seven. The members of this family are, as their English and Latin names denote, slow-moving, and they are confined to Central and South intertropical America. Many fossil species are known, which extended further south to the plains in the neighbourhood of Buenos Ayres, and as far north as Oregon.

The Megatherium, described by Cuvier, was the leading and largest member of this family of extinct Sloths, where it inhabited the districts washed by the present Pliocene strata of Buenos Ayres, Paraguay, Uruguay, and Bahia Alta. Its form was that of a gigantic vegetable-feeding animal, resembling a magnified Sloth in all its essential points, but unlike the arboreal Bradypi and Cholcepi, being terrestrial, the hinder limbs with the long and powerful tail forming a tripod on which the animal might support itself, while with its powerful prehensile fore-limbs it wrenched down the stems of the neighbouring trees. Nearly eighteen feet in length, and as bulky in its body as an Elephant, the 
structure of its fore-feet shows that they were not merely used for digging but for grasping purposes; and the theory of Pander and D'Alton that it was a gigantic ground-digger like the Mole, and that of Lund that it was a scansorial form like the existing Sloths, were proved by Owen to be erroneous. Five genera of these gigantic Sloths are known, respectively termed Megatherium, Mylodon, Megalonyx, Ereptodon, and Guathopsis. In the Armadillos (Dasypus) the teeth are small cylindric, in various numbers in both jaws. Body covered by very hard mail formed of regular scutes, mostly hexagonal, the back intersected by zones. The ears are somewhat large. Hairs are scattered between the scutes and the zones. The tail of various length, either covered by small scutes, by tubercles, or naked. The feet are either all pentadactylous or the four feet are four-toed. All live in South America. In the skeleton the first rib is enormously broad; there are well-developed clavicles; under the spine of the scapula there is a second projecting line, and the acromion process is elongated over the humerus. They are burrowers, and the flesh is wholesome. The existing Armadillos are invested in a series of bands of jointed plates, which, like an old Italian suit of scale armour, fits in with every joint of the body, and permits the animal to roll itself up like a ball, which, according to the number and breadth of the bands, was more or less protected. These bands are always applied round the most vital parts of the body. In a fossil allied form (Glyptodon), this scaly armour was converted in to one solid plate, like the upper shell of a Tortoise, under which the animal retracted itself, the head being furnished with a solid plate of mail, and the tail, which does not seem to have been movable, being one solid 
rod of armour-encased bone. The various sculptured patterns on the armour of the different species of Glyptodons or Armadillos are indicative of species, and

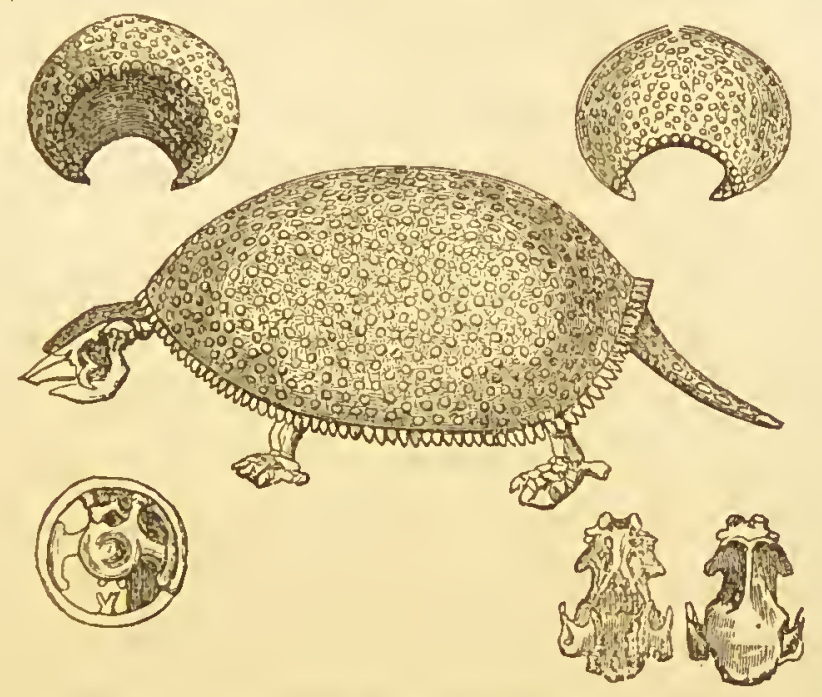

Skeleton of Glyptodon.

afford convenient tests for the zoologist. Every little district of South or Central America appears to possess a separate species of Armadillo. In one of the allied genera, Chlamyphorus, the Pichyciégo, or Blind Armadillo, the molar teeth are $\frac{8-8}{8-8}$; the ears are almost absent and concealed under hair; the back covered with a thick coriaceous test, truncated posteriorly, composed of transverse rows of scutella; the legs, belly, and sides are hairy. There are five toes; the claws of the fore-feet are very long and acute. The tail, as in the Glyptodons, is stiff and bent under the body. In part of its skeleton it resembles the extinct Megatherium, but the acromion process of the scapula is much longer than in any other mammal. The Pangolins (Manis) fall into two divisions, - the true Pangolins, which inhabit the Indian Archipelago and the land surrounding the Bay of Bengal, also the eastern 
coast of Africa from Sennaar to the Cape and the wcst coast from Senegal to the Niger. In this genus the teeth are entirely absent; the ears are small and indistinct; the tongue is round and capable of being projected far beyond the tubular jaws. The body and tail are covered with thick, horny, imbricate scales, and the tail is of enormous length, in some species (MI. tetradactyla) from the coast of Guinea. All these animals live in warm countries of Asia or Africa. There are no clavicles in the skeleton. They have the faculty of rolling themselves up into a ball, when they are protected by their scales.

In the true Anteaters (Myrmecophaga) there are no teeth, the ears are small, rounded, and oval. The body is covered with hair, and the tail is long. These are the representatives of the scaly Anteaters (Manis) of the Old World. They occupy the whole of South America east of the Andes and north of La Plata, but are confined to the wooded districts. It is said that in the Anteaters the females exceed the males in great number. The skull is long and slender, and the framework on which the tongue-bones are hung almost equals the size of the jaws. Frequent in America; allied to the types of existing Armadillos and Anteaters, but of more gigantic size. In one of these, Glossotherium, the apparatius for the attachment of the tongue-bones appears to have been vast and powerful. All these spccies are represented by existing forms of Bruta or Edentata, with which they seem to have had the closest connection. The Pangolin gigantesque or Macrotherium was founded by Cuvicr on the cridence of a solitary phalangeal bonc, in which the concave arch formed by a double pulley curves farthest back at its upper part, so as to prevent the claw from being retracted upwards, 
as in the Cat tribe, and constrain the flexion downwards. The phalanx must consequently have belonged to an Edentate animal allied to the Pangolin, of which the length could not have been less than about eighteen feet.

\section{Sub-Class-Lyencephala.}

In this, the lowest and most bird and reptile like division of the class, the hemispheres of the brain are merely connecter by a round and a "hippocampal" commissure. The cerebral hemispheres are usually without folds, and leave the cerebellum, olfactory lobes and optic lobes exposed. The structure which has been termed "corpus callosum" is accordingly absent in the Lyencephala, from which the smooth-brained or lissencephalous mammals make an ascensive

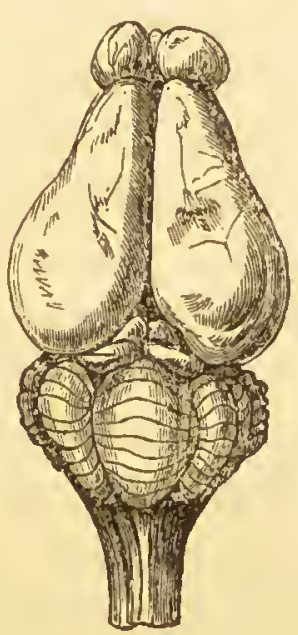

Brain of Opossum. step, equal in degree to that between the Archen- and Gyrencephala.

\section{Order 14. - Maristialia.}

These are mammals distinguished by a peculiar pouch, or duplicature, of the abdominal integument, which in the males is everted, forming a pendulous bag, and in the females is inverted to form a hidden pouch containing the nipples, and usually sheltering the young for a certain period after birth. Most of the species have marsupial bones. The dentition is varied, 
especially as regards the number of incisors, but usually ineludes four molars; there are never more than three premolars; the angle of the lower jaw is more or less inverted. One genus (Didelphis) is found in America; but all the other forms belong to Australia, Tasmania, New Guinea, and some adjaeent isles. Most of the Marsupials are nocturnal. The mammæ are ventral, eontained in the poueh or placed between two oblong cutaneous folds. The elavicle is single, and, unlike that in the Monotremata, is not assoeiated with an epieoracoid bone. The order of Marsupials has been divided by Owen into Sarcophaga (earnivorous forms like Dasyurus and Thylacinus); Entomophaga (inseet-feeders, as Myrmecobuis, Perameles, Didelphis, and the Opossums properly so called); Carpophaga (fruit-eaters, as Phalangista; the Flying Opossums, Petaurus; and the Koala, Phascolarctos; Poëphaga (vegetable-feeder's, as the Kangaroos Hypsiprymnus and Macropus); and Rhizophaga (root-eaters, such as the Wombat, Phascolomys). We shall mention the ehief eharacters of eaeh of these groups.

In the Sarcophaga, the cæcum is absent, and the construction of the jaws and teeth are on the carnivorous type, with sharp and small incisors, eanines of the same general form as in the Wolres, whence the inaccurate name "Tasmanian wolf" given to one of the speeies (Thylacinus cynocephalus), and the still more inappropriate term of "Tusmanian devil" given to the Dasyurus ursinus. In one of the speeies of Dasyurus they had the same form and relative proportions is in the Leopard. Sectorial molars and premolars complete the carnassial apparatus of these predaceous Marsupials, which fulfil the same funetions in Australia as the Carnivora in the Old World. There are also 
types which represent the placental Insectivora, as Phascogale, in which there is almost a transition between the Dasyurus and the Opossums. The two middle incisors in the upper jaw are longer than the rest, and separated from them by a brief interval. The true molars resemble those of Dasyurus, but are more acuminate, and bristle more with projections. This type of Marsupials appears to have been the first Mammalia which appeared on this planet. The Microlestes and Dromatherium of the Triassic rocks, the Amphitherium and Phascolotherium of the Middle Oolite, the Spalacotherium, Triconodon, and Placiaulax of the Purbeck beds are all forms of carnivorous or insectivorous Marsupials, which preceded the true or placental Carnivora and Insectivora in time, and fulfilled their fanctions during the countless ages which were marked by the deposition of the secondary strata.

The second family, Entomophaga, is the most extensive and varied of the primary groups of the marsupial order. In one of the genera, Myrmecobius, the extraordinary dentition is presented of incisors $\frac{4-4}{3-3}$, canines $\frac{1-1}{1-1}$, premolars $\frac{3-3}{3-3}$, molars $\frac{6-6}{6-6}=54$. The number of molars, eighteen in both jaws, exceeds that of any other known existing marsupial animal, and almost approaches that of the Armadillos, which they further resemble by the small size of the molar teeth, their separation from each other by slight interspaces, and their implantation in sockets which, unlike the majority of Mammalia, are not formed on a welldeveloped alveolar ridge or process. They are scansorial and insectivorous, sheltering themselves in the hollows of trees. In the Bandicoots (Perameles) a far more carnivorous type of molar exists; yet the diet 
appears to be purely insectivorous. Charopus ecandatus, an allied form, has the two outer toes of the fore-foot deficient externally; the inner toe is wanting on the hind-foot. In this genus, as well as in Perameles, the marsupial pouch opens backwards and downwards instead of upwards. True Opossums (Didelphis) fulfil in South America the office of the insectivorous Shrews of the Old Continent. Some have even been mistaken for placental individuals of the genus Sorex. The

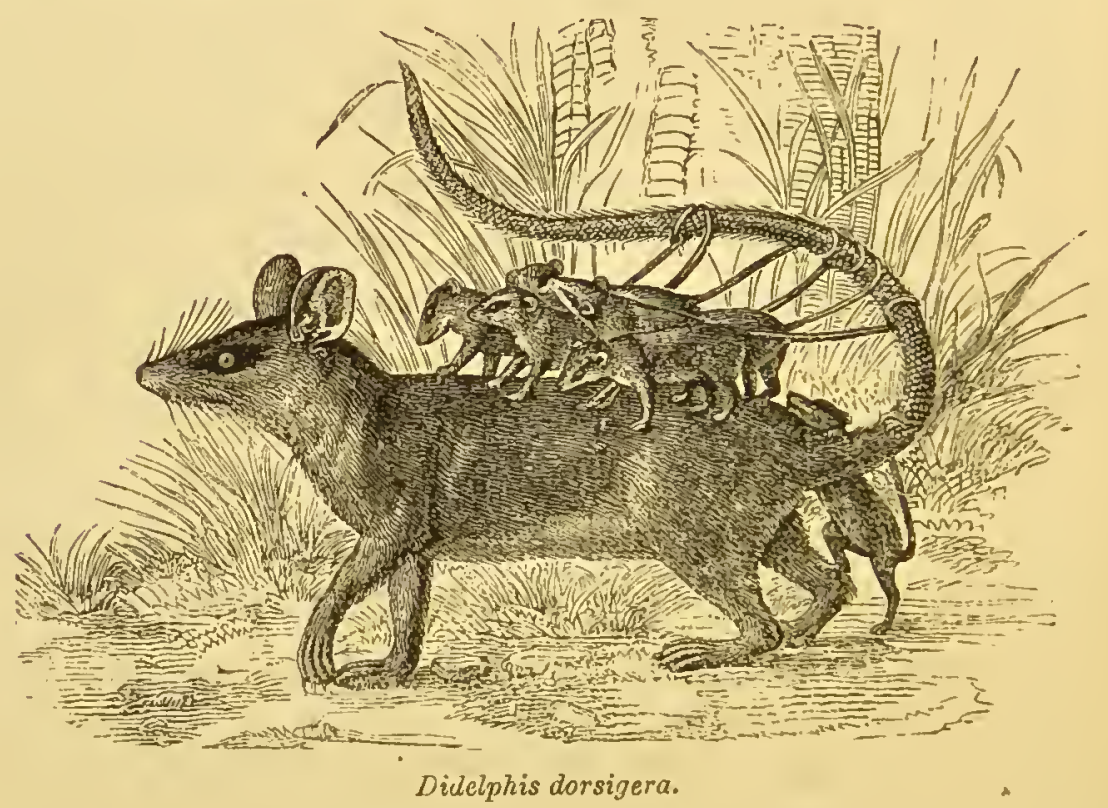

larger ones prey on small quadrupeds and birds, and occasionally on reptiles and insects. One of the species, Chironectes Yapock, frequents the fresh waters, and preys almost entirely on fish; it has, in fact, all the habits of an Otter, is webfooted, and the anterior extremities present an unusual developinent of the pisiform bone, which supports a fold of the skin like a sixth toe. In all the Opossums the inner digit of the hind-foot is converted into a clawless thumb. The tail is scaly and prehensile in nearly all the species. This 
enables the young in the Didelphis dorsigera to affix themselves to the back and tail of the mother by the action of their little prehensile tails. In the Carpophaga the stomach is simple and the cæcum is very long. Here the incisor teeth, especially the two middle ones, depart from the type which we have described in the former families, and become more rodent and vegetable-feeding. The Phalangers (Phalangista) form the first type of the family. In them the phalanges of the second and third digits are inclosed in a common sheath of integument, the innermost toe being modified to answer the purposes of a thumb. This hinder hand being associated in most of the species with a prehensile tail, they are closely allied to the Opossums, from whom, however, they differ iin the condition of the intestinal tube. They are the widest distributed of all marsupial forms in the Eastern Archipelago. Some closely allied forms, Petaurus, posssess a separate fold of the skin between the hind and ffore legs, which when outstretched forms a lateral wind or parachute, but when the legs are in the position for ordinary support and progression is drawn slose to the side of the animal by the elasticity of the cellular membrane under the skin. These Petauri in all their habits resemble the Flying Squirrels (Pteromys), which we have described under Rodentia. The third ype of fruit-eating Marsupials is that to which the ijoala (Phascolarctos fuscus) belongs. Here the middle ncisors approach more closely to that rodent type vhich in the next and last families becomes prominent. The Koalas are strictly vegetable-feeders, consuming he buds and leaves of trees.

In the fourth family, Poëphaga, the most strictly egretable-feeders exist; all the species have a complex 
sacculated stomach, and a long simple cæcum. The hinder limbs are enormously developed, being used for progression, while the fore limbs are armed with claws for combat. All the Kangaroos are found in Australia and New Guinea, the northern types being most

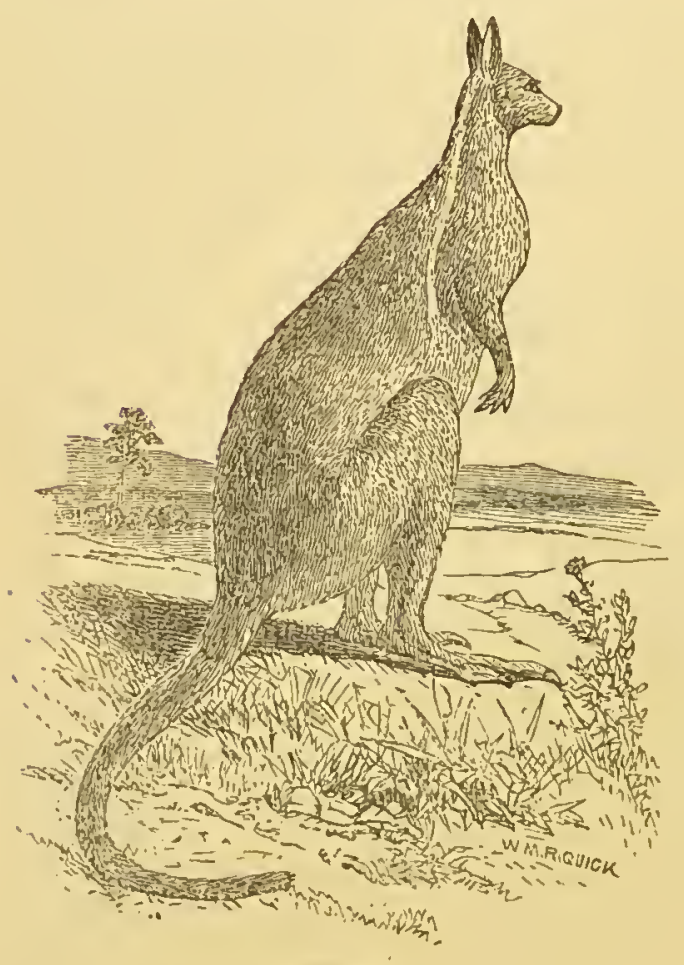

Kangaroo. arboreal. They traverse the arid plains and deserts of Australia, where their peculiar marsupial conformation enables them to carry the young for enormous distances.

In the fifth tribe, Rhizophaga, the stomach is simple in outward form and complicated within by a large cardiac gland; the cæcum is short and wide, and has a vermiform appendix. The figure is heavy and shapeless, the trunk large, and the legs short and equally dereloped. The incisor teeth are true dentes scalprarii, with persistent pulps, though they are inferior, especially in the lower jaw, in their relative length and curvature to those of the placental Glires. The Wombat also differs from other Marsupir:ls in the number of its ribs, which are fifteen pairs instead of twelve or thirteen, as in the other forms. Australia is pre-eminently the country of marsupial animals. The entomophagous type of Opossums is only found in 
America, where it ranges from the fourteenth degree of north latitude to the fortieth of south latitude. In secondary and tertiary times they appear to have been the solitary forms of Mammalia which then existed. The place of the true placental Mammalia was filled by forms which closely resembled them in function, but differed in having one common character, that of bringing forth the young in an imperfect condition, and nourishing them for a long period after birth in the pouch of the mother.

\section{Order 15.-Monotremata.}

This is the lowest of all mammalian types, and merely consists of two genera, which accord with each

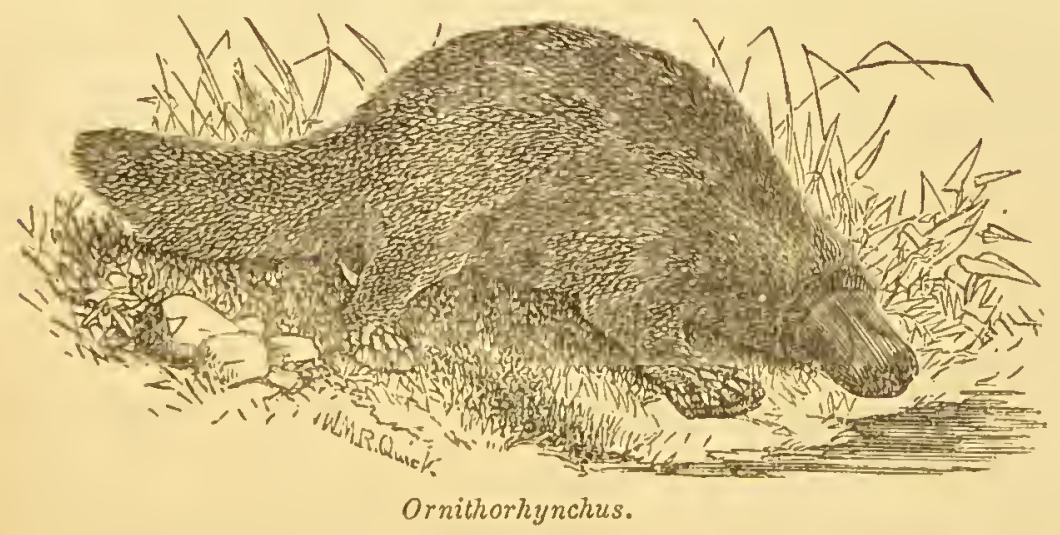

other in the following characters. The coracoid is (extended, as in birds and lizards, from the scapula to the sternum, and at full growth anchyloses with the scapula. There is an epicoracoid as in lizards; marsuipial bones, a supplementary tarsal bone supporting a perforated spur; the cloaca receive the outlets of the rectum and the urethrogenital canal, whence the name; there are no external ears; the teeth are horny or none. 
Two genera of Monotremata are known. In one (Ornithorhynchus) there are eight horny teeth, destitute of fangs, composed of perpendicular horny tubercles, the anterior long and narrow, and the posterior oval; the snout is depressed, flat and broad; the lower jaw is narrower, shorter, marked at the posterior margin by several transverse striæ. The body is hairy; the tail is broad and depressed, beset with rigid hairs. The spur of the male consists of a conical and perforate bony piece, covered by a horny investment, through which runs the excretory duct of a gland situated on the thigh; some observations, from which it had been concluded that the fluid secreted by this gland was possessed of venomous properties, and that the spur was used by the animal as an offensive weapon, have not been subsequently confirmed. Meckel found in the female Water Mole a small cavity in the same situation, which appeared to be adapted for the reception of the spur.

The Water Moles live in the rivers and lakes of New Holland and of Van Diemen's Land. They dive and swim like water birds, and secure their prey, as Ducks do, with their bill whilst swimming. They feed on worms and insects; fragments of shell and parts of water insects have been found in their cheek-pouches and in their stomach. They dig holes of twenty or more feet long, which have a double entrance, one close above the water and another below the water, and ending in a larger space covered with rushes and other dry plants. The young animal is naked, and has a short beak with flexible jaws. The adults attain a length of from seventeen to twenty-two inches, from the anterior margin of the upper jaw to the point of the tail, which is about five inclies long. 
The second genus comprises the Spiny Anteater (Echidna). There are no teeth; the snout is subulate, somewhat depressed, with the gape of the mouth at the apex small. The tongue is round, long, and, as in the Anteaters, capable of being protruded outside the long and slender mouth. The body is covered with hairs and spines. The claws are large, the second and third of the hind-feet very long and falciform, the tail is short and truncated at the apex. These animals burrow under ground, live on Ants and other insects, and are even more than the Ornithorhynchus nocturnal animals. They attain a length of from fourteen to seventeen inches. All the Monotremata are confined to the eastern and southern parts of Australia and New Holland. They exhibit many points of affinity with the anteating forms of Edentata, and in their bird-like and reptilian, characters with the two classes immediately beneath Mammalia in the genetic series. 


\section{Class II.-BIRDS (AVES).}

THEE class Birds are composed of vertebrate, oviparous, 1 biped animals; the pectoral limbs are organised for flight; the integument is covered with feathers; the respiration and circulation are double; the lungs fixed and perforated. The following negative characters can be predicted of the class - there are no earconches, lips, teeth, epiglottis, diaphragm, fornix, corpus callosum, nor scrotum.

The classification of birds has formed a test of the methods by which zoologists have been led to define the separate ordinal characters of each group.

Owen has primarily divided the class into two great groups, founded on the condition of the newly-hatched young, which in some orders are able to run about and provide food for themselves the moment they quit the shell (Aves proecoces), whilst in others the young are excluded, feeble, naked, blind, and dependent on their parents for support (Aves altrices).

A division resting on more arbitrary distinctions was invented by Nitzsch, who grouped birds under three series-the birds of the air, exemplified by the Eagle and Lark; birds of the land, by the Ostrich and common Fowl; and birds of the water, as the Heron and the Gull.

Linnæus made the division into five orders-Raptores, Passeres, Pice, Gallinacece, Gralle, and Anseres- 
which classification, abrogating the Picce and breaking up the Pusseres into Volitores and Insessores, has been generally adhered to up to the present time. Vigors proposed a more definite system upon a similar principle, distributing birds into five orders. The first includes those which soar in the upper regions of the air, and which build their nests and rear their young on bigh cliffs or lofty trees. They are the chief of aerial birds, and form the order termed Raptores, from the rapacious habits and animal food of the species so grouped together.

The second order affects the lower regions of the air: the birds composing it are peculiarly arboreal in their habits, and are therefore termed "Perchers" (Insessores).

The third order corresponds with Nitzsch's Aves terrestres, and is denominated Rasores, from their general habit of scratching up the soil in quest of food.

By dividing his Ares aquatice into those which wade to obtain their food, and into those which swim, we get the two remaining orders of the quinary arrangement-viz., the Grallatores and Natatores. The merit of this system mainly lies in the endeavour to trace the natural affinities of the several familios, and to show how they pass one into another to form a connected circular whole.

The Raptore's of Vigors answers to the Accipitres of Linnæus and Cuvier; the Insessores to the Passeres and Pici of Iinnæus, and to the Passeres and Scansores of Cuvier; the Rasores to the Gallina of Linnous, plus the Columber, and to the Gallinacere of Cuvier; Grallatores to the Grallice of Linnæus and Cuvier; the Natatores to the Anseres of Linnæus and the Palmipedes of Cuvier. 
In birds, most of the dorsal vertebræ are immovably connected with each other, and sometimes even the bodies of some of them have partially coalesced. The cervical and caudal vertebræ are so attached together by their articulations that they admit a slight degree of motion, which varies in different orders of birds. The cervical region of the vertebral column is the longest, and is often longer than the whole remaining series of vertebræ. Unlike mammals, the number of cervical vertebræ is constantly not less than nine, usually between ten and fifteen, and in the wading and swimming birds still more. The first two cervicals are shorter than the others, the atlas having nearly the form of a ring, receiving the single condyle of the skull into a deep pit; the rest have elongated bodies, the perforated transverse processes forming a canal through which the vertebral artery and nerves pass. The dorsal vertebræ have movable ribs; they are much less numerous and shorter than the cervicals, the dorsal region accordingly not forming more than a fourth part of the length of the vertebral column; in longnecked birds like the crane they form an eighth part. The anchylosed lumbar and sacral vertebræ are usually from ten to fourteen in number. The tail forms the smallest part of the vertebral column, and commonly consists of seven or eight vertebræ (coccygeal), which are movably connected with each other, the last, which supports the tail, being very short. The sternum is very large in all (except the Apteryx). It is forwardly convex, and the under or fore surface is strongly keeled or marked with a projecting bony plate in the direction of the longitudinal axis of the body. In some cursorial birds, as the Ostriches, this is entirely absent. Both clavicles and coracoids exist, except in some Parrots, in 
which the former is absent. The humerus is cylindrical, longest in Pelicans; in the rasorial birds it is exceptionally short. The Ostrich has a long humerus, the Cassowary a short one; yet the wing in neither animal is used for flight. The ulna and radius are distinct, the wrist formed of two short little bones; there are never more than three fingers, of which the outermost is small, and consists of one joint alone ; the central one is composed of two, or more rarely of three, joints, of which the first is broad and flat. The ilium coalesces with the lumbar and sacral vertebræ; it is elongate and deeply excavated on the inner side to receive the kidneys. The pubic bones are unconnected, except in the Ostrich and (to a certain extent) in one of the Vultures (Gyps fulvus). The ischium is short and broad, extending from the cavity of the hip-joint backwards parallel to the pubic bones. The femur is shorter and thicker than the leg-bone (tibia); it is nearly cylindrical and slightly curved forwards; on the outside of the head there is a single trochanter. The wingless division of birds (Cursores) exhibit species wherein the fore-limbs not being developed as wings, the thigh-bone is very strong, and surpasses the humerus, which is usually much longer, in thickness. In the Cassowary and Apteryx it also surpasses it in length. The tibia is constantly the longest bone of the hindlimbs; the fibula is imperfect, and coalesces with the tibia; the knee-pan is nearly always present; and in the Ostrich, where the motion of the knee in the swiftrunning bird is enormous, there are two patellæ. The tarsus and metatarsus are represented by a single bone, of which the upper extremity resembles the human tibia in its degree of excavation. Two cavities, with a projecting line between them, receive the two articular 
tubercles of the inferior extremity of the tibia. Most birds have four toes, three anterior and one posterior; the hind-toe articulates on the same plan as the others in grasping and perching birds, but on a higher level in terrestrial and aquatic kinds. By the analogy of the number of the phalanges of these toes with those in Lizards, the back toe is the innermost, answering to "hallux," the inner of the front toes is the second, the middle one is the third, the outer one is the fourth. It will be seen that the number of pbalanges progressively increases from two to five. The fifth toe of the four phalanges in the Monitor Lizard is not developed in any bird. The constancy of the number of phalanges in each toe is such that the toes retained in a tridactyle bird, e.g. Emeu, are seen to be the second, third, and fourth; those in a didactyle bird, e.g. Ostrich, to be the third and fourtb; and altbough the latter is much the smaller toe, it retains its superior number of joints. Among the very few exceptions to this rule may be cited the outer toe of the Caprimulgus and of the Swift, which has but four phalanges; in the Swift, also, the innermost toe is directed forwards like the rest. The last phalanx in each toe is pointed, and usually curved, corresponding in some measure with the shape of the claw it supports; the articular ends of the phalanges are slightly expanded and coadapted with the trochlear joints, limiting motion to one plane.

The mandibles of birds bave no teeth, and are covered with a horny covering (bill). In the birds of prey this is hardest, the hindermost part being invested by short skin (the cere). In the natatorial birds the texture of the bill is much softer; the œsophagus is folded longitudinally, and in most birds contains an expansion, to which the name of 
crop (ingluvies) is given. Here the food is softened and penetrated by the fluid secreted by mucous glands. There are two crops in the Pigeons; the stomach is divided in two, the glandular stomach (proventriculus) and the muscular stomach or gizzard. In some birds-the Heron, Pelican, \&c.-there is another separate dilatation or spherical stomach resembling that in the Crocodile. The heart is divided into two chambers, and in place of the tricuspid valves of the heart of mammals, a single muscular and thick valve is situated at the upper part of the ventricle, in front of the venous aperture or the opening of the auricle. The aorta, after giving off at its origin the coronary arteries of the heart, divides almost immediately into two principal branches, of which the right is the widest. This divides into a descending artery, which is situated lower down, bends to the right and runs backwardly under the vertebral column and into an innominate or subclavian artery destined for the anterior parts of the body. The left branch is the left innominate or left subclavian artery. Commonly there arises a carotid artery on each side, but in some Insessores it is only found on the left side. The two lungs which exist in birds do not cover the heart, and are not divided into lobes. The bronchi are short. Through the apertures of the bronchial tubes on the surface of the lungs the air passes into large air-sacs, which are situated partly in the thoracic and partly in the abdominal cavity. These air-sucs conduct air to the hollow bones and form reservoirs of air for breathing ; and as they receive air from the lungs, so they can return it to them again for respiration. The humerus, sternum, and cranial bones are those which are most usually hollow; and after the vertebræ, the ribs, scapulæ, clavicles, pelvis, and thigh- 
bones are rarely hollow when those of the humerus are not so.

The feet of birds, which, as we have seen, vary in the number of the phalanges of their toes, offer other points of wide differentiation, according to the various methods of progression used by the different species. Some birds walk by bringing their feet alternately forwards, others by a simultaneous hopping motion; some run with great velocity, while others are scarcely able to walk; some can scarcely stand; most birds walk only on a flat surface, but some (the Scansorials) are enabled to ascend a vertical plain; many, by having their toes joined by membranes, have their feet converted into paddles, and are thus fitted for aquatic progression. A bird flying has its centre of gravity under the origin of the wings; a bird standing has it behind. The legs being articulated behind the centre of gravity, it is necessary that, they should be very much bent, and that the toes should project beyond the vertical line drawn through the centre of gravity, in order to give stability when the feet are very short. The bird is obliged to stand and walk with the body nearly in an erect position, but when the leg-bones are moderate or large, and especially when the neck is long and flexible, the feet are brought forward and the head backward, so that the body remains nearly in a horizontal position. Birds usually rest on one leg, and most species are enubled to maintain this attitude without fatigue by a peculiar arrangement of the tarsal joint, there being a process from the anterior part of the head of the metatarsal bone which fits into a corresponding cavity at the lower end of the tibia, from which it is not again withdrawn without an effort on the part of the bird; others are rendered secure during 
repose by the weight of the body, which bending the joints of the legs brings into a state of tension the long flexor tendons that go to the extremities of the toes, which they thus cause to grasp their perch. Some birds lie flat on the ground. All birds are covered with feathers. The corium, or true skin, is very thin, but vascular; the epidermis in some places continued as a simple layer over the corium, as around the beaks of vultures. It is moulded upon the bony mandibles to form the beak, and in some birds adheres to osseous protruberances on the cranium, where it forms a species of horn; and it is remarkable that these instances occur chiefly in those orders of birds - the Cursores and Rasores-which are most analogous to the Ruminantia among quadrupeds. The Cassowary and Helmeted Curasson are examples. The Hornbills are, however, instances of the volitorial and the Kamichi in the grallitorial order. The cuticle is sometimes developed into spines or spurs, as upon the wing of the SnakeVulture, Cassowary, and Palamedea, and upon the leg of many gallinaceous birds. The claws which sheath the ungual phalanges of the feet assume various forms adapted to the habits and manner of life of the different orders. A remarkable artificial form is given to the claw of the middle toe in certain birds, the inner edge being produced and divided into small parallel processes, like the closest teeth of a comb. These teeth are not reflected nor recurved, as they might be expected to be if they had been intended to serve as holder's of a slippery prey, but are either placed at right angles to the claw, or are inclined towards its point. The common Barn Owl (Strix flammea), the Night-jar genus (Caprimulgus), the Heron and Bittern kind, afford examples of this structure; and as each species of bird appears 
to be infested by its peculiar louse, the solution of the final intention of so singular a contrivance, which is limited to so few species, and these of such different habits, may yet be affurded by the entomologist. Scales defend the naked parts of the legs in birds which closely resemble those in Reptilia. The number of tarsal scales is a specific test in most birds. The epidermis is covered with a series of objects which are commonly called feathers; each of these is composed of a quill or barrel, a shaft, and a vane or beard. The vane consists of barbs which proceed at right angles to the shaft, and barbules which interlock the barbs together so as to unite them altogether in one flat mass. They are usually short and close set, but in the Ostriches and Peacocks the barbules are long and loose. The feathers vary in form in different parts of the bird according to their functions, and aftord zoological characters for the distinction of species; they bave therefore received in ornithology distinct names. The ordinary imbricated feather's which cover the body are called "clothing feathers;" the larger" ones, for" special uses, "quill feathers;" those which surround or cover the external opening of the ear are termed "auriculars;" those which lie above the scapula and humerus are called the "scapulars;" the small feathers which lie in several rows upon the bones of the antibrachium are called the "lesser coverts" (tectrices prime); those which line the under or inner side of the wings are the "under coverts;" the feathers which lie immediately over the quill feathers are the "greater coverts" (tectrices sccunda); the quill feathers supported by the wings are the remiges or "rowing feathers;" the largest of these remiges, which arise from the bones of the hand, are termed the "primaries;" those which 
rise from the ulna towards its distal end are the "secondaries ;" those which are attached to its proximal extremity are the "tertiaries." These in some birds, as the Woodcock and Snipe, are so long as to give them the appearance when flying of having four wings, the quill feathers which grow from the phalanx representing the index from what is termed the bastard wing (ulula spuria). Those forming what is called the tail of the bird, and supported by the coccyx, are the rectrices or steering quills. The overlying feather's are the tail coverts (ialypteria); these bear the ornamental "eyes," and are so developed in the Peacock as to form what is called the "tail," or "train," of that bird. The texture of the quill feathers varies in different birds; while in the Falcons each primary quill feather is elongated, narrow, and tapers gradually to a point, the webs are entire, and the barbs closely and firmly connected together. In the slow-flying Owls the plumage is loose and soft, and filaments from the barbules extend upon the outer surface of the vane. The plumage is commonly changed several times before it attains that state which is regarded as characteristic of the adult bird. The time required for this varies from one to five years, and several birds rear a progeny before they acquire the plumage of maturity.

When the male bird assumes a vestment differing in colour from the female, the young birds of both sexes resemble the latter in their first plumage (Blackbird); but when the adult male and female are the same colour, the young have then a plumage peculiar to themselves (Swan). When adult birds assume a plumage during the breeding season decidedly different in colour from that which they bear in winter, the young birds have a plumage intermediate in the tone of its colour 
compared with the two periodical states of the parent birds, and bearing also indications of the colours to be afterwards attained at either period (Ruff). When both males and females are alike in colour, but species of the genus differ widely in colour, e.g. the black and white Swans, the young of such species are alike and of an intermediate hue.

Changes in the appearance of the plumage of birds may be produced:- by the feather itself becoming altered in colour; by the birds obtaining a certain number of new feathers without shedding any of the old ones ; by the wearing off' of the lengthened lightercoloured tips of the barbs of the feathers on the body, by which the brighter tints of the plumage underneath are exposed; by the entire or partial moulting at which old feathers are thrown off and new ones produced in their places.

The first three of these changes are observed in adult birds at the approach of the breeding season; the fourth change is partial in spring and entire in autumn.

The young are produced in eggs which are developed in a single orary, that which represents the left ovary in other Vertebrata:

The structure of the egg demands careful examination. The yolk forms an ellipsoid mass, somewhat flattened on the cicatricular surface, and consists of the external coloured part, in concentric layers, denoting successive deposits, and of a central lighter-coloured part about one-fourth of the diameter of the whole. The bird's egg differs from the egg of the cold-blooded non-incubating ovipara in the presence of the chalazx of the air-chamber in the former, and more complex structure of the shell and the greater proportion of albumen. The cicatricula or germ is on the upper- 
most part of the floating yolk, the thinner part of which occupying the nuclear tract makes that half the lightest. Swung on the chalazæ like a compass on board ship, a partial rotation of the egg in the direction of its long axis causes the chalazm to twist and balance the yolk so as to keep the cicatricula always uppermost. Birds differ in the number of eggs
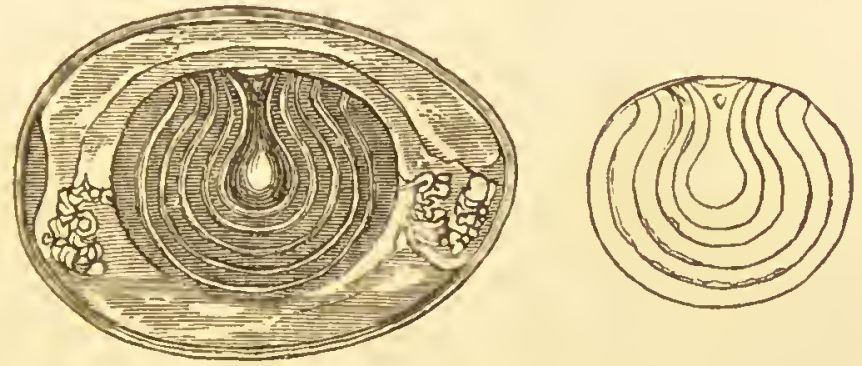

which they lay at one breeding season. The Penguins and Petrels lay but one egg at a time; the Ducks and most Rasores hatch many eggs at a brood. In the Megapodes, or Brush Turkeys of Australia, the eggs are laid in a huge mound of decaying vegetable matter. The eggs are deposited vertically in a circle at a certain depth near the summit by the heat in the f fermenting mass.

\section{Order 1.-RAPTORES-}

IRapacious birds with strong, curved, sharp-edged, and sharp-pointed bills; the legs are short and robust, with three toes before and one behind, armed with long, strong, crooked talons. The feet are strong, with toes padded beneath. There are ten primary feathers, the wing-covers are large, and the tail has twelve or fourteen feathers. The raptorial or accipitrine birds are naturally divided into two groups, ihe diurnal and the nocturnal. In those Raptores who 
seek their food by day the base of the bill is covered by cere, the eyes are lateral, and the outer toe is not shorter than the inner, and in most is longer. In the night-feeding Raptores, on the other hand, the bill is

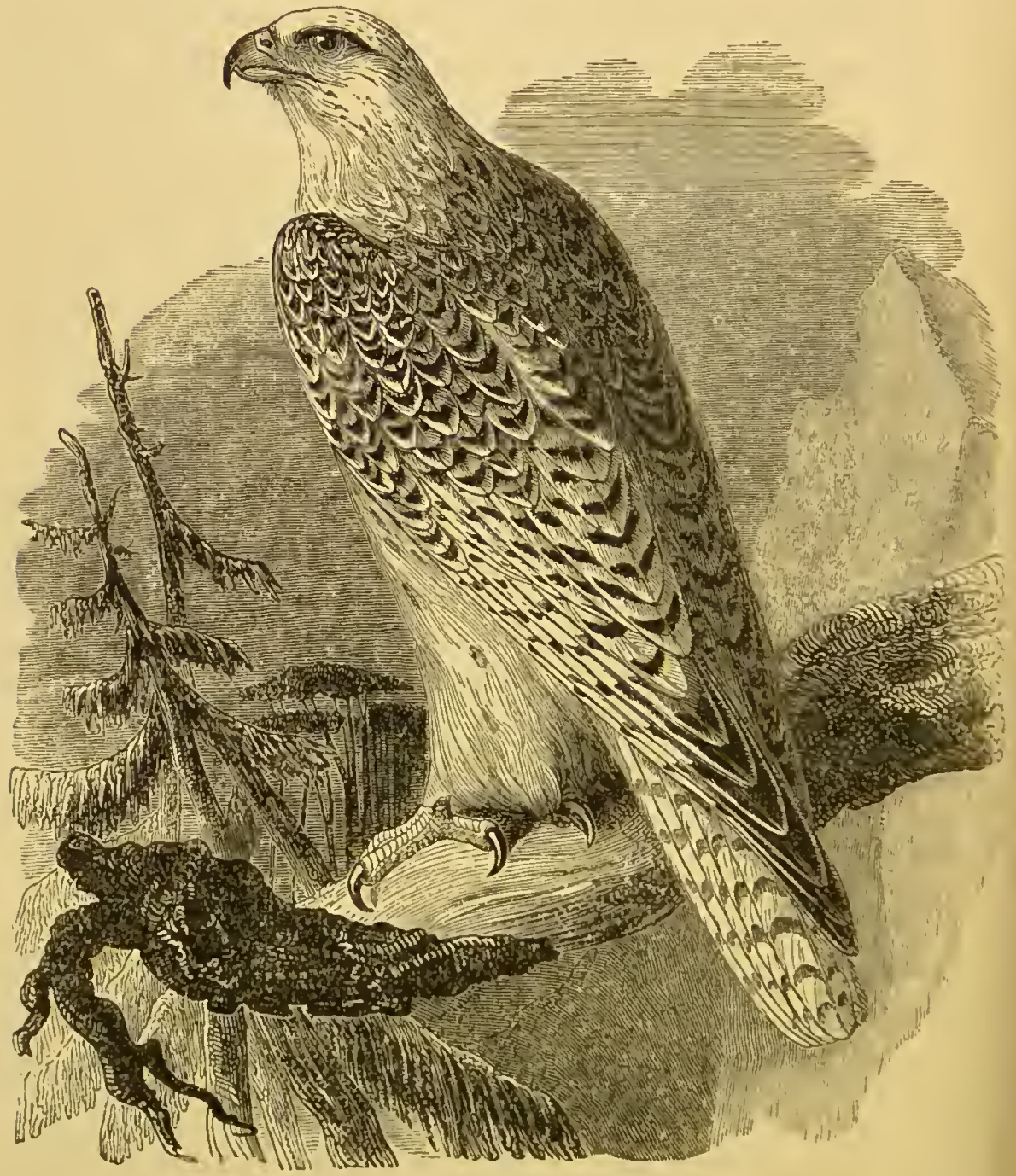

Fralcon.

short, covered at the base by recumbent velæ; the nostrils are placed at the anterior margin of the cere; the head is large, densely plumed, with large forwardlyturned eyes; the tarsi are reticulate, with scales covered 
with dense plumes. The toes are often woolly; the outer toe is shorter than the inner. The first quill feathers are ciliated externally with barbs recurved and separate at the point. Two broad divisions again exist of the diurnal Raptores, those of which the Eagle, or rather the Hawk (Accipiter), is the type, and those which group themselves around the typical Vultures. In the genus Falco of Linnæus, which may be taken as the type of the family, the bill is moderate and shorter than the head, hooked, mostly bent in an arch from the base downwards, with margin of upper mandible often dentigerous; the nostrils are lateral, rounded or oval, placed in the cere, and open. The eyes have the upper margin covered by crowded plumes, and the lhead is almost always densely plumed. In the Vulitures, on the other hand, the bill is moderate, with the culmen straight at the base, constricted in front of the cere, curved towards the top, the upper mandible has the margin sinuate, and never dentigerous. The tarsi are reticulate with scales, sometimes hairy or semibairy; the middle toe is much longer than the lateral toes; the outer ones are conjoined at the base by membrane. The claws are slightly curved and obtus:. [n most species the head and neck are naked, or beset with scattered plumules. The eyes are surrounded by the Hattened face, not placed in a depression under projecting plumes. All the Vultures-of which the Lammer;eyer (Gypaëtos barbatus), the Egyptian Vulture (Neohron percnopterus), the Angola Vulture (Racama Angoensis), the common Vulture (Vultur monachus and uluss), the Turkey Buzzard (Cathartes aura), and the jondor (Surcorluamphus gryphus), are the leading forms -are carrion feeders, and are found in tropical and ubtropical regions of the Old and New World, usually 
being of gregarious habits, and associating themselves together in large numbers, but in some few cases, as in the representative European and American species, the Lammergeyer and the Condor, of solitary habits.

The non-carrion feeding Raptores are of greater number of species than the Vultures. One type, the Secretary Bird (Gypogeranus serpentarius) has been alternately classed by ornithologists in the present or preceding family. Its legs are long, and adapt it as a grallatorial type among the Raptores, whence the name

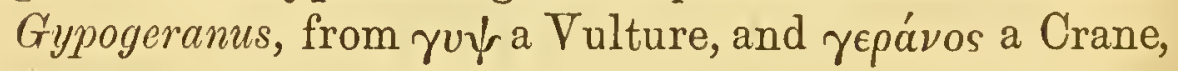
was given it.

The other forms offer as types the Brazilian Kites (Polyborus), the Buzzards (Buteo), Eagles (Aquila), Falcons (Falco), Kites (Milvus), Sparrow-bawks (ACcipiter), and Harriers (Circus). In these the skull is only slightly pneumatic, the furcula is broad, strong, and expanded, the sternum is large and not incised behind, the cæca are very short. At different periods of life the plumage varies extremely; the females are always larger than the males; they rarely lay more than five eggs, and the larger species only two, which are almost always white with reddish brown spots. Most of the species feed on living animals. A part of the Falcons which are termed "noble," having longer tails and shorter toes than the Hawks, have been domesticated by man for the chase. The greater number of the allied forms, which all resemble each other closely in their plumage and their habits, are becoming extinct in European countries at least. The Falconince are of wide distribution, and separated by an enormous interval of distinction from the species in the next family. The Falconince prey on quadrupeds, birds, reptiles, fishes, and insects, which they pursue by flying not by 
walking; indeed, most of the species, owing to the form of their feet, are incapable of progression on the ground, and when they have to move to short distances are obliged to leap with the aid of their wings. They seize their victims with their talons, thrust into them their long acuminate claws, and when of sufficiently small size carry them off to some secure retreat. The bill is root generally used for inflicting wounds, but with it they remove the hair and feathers previously to eating the flesh, which they tear up with ease, often swallowing the bones. Having filled the cosophagus, which is always capable of being much dilated, they retire to some sequestered place, and remain quiet until the food is digested. The insoluble parts are vomited in roundish pellets, in which the bones are enveloped l by the hair and feathers. Their sight is very acute, cas is their sense of hearing: Their flight presents modifications according to the species, being strong and rapid in the Falcons, more buoyant in the Harriers, llight and gliding in the Hawks, heavier in the Buzzards and Eagles; but in all it is remarkably powerful. They perch with ease, and when at rest on a branch or pinnacle keep the body nearly erect, and the neck much retracted. On a level surface they incline the body forward and draw up their claws.

These birds are for the most part solitary, and although some species congregate at times when food is abundant, none of those that occur in Britain are -gregarious in the slightest degree. Their cries are loud and shrill with little moderation; their trachea being of nearly uniform width, its rings generally cartilaginous, and the inferior laryngeal muscle reduced to a single pair. They pair early in spring, and form a rude flat nest of sticks, twigs, and other materials, 
lined with wool or hair; the eggs vary from two to seven or eight, the larger species having fewer than the smaller, and are of a roundish or elliptical form. The young are at first clothed with light-coloured down, and remain in the nest until fully fledged, when they differ considerably in colour from their parents, it not being until the third or fourth year that the adult plumage is complete. When the old birds hare transverse bands the young generally have longitudinal spots; in many species the spots and streaks of the young disappear with age; the tints usually become purer and lighter the older the individual; and on the other hand many which are patched or spotted with white when young gradually assume a darker tint. In consequence of these variations great errors have been committed in naming and distinguishing the species. The moult commences in the end of the summer, and is completed by the beginning of winter' and in some species, the Eagles in particular, new feathers are found at all seasons.

The true Owls form a very natural family. They seek their prey mostly by twilight and also by night in moonlight. It consists of small mammalia, birds which they mostly surprise when asleep, and large insects; some species eat frogs, and all mice. The females are only slightly larger than the males; in other respects there is little difference between the two sexes of diurnal and nocturnal birds. A few eggs of a whitish colour are usually laid. The cranial bones are highly preumatic and have a large circumference. The furcula is thin beneath and sometimes even membranous, as in some Scansores-a link to the order beneath it in the scale. There are two large cæca.

The genus Strix, which comprises most of the old 
typical owls, has for its leading representative in England the Strix flammea or Barn Owl. This species is dispersed throughout nearly the whole of Europe, the North of Africa, and Western Asia; there is a representative species in North America and another in Cuba, which on the derivative hypothesis may have originated from the same ancestors. The Howlets (Ulula) and the Long-Eared Owls (Otus) occur in Europe, whilst in South Africa, India, Australia, Asia, and America different genera occur which represent the Owls of Europe, and accord with them closely in habit and plumage.

\section{Order 2.- Scansones.}

In this order the toes are arranged in pairs, two before and two behind. Most lay their eggs in holes of decayed trees. The larynx has three muscles. They are monogamous. Seven orders are known: the Ramphastidce (Tuucan), Bucconidce (Barbet), Cuculidle (Guckoo), Picidce (Woodpecker), Mrusophagidce. (Turaco or Plantain-eater), Coliidae (Colies), and Psittacidce or Parrots.

In the last family, which as they offer many analogies with the Raptores, we shall treat first, the bill is thick, strong, and high, of moderate length or shorter than the head, with the upper mandible hooped and the lower shorter and obtuse; the nostrils are placed at the base of the mandible, near the culmen, rounded, and are mostly small. The tarsi are reticulate, with small scales mostly short and thick. There are two anterior toes conjoined by membrane at the base. The wings are moderate in length or somewhat long, mostly with the second quill longest of all. Their lower larynx is rather 
complicated, and provided on either side with three muscles, which contribute to their imitation of the human voice. They have very long intestines, but no cæca. Their food consists of fruit of every description. They climb to the branches, aiding themselves with their beak and feet, nesting in holes in trees. Their voice is naturally harsh and loud; they are nearly all painted with the most brilliant colours. They are only found in the torrid zone, the Parrots of each district varying. Even each island in the Indian Archipelago has its own separate species. The Parrots are short-winged, and the majority are gregarious; they are not migratory to any great extent. Nearly three hundred species are known, dispersed in the Southern Hemisphere, in America, in the islands of the Indian Ocean, and in Australia. In the Northern Hemisphere Psittacus carolinensis is found up to the forty-second degree north latitude. There are only a few species in Africa. The skull in Parrots is large, with a transverse incision behind the base of the bill where the movement of the upper jaw occurs. There are usually twelve vertebræ in the neck, the sternum is long and narrow; and has an oval aperture of the inferior margin on each side. The furcula is thin; the tongue is thick and fleshy. Parrots are divided as follows: the true Parrots (Psittacus), comprising as sub-genera the Mácas, erroneously termed Macars (Macrocercus), and the Cockatoos (Plyctolophus). The Colies (Coliidee) are nearly all African birds, feeding on fruits, berries, \&c.; they climb on trees, and fly little and only short distances. In the Turacos or Plantaineaters there is usually only one incisure on each side behind. The furcula is perfect. All species are African, where they fulfil the same part as the Banana birds of the New World. 
Picidae or Woodpeckers form a well-defined group, of which the affinities are not obvious. Their more essential characters are to be found in their straight, tapering, angular bill, which is wedge-shaped at the end, and constructed for the purpose of splitting or perforating bark and decayed wood; and their graduated decurved tail, of which the feathers have very strong lastic shafts, with attenuated webs; together with their short, strong zygodactylous feet, and stout, comopressed, curved acute claws. The peculiarities of their congue and digestive organs have already been described. The skeleton presents several remarkable peculiarities as compared with that of a Jay or other osird of that family.

The skull is of moderate size, roundish oblong, the urbits with very prominent margins which are nearly complete, and thus approach to those of the Psittacince. It double groove for the horns of the hyoid bone is pparent in the medium part of the skull, and there is deep and broad cavity on the forehead, between the nterior parts of the orbits. The jaws are straight and ather long; the lower very deep at the base. There re twelve cervical vertebræ, eight dorsal, twelve lumar and sacral, and eight caudal. The ribs, eight in umber, are stout, the two anterior incomplete. Of he caudal vertebræ, the last or eighth is extremely urge, presenting a broad plate beneath; the seventh I anchylosed with it; the eighth has a deep notch ehind at its lower part, into which is received the ery strong inferior spinous process of the sixth hen the tail is depressed. The downward curre of ie tail is performed chiefly at the joints between the fth and sixth and the sixth and seventh. In the tter the tail may be curved upwards, so as to lie flat 
on the back. This, however, is not peculiar to Woodpeckers. The lateral processes of the caudal vertebræ are very large, so as to prevent much lateral motion. In the sternum of Picus pileatus the body is seen to have two notches on each side, behind which, however, is much prolonged anteriorly a slender furcula, of which the cruca are extremely compressed and not widely separated, long coracoid bones and scapulæ singularly

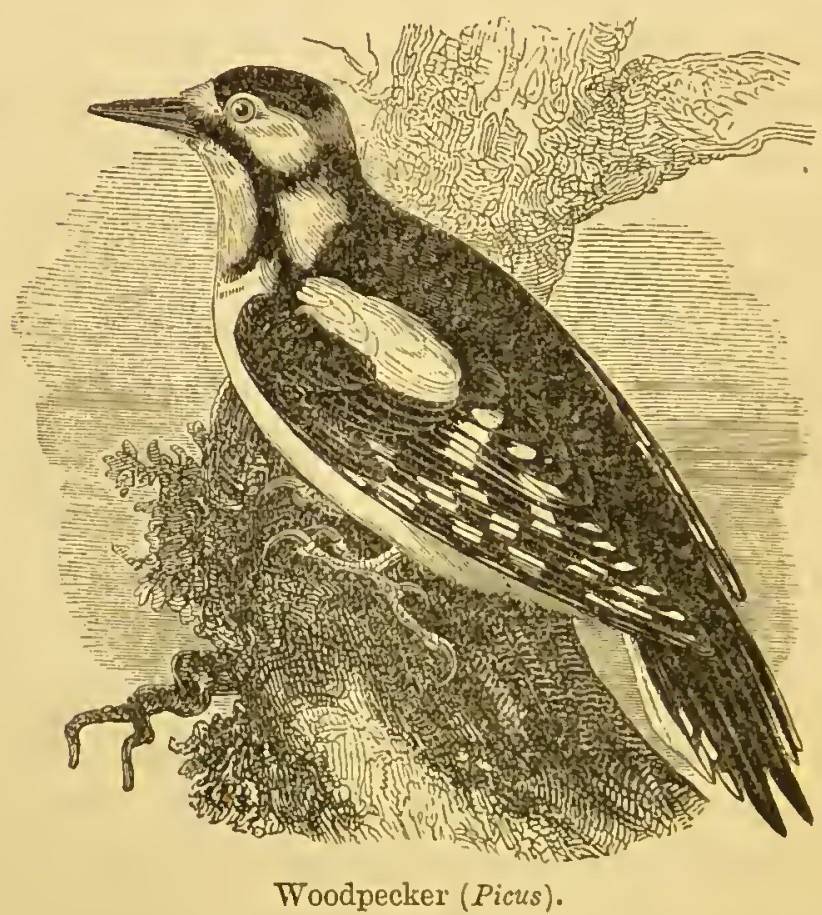

curved downwards and enlarged at the end, in which respect they differ from most other birds. The humerus is large, and has a small bone in its articulation. The metacarpus consists of two undivided bones; there are, besides the pollex, two digits, one of two phalanges, the other of one. The pelvis is of moderate size; the femur also moderate; there is a small patella; the tibia is rather stout, and the fibula extends to half its length; the tarsal bone is slender; the phalanges are 
two, three, four, and five as usual, the last phalanx of each toe large, compressed, with a deep lateral groove. The European forms of Woodpeckers. (Yunx, Picus) may be roughly divided into black, variegated, and green or ground Woodpeckers.

The Cuckoos (Cuculidce) form a group which is not well defined, in which the species have a bill of various length, often slender, moderately curved, naked at the obase, sometimes emarginate towards the top, with margins elsewhere entire. The gape of the mouth is large, und it is often produced under the eyes. In the Cuckoos the eggs are slowly developed in the ovary, whence there is no inclination to brood ; it is therefore content ico lay its eggs in the nest of other birds which feed their young with insects. Small species of singing birds ure chiefly selected for this duty of involuntary nursing.

The Bucconidce, or Barbets, are found in Africa, Iindia, Sumatra, but especially South America. The T.oucans (Ramphastidce) are a family of birds in rhich the beak is formed of the lightest cellulose isseous tissue, and occupied internally by a trellisroork of laminæ, which are very vascular. They are onfined to the warmer regions of America, where hey live in small troops, nourishing themselves on ruits and insects, devouring occasionally eggs and (ewly-hatched birds. The structure of their beak compels them to swallow their nourishment without rushing it; when they have seized it they throw it in the air to swallow it more conveniently. Their eet are short, their wings little extended, their tail ather long. They nest in tree-trunks; their ordinary blour is black, with bright colours on the neck, breast, nd rump. The next family of Volitores in part is nked with the Ramphastide. 


\section{Order 3.-Volitores.}

They move solely by flight. The skeleton is light, and highly pneumatic. The sternum has a simple manubrium and a deep keel; in some species it is entire, but in most has two hind notches on each side. The larynx is trimuscular; intestinal cæca usually absent or large; wings powerful, in some long and pointed. The legs are small, and, with few exceptions, not used in locomotion; the back toe short (sometimes, as in Cypselus, turned forward; sometimes, as in Ceyx, wanting altogether); the outer toe is reversible in some (Trogon), in others united to the middle toe as far as the penultimate joint.

Many nest in holes or in the earth; the eggs are white and subspherical. They are monogamous. The head is large, and in most the beak is remarkable for its length or width, or both. The gape is wide; the food is taken on the wing. There are at least eleven families-the Hornbills (Bucerotidce), the Kingfishers (Alcedinidce), the Puffbirds (Capitonidce), the Rollers (Coraciadce), Jacamars (Galbulidee), Bee-eaters (IFeropidce), Motmots (Prionitida), Trogons (Trogonida), Nightjars (Caprimulgidae), Humming-birds (Trochilide), and Swifts (Cypselidae).

In the Hornbills (Bucerotidce) the bill is large, hollow, and in adults obsoletely serrate or denticulate at the margins, and often furnished with a hollow appendage above the culmen. The nostrils are small, and placed at the base of the bill, near the culmen. Either the space round the eyes, or the whole face and part of the throat, are destitute of feathers. The wings are moderate, with the first three quills gradually 
longer; the fourth or fifth longest of all. All these birds live in warm countries of the Eastern Hemisphere. They are the largest of this order ; their food consists principally of buds; their voice is not modulated.

The Alcedinidce, or Kingfishers, form a natural family, which is almost entirely confined to the Old World. Most of the species inhabit the islands of the Indian Archipelago or of Polynesia. The Kingfishers feed entirely on fish, and watch for their prey for hours together on the banks of rivers. The nest is a narrow hole dug in the bank and lined with fishtbones. The young are born entirely'naked, and are ffed on dragon-flies. They are said to burrow in the holes off water-rats. The entrance to the nest is usually from boeneath upwards. The flight is rapid, direct, and imppetuous.

The Rollers (Coraciadce) have the bill moderate, osompressed towards the tip, which is abruptly curved. The outer toes are free. The tarsus is shorter than the anterior middle toe. The wings are elongate, with second quill longest of all. The tail is even and rounded, with the outer feathers on each side often onger than the rest, sometimes elongate and acuminate. [n their internal structure the Rollers correspond to a great extent with the Kingfishers. The Roller is about tihe size of a Jay. They are peculiar to the old coniinent and its islands, species occurring in the warmer Jarts of Asia and in Africa, and one of them extending nto Europe, where, however, it is in England only an ccasional visitor.

The Jacamars (Galbulida) inhabit tropical America, where they feed on insects. The bill is elongate, traight or somewhat straight, tetragonal, and acumi1ate. The feet are very short, with two anterior toes 
united almost to the point, and the hallux short or absent.

The Bee-eaters (Merops) are confined to the Old World. The bill is moderate or long, arched, acuminate, with margins very entire; tongue narrow, with apex horny, laminate; tail long, subeven; tarsi short, recticulate posteriorly; tibiæ denuded above the heel; wings with first quill mostly very small, second, more rarely third or fourth, longest of all. There is a close affinity between Meropidce and the next family of Motmots (Prionitidce). These are composed of South American birds, which represent the genus Merops of the Eastern Hemisphere. They live in forests, and are insectivorous. The usual colours are green and blue. The Trogons, or Couroucous, are tropical birds of the Western and Eastern Hemispheres, which live in woods and feed on insects. They have some affinity with the genus Caprimulgus. Their plumage is soft and thick, and mostly glossy, with a green metallic lustre. Their furcula is closed in front. The bill is short and curved; it is broad at the base; the margins are mostly serrate or denticulate. The gape of the mouth is ample. The feet are short; the inner toe is turned backwards, the outer one forwards; therefore the two outer toes are shorter than the two inner ones.

In the Nightjars (Caprimulgide) the general form is slender, the body, when deprived of feathers, very small indeed; the neck rather short; the head rery large, depressed, and flattened above. The feet are extremely small; the tarsus very short, roundish, antericrly feathered, excepting at its lower part; the first toe is very short, slender, and directed inwards; the second and fourth about equal, the third much 
onger; the anterior toes directed forward and connected by membranes as far as the second joint. The laws are very small, arched, compressed, rather blunt, that of the middle toe proportionately longer, curved outwards, and having its inner convex edge expanded ind pectinated, being cut into parallel teeth. The slumage is full, blended, and very soft; the feathers yenerally ovate and obtuse. Along the base of the upper mandible is a series of very large, flattened, oristle feathers, which are directed outwards. Wings rery long and narrow, with twenty quills; the priuaries very strong, the second quill longest, the first little shorter, the rest rapidly graduated; the secondries rather short, broad, and rounded. Tail very long, fften broad rounded feathers, and generally rounded, out sometimes even, or emarginate, or forked. The froatsuckers fly in the dusk, in gloomy weather, or un the shade of woods, and feed on insects of various inds, but especially moths and beetles, which they eize on wing. They move with great velocity, but rithout producing a noise audible at any distance, and (erform their evolutions in the same manner, and early with as much ease, as the Swallows. Many uthors state that they fly with open mouth; but this ssertion is not founded on observation, is contrary to nalogy, and, indeed, to reason; for as the pharynx is ride, and as there is no valve or peculiar stricture on ae ${ }^{2}$ sophagus, that and the stomach would necessarily e filled with air were the bird to advance with veloity. Their feet are not formed for grasping, so that then resting on a bough they generally place themelves directly, and not transversely, upou it. They ften also rest on the ground. They are incapable of 'alking otherwise than in a constrained and hobbling' 
manner. They breed on the ground, depositing their eggs, which are generally two, in a bare place, either exposed or in the shelter of trees. Species of this genus occur in most parts of the globe, but are not numerous.

The Humming-birds, which have received an unusual and unnecessary degree of attention from those home naturalists who have been impressed with ideas of their alleged beauty, are confined to America; they feed on insects. The cornua of the hyoid bone, as in some of the Woodpeckers, extend over the cranium. The humerus is very short; the bones of the fore-arm are also short, less in extent than in the hand. The neck is long, though the vertebræ are only thirteen in number. The tongue is bifid at the extremity, and serves as an instrument by which insects are caught at the bottom of the flowers. The Humming-birds are peculiarly small.

The Swifts (Cypselus) afford many points of analogy with the Swallows (Hirundo) in the next order. Like them, their flight is rapid; and it is in the Swift that the greatest proportional length of wing exists in comparison with the body. The second quill of the wing is longest of all. The intestines have no cæca. All the toes are directed forwards, and have but two phalanges, three of them nearly equal. They are purely insectivorous.

Order 4.-ChNtores, or Oscines.

These comprise the Passerine Birds of Linnæus and the Singing Birds of ordinary zoologists. The legs are short and slender, with three toes before and one 
behind, the two external toes being united by a very short membrane. The sternum has one hind notch on each side, the manubrium is tbifurcate, and the larynx muscular. The brain is reliatively larger than in other tbirds, and the organ of voice is more complex. The nests aare elaborate, and the eggs aare usually coloured. All the Cantores are monogamous. There are four great families-the Dentirostres, Conirostres, Tenuirostres, and

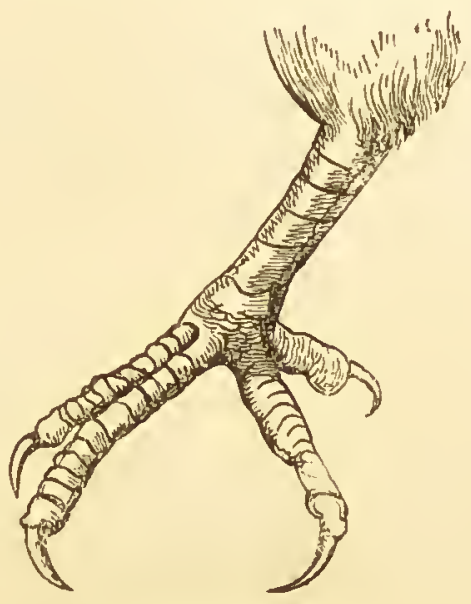

Foot of Cantor.

EFissirostres. The Manakins (Pipra), Shrikes (Lanius), W Wrens (Reguhus), Wagtails (Motacilla), Warblers (Sylia), Thrushes (Turdus). All these, with the exception if the Shrikes, are vulgarly called soft-billed birds. The Dipper (Cinchus), the Oriole (Galbula), the Hedge parrows (Accentor), Redbreasts (Erithacus), Nightinales (Philomela), also form frequent English examples. 'he tropical forms are of enormous number and wide i istribution.

The Conirostres comprise the Paradise Birds (Paraisea), the Crows (Corvus), the Starling (Sturnus), Suntings (Emberiza), Titmice (Parus), Lark (Alauda), inch (Fringilla), and Grosbeak (Loxia). All these "rms, with the exception of the Titmice and Larks, re commonly hard-billed birds. The birds of which uis family is composed are, in fact, remarkable for a eneral similarity of form, and more especially for a iutual resemblance in the shape of their bill, which is iore or less stout and conical, although it presents insiderable differences in its outlines and apex, being 
commonly short, and rapidly tapering to a point, sometimes very short and bulging on the one hand, and on the other sometimes rather long and acuminate. Birds of this order occur in all parts of the globe, but are more numerous in the temperate than in the tropical regions. They are generally gregarious after the breeding season and feed for the most part on seeds, which

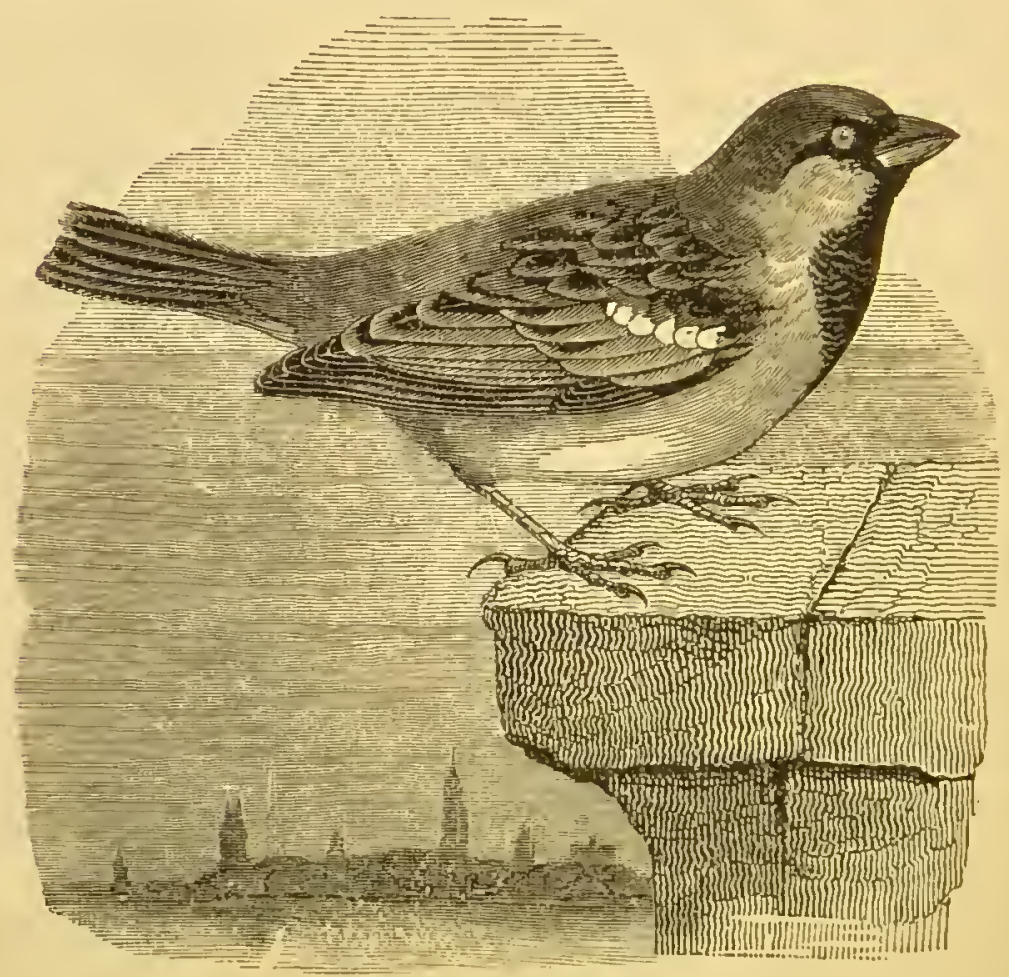

Ilouse-Sparrow.

they deprive, by means of the sharp edges of the bill, of their outer covering or pericarp, whence the name Huskiers given to the order. Many of them, however, feed on berries and fruits of various kinds; and the larger species of the family eat also worms and various other matters; approaching in this respect, as well as in appearance, to the Corrince. Their mode of progression on the ground is generally by a suc- 
cession of short leaps, and on trees they cling with ease to the twigs, some of them being more arboreal than terrestrial. Their flight is rapid, light, and sustained, generally undulating, or performed by successive bounds. 'They are fond of basking in the sun, whether' on trees or on the ground; and in dry weather may be seen fluttering among dust or sand, which they throw up about themselves. The purpose of this habit has been supposed to be to rid themselves of parasitic insects, but it is more probably connected with the gratification imparted by the warmth communicated by the heated sand. They wash occasionally in pools or streams, standing or crouching in the water, and throwing it up by repeated flutterings. They drink by immersing their bill and taking up a little at a time, elevating their head in swallowing it. They construct an elaborate nest, greatly diversified in form and texture according to the species. The eggs, which vary from four to nine, exhibit great diversity of marking, being, however, generally spotted or' dotied. The young are born blind, at first thinly covered with down. The males are almost always more gaily attired than the females; the young are generally similar to the latter, and the young males sometimes moult several times before the plumage is completed.

The digestive organs of these birds are obviously adapted for seeds or other hard bodies. The strong, conical, pointed bill, with its fine, point and sharp edges, performs the part of a forceps and husking instrument; the dilatation of the osophagus receives the food collected; the gizzard, as muscular as that of the Rasores, with an equally tough and rugose intermal coat, readily triturates the frequently hard seeds, with 
the aid of gravel or sand, and the ingesta being highly nutritious do not require to undergo a protracted elaboration in the intestine, so that the cæca are merely mucous crypts, as in the Pigeons, whose food is pretty similar. The variation of species in different genera of Fringilla affords a good test of distinction. Though nearly every species breed together freely, and the progeny is fertile, yet each district preserves its own local marks of distinction from the rest, and such differences appear to be constant and unchangeable.

Of the Tenuirastres, the Sunbird, the Nuthatch (Sitta), and the Creeper (Certhia) are the leading types. The Hoopoe (Upupa epops) is a rare visitor to England, yet forms a characteristic example of the family. The bill is long and slender and tapering, much compressed. They are usually termed Creepers, on account of their woodpecker-like motion on the sides of trees; with the true Scansores, however, they exhibit little affinity.

The Fissirostres, which bear strong analogies to the Cypselidce in the preceding order, comprise the Swallows and the Martins (Hirundo). The Swallows have especially long, pointed wings, and fly very rapidly and continuously to capture insects as they fly for food. For this purpose the bill, of which the horny part is unusually short, can be opened very wide. They build their nests mostly in society, and lay from four to six eggs. In England all the species of this family are birds of passage. This fumily may be separated into two divisions, which are united by Linnous under his genus Hirundo, yet, with much resemblance, still so greatly differ from each other that most modern writers have found occasion to remove them far apart. The first division alone possesses special muscles for song, as in the rest of the singing-birds. 


\section{Order 5.-RAsores-Gallinacei.}

In these scratching-birds the feet are provided with obtuse claws for scratching up grain, \&c.; the upper mandible is vaulted; the nostrils are pierced in a membraneous space at the base, and covered by a cartilaginous scale. The nest is rude. The sternum has four, rarely two, deep fissures. Two broad divisions of the Rasores exist, those which are polygamous, as, e.g., the Megapodius, Peafowl, Partridge, Quail, Pheasant, Goura, Grouse,

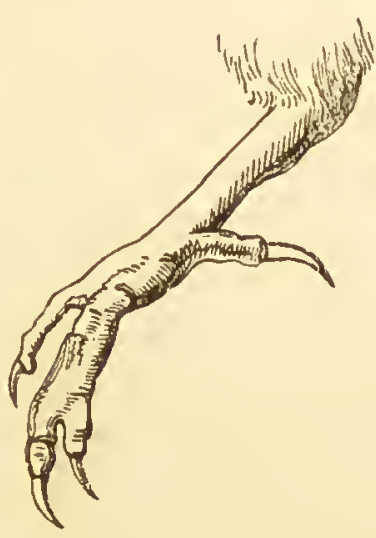

Foot of Rasorial.

Pintado, Tinamou, Turkey, Curassow, and Guan. These are termed Gallinacei, Clamatores, or Crowers. The next family, if, in fact, by reason of the differences between it and the Crowers it cannot be raised to a sub-order, is the Gemitores (Doves, Goura, and Vinago).

Representatives of this order are found in all parts (of the world, from the forests and jungles of the Indian isles, where the Peacock is a type, to the frozen shores of Labrador and Greenland, where the Ptarimigan, as well as other species of Grouse, are found. (Certain genera are peculiar to particular regions, as the Turkeys to America, the Argus to India and China, the Pheasants to the warm and temperate parts of Asia, the Guinea-fowl to Africa; while others, as the Grouse and Partridges, are generally distributed. The affinities of the Rasores are various: on one hand with the Pigeons, through Crax and Penelope; on the other 
with the Bustards, which lead to the Plovers; and with the Gallinules and Rails. In the true gallinaceous birds the breast-bone is truncated in front, forms a nar'row bony band on each side of the keel, and is, besides, in great part represented by membrane, with a

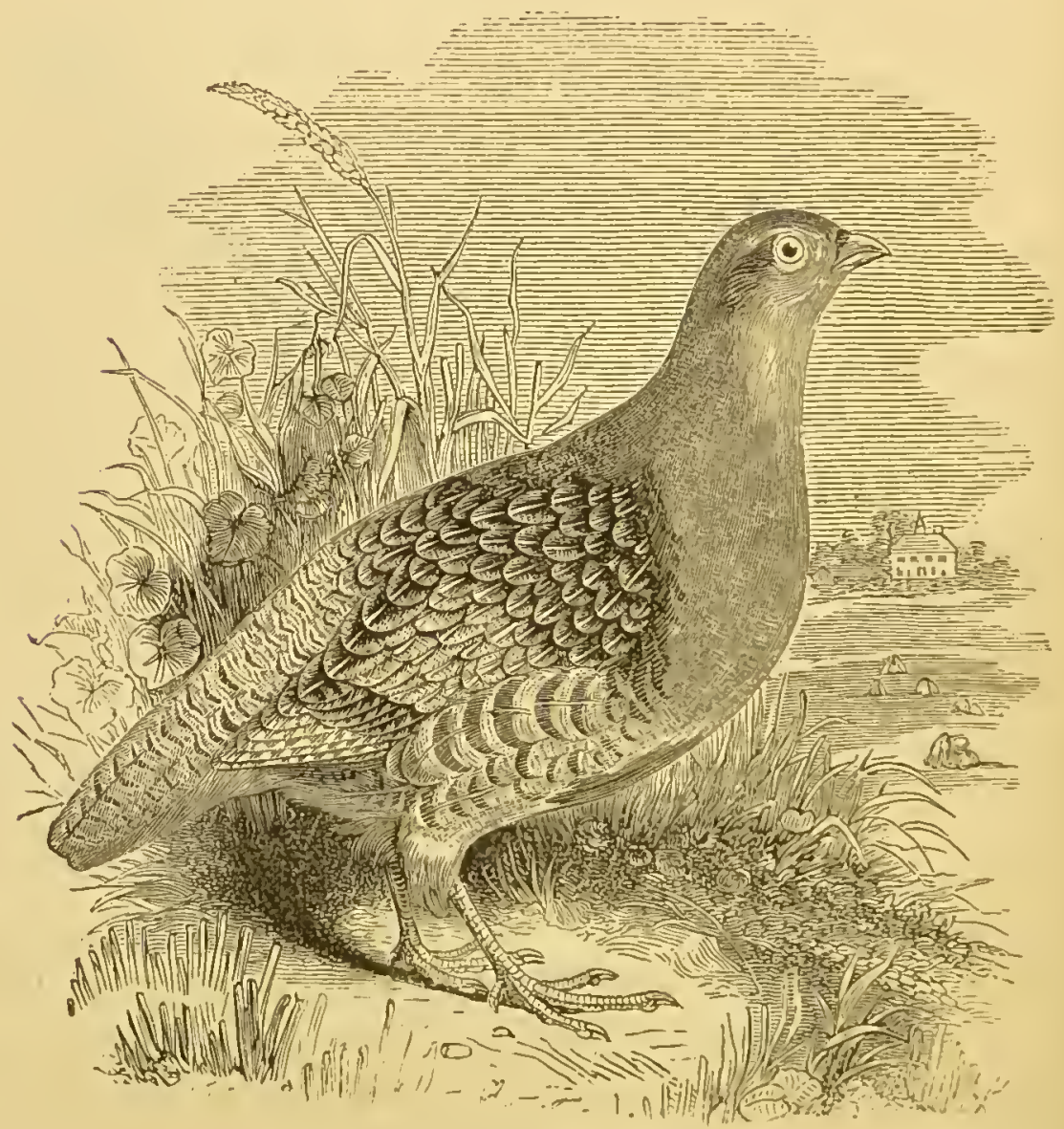

Partridge.

forked bony piece at the outer margin. The furcula does not reach the sternum, but is connected with it by ligament only. The bones of the arm are short; the upper arm-bone does not reach further than the crest of the ilium. The spinous processes of the dorsal vertebre coalesce to form a simple lamina. The pelvis 
is broad and spacious. The crop is large, and the muscular stomach very powerful.

To this order belong most of the species of birds domesticated by Man, and of which none according to the Mosaic law were declared to be unclean. These birds live for the most part in polygamy; they make a rude nest on the ground of straw and fibres of plants, and lay many eggs. They feed principally on the seeds of plants, which are softened in their crop before they are triturated in the stomach or gizzard. The length of the middle toe and some other peculiarities give to the gallinaceous birds a remote resemblance to the Vultures.

The Megapodii, or Brush Turkeys, of Australia, of which there are several allied genera, all agree in one character, that their eggs are laid on heaps of leaves or on decaying vegetable matter. The Curassows (Penelope) represent in South America the Asiatic genus Phasianus; the bases of the beaks are in all the species surrounded by caruncles, and the cheeks and throat are frequently destitute of feathers. The true Phasianidce present those birds which during the last thousand years have been the fowls most familiar to European nations. The Guinea-fowl (Numida), the Turkey ( $M_{\epsilon}-$ leagris), the Peacock (Pavo), the Eyed Pheasant (Argus), the common Pheasant (Phasianus), and the ordinary Cock and Hen (Gallus) are familiar domestic types. I I has been supposed that the domestic fowls are related by descent with the Malay breed (Gallus bankiva), or with a Bengal species (Gallus sonneratii). With the "nimer species the domestic game fowl agrees in most of its characteristics. Ceylon also possesses a distinct species of fowl (G. Stanleyi), the voice of which is oeculiar, and which does not appear to be identical 
with any of the domestic breeds, with which, however, it crosses freely. It is probable that G. bankiva is the true origin of our domestic fowl, which has varied into an enormous number of breeds, all of which exhibit wider marks of distinction than do any of the wild species. The Tinamons (Tinamidoe) of Paraguay and the Grouse (Tetraonidoe) form aberrant examples of the Clamatores. To the latter group belong the Quails (Coturnix), the Partridges (Perdix), the Ortyx or Californian Quails, and the true Grouse (Tetrao), which are essentially boreal species, and are familiar examples. The Pterocles of the south of Europe forms a transitional link between the Crowers and the Cooers. The Cooers (Gemitores) at first sight appear to form an order by themselves,

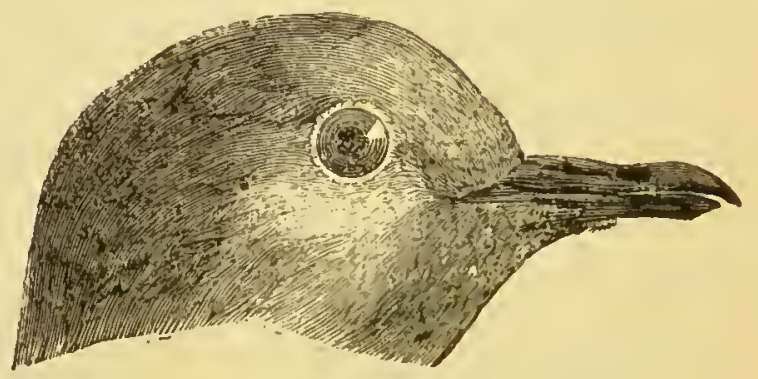

Head of Dove.

separated by weli-defined limits from other birds, and yet presenting modifications of form which group them as truly rasorial. The peculiar shape of the head and bill, more than any other external feature, serves to render the different species readily cognizable as belonging to a single tribe, for whatever may be the size, colour, or even shape of a Pigeon it cannot be mistaken; but the relations of the family, it would appear, are not so readily perceived, some of our most approved systematists having associated them with the passerine, others with the gallinaceous birds, 
while a few consider them as constituting a distinct igroup. Although essentially rasorial in their nature, the Doves, of which more than two hundred and fifty : species are now known, form a well-marked and separate group amongst the Rasores, being distinguished 1 from the other members by their very small cæca. They are found in almost all parts of the world, the American forms having a tendency to become less sarboreal and more ground-loving than those of the Old World. One of the most singular of the genera of IDoves is the Dodlet (Didunculus), in which the beak iis moderately thick, depressed at the base, curved, with a sharp, hooked tip; the lower mandible has a truncate ttip, with a somewhat prominent angle.

The Didunculus strigirostris affords a link with the cextinct Dodo (Diclus), which was an unwieldy bird f from the Mauritius, and appears to have been destroyed ffor the sake of its flesh by the Dutch voyagers, and now to have become extinct for nearly two icenturies. Fragments of its body were presserved for years in England, of which Owen, štrickland, and other somparative anatomists were able to reconstruct the skeleton, which has since been found in an entire condition, and proved to illustrate the

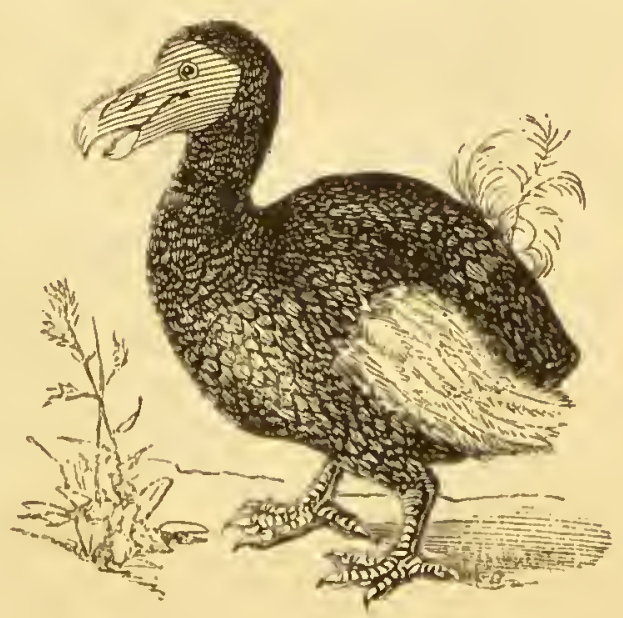

Dodo. form of a gigantic, wingless, terrestrial dove, similar in its general conformation to the Didunculi. The Solitaire, a bird allied to the Dodo, but with longer 
legs, as well as another short-winged bird from the isle of Mauritius, are probably referable to the same group as the Dodo. The affinities of these forms are more doubtful than those of the Dodo, yet they afford much analogy to it in their terrestrial mode of life.

\section{Order 6.-Grallatores.}

In these birds the legs are long, naked from above the distal extremity of the tibia downwards. There

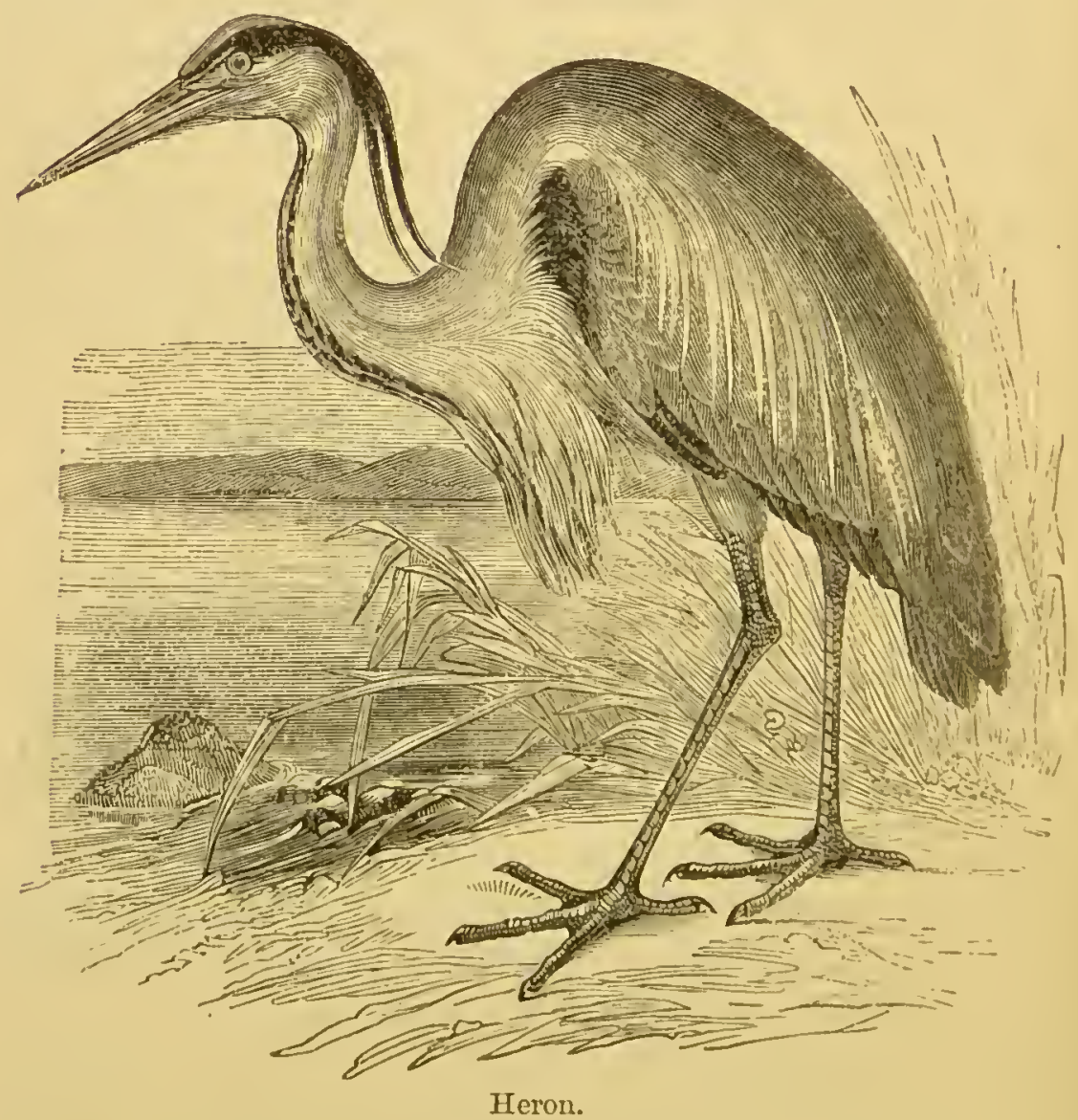

are four families: the MLacrodactyli, amongst which may be counted the Coots (Fulica), Rails (Rallus), Crakes 
(Crex), Screamers (Palamedea), and Jacana; the Cultirostres, e.g. the Boatbill (Cancroma), Crane (Grus), Heron (Arrea), Ibis, Stork (Ciconia), Tantalus, Spoonbill (Platalea); the Longirostres, e.g. the Stiltshank (Himantopus), Avocet (Recurvirostra), Snipe (Scolopax), Ruff (ILachetes), Turnstone (Strepsilas), Sandpiper (Tringa), Godwit (Limosa), Curlew ; and the Pressirostres, as the Oyster-catcher (Hcematopus), Thick-knee (Edicnemius), Plover (Charadrins), Lapwing (Vanellus), Bustard (Otis). The neck in all these birds is moderate or elongate in size. The bill is usually long, of various fforms. The wings are long in some of the Snipes; the unfeathered part of the tibia is very small and confined to the posterior surface of its lower part. In most species, however, it is very large, especially in the Stiltshanks and Avocets. The majority of these birds llive in fenny districts or on the banks of rivers ; many are partially carnivorous, and some large and stronglbilled birds swallow fishes, reptiles, and small mamimalia. Most of the species fly very well, and during ifight extend their legs backwards. In the first or Macrodactylous division of Grallatores, the feet are ffour-toed, sometimes elongate, sometimes lobate, the itarsi are covered antericrly with transverse scutella, the wings are moderate or short, the body slender, and the breast compressed, with a narrow sternum. The (Joots or Water Hens (Porphyrio) have a bony enlargenent of the upper mandible, which extends into a ieatherless shield over the forehead. They inhabit noist meadows, marshes, and the sides of lakes and ivers. Some of them are strictly terrestrial, but by ar the greater number readily betake themselves to he water, and many habitually reside upon it. They 'un with great speed, and make their way with 
wonderful ease among the rank and dense herbage, where they conceal themselves, and from which they are with difficulty raised. Their flight is heavy but rather quick, and usually not extended, so that they seem unfitted for long migrations, which, however, some of them perform. They construct bulky nests, which are placed on the ground or raised amidst shallow water, and lay numerous spotted eggrs. The young are covered with stiffish down, and are active from the first. Seeds, insects, worms, and other small animals form their food. They are more numerous in warm climates; but one species or other is met with everywhere, and a few occur in the coldest.

They can scarcely be disposed into families, their mutual affinity boing so obvious that a separation of them into groups would be merely arbitrary.

The genera Aramus and Rallus, however, have the bill so elongated, and so different in form from the short, thick, strong bill of the other genera, that they seem to constitute a group apart. At all events, a division into the two families of Rallinæ and Gallinulinæ would not be productive of the least confusion, or give rise to any misapprehension of importance.

In the Parras, or Jacanas, the wings are spurred or tuberculate, the spur on the joint of the wing being used as a powerful weapon.

In the Cultirostres the bill is longer than the head, thick, strong, mostly compressed, more rarely depressed, broad. There are four toes which are conjoined at the base semi-palmate. The Ibises occur in all the warm countries of the world. A species of Ibis in Egypt, the black and white Ibis religiosa, had divine honours paid to it, and it was embalmed by them with the greatest care. In the Spoonbills (Platalea) the bill 
is elongate, subdepressed, with tip orbiculate and broad. The White Spoonbill, a southern European species, is coccasionally found as far north as Holland. In the anomalous genus Balceniceps the bill is much longer than the head, robust, broad, and terminating in a rpowerful hook. The tip of the lower mandible is truncated. The nostrils are placed in a narrow slit at the tbase of the bill, close to the culmen, and scarcely per(ceptible. The orbits are denuded; the skin of the throat is loose and expansile. The wings are very Ipowerful, the third, fourth, and fifth quills being the Hongest. It inhabits the upper part of the White Nile iin Africa. The true Storks (Ciconia) are common in IHolland and Northern Europe, but are rare visitors in 1England. Allied genera, such as the Marabout Storks ('Argala), are found in nearly all old World tropical countries; the Boatbill (Cuncroma) is found in Surinam and other parts of South America. This bird lives on fish, like the Herons, from which it differs by the appearance of the bill, the upper mandible of which ooks like a reversed spoon. In the Herons (Ardea) the bill is elongate, straight, thick, and compressed; the neck is long. They live in marshy regions or on the oanks of rivers and lakes. They feed chiefly on fish, ratch long for their prey, and then shoot out their rong necks to catch the food. The Cranes (Grus), the Bitterns (Botaurus), and the Trumpeters (Psophia) of jouth America are also well-marked modifications of he cultirostrial type.

In the Longirostres the bill is mostly elongate, slender, and soft. The nostrils are placed in a groove of the iill. Most of the species of this family live on insects, or which they feel or seize them with their bill on or nder the ground, or in the mud. Tho Snipes and 
Sandpipers (Tringa) and the Godwits (Limosa) are able to move the extremity of the upper mandible separately. To aid the Snipe in this task, the tip of the bill is supplied with many nervous filaments from the fifth pair, which pass through small bony cavities of the upper mandible.

The Snipes (Gallinago), the Woodcocks (Scolopax), are forms in which the bill is straight; in the Curlew (Numenius arquata) it is incurved downwards, and in the Avocet (Recurvirostra arocetta) it is recurved upwards.

The Pressirostral, Stalking-birds, have the bill moderate, seldom longer than the head, with the tip prolonged, hard, and compressed. The Pratincoles, Thickknees, Plovers, Sandpipers, Sanderlings, Lapwings, Turnstones, Dotterels, are familiar English examples. The Bustards (Otis) resemble the gallinaceous birds in many of their characters. They are not migrating birds, but stragglers, and live mostly in society in corn-fields and widely-extended plains. Many of the Bustards show marks of affinity towards the last order, Cursores, with which they are to be connected probably by direct genetic relations of descent.

\section{Order 7.-NatatoRes.}

These are the usual and well-known types of swimming-birds. The toes are united by a membrane, the legs are placed behind the equilibrium, and their body is covered with a thick coat of down beneath the feathers.

There are three families: Breriponnate, as the Penguin (Aptenodytes), the Auk (Alca), the Guillemot 
(Uria), and the Grebe (Podiceps); the Longipennatce, as the Skimmer (Rhynchops), the Tern (Sterna), the (Gull (Larus), the Petrel (Procellaria), and the Albatross (Thalassidroima); the Totipalmatce, as the Pelican (Peli(sanus), Gannet (Sula), (Cormorant (Phalacrororax), Anhinga (Plo-

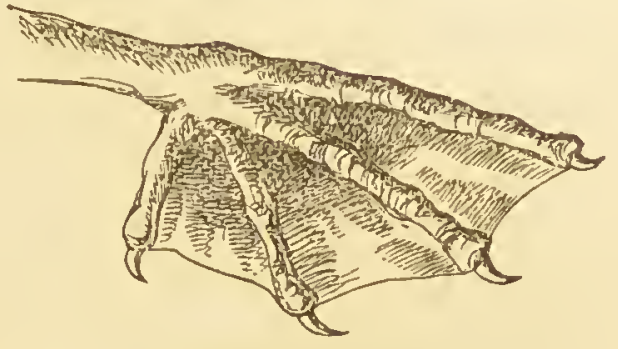

Foot of Duck. thus), Frigate-bird (Tachypetes), and the Tropic-bird ('Phaeton).

In all the Natatores the feet are moderate or short in ize, placed more or less behind (aversi), palmate or

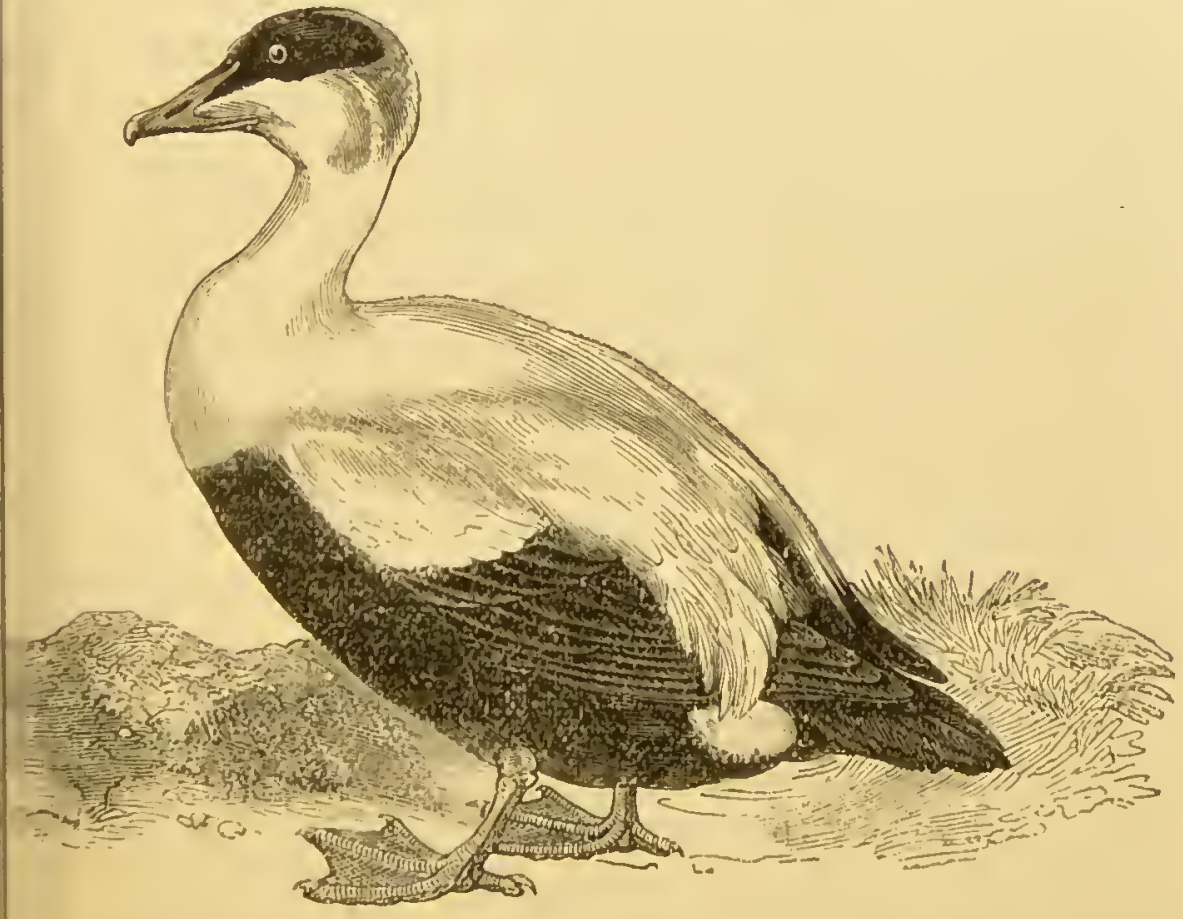

Duck.

sso-palmate; the entire thigh or basal portion of the bia is included by the skin of the trunk. In the wimming-birds the inferior parts of the tibia are 
covered with a horny skin, as also the tarsi and toes. Legs of this kind are called stilted (pedes vadantes); the legs are little longer than half of the trunk (mediocres), or even shorter than this half (breves), and are placed towards the back part of the trunk (aversi). The plumage is thick, and penetrated, as it were, with much oily fluid, and thus protected from the water. The neck is often much elongated, so that these birds, by extending their head over or under the water, seek for and seize their food on every side. The breastbone is large, more or less convex, and extends over the abdomen far backwards; it is incised at the posterior margin on each side, or provided with an oval opening close to that margin.

The Lamellirostres possess the bill of moderate form, sometimes longer than the head, straight, rather thick, covered with skin, only at the middle of the tip it is harder, horny, with margin denticulate, as in the Mergansers, or furnished with transverse parallel crowded lamellæ. The wings are fitted for flying, the quill feathers elongate, the second primary equalling the first or somewhat surpassing it in length. The feet are palmate, four-toed, with the thumb separate. The Mergansers swim rapidly and dive under water; they fly also very well, but walk with difficulty and a waddling gait. They chiefly feed on fish, and are coufined to northern latitudes ; three species are known in England, all of which agree in having the bill subulate, hooked at the tip, with the margins denticuloserrate. The hallux is enlarged by a lateral membrane. The Goosanders and Smews are rapidly becoming extinct in the British Isles. The Ducks (Anas) and the Sea Ducks (Fuligula) ufford many marks of resemblance, especially in their external form. They are, howerer, 
distinguished by the form of the inner toe, which in the true Ducks is simple, but in the Sea Ducks (Fuligula) is furnished with a lax rudiment of membrane. The common Duck (Anas boschas), the Shieldrake ( $A$. tadorna), the Garganey ( $A$. querquedula), the Teal ( $A$. crecca), and the Widgeon (A. penelope), are familiar forms of the Anatidae; whilst the Eider Duck (Somateria mollissima), the Pochard (Aythya ferina), the Scaup Duck (Fuligula nyroca), the Scoter (Oidemia fusca), the Garrot (Clangula histrionica), form the chief English types of the family of Sea Ducks. Both these families seem to be distributed over the whole of the globe. The Geese (Anser) have their legs higher, and placed not so far backwards as the Ducks; hence also they irun better. Their swimming membranes are shorter; they swim less, and do not dive. The difference of iplumage between the two sexes, which is so remarkable in the Ducks, is in the true Geese scarcely observable. IIn ancient Egypt the Chenalopex, or Fox Goose, was saacred on account of the love it shows for its young. The Barnacle Geese (Bernicla) is an aberrant form; whilst the Spur-winged Goose (Plectropterus) has, like the Jacana, the extinct Archoopteryx, and a few other lbirds, spurs developed on the wrist-bones of the wings. This species is indigenous to Northern and Western Africa, but one specimen has been killed in Cornwall. IThe true Swans (Cygnus) have the bill with the margin amelloso-dentate, higher than broad at the base. 'l'he nostrils are in the middle of the bill, and the neck is very long. In the common Swan (C. olor) the trachea s straight, and the bill is orange-red on the fore part, he base being black, with a prominent black tubercle, or knob on the upper part or point of the forehead. in the Hooper, or wild Swan (Cygnus ferus) the bill is 
black, yellow only at the base, and there is no knob on the forehead. Bewick's Swan, a species which is occasionally found in England, exhibits a bare space on the forehead and between the eyes, and bill bright yellow, as is the base of the upper mandible. It is said to be more frequent in Ireland than either of the other two species. The Cygnus Americanus and the Cygnus immutabilis are also said to occur in England, though rarely.

The Totipalmate form of water-birds comprise forms in which the bill is long or moderate; the long wings are adupted for flying; the feet are short and four-toed, with the hallux placed internally, and directed forwards, joined by membrane to the inner toe.

The Pelicans (Pelicanus) occur both in the Old and in the New World. They live on fish; the skeleton has many hollow bones. The throat is loose and lax, forming a pendulous bag, in which the prey is retained for a short while after prehension. The Cormorants and Shags extend over the whole world; they are almost all coloured black. The Gannets, or Solan Geese (Sula), are the largest sea-birds in the British Isles. They are of a white colour. In China one of the species is trained to catch fish. A species of Gannet is the chief bird which produces the guano deposits of the islands off Peru. In the Darters (Plotus) the neck is long and slender; they make their nests in trees, and are common throughout the whole of the American tropical regions. The Frigatebirds and Tropic-birds are high-flying, dark-coloured birds, which are to be found accompanying ships at an enormous distance from the land. The long-winged family comprises a series of birds which are peculiarly erratic, and, unless when theyr are fixed to a place for a 
time by the cares of breeding, wander about in search of their food, which consists essentially of fishes, but also ( of crustacea, mollusca, worms, insects, and sometimes carcases of whales, land mammals, and birds. They (can usually wade with ease in the shallows, swim lightly, and fly in an easy, buoyant manner. They

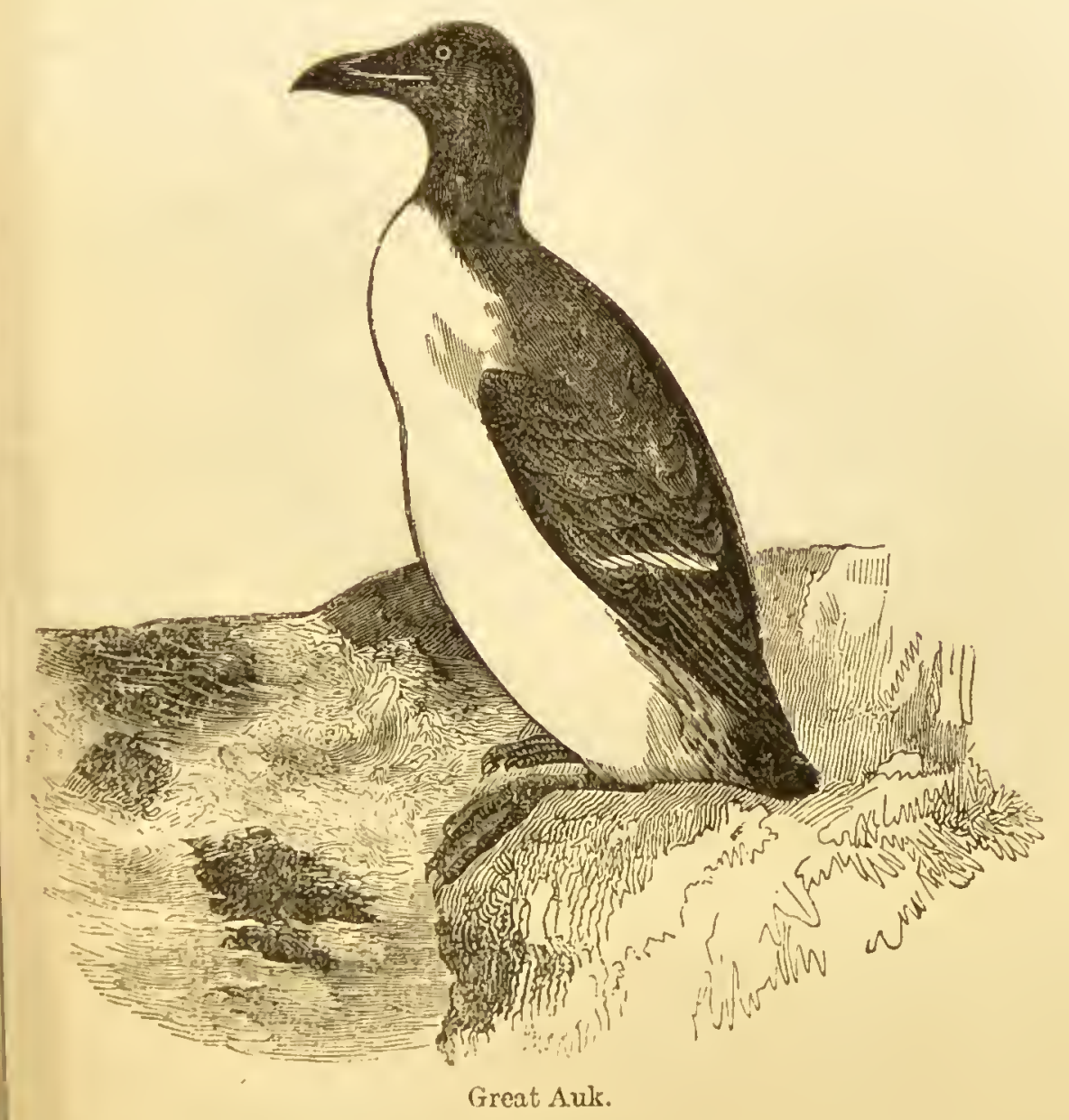

sually nestle on the ground, laying from three is five eggs. The males are little larger than the emales, and generally the sexes are coloured alike. 'he Brevipennato, or short-winged family, present aose members of the order which are the most aberunt from the avian type. The majority are upright 
in their gait. Two broad divisions of this family are known, the Grebes (Podiceps) and the Auks and Penguins (Aptenodytes), and Alca. The Puffins and Guillemots, Mormon and Uria, form better-known examples. The Great Auk or Gair Fowl (Alca impennis) has become extinct in Europe during the last hundred years. In it the wings are reduced to mere rudiments, the quills being scarcely longer than their coverts, and the bird, like the Penguin of the Southern

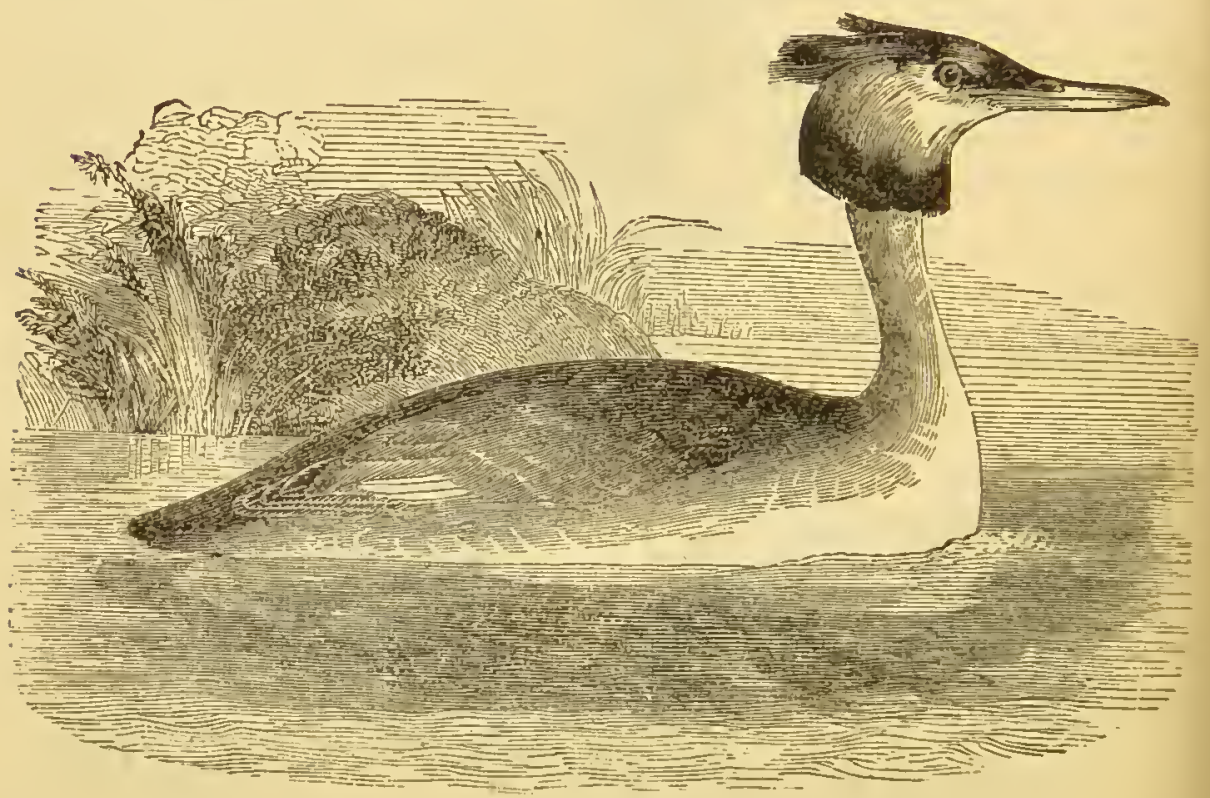

Crested Grebe.

Seas, which it represents, was sustained upright on the posterior extremities by a pair of powerful feet. The Manchots, or Southern Penguins, all agree in the general character of the plumage and in their gregarious habits.

\section{Order 8.-Cursonts.}

'This is not a natural order of birds. Its member's have been characterised under the name Cursores, or 
Running-birds, by the arrested development of the wings unfitting them for flight, and by the compensating size and strength of the legs by which they are enabled to run swiftly on the ground. Some of the members of the order have still closer affinities to other groups of which they are wingless members, just as the Penguins and Auks bear relation to families of the inatatorial order. The Notornis of New Zealand is a smodified Coot. The Ostrich (Struthio) has a close relaition to the Otidince, or Bustards ; the Didus and Pezoiphaps are most clearly allied to the dovelike or columtbaceous group of Rasores. Apteryx, Dinornis, and Palapteryx bear affinity to the megapodial family of Egallinaceous or rasorial birds. In all the cursorial genera the sternum is devoid of keel. In the struthious lbirds, the wings are without quill feathers, unfit for fflying. The feathers of the body are loose. The bill iis of various shapes, mostly depressed, with the culmen ddistinct, and the upper mandible with the tip produced beyond the lower mandible. In the genus Apteryx, the Ifeet are four-toed, with short and raised hallux; the tbill is long and slender, with the culmen depressed, and the tip subclavate and obtuse; the nostrils are placed near the tip of the bill, at the inferior part of the lateral groove; the wings are very small, concealed under the coverts; the tail is scarcely visible; the tarsi are thick, reticulate with irregular unequal scales, which are broader in the anterior row, and transverse; the fore-toes are thick, rather long, with strong curved fossorial claws; the internal rudiment of the hallex resembles a spur. The Kiwi, or Apteryx Australis, lives among the New Zealand ferns, where it feeds upon insects and worms. Its anatomy offers some curious analogies with that of the lower Mammalia 
and the higher forms of Reptilia. In the true Ostriches (Struthio) the feet are cursorial, three-toed, or two-toed. In the Cassowaries the wings are very small, with naked quills; the feathers are double, narrow and lax; there are three toes, and the tail is scarcely visible. Two divisions exist, one with bill depressed, in which the nostrils are placed in a broad groove, opening at the anterior part of the bill; the wings are concealed under the plumes. The New Holland Cassowary (Dromaius Novce Hollandice) is an example of the division. In the Cassowaries, which have a compressed bill, the nostrils open in the middle of the beak; on the head is a tubercle, covered with a horny envelope; the head and neck are in part naked, with warty swellings; the feathers are black. The bird inhabits the Malacca Islands and New Guinea, and was first brought alive to Europe by the Dutch. In the Ostriches the wings are unfit for flying plumed; the bill is depressed; the foot tridactylous or didactylous; and the tail moderate, with lax plumes. Those which have tridactylous feet are named Rhea, and are confined to the New World. They are vulgarly called Enus, or American Ostriches. The two-toed forms (Struthio) are essentially African and Arabian. They are the largest known existing birds, run with great speed, and live together in troops. The hens live in society, and lay their eggs in the same nest, or rather in a round hole in the ground. Around this is raised a kind of mound, against which the eggs rest. When the hole, which contains sometimes eighty eggs, is full, a few more eggs are laid round the nest as food for the young ones when they quit the shell. These eggs are broken by the adult birds. The egg of the Ostrich commonly weighs at least three pounds, and is considered to equal twenty-four Hens' eggs. Another 
division of cursorial birds comprises a series of extinct forms which inhabited New Zealand during the early human period. The Dinornis and Palapteryx of New Zealand, the AEpiornis of Madagascar, were gigantic forms which resembled the Ostrich in the character of being, like it, unprovided with a keeled surface to the rounded sternum or breastbone.

Among the natives of New Zealand there are traditions of large extinct birds termed Moas, which were extirpated by Man, and which were used for food by the Maories or natives of New Zealand. The remains of feasts at which the semi-burnt bones of the Dinornis are found associated with charcoal, and other evidences of human cookery, are frequent in New Zealand. Some travellers think it within the bounds of probability that the Moa may be still alive in New Zealand, which opinion is partially corroborated by the fact that the bones are of very recent origin. They are found in alluvial soil and in the beds of rivers. The largest species of Dinornis probably attained the height of twelve feet.

\section{Order 9.-URIONI.}

This group of birds affords marks of distinction from all other members of the class by reason of the peculiar modification of the caudal vertebræ, which retains the reptilian form and shape. The tail was a conspicuous appendage to the trunk, formed by about twenty elongate vertebræ, each of which supported a pair of small and slender quill feathers. Owen remarks, speaking of birds in general: "The terminal vertebræ, ungrasped by the pelvis in the embryo bird, may equal in number 
those of the ancient feathered fossil ; and if such vertebræ participated in the ratio of growth of other parts of the skeleton, without subsequent stunting and confluence, they would more or less repeat the strange feature in the skeleton of Archeopteryx; but the metamorphosis of the tail which has taken place in the bird's skeleton in the transition from the Mesozoic to the Neozoic life-periods of the class, is analogous to that from the protocercal to the homocercal type of tail, which marks the progress in fishes from the Palæozoic to the Mesozoic periods."

In some birds, as e.g. the Syrian Blackbird (Merula dactyloptera), the spur-winged Goose (Plectropterus),

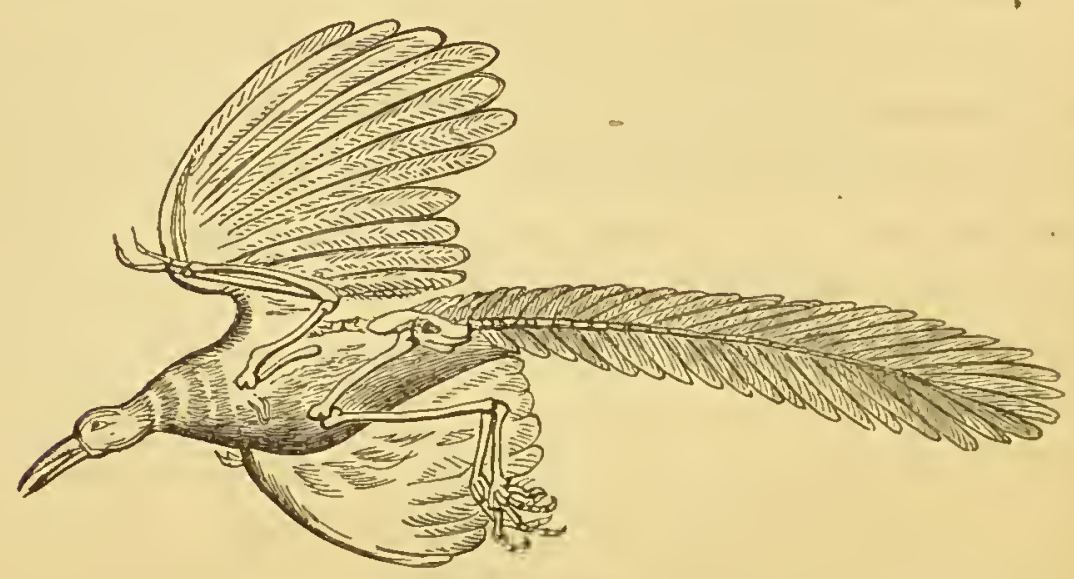

Archaopleryx.

the Dodlet (Didunculus), a single claw or spur is dereloped from the finger of the wing. In the Screamer (Palamedea) there are two claws or spurs. In Archceopteryx, the claw on the index digit was curred and sharp, and the fossil remains lead us to infer that the hand had a second free clawed digit, in which respect the Archcoopteryx differed from all known birds.

The skeleton of this extraordinary bird was found in the lithographic sandstones of Middle Oolite age, at 
Sojershofen, in Cicornarny, wheres a split slab expresed impresengorss of the remains of a bird in whish there wore a seriosof of long fiun-like freatheres diverging oblicquely

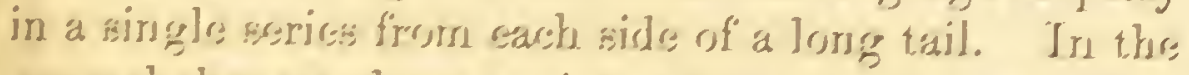
gencral shape and proportions of this tail it resemblowd the tail of a Petriurus or Squirrel rathor than that of a bird, whiles the wings in thesir present states of presecrvation agress in form and proportion with theses of the gallinacesous or round-winged birds. Je rivatively,

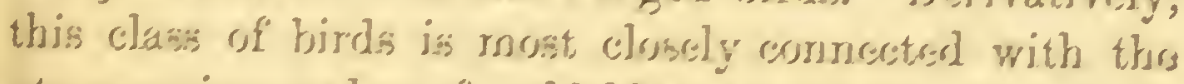

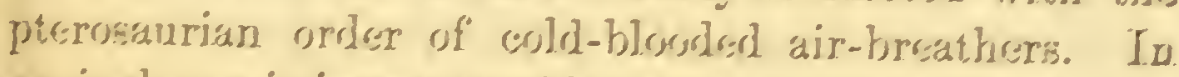
equivalency it is comparable rather with such a group than with thes Tisytilia in totality or withs thos Marnomalia; and hences the cerrsenponding inferiority of value of the avian "orderse" to the sutulivieions an eallesd of those largor classcs.

In rejation to tirnse, indications of $A$ wes date as far back as thoses of Jeteromaturia in the "orrithichnitoses" or

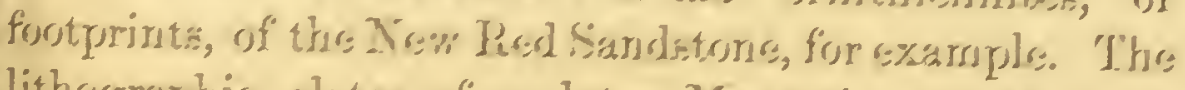

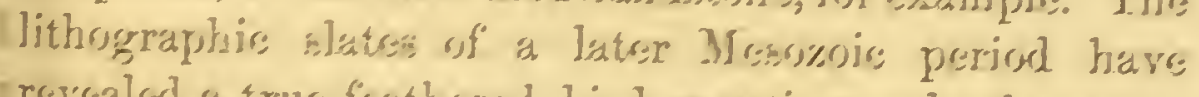
revealed a true featherred birrd, wariting only the axdap-

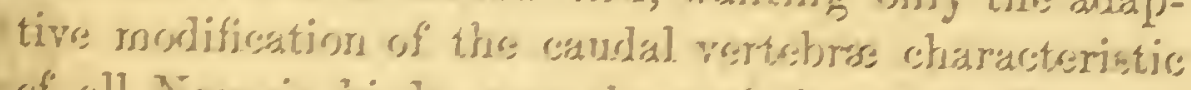

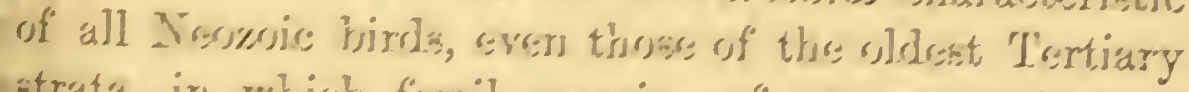
strata, in which fressil romains of representatives of nearly all the prosent orders of A wes have been found.

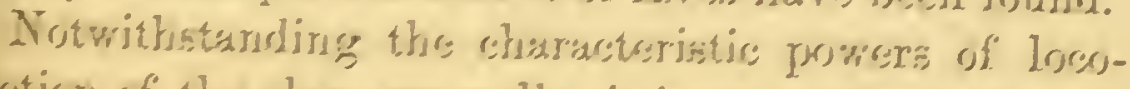

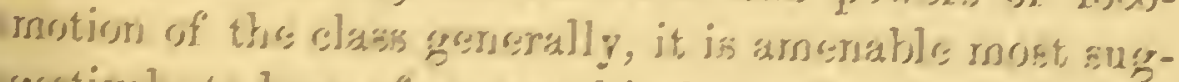
gostively to lawe of gorgeraphiceal distribution and linitation. 


\section{Class III.-REPTILIA.}

THESE are divided into Monopnoa and Dipnoa. In 1 the Monopnoa, the endo-skeleton is ossified; the exoskeleton in most appears as horny scales, in some as bony scutes; there is one occipital condyle; the vomer is usually single, and the trunk ribs are long and curved. The prosencephalon of the brain is large. The labyrinth has both fenestri vestibuli and fenestra rotunda; there is a tympanum in most ; true lungs; a heart with two auricles, and with the ventricle more or less completely divided. The testes have ducts. There is an amnios and allantoid, and no metamorphosis in any of the members of the class. In many fishes there is a bladder of air between the digestive canal and the kidneys, which in some is connected by an air-duct with the gullet directly, but its office is chiefly as a swimbladder. When this bladder becomes vascular, and when it is termed a lung, the limbs acquire the form and character of feet; sometimes, as in Lepidosiren, threadlike and many-jointed; sometimes, as in Amphiuma, two-fingered; sometimes, as in Proteus, three or four fingered, but confined to the pectoral region. There are transitional forms from all these to the fourfooted and strong-limbed Crocodiles and Dinosauria. The heart has two auricles; the ventricle is imperfectly divided, and more or less of the venous blood is commingled with the arterial, which circulates over the 
body; the lungs retain the form of bags with cellulovascular walls varying in thickness, and situated with the other organs of vegetative life in a common cavity for the abdominal viscera and respiratory organs.

Most reptiles have teeth, excepting in all the Tortoises and a few Frogs. In some of these the jaws are covered with a fine horny tissue. The teeth serve not so much for dividing and chewing as for holding the food. Some reptiles have the teeth in a single row only in both jaws; in some there are also teeth in the palate. In Serpents there is a row of teeth on each side in the palate, and usually in both jaws. The Frogs have teeth on the vomer, and also a row of small thin conical or cord-shaped teeth in the upper jaw, which are not found amongst some of the Toads. Salamanders have their teeth in both jaws. In the Batrachians the true salivary glands are absent; but in many Lizards and Snakes small glands are situated along the jaws or in the lips, which give out the fluid secreted by them. Serpents, Lizards, and Tortoises have a large sublingual salivary gland.

The length of the intestinal tube in most reptiles is only twice that of the body. Sometimes the length of the body even exceeds that of the intestinal canal. The larvæ of Frogs and the land Tortoises which live on vegetable food have the longest intestinal canal; in these its length surpasses that of the body three or six times. The liver is large in reptiles, often not divided into lobes, but incised at the margin. In the Crocodiles, however, it is divided into two distinct lobes, perfectly separate from each other, and solely connected by a duplicature of the peritoneum. The liver receives a large quantity of venous blood. In almost all species there is a gall bladder. The pancreas is also large, but 
varies much in form; the spleen is always present. The brain only forms a small part of the weight of the body, and presents on its upper surface a great resemblance to that of fishes.

The true skin in reptiles is very firmly connected to the muscles or bones which are situated beneath it; in Frogs it forms a loose, inflatable sac, except only on the head. The skin is always composed of several layers of fibres, which lie close together.

Many reptiles cast or moult their skin. The external covering of the eyeball is in Snakes moulted with the cuticle. Some Lizards, as the Crocodile, and in many of the extinct forms, the scales or scutes are ossified, and form bony plates, which extend over the whole of the body. The sense of taste is feebly developed, and most reptiles gulp their prey without any comminution of the food from the salivary glands.

The intelligence of reptiles is very feebly developed, and in this respect they stand on scarcely a higher footing than fishes. Growing slowly, they live long; in regions where the thermometer is beneath a certain average they undergo hibernation or winter sleep; they are very tenacious of life; some remain for months in captivity without food, and great heat or cold can be endured by them. As in lower members of the vertebrates, irritability of the muscles persists for a long time after death, as also in amputated parts of the animal. The reproductive power is very great, especially in the Water Salamanders; in these, not only the tail and legs that have been removed grow again, but the eye also can be restored, if only the entire ball as far as the optic nerve be not away.

The geographic distribution of reptiles is interesting. In cold regions the number of genera is very small, and 
in the tropics alone is there found a full exhibition of their class. The Batrachians are most universal, and are found in nearly every quarter of the globe. The Serpents, properly so called, have the majority of their species dwellers in warm regions. Most of the Lacertines are also tropical. A few species of Lizards, Serpents, and Frogs are found in cold regions, of which the Frogs are most numerous in species, and especially in individuals; whilst, on the contrary, no Tortoises live in those regions, being limited to warm countries. The Frogs and Tortoises thus form the two extremes of the geographic distribution of reptiles, of which the first have the widest dispersion in cold regions, while the last are the most limited to warm countries. There are nine orders of reptiles. In the first, Pterosauria. characters are developed which are superinduced on the primitive reptilian type, and afford analogical relation with the true birds.

\section{Order 1.-Pthrosauria (Extinct).}

The pectoral members in this order are always adapted for flight by the elongation of the antibrachium and fifth digit. The vertebræ are procœlian (i.e. the cavity for the reception of the centrum of the vertebræ immediately in front or on the fore part). The cervical vertebræ are very large; those of the pelvis are small. The anterior trunk ribs have bifurcate heads. Most of the bones are, as in birds, pneumatic. The head is large; the jaws are long and armed with teeth. It may be inferred from the fossil evidences that the ventricle of the heart of these highly-organised reptiles was double. Three types of Pterosauria existed-Dimorphodon, Ramphorhynchus, and Pterodactylus. In the 
first genus, from the Lower Lias of Dorsetshire, the teeth are of two kinds-a few at the fore part of the jaws are long, large, sharp-pointed, with an elliptical base; behind them is a close row of short, compressed, very small, lancet-shaped teeth.

The skull was eight inches long, and the expanse of wing about four feet. The genus had probably a short tail. In the Ramphorhynchus, the fore part of each jaw is without teeth, and may have been encased by a horny beak, but behind the edentulous part of the jaw there are four or five large and long teeth, followed by several smaller ones. The tail was very long in all the Ramphorhynchi. In the third division, or true Pterodactyles, the jaws are provided with teeth to their extremities; all the teeth are long, slender, sharp-pointed, and set well apart. The tail is very short.

Some of these extinct forms of flying reptiles had an expanse of wing of from eighteen to twenty feet. The P. Fittoni and Sedguickii, from the Greensand, were amongst the gigantic species. But most of the Oolite and Greensand forms were of gigantic dimensions. The oldest known species of the order is the Dimorphodon macronyx of the Lower Lias. Pterodactyle bones have been also discovered in the Würtemberg Liassic deposits. The forms appear to have increased in size as the order lasted in time, for the Pterodactyles of the Upper Greensand and Chalk are far larger in size than the earlier existing types.

\section{Order 2.-Dinosauria (Extinct).}

In this order the cervical and anterior dorsal vertebra have par-and diapophyses, articulating with bifurcate ribs a few ; anterior vertebræ are more or lcss convex in 
front, and cupped behind, the rest have flat or slightly concave articular ends; the dorsal vertebræ have a neural platform ; sacral vertebræ exceeding two in numtber; body supported on firm, strong, ambulatory, unguiculate limbs. The skin in some is armed with bony sscutes; the teeth are confined to the upper and lower jjaws, and are implanted in sockets; the ventricle of the theart was probably double.

The femur has often a third trochanter. In the Triassic sstrata of Bristol the Belodon is found, which apparently iindicates the first representation of the present order. IThe genera Scelidosaurus, Cetiosaurus, Megalosaurus, IHylcoosaurus, and Iguanodon form the principal types. IWhile they were the most gigantic as well as the most cquadrupedal of reptiles, the four comparatively high llegs supporting an enormously bulky trunk, there are zoot wanting exceptional characters, which have led some of the describers of Dinosauria to imagine that they possess a greater affinity with birds than is the case with the Pterosauria. Reasons for this argument have been adduced by Professor Cope, of Philadelphia, and others, who have pointed out that the approximaion between birds and reptiles appears to be by two ooints-the first by the Pterosauria, to which the peculiar Archcoopteryx presents traces of affinity, the second by the Dinosauria. He considers the bones of Itguanodon, which have been described as clavicles, to se pubic bones. There is much plausibility in the rgument of Professor Cope ; and the restoration of the imbs of Dinosauria appears to show that the structure if the pelvis in the extinct reptile indicates, by its long ind slender ischial and pubic bones, a close analogy vith such birds as the Emu. The sacral vertebrx are, rowever, few in number, rarely exceeding four. 
The relationship of Megalosaurus are well described by the late Professor Phillips. What may be regarded as the family affinity and personal history of Megalosauras Bucklandi has become much more interesting, and even important in science than it was in the days of its discoverer. The creature was a Lizard, allied to the Crocodile in his vertebral system and the general character of his respiratory structure, claiming kindred with the Monitors in his dentition, and offering analogy with pedestrian birds in the scapular and pelvic girdles, and, to some extent, in the limbs. He was carnivorous, if we may trust the finely-crenulated, sabre-like teeth, and the large and powerful hinder claws.

He was habitually able, and probably preferred, to move upon the land-whether bipedally is not ascertained, though the fore limbs appear to have been only half as long as the strong yet not clumsy hind-legs. These appear by the enormous ilium to have been well devised for firmly supporting and propelling the body. The remains are found scattered in a lagoon or shallow estuary, and it is conceivable that the fishes which abounded in that water were the favoured food of the carnivorous reptile. One seems to behold him wading by his long legs or swimming by help of his tail, a gigantic triton among not inconsiderable cephalopods, whose tough muscles he shared with the frequent roracious Sharks. At other times he may have been content with the spare diet of marsupial quadrupeds wbich lived on the borders of the water. It is perhaps worthy of remark that the teeth are very little or not at ali worn, even toward the point; they seem to have fallen easily out of their incompletely separated sockets, which are almost united into a long groove, and to have been replaced by several renewals, so that be was 
as well supplied with weapons as the Sharks, with whom, probably, he was not on good terms.

The true dinosaurian character of this animal was established by the discovery of the sacrum, which contisted of five interlocked vertebræ, soldered together; the neural arches being supported alternately upon the centra of the vertebræ. The articular surfaces are nearly flat, and the neural arch develops a platform which in the anterior dorsals supports very long and strong spines.

The teeth in Mregalosaurus were subcompressed, slightly recurved, sharp-edged, and sharp-pointed, the ‘ edges being minutely serrated, forming a sabre-like istructure, something like that of the edge of an oldifashioned champagne-knife; these teeth succeeded each other with uninterrupted and frequent succession, from lbelow upwards. Buckland, describing this, has said : "In the structure of these teeth we find a combination of mechanical contrivances analogous to those which are adopted in the construction of a knife, a sabre, or a saw. When first protruded above the gum, the apex of each tooth presented a double cutting edge of serrated enamel. In this stage its position and line of action were nearly vertical; and its form, like that of a two-edged point of a sabre, cutting equally on each ide. As the tooth advanced in growth, it became urved backwards in the form of a pruning-knife, and he edge of serrated enamel was continued downwards o the base of the inner and cutting side of the tooth, whilst on the outer side a similar edge descended, but 'short distance from the point; and the convex porion of the tooth became blunt and thick, as the back of a knife is made thick for the purpose of producing itrength. The strength of the tooth was further in- 
creased by the expansion of its side. Had the serrature continued along the whole of the blunt and convex portion of the tooth, it would in its position have possessed no useful cutting power; it ceased precisely at the point beyond which it could no longer be effective. In a tooth thus formed for cutting along its concave edge, each movement of the jaw combined the power of the knife and saw ; whilst the apex, in making the first incision, acted like the two-edged point of a sabre. The backward curvature of the full-grown teeth enabled them to retain, like barbs, the prey which they had penetrated. In these adaptations we see contrivances which human ingenuity has also adopted in the preparation of various instruments of art."

The Megalosaurus was probably thirty feet in length. The Scelidosaurus found in the Lower Liassic rocks of Dorsetshire is the fossil Dinosaurian with whose skeleton we probably are best acquainted.

In the Hylcosaurus of the Wealden the length of the animal was probably at least twenty-five feet, and an enormous series of dermal bony spines supported a strong serrated defensive crest along the back. The diet was probably rather mixed, more vegetable than carnivorous.

The third and best known type of the dinosaurian reptile is that whose general resemblance to the existing Iguana induced. Mantell, its discoverer, to term it Iguanodon. In it the vertebræ were subconvex anteriorly in the neck, but along the rest of the trunk subconcave at both articular extremities; having in the dorsal region lofty and expanded neural arches and doubly articulated ribs; with the sacral vertebræ of unusual number and complication of structure; with a lacertian pectoral arch, and unusually large bones of 
the hind limbs excavated by large medullary cavities, and adapted for terrestrial progression. The Iguanodon was a reptile whose teeth resembled in shape those of the Iguana, yet differed in structure from the teeth of that and every other known reptile. As in the Iguanu, the base of the tooth is elongated and contracted, the crown is expanded and marginally notched; when first formed it is accuminate and compressed. The marginal notches under a lens present the form of transverse ridges, which are themselves notched so as to resemble the margins of the unworn plates in the grinder of the Elephant. The Iguanodon and other. forms of Dinosauria are not found in the Cretaceous series. The Iguanodon has been found in the Greensand.

\section{Order 3.-CROCODILIA.}

The Crocodilia have teeth in a single row, implanted in distinct sockets; the external nostril is single and terminal, or subterminal. The anterior trunk vertebræ have par and diapophyses, and bifurcate ribs; the sacral vertebræ are two, each supporting its own neural arch; this arch is usually articulated by suture.

The tail is long and vertically compressed; the feet are short and webbed. The skin is protected by bony plates, which are usually pitted. The rentricle of the heart is double. There are three sub-orders, respectively termed Amphicalia, Opisthoccelia, and Proccelia. In the first form the vertebræ are cupped at both ends; in the second they are convex in front, concave behind; and in the third they are concave in. front and convex behind.

In the first order, Amphicatia, we have since the time of the deposition of the Lower Liassic strata, Croco- 
diles which in general form closely resembled the long and slender-jawed Crocodiles of the present day, termed Gavials, or Ghárrials, with similarly long slender teeth employed for the prehension of fishes. They were essentially aquatic, the vertebral surfaces being concave, the hind linbs relatively larger and stronger, and the sunken orbits around the eyes forming no great obstruction to movements under water. The Crocodiles appear to have been essentially marine, and all members of the sub-order are entirely extinct. The second group, Opisthoccelia, comprises such extinct forms as the Streptospondylus and other forms. All existing Crocodiles belong to the third proccelian form. In the genus Alligator, the fourth tooth of the lower jaw, or canine, is received into a cavity of the palatal surface of the upper jaw, where it is concealed; when the mouth is shut in old individuals the upper jaw is perforated by these large inferior canines, and the fossæ are converted into foramina. The upper jaw is broad, obtuse, with margin extended beyond the teeth of the lower jaw.

In the true Crocodiles the first tooth in the lower jaw perforates the palatal process of the intermaxillary bone when the mouth is closed. The fourth tooth of the lower jaw is received into a notch excavated in the side of the alveolar border of the upper jaw, and is visible externally when the mouth is closed. The upper jaw is not wider than the lower jaw. In both these forms the teeth are of unequal size, and the alveolar borders of the jaw have consequently an uneren or wavy outline. In the Gavials the teeth, which are always greater in number than in either the Crocodiles or Alligators, are nearly equal in size and similar form in both jaws, the first as well as the fourth tooth passing into 
a groove in the margin of the upper jaw when the mouth is closed.

The geographical distribution of the Crocodilia is peculiar. All the true Alligators are from the New World, and most of the true Crocodiles are found in the Old World. But some species of Crocodile, Crocodilus rhombifer, from Mexico and Cuba, and Crocudilus acutus, found in the fresh-water lake of Nicaragua and at Haiti. The Crocodile of the Nile (C. vulgaris), the Sunda Crocodile ( $C$. biporcatus), the Bornean species with an elongated snout ( $C$. Schlegetii), are well known. The Alligators or Camans of the New World are found in higher latitudes than the Crocodiles of the Eastern Hemisphere. All these large lizards live in fresh water, though they are capable of swimming out to sea for some distance from the land. They are voracious, predaceous, and exhale an odour closely resembling that of musk.

\section{Order 4.-OpHIDiA.}

In the Serpents the vertebræ are very numerous, procœlian, with single-headed hollow ribs; no sacrum ; no visible limbs; two external nostrils; no cavum tympani; eyeball covered by an immovable transparent lid; the body is covered by horny scales, the teeth are anchylosed to the jaw. In the non-venomous Serpents, as c.g. in the Ringsnake and Boa Constrictor, the upper jaw and the palate bones are all lined with sharp teeth, so that there are four rows of dental organs, two placed along the margins of the jaw and two projecting from the roof of the mouth. All these teeth are simple, very sharp, and point backwards. The function of these is not to hold or destroy the prey. Serpents kill their 
victims by coiling their Jengthy budies round the chest, and then by strong muscular contraction compressing the thorax of their prey so firmly that, its movements being completely prevented, respiration is put a stop to,

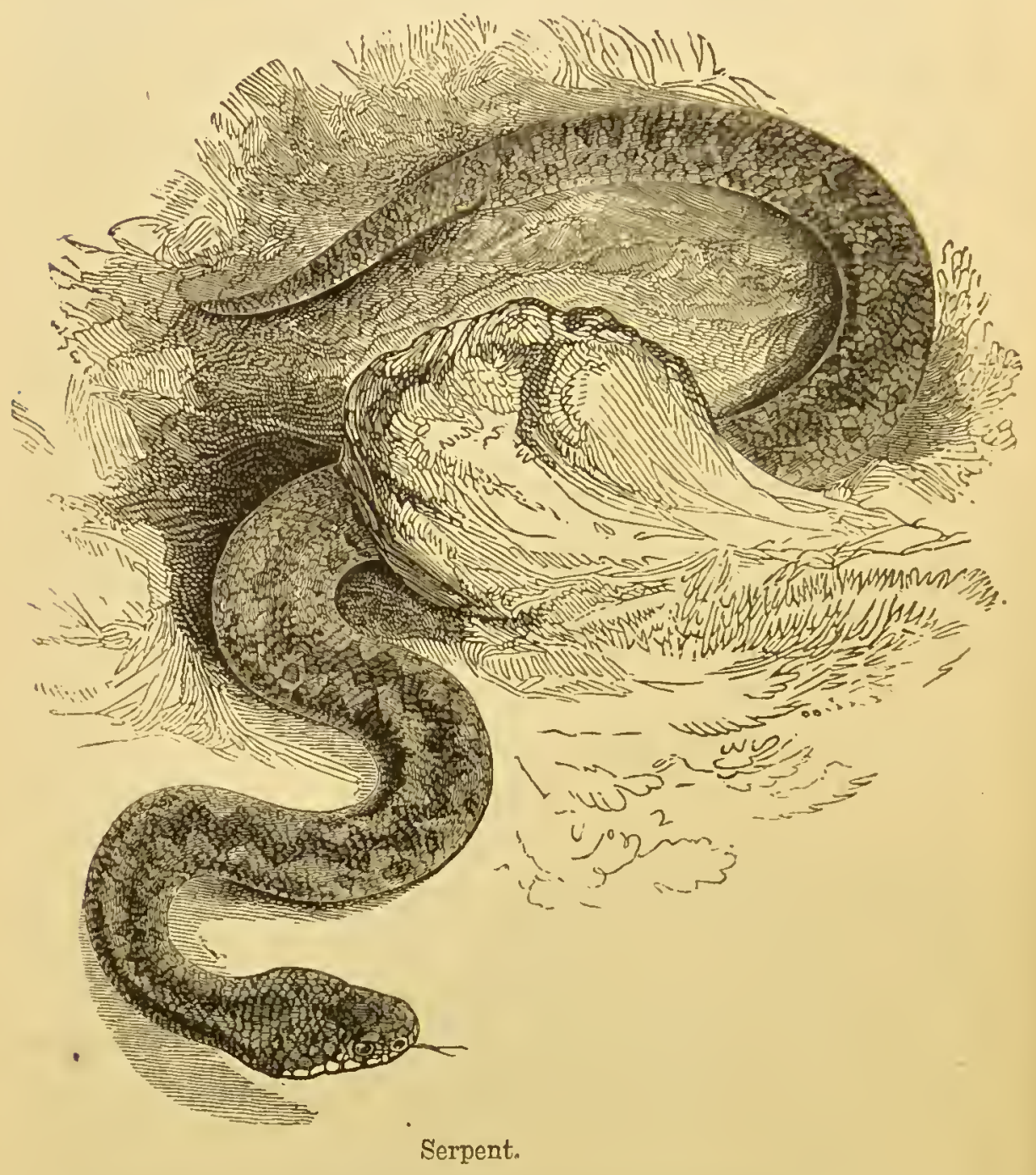

and the animal so seized speedily perishes from suffocation. The animal being dead, the difficulty remains how to swallow it, as the Serpent, destitute of all external limbs, cannot force down its throat the carcass of a creature many times thicker than its own body. The 
method adopted is by thrusting the head into the mouth, when the elastic ligament at the symphyses of the lower jaw gives way and the branches of the mandible become widely separated, so that the mouth is stretched enormously as the food is forced into it. Swallowing is thus a slow process, as one at a time a jaw is unfixed and the teeth withdrawn by being pushed forward, when they are again unfixed farther back upon the prey; the

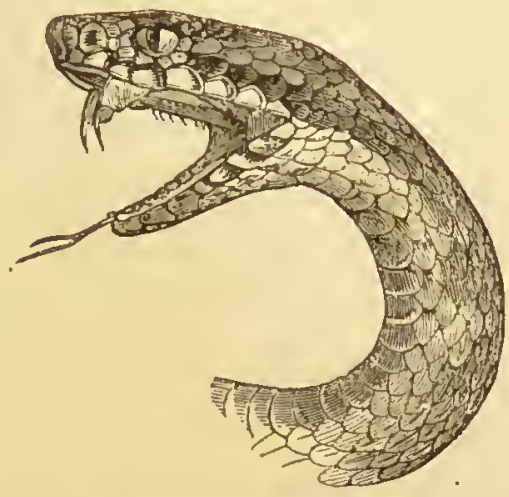

Poisonous Serpent. next jaw is then unfixed, protruded, and re-attached; and so with the rest in succession. By these successive movements the food is slowly and spirally introduced in to the wide gullet.

In most poisonous Serpents each superior maxillary bone has only a single tooth projecting from the gum, and to succeed to which two or three others behind and above it lie upon the palate with their points turned backwards. Through these teeth there runs a canal which opens close to the point on the convex anterior surface with a fine fissure. In some poisonons snakes the upper maxillary bone has some smaller teeth in addition, which are not perforated, and succeed farther back to the poison tooth. There are also forms in which there is one tooth behind a row of imperforate teeth which is a little longer than the rest, and is not perforated but grooved. The large perforated tooth placed on each side of the midplane at the fore part of the mouth, is the means by which the venomous Serpents inflict wounds and shed the poison into them. The poison is secreted by a gland of an elongate form, 
which is situated behind and under the eye upon the upper jaw; and is compressed by the temporal muscle. The long excretory duct of this gland runs forward and ends in a membraceous sheath which surrounds the base of the poison gland. Here the poison is received in an aperture situated in front of the base of the tooth. The poison itself is an unctuous gelatinous fluid, without taste, and drying in the air into little plates and scales. It long retains its injurious power, is soluble in water, insoluble in spirits of wine and volatile oils; it reddens litmus paper slightly. It is innocuous if introduced into the digestive passages by swallowing, but shows its natural action when by a wound, or by being introduced into a vein, it enters the current of the circulation.

There are eleven families of Serpents: the Viperina, Elapina, Hydrophes, Asineophes, Colubrina, Aeroehordina, Pythonina, Cylindrophes, Rhinophes, Typhlina, and Amphisbcence. We shall only give examples of a few of these forms. In the Viperina, the upper jaw has a single large perforate tooth on each side. The head is heart-shaped or three-cornered, broader than the trunk. The Rattlesnakes (Crotalus) are all found in America. In them the last vertebræ of the tail are coalesced, and form a terminal bone of a conical form, covered by muscle and skin, which secretes a series of from twenty to thirty hollow horny joints, which hang so loosely together that the animal employs the rattle voluntarily as an instrument producing sound. The Fer-de-lanee (Trigonocephalus) is another fatal and highly venomous American species. All the true Vipers are from the Eastern Hemisphere. The common Viper (Viperus berus) and the horned Viper (Coluber cerastes) are commom English and European forms. The Elapina 
have the head shield-shaped, but slightly differing in breadth from the trunk. Most are from the Eastern Hemisphere. Some of them have the anterior part of the trunk behind the head expansible into an oval depressed disc, which in the Spectacle Snakes is marked by two eye-like spots. The Cobra de Capello (Naja haje), the Egyptian hooded Viper (Naja tripudians), and the coral Snakes (Elaps), are also highly poisonous forms of this family. The Hydropkes are, as the name denotes; water Snakes. Some species occur occasionally at the mouths of rivers; others live in the open sea, where they are often to be met with far from all land. They swim together in large troops, and are very venomous. The tail is compressed, broad, and two-edged. The innocuous Serpents exceed the poisonous in the proportions nearly of seven to one. The Ringsnake (Tropidonotus), and an enormous number of forms which occur in the tropics, belong to this division of Snakes. The Boa is found in America, and the Python in the Old World. Both genera have many traits in common. The true Boa (Constrictor) seldom attains a length of more than ten feet, and the Pythons (Seba, Molurus) of the Old World a length of twenty or more feet long. No larger forms of Serpent are known. There is a progression from the true Ophidian Reptiles to the Lizards through the Amphisbcence, in which the two branches of the lower jaw are united together by symphyses, and the tongue is short, thick, posteriorly bilobed, instead of being, as in the Serpents, narrow and forked. Some forms closely allied to Amphisbrena exist, in which, as Chirotes, there are two small anterior limbs placed near the head, with broad, short, five-toed feet. These link the Ophidia with the next order of Lacertilia. 


\section{Order 5.-Lacertilia.}

In this order the vertebræ are procœlian, with a single transverse process on each side, and with singleheaded ribs; the sacral vertebræ are wanting or do not exceed two; there are two external nostrils; the eyes have movable lids; the body is covered with horny, sometimes bony, scales. The carity of the tympanum is distinct, and covered in most by a naked tympanic membrane, or by muscles in some. The eyelids are mostly distinct and movable. This order comprises many species which externally correspond with Serpents to such a degree that formerly they were classed with them. There are six families: the Scincoidei, Zonosauri, Lacertina, Iguanoidei, Chameleonidei, and Ascalobotoe. In the Scincs, the whole body is covered with scales, that lie over one another in the fashion of roof tiles. Only a few have palatal teeth. The Anguis or Slow-worm (Anguis fragilis) is viviparous, feeds on slugs, insects, and earth-worms, and has a distribution over the whole of Europe, Asia, and Africa. Some of the Scincidae have short feet, often imperfect, sometimes none. In the Zonoscuri there is a broad, belt-like covering of scales which distinguishes these lacertian animals from all the rest. The family of true Lizards (Lacertini) have the tongue exsertile, slender, bifid; the membrane of the tympanum is open, superficial, or depressed; the body is elongate, with four pentadactylous feet, the toes free and unequal. The genus of true Lizards (Lacertce) are all from the Old World, principally from Africa. The Lacerta agitis, or sand Lizard, is one of the common British representatives. The true Monitor Lizards (Tegris monitor') are confined to Brazil, but the so-called 
Monitor Lizards (Varanus) are Old World species. All of this genus are, after the Crocodiles, the largest of lacertine animals; sume attain a length of more than six feet. In most of the species the tail is compressed laterally and keeled above. The long narrow under jaw is only loosely united, as in the Serpents. In the Iguanoidei, the tongue is fleshy and thick, the eyelids are distinct and free, the head is mostly covered with scales or small scutella, the back and tail are often crested. The four feet are pentadactylous in most. A number of genera exist of which only a single species occurs in the south-east of Europe; all the rest are from other quarters of the world, many from Asia, but by far the most from South America. In the American species the teeth are attached to the inside of the jaw, forming the pleurodont type. In the Old World they are with one exception placed on the edge of the jaws, and soldered there (Acrodontes). Wiegmann has proposed another division of Lizards: i.e. into ground Lizards, or Agamas, with flat heads and flat depressed body; and tree Iguanas, with compressed body. Each of these may be respectively subordinated into its acrodont and pleurodont types. The Agamina and the Stellio, famous in the Middle Ages as a medicinal ingredient, form examples of the acrodont type of flat Lizards, while the pleurodont type is exemplified by the Tropidurus, the Phrynosoma and the Urocention. The Iguanas or Lizards, with body compressed, with back keeled, often crested with a tetragonal pyramidal head, and with the membrane of the tympanum mostly naked and superficial, are chiefly American. Tho Iguana (Iguana delicatissima) is used as edible food by the natives of tropical America. It roosts in trees, where it remains nearly immovable during all the heat 
of the day, seeking its food at night, but remaining during the noontide heats at the end of a branch with the neck outstretched in sleep. On being shot at it drops in the water, dives to an enormous depth, and swims rapidly away to a distance from the spot where it was attacked. In other genera (Corytophanes) the back has a membranous crest along its extent somewhat analogous to the crest in the extinct Hyloosaurus. The genus is found in Mexico, and occurs in Nicaragua. The individuals almost rival the Iguana in size. In the Basilisks (Basiliscus) the membranous crest on the back and tail is very high, and is supported by the spinous processes of the vertebræ. In the Chlamydosaurus the head is scaly, the membrane of the tympanum superficial; the back not crested, the scales lanceolate and keeled. A scaly, folded, ample membrane covers the neck like a cloak affixed above the tympanum on either side. The toes are simple, and the tail is very long and round. This Australian species attains a considerable size, and appears to represent the large Histiuri of Amboyna and the Iguanas of America. In another genus (Draco) there is a duplicature of skin on each side of the body, supported by the anterior false ribs, which are elongate and straight. The throat is furnished with a middle pendulous dewlap, which is longest in males.

The Lyriocephatus of Ceylon appears to afford some analogy to the Pterodactyli. The Chameleon is remarkable both for its change of colour dependent on the motion of transverse layers of colouring matter under the cuticle, and for the action which produces a rapid motion of the tongue by which the Chameleon captures the insects on which it feeds. It never seizes the prey by the mouth or feet, or with any other means 
than the tongue. The Ascalobota or Geckos have usually a shortened and abbreviated tail. They have also many remarkable characters by which they are distinguished from the other families of this order, and like the Chameleons form an independent group. The eyes, as J. Müller pointed out, are, as in the Serpents, covered by a transparent eyelid, behind which the eye has a free motion. These animals have mostly a leaf-like expansion at the toes which is folded below, and the nails (which, however, in some species are wanting in some of the toes, or even altogether) are capable of retraction, as in cats.

These animals feed on insects. The name Gecko is derived from the sound which they make, and which in one or more Indian species resembles this word. Species of this family are found in the warm regions of both hemispheres of the earth ; many live in houses, and climb with ease the walls and ceilings.

True Lacertilia appear to have originated in the middle of the Oolite period, and to have increased in number up to the present day. Though the gigantic Mosasaurus of the Chalk was of greater size than any known Lacertian, its characters are such as place it in a distinct category from the Dinosauria on the one hand and Crocodiles on the other.

\section{Order 6 -Chelonia.}

In this order the trunk ribs are broad, flat, suturally united, forming with their vertebræ the sternum and dermal bones; an expanded thoracic abdominal case, into which the limbs, tail, and usually the head can be withdrawn; the sacrum has more than 
two vertebrx; there are no teeth; the external nostril is single, with a cavum tympani; the body is covered

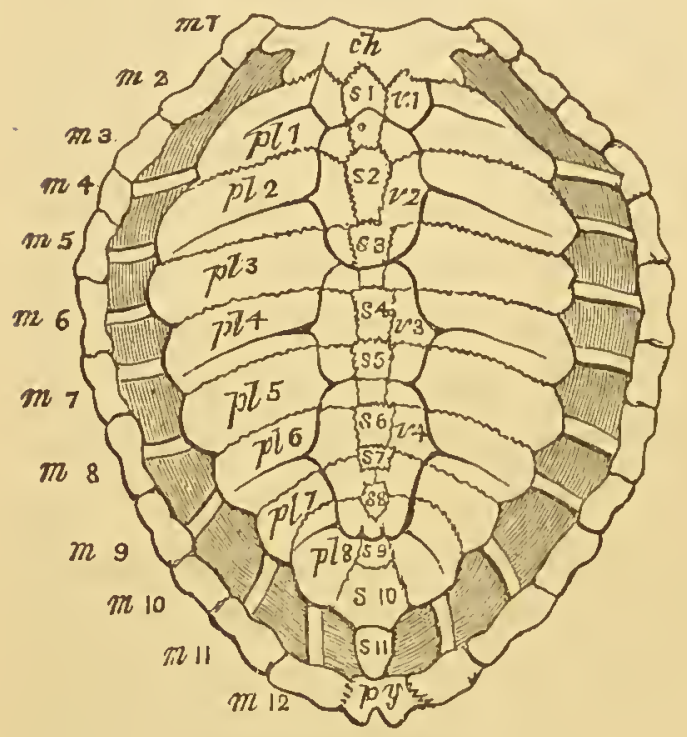

Carapace of Turtle. by horny scales in most; the ventricle of the heart is single.

Three great groups exist: those in which the limbs are natatory, as Turtles (Chelone); those in which they are amphibious, as the Terrapens (Emys) and. the mud Turtles (Trionyx); and those in which they are terrestrial, as in the true Tortoises (Testudo). They are tenacious of life, and exhibit a long persistence of irritability in parts that

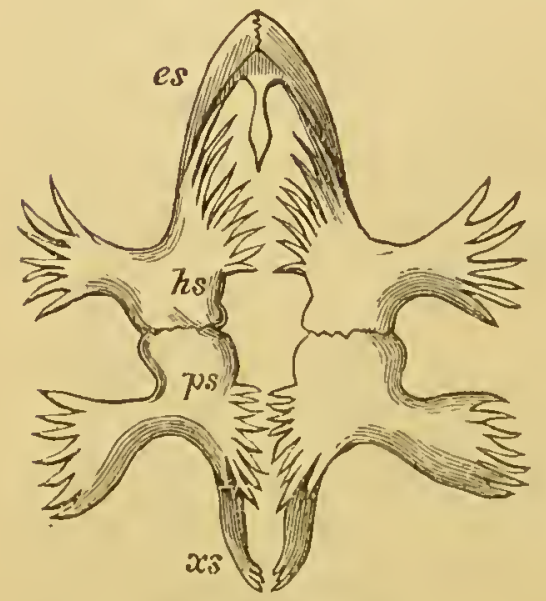

Plastron of Turtle. have been divided from the body. They attain a great age. Most live on regetable food. The females lay their eggs on the land, and bury them in open places exposed to the sun. The number of eggs is various; the land Tortoises lay the smallest number, four or five; some species, however, more, twelve to twenty; the fresh-water Tortoises more; and the sea Tortoises the greatest number, commonly a hundred or more. The formation of 
the bony covering of the Tortoises should especially be studied.

In the marine Turtles (Chelone) and soft Turtles (Trionyx) the floor and the roof form the essential elements of the dwelling chamber, to which in the fresh-water and land Tortoises are added side walls of variable extent. The whole consists chiefly of osseous plates with overlying horny scutes; special names are given to all these scutes and to the vertebræ which support them. Those in the plastron, or under flat surface of the body of the Tortoise, are of easy distinction and separation. The plastron consists of nine pieces. The median and symmetrical one, $s$, is termed entosternal; the four pairs counted from before backward are the episternals $(e s)$, the hyosternals $(h s)$, the hyposternals $(p s)$, and xiphisternals $(x s)$.

In the soft Turtles (Trionyx) the covering of the beak is horny, the lips distinct and soft, and the nose with a trunk-like expansion. The neck is very long; the shell depressed, covered with smooth skin; the feet have only three internal toes clawed; the tail is short. All the species live in fresh water, and are carnivorous. The Trionyx AEgyptiacus lives in the Nile, where it feeds on the young Crocodiles as soon as they have escaped from the egg.

The snapping Turtle, or Gopher (Trionyx ferox), lives in North America, but the majority of the genus are found in the East Indies. The Matamata Turtle (Chelys fimbriata) is found in stagnant fresh water in Guiana and Brazil. This singular species inhabits the rivers of South America, and its shell, as in all the other alligator Tortoises, is much too small to receive the head and feet; the nose is prolonged into a short thin proboscis; the mouth opens crosswise; while the jaws, 
instead of being horny, like its congeners, are covered with a soft skin, "much resembling," observes Cuvier, "some of the Frogs, particularly the Pipa, or Surinam Toad." The head and neck are large, thick, and more than half the length of the shell; the skin in these parts is not only warty, but has several fimbriated or membranaceous appendages, particularly two which stand nearly erect above the ears, and thus resemble horns. Other appendages are on the neck, so that the whole animal has a most singular and grotesque aspect.

The Emydes are found chiefly in America; the anterior feet have mostly five nails, and the posterior four. The true Tortoises have the toes indistinct, and the covering of the beak horny and the back gibbous. Testudo Grocea occurs in Spain, Italy, and Greece. Many of the species are derived from Africa.

In the sea Turtles the feet are changed to flat fins, the anterior very long and falcate; the back is depressed; the sternum is imperfect, in part cartilaginous, and the back covered with horny scales. The Chelone mydas, or edible Turtle, is found in the Atlantic Ocean, in the Indian, and other seas. The shell is rarely employed for ornamental purposes. The Chelone imbricata has smooth horny scales on the dorsal shield, covering each other like house-tiles, of a yellow colour, with large black spots. This species is found in the various seas of warm regions. They feed entirely either on marine plants or on molluscous animals. The loggerhead Turtle (Chelone caretta) is nearly confined to the Mediterranean. This group is limited, there being only seven species of the genus Chelonia and one of Sphargis. The shells of the different marine Turtles are singularly varied; in some the scales are 
imbricated or laid over each other in the manner of tiles; in others they are fixed with their sides joining each other in the same manner as we see in the land Tortoises; while in the Spargis, or coriaceous Turtle, the shell is covered by a thick leather-like skin.

In the leather Turtle the back is covered with leathery skin, which in the younger individuals is warty ; it attains a length of six to eight feet, and lives in various seas. It is occasionally found on the English coast. The form of the anterior fin in the Turtles nearly resembles that of the wings in the genus of the Penguins (Aptenodytes); it is a mere flapper, whose slow, laterally exercised motion paddles the Turtle onwards. Fossil Turtles are as ancient as the Stonesfield Slate, while impressions on sandstones of triassic age in Dumfriesshire probably indicate an animal of chelonian affinity. Fossil Turtles are frequent during the deposition of the Portlandian and London clay-beds.

\section{Order 7.-Anomodontra.}

In this order teeth are wanting, or are limited to a single maxillary pair having the form and proportions of tusks. There is a foramen parietale; two exterual nostrils; the tympanic pedicle fixed; the vertebræ biconcave; the anterior trunk ribs, with a bifurcate head and the ischiopubic symphysis continuous. All the forms of these extraordinary reptiles are extinct.

There were three families. The Dicynodontia, which have a long ever-growing tusk in each maxillary bone; the premaxillaries connate, forming with the lower jaw a beak-shaped mouth, probably sheathed with horn. 
There were more than two vertebræ in the sacrum. The Cryptodontia had the upper as well as the lower jaw edentulous; the premaxillaries were distinct and produced in some, e.g. Rhynchosaurus, and in some, as in Oudenodon, the premaxillaries were confluent and short. In the Cynodontia there were a pair of teeth in each jaw resembling, in shape, position, and relative size to the other teeth, the canines of carnivorous mammals, and dividing the incisors from the molars. The South African Gatesaums is an example of this type.

The evidences of this most singular dicynodontian family of reptiles have hitherto been found only in South Africa, where they occur petrified in a hard stone of probably Triassic age. In the modifications of the skull may be discerned characters of the Crocodile, Tortoise, and Lizard, coupled with the presence of a pair of huge sharp-pointed tusks, growing downwards, one from each side of the upper jaw, like the tusks of the mammalian Morse (Trichechus). No other kind of teeth were developed in these singular animals; the lower jaw appears to have been armed, as in the Tortoise, by a trenchant sheath of horn. The vertebræ, by the hollowness of the articular surfaces, prove the Dicynodontia habitually existed in water. The construction of the bony passages of the nostrils proves that they came to the surface to breathe air. The pelvis was composed of five confluent vertebræ. The physiognomy of the Dicynodon, with its two large walrus-like tusks overhanging a horny beak like that of the Tortoise, must have been most extraordinary. In an allied genus, Ptychognathus, the mouth opened obliquely upward, as in some fishes.

In the Cryptodontia, the aspect of the skull differs from that of existing Lacertians, and resembles that of 
a bird or Turtle, the absence of teeth increasing this resemblance. The ends of the premaxillary bones were of more dense structure than the other parts, indicating the existence of a powerful bill, as in the snapping Turtles.

The indications of teeth are much more obscure in the Rhynchosaurus than in any other Lizard. There is no coronoid process in the jaw.

In the Galesuurus, a remarkable resemblance is presented to the dentition of carnivorous Mammalia. The skull is depressed and flat, tapering from the zygomæ to the muzzle. There is an upper and lower canine tooth on each side, having the same position in the skull and relative position to each other as in the carnivorous Mammalia. In no other Saurian are incisors so divided from molars by a single canine. The reptilian nature of this extraordinary animal is shown by the single occipital condyle associated with the contracted cranium and the complex frontal bone. The crocodilian affinities are illustrated by its terminal single nostril. In the Cynochampsa laniarius the jaw must have terminated in a more or less produced narrow muzzle, which, as in the Gavials and Teleosauri, was nearly cylindrical. Owen has remarked that the predominance of the canines in Galesaurus, their seeming want of incisorsthe certain absence, at least, of such evidence as would have appeared had the canines been subject to the ordinary laws of saurian dentition-point to a relationship with the Dicynodonts. The structure of the occipital region of the skull, and the expanse of the tympanics and zygomatic arches, also conform to the type of those singular South African reptiles. The breadth and flatness of the skull, and the proportions of the orbits and temporal fossæ, recall the proportions of Simosaurus 
amongst the peculiar saurians of the Triassic deposits of Germany.

The order Anomodontia has become extinct since the Triassic period. It appears only to have been found in the earlier Mesozoic periods, and no representatives at present exist_one of the most singular order's of reptiles, which united character now presented by animals of types far distant.

The restoration of Dicynodon and Ptychognathus was perhaps one of the greatest and most interesting steps in palæontology.

\section{Order 8.-SAUROPTERYGIA.}

In this order the neck is generally long; the limbs are natatory, and are not furnished with more than five digits; there exists an episternum, and also clavicles; the vertebræ have flattened, or sometimes slightly cupped, articular surfaces; there is also generally a sacrum of one or sometimes two vertebræ, which serve for the attachment of the pelvic arch, to which the posterior limbs hang in some of the species; the ribs are furnished with simple heads; there are no postorbital nor supratemporal bones; there are large temporal and other vacuities between certain cranial bones; there exists a foramen parietale; there are two antorbital nostrils; the teeth in this order are simple, they are implanted in distinct sockets of premaxillary, maxillary, and premandibular bones, rarely on the palatine or pterygoid bones; the maxillaries are larger than the premaxillaries.

The Nothosaurus mirabilis of the German Triassic rocks may be taken as an example of the earliest known 
type of Sauropterygia. The skull is not defended by a continuous covering of sculptured plate-bones; the vacuities behind the orbits for the temporal muscles are large and open; there are twenty cervical vertebræ; the scapula is short and broad. The bones of the limbs, though evidently those of fins or paddle-shaped extremities, are better developed than in Plesiosaurus, and more resemble the corresponding bones in the Turtles (Chelone). The processes for muscular attachment are better marked, especially on the concave side of the shaft. The whole bone is more curved than in any Plesiosauri. The femur is long and narrow, and the bones of the fore-arm are slender. Only four digits appear to have existed in the fore and hind paddles of Nothosaurus. Nine species are known. The German Triassic strata contains two other closely allied genera, Pistosaurus and Conchiosaurus.

In Simosaurus, the facial part of the skull was much shorter than in Nothosaurus; the muzzle forms the obtuse end of the short depressed face, of which the premaxillary part is the narrowest. The roof of the mouth is completely ossified, and the vertebræ have flat or slightly concave articular surfaces on the body; the neural arch articulates by suture; no cervical vertebræ are known. The genus Placodus affords an example of reptilia whose teeth are larger in relation to the size of the body than in any known species of animal. The teeth resemble paving-stones in their structure, and were evidently adapted to crack and bruise shells and crusts of marine Invertebrata. The teeth in the upper jaw are arranged in an external or maxillary and an internal or palatal series. The maxillary series are implanted in the premaxillary and maxillary bones, and palatal in the palatines and pterygoids. The palatal 
teeth are large, and in proportion to the entire skull; they are the largest grinding teeth in the animal kingdom, not even excepting the Elephant. All these teeth are implanted by short simple bases in distinct hollow sockets, subject to the same law of displacement and succession as in other reptiles. With the Placodus are found an enormous number of fossil shells, which were crushed by the powerful molars. It is probable that they were reptiles frequenting the sea-shore, and good swimmers.

Another genus, Tanystrophceus, possessed long and slender vertebræ in the tail at least. Sphonoscurus was also found in the Bohemian trias. The Plesiosaurus is the best known genus of sauropterygian reptile. In the words of Cuvier, "To the head of a Lizard it united the teeth of a Crocodile, a neck of enormous length resembling the body of a Serpent, a trunk and tail having the proportions of an ordinary quadruped, the ribs of a Chameleon, and the paddles of a Whale."

The genus was discovered at Lyme Regis in 1822 by Conybeare and De la Beche, and named Plesiosaurus, a name which signified its relationship with the Lizards. Restoration of many species have been made known since. The vertebræ bave their terminal bodies either flat or slightly concave. The tail is much shorter in the Plesiosaurus than in the Ichthyosaums. The skull is subdepressed; its length is rather more than twice its breadth, but the proportions vary in different species; the orbits are near or at the middle of the skull; there is no trace of sclerotic plates; the temporal fossæe are large and subquadrate. The nostrils, which are a little in advance of the orbits, are scarcely larger than the pareital foramen. The lower jaw is comprised of angular, surangular, splenial, and dentary elements. There is no vacuity between the angular and surangular or any 
other element of the jaw. In the skull the affinities to the Crocodilia are common and constant; in the simple mode of articulation of the ribs the lacertian affinity is manifested. The connation of the clavicle with the scapula is a character in which the Plesiosanwus and Turtles unite. More than twenty species of Plesiosaurus are known, the remains of which occur in the Oolitic, Wealden, and Cretaceous formations, ranging from the Lias up to the Chalk. The tail being comparatively short, could not have been used like the tail of fishes as an instrument of rapid impulsion in a forward direction, but, as Buckland suggested, was employed more as a rudder to steer the animal when swimming on the surface, or to elevate or depress it in ascending or descending through the water. The same consequence as to slowness of motion would follow from the elongation of the neck to so great a distance in front of the anterior paddles. The total number of vertebræ in the column was about ninety. It may be therefore inferred that this gigantic animal had to seek its food by rapid and quick darting movements. Buckland even supposed that, like the Chameleon, it possessed the power of changing its colour. The number of joints in the paddles of Plesiosaurus exceeds that in most vertebrate animals. It was an air-breather.

Another genus existed of close affinity to Plesioscurrus, and which is named Pliosaurus. In this genus the neck was excessively short, and the vertebræ were cupped at both ends, indicating the greater aquatic habits of the reptile. The teeth in this genus are thicker in proportion to their length than in Plesiosaumus, and are subtrihedral in transverse section, with one side flattened and bounded by prominent ridges. In the neck the articular surfaces of the vertebre are flat, 
and the proportion of the body, with the exception of being far more massive, agree closely with those of Plesiosaurus. The remains of this reptile are peculiar to the Upper Oolite beds, and evidences of an allied species are found in Russia.

The allied genus Polyptychodon is found in the Chalk deposits of England and the Greensand beds of England and Russia.

\section{Order 9.-IChthyopterygia.}

The bones of the head include the supplementary postorbitals and supratemporals, and there is a foramen parietale; but. there are small temporal and other vacuities between the cranial bones, a single convex occipital condyle, and one toothless vomer. The vertebral centre are ossified and biconcave; the ribs of the trunk are long and bent, the anterior ones with bifurcate heads. The teeth have converging folds of cement at their base, and are implanted in a common alveolar groove, but confined to the maxillary, premaxillary, and premandibular bones; the premaxillaries much exceed the maxillaries in size. The orbit is large, and has a circle of sclerotic plates. The nostrils are near the orbits. The limbs are adapted for swimming, with more than five multi-articulate digits. There is an episternum and clavicles, but no sacrum.

This order has been by many united with the preceding, under the name of Enaliosauria, or sea Lizards. Both groups were adapted for marine life, but breathed the air like the Cetacea. The fact that they respired atmospheric air immediately, and did not breathe water by means of gills like fishes, is shown by the absence of 
the bony framework of the gill apparatus, by the presence, position, and structure of the air passages leading from the nostrils to the mouth, and by the bony mechanism of the capacious chest, or thoracico abdominal cavity. It has been said that in these animals the snout of a Porpoise is combined with the teeth of a Crocodile, the head of a Lizard with the vertebræ of a Fish, and the sternum of an Ornithorhynchus with the paddles of a Whale. The general outline must have most nearly resembled the modern Porpoise or Grampus. There were four broad feet, or paddles, and the body terminated behind in a long and powerful tail. Some of the larger reptiles must have exceeded thirty feet in length. The position of the nostrils was not, as in Crocodiles, near the point of the snout, but, as in Lizards, near the anterior angle of the orbit of the eye; the teeth were conical, and much like those of the Crocodile, though more numerous, amounting in some cases to a hundred and eighty; they were arranged in one continuous furrow along the maxillary bone. A fracture of the bones of the tail about one-fourth of the way from the extremity indicates that the Ichthyosaurus possessed a large vertical tail-fin, as in fishes, and unlike the horizontal tail-fin of Whales. The enormous size of the eye of the Ichthyosaurus is one of its most striking characters, the sclerotic plates resembling those in the bony circle round the eye of the Eagles and Owls, and enabling the gigantic fish-lizard to serve as an optical instrument of immense power, enabling the Ichythyosaurus to descry its prey at great or little distances in the obscurity of night and in the depths of the sea; it also tends to associate the animal with Lizards and not with Fishes. In these there are analogous contrivances for the purpose of resisting pressure, 
to maintaining the form of the eye by the partial or total ossification of the exterior capsule; but in fishes this ossification is usually simple, though carried to a different extent in different species, and the bone is never divided transversely into many plates, as in Lizards and Birds. These capsules of the eye are often preserved in the heads of fossil fishes; they abound in the London clay, and occasionally occur in the chalk. The jaws of the Ichthyosauri were, as in Crocodiles, composed of many thin plates, so arranged as to combine strength with elasticity and lightness in a greater degree than could have been effected by single bones, like those of the jaws of Mammalia. There were more than ninety vertebræ, which in their biconcave nature resembled those in fishes. The ribs were slender, and a considerable number of them were united in front, across the chest; the animal being empowered to remain long beneath the water, without rising to the surface for the purpose of breathing. The bones composing the sternal arch are combined nearly in the same manner as in the Ornithorhynchus of Australia, which seeks its food at the bottom of lakes and rivers, and is obliged to be continually rising to the surface to breathe air. That the Ichthyopterygia occasionally sought the shore, may be inferred from the form of this scapular arch, which spans across from one shoulder-joint to the other. The Ichthyosaurus was probably a slow creeper on the shore, like the Seal or the Manati.

Of no extinct species are the materials for a complete and exact restoration more abundant and satisfactory than of the Ichthyosauns. They plainly show that its general external figure must have been that of a huge predatory abdominal fish, with a longer tail and a 
smaller tail-fin. It possessed no scales, and was probably covered by a smooth or finely wrinkled skin, as in Whales. Masses of masticated bones and scales of extinct fishes, that lived in the same seas and at the same period as the Ichthyosaurus, have been found under the ribs of fossil specimens at the spot where the stomach of the animal was placed; small masses are also found, harder and better digested, containing fish-bones and scales separate from the skeleton. These bear the impression of the structure of the internal surface of the intestine of the reptile. Remains of Ichthyosaurus are first found in the Lower Lias, and occur more or less abundantly through all overlying marine strata up to and inclusive of the Chalk formations. They are most numerous in the Lias and Oolites. More than thirty species of Ichthyosaurus are known. The greatest and closest affinities of the Ichthyopterygia is gained by comparing them with the lower forms of labyrinthodont reptiles, with whom their greatest analogies seem to exist. Yet the labyrinthodont reptiles appear to have been terrestrial, whilst the Ichthyopterygia were undoubtedly aquatic.

\section{Order 10.-Batrachia.}

Endo-skeleton ossified; two occipital condyles; vomer divided, in most dentigerous; temporal fossæ unroofed; scapular arch detached from occiput; ribs as processes, or short, straight, and free; skin nude, often lubricous limbs; digitate, trisegmental ; intestine without spiral valve, vent posterior to urethra; embryonal gills, in some retained, in most lost, with a metamorphosis associating a tailless body with pul- 
monary respiration; and a heart of two auricles and one ventricle.

The skin in Batrachia is glutinous, smooth, mostly

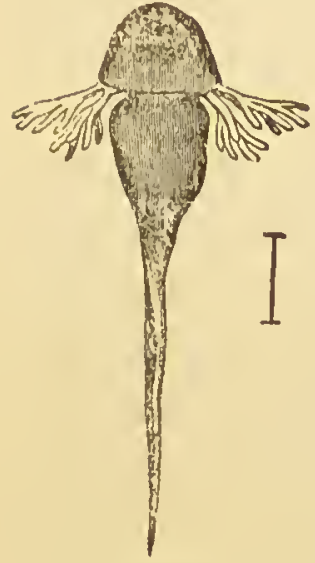

Tadpole. destitute of scales, sometimes with colourless thin scales, concealed amongst folds of skin. There are two occipital condyles. The terms Diplopinoa or Dipnoa are often used with regard to these amphibious reptiles which undergo an enormous change and metamorphosis during their existence. While passing through their earlier existence as fishes they respire by means of branchiæ; when they emerge into the air they have lungs ready for use. Some of them, as Menobranchus and Axolotl,

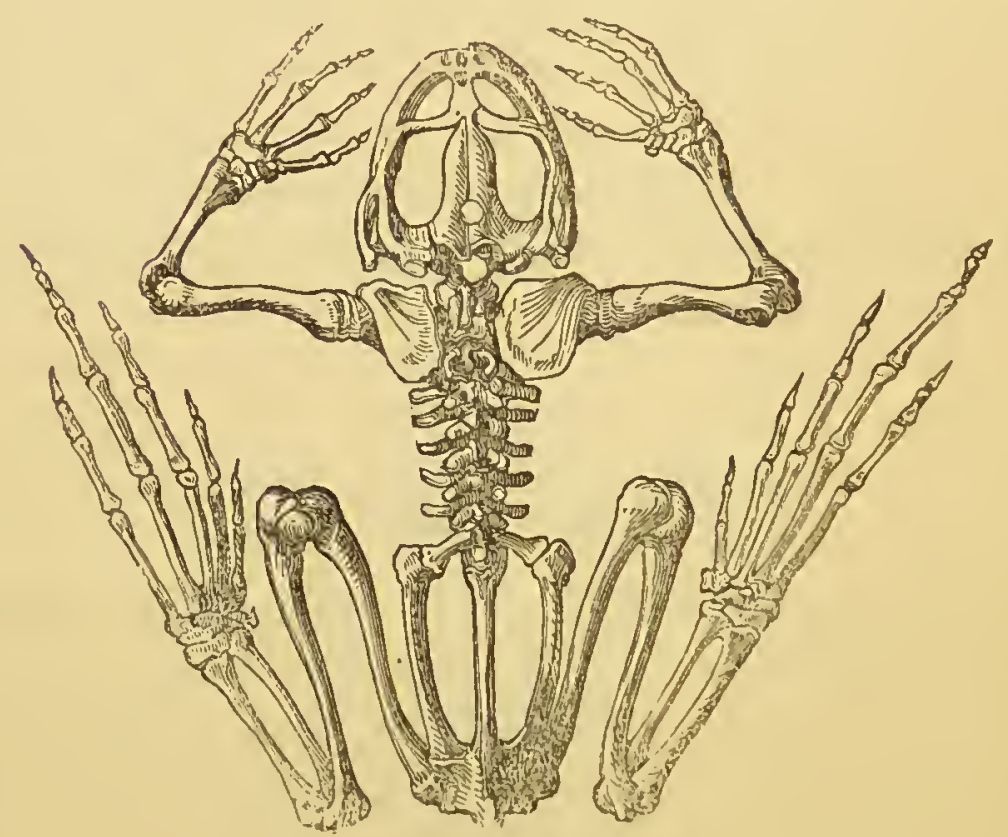

Skeleton of Frog.

preserve their branchix or gills through the whole period of their lives, and are for this reason denomi- 
nated Amphibia peremibranchiata. But there are other genera which, although in the early part of their existence they are equally provided with both gills and lungs, ultimately become sufficiently perfect in their organisation to enable them to enjoy a more or less complete terrestrial existence, and, consequently, their branchiæ become obliterated as the lungs grow more efficient, until at length no vestiges of the former remain perceptible. These are the Amphibia caducibranchiata.

The perennibranchiata Batrachians afford so many analogies to extinct forms of life, we must refer to them more or less in detail. The Lepidosiren has been proved to be a protopterous fish, and is therefore excluded from the present systematic comparison, whilst it is placed among the fishes in the description of the next class. Some of the perennibranchiate amphibia, as, for example, the Siren lacertina, attain a large size. The Siren is two or three feet long; its body closely resembles that of an Eel, but instead of pectoral fins it has two rudimentary feet, each provided with four fingers, the hind-feet, or representatives of the ventral fins, being entirely wanting; it is, moreover, furnished with gills, placed on each side of the neck, while internally it possesses two capacious membranous lungs, adapted to aërial respiration. The Proteus anguinus, which is found in Carniola, is also eelshaped, but the legs are four in number, though still very imperfectly developed. The gills are fringes of blood-vessels, placed externally upon the sides of the neck, and the lungs, as in some fishes, extend nearly the whole length of the abdomen. In the true Sirens, the branchiæ are persistent; there are two short feet, emerging from the trunk behind the branchiæ, four or three toed, without hind-feet; the head is obtuse; the 
upper jaw is produced beyond the lower; the skeleton has about ninety vertebræ, eight pairs of short ribs, of which the first pair is affixed to the axis, and no trace of pelvis. The Amphiuma is peculiar to North America; it closely resembles the Proteus, but the gills are not permanent. In the Menobranchus, which appears to attain a length of two feet, the branchix are persistent, broad, with short fingers adhering to a depressed footstalk. All the feet have four toes. The eyes are small. The Japanese Salamander (Cryptobranchus) has branchiæ which dissappear as growth progresses. The head is depressed and broad; the teeth in the jaws and in the palate are cylindrical, with the apex pointed, and crowded in rows; the palatine teeth are arranged in a parallel row near the maxillary teeth. The fore feet have four, and the posterior five toes; the skin is folded, waved, and loose at the sides of the body. Two species at least are known of this genus, closely allied to each other-the C. menopoma, with a permanent gill aperture, which is met with in many North American rivers, and the gigantic C. Japonicus, which becomes more than three feet long, and in which there is no gill aperture present, or in which it has early disappeared. This is the largest of all known naked amphibia. Another form, belonging to a genus (Andrias) so close as scarcely to merit separate distinction, is the fossil which, when it was discovered in 1726, in the Miocene rocks of CEningen, was alleged to be the skeleton of an extinct Man. Schenchzer, the predecessor of the modern guessers as to the history of the Manderthal skull, described it as Homo ditwoii testis, and imagined its close resemblance to the skeleton of extinct Man. It was afterwards proved merely to belong to a Salamander, akin in general appearance and constitution to 
the Menopoma, or Cryptobranchus. Slow-worms (Ccecilia) also form a division of Batrachia in which external gillapertures appear; the teeth are pointed, recurved in the jaws or palate; the eyes are concealed by skin, and are either small or indistinct; there is no tail; the vertebræ are connected together by conical cavities, which are filled with a cartilaginous or gelatinous remnant of the primitive notochord. There are about ten species known, C. glutinosa from Java being the best known and most prominent. But in South America there are numerous species of Caceitice, especially from Surinam.

The family of Salamandridce, in which respiration is in the perfect state simply pulmonary, and external branchiæ merely exist in the larvæ, is of wide distribution in the Northern Hemisphere. The eyes have distinct eyelids. There are always four feet, with the carpus and tarsus osseous in most; the anterior feet have four and the posterior almost always five toes. There are two divisions, the land and the water Salamanders. In the former, the tail is round and fusiform ; in the latter, the tail is compressed throughout, or towards the extremity. The Triton cristatus is the largest Salamander in Europe, being six inches in length. Allied species exist in Britain.

The order Anura have no metamorphosis, and in the adult state have no tail. The chief examples of this order are the Frogs, Toads, Pipas, and Hylæ or tree Frogs. In the Tadpole of the Frog, the hind-feet appear first, and they become of some length before the forefeet are visible. In the Salamanders it is the reverse, whilst in the Sirens the hind-legs never appear. The tail of tho 'Tadpole continues to grow in the Salamander and Proteus with the rest of the body, but in the Frog and many others the tail wastes away and disappears. 
About this time the lungs appear and begin to perform their functions, so that at this period" the Tadpole is strictly an amphibious animal. But although this strictly amphibious state continues in some, in the majority it does not; the gills disappear, and in the adult there remain no traces of such an apparatus.

When in the egg the animal is not surrounded by the membrane called amnion, neither have they an allantois as in other Reptilia. At birth they strongly resemble fishes. The lungs receive blood from two small branches of the aorta, which thus performs the office of a pulmonary artery. Thus the pulmonary respiration is feeble, but the cutaneous respiration active.

\section{Order 11.-Labyrinthodontia.}

The head was defended, as in Ganocephala, by a continuous casque of externally sculptured and un-

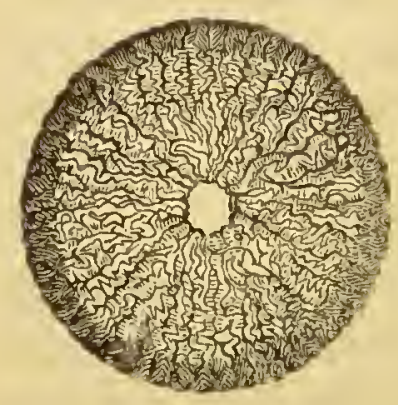

Section of tooth of Labyrinthodont. usually hard and polished osseous plates, including supplementary postorbital and supratemporal bones, but leaving a foramen parietale. There were two occipital condyles. The vomer was divided, and bore teeth. The vertebral bodies, as well as the arches, were ossified and biconcave. The trunk ribs were long and bent. The exoskeleton was developed in some as small ganoid scales. The teeth were rendered complex by undulation, and side branches of the converging folds of cement, whence the name.

There are mauy genera of these singular toad-like 
reptiles which were characteristic of the Triassic beds. In Baphetes, the skull was broad and depressed, presenting external sculpturing as in the Labyrinthodonts. It was found in the Pictou coal of Nova Scotia, belonging to the true carboniferous age, and is the oldest known labyrinthodont form. From the Edinburgh coal-field another Labyrinthodont (Ioxomma), and from Gilmerton a form named Pholidogaster, have been described, but their affinities are doubtful. At the period of the deposition of the Triassic, or New Red Sandstone, reptiles existed which have the essential bony characters of modern Toads (Batrachia), but combine these with other characters now peculiar to Crocodiles, Lizards, and ganoid fishes, with a tusk which was equal to that of the largest existing Crocodiles. The form of the Labyrinthodonts, if we may judge from the great breadth and flatness of the skull and the proportions of certain bones, seems to have been something between that of the Toad and land Salamander.

In the smooth-skinned Batrachians no fixed type of external form like the existing higher orders of reptiles seems to exist. Some, as the broad and flat-bodied Toads and Frogs, most resemble the Chelonians, especially the soft-skinned mud Turtles (Trionyx); others, as the Ccecilice, resemble Serpents; the Newts and Salamanders represent the Lizards; and among the perennibranchiata reptiles there are species (Siren) which combine with external gills the mutilated condition of the apodal fishes. The batrachian character of two occipital condyles joining the skull with the vertebral column is presented in the Labyrinthodonts. It is only in the Batrachians, amongst existing reptiles, that examples are found of two or more rows of teeth in the same bone, especially in the lower jaw (Crecilia. 
and Siren). Some Batrachians have the vertebræ united by ball-and-socket joints, with the cup behind (Pipa) or in front (Frog), as in most recent reptiles; others have biconcave vertebral joints, as in a few recent and most extinct Saurians. Some have, and others lack, ribs.

In existing Batrachians the teeth vary much, and the only dental character in which they differ from all other orders of reptiles is the fact that they possess teeth on the vomerine bones. The Labyrinthodon, which was the gigantic Toad of the Triassic age, is found in the New Red Sandstones of Warwickshire. Its tooth showed on examination of the transverse section a convergence of numerous inflected folds of the external layer of cement. To this structure a slight approach was made in the teeth of Ichthyosaums as well as in certain ganoid fishes. It was therefore concluded that, as the extinct animals in question showed an analogy to fishes in the minute structure of their teeth, it might be inferred that if they really belonged to the class of reptiles the rest of their structure would manifest the characters of the lowest or batrachian order, the existing members of which show so many points of analogy towards the lower aquatic class. Remains were afterwards found which showed the justice of the inference to which Owen had been led, by the discovery of the occipital bone showing the separate condyles, and the double row of teeth on the vomer.

The largest species known (L. jagaeri) had a skull upwards of three feet in length and nearly two in breadth. The modifications of the jaws, and especially those of the bony palate, are batrachian; in the arrangement of the larger fangs at the anterior ex- 
tremities of the jaws there is a resemblance to the Plesiosaurus, and in the minute structure of the teeth, the form of the episternum, and the biconcave vertebræ, to the Ichthyosanms. By the anchylosis of the base of the teeth to distinct and shallow sockets the Labyrinthodon resembles the Sphyrcena and certain other fishes. There is no trace of excavation at the inner side of the base of the functional teeth, or of alveoli of reserve for the successional teeth, and we may therefore conclude that the reserve teeth, as in the Newts and in many fishes, were produced in the soft mucous membrane which covers the alveolar margin, and that they became afterwards fixed to the bone by anchylosis, as in the Anglers and Pikes. The cranium of Labyrinthodon pachygnathus shows that it had subterminal nostrils, leading to a wide and shallow nasal cavity, and consequently that the apparatus for breathing by inspiration existed. The skeleton was provided with welldeveloped costal ribs, unlike the Batrachia, in which the animal breathes by deglutition above; the costal ribs are small or absent. Other genera of Labyrinthodonts have been described, to which the names Mastodonsaurus, Trematosaurus, MLetopias, Capitosaurus, Zygosaurus, Dasyceps, Brachiyops, Bothriceps, Odontosaurus, and Xestorrhytias have been given. Owen has remarked with regard to the affinities of the order: "The relation of these remarkable reptiles to the saurian order has been advocated to be one of close and true affinity, chiefly on the character of the extent of ossification of the skull, and of the outward sculpturing of the cranial bones. But the true nature of some of these bones appears to have been overlooked, and the glance of research for analogies has been too exclusively upward. If directed downward from the 
Labyrinthodonts to the Archegosauri and certain ganoid fishes, it suggests other conclusions."

The conformity of pattern in the dermal, semidermal, or neurodermal bones of the outwardly well-ossified skull of Polypterus, Lepidosteus, Sturio, and other ganoid fishes, with well-developed lung-like airbladders, and in the same skull-bones of Archegosaurus and the Labyrinthodonts; the persistence of the notochord and branchial arches in Archegosaurus, as in Lepidosiren; the absence of occipital condyle or condyles in Archegosaurus, as in Lepidosiren; the presence of labyrinthic teeth in Archegosaurus, as in Lepidosteus and Labyrinthodon; the large median and lateral throat-plates in Archegosaurus, as in Megalichthys and in the modern Arapaima and Lepidosteus; - all these characters point to a great natural group or series, showing the gradations of development which link and blend together fishes and reptiles within the limits of such group. The salamandroid (or so-called "sauroid") GanoidsLepidosteus and Polypterus - are the most ichthyoid; the true Labyrinthodonts are the most sauroid of the group. The Lepidosiren and Archegosaurus are intermediate gradations, one having more of the piscine the other more of the reptilian characters. The Archegosaurus conducts the march of development from the ganoid fishes to the labyrinthodont type, the Lepidosiren to the perennibranchiate type. Both illustrate the artificiality of the supposed class-distinction between fishes and reptiles, and the unity of the "Hæmatocrya," or cold-blooded Vertebrata, as a natural group. There is nothing in the known structure of the so-named Archegosaurus or ICastodonsaurus that truly indicates a belonging to the saurian or crocodilian order of reptiles. The exterior ossifications of the skull and 
the canine-shaped labyrinthic teeth are both examples of the salamandroid modification of the ganoid type of fishes. The Ganocephala and Labyrinthodontia characterize the transitional period between the Palæosoic and Mesozoic epochs.

\section{Order 12.-Ganocephala.}

The endoskeleton is notochordal and osseous; there is no occipital condyle; the vomer is divided; the temporal fossæ are roofed over by bone; the hyoid arch is not connected with the tympanic pedicle; the branchial arches were probably unconnected with the hyoid; the exoskeleton has ganoid or shiny scales; the ribs were short and free; the teeth had converging inflected folds of cement at their bases; the pectoral and pelvic limbs were short and slender, with three or four toes. The animals were natatory. This order unites with the preceding by common characters which are above described, at the same time that it manifested a more piscine form and more aquatic habits of life. The Archegosaurus of the German Coal measures may be taken as a type of ganocephalous reptile. The notochord has clearly been persistent in the trunk, and the occipital condyles have not, as in Batrachia, been ossified. The skull appears to have retained much of its primitive cartilage internally, and ossification was most active at the surface. The skull is flattened or depressed and triangular. The teeth have a simple conical-pointed shape; they are implanted in the premaxillary, maxillary, mandibular, and vomerine bones, but in a single row in each. The internal structure of these teeth closely resembles those of 
Lepidosteus. This structure repeated in a true reptile indicates the nature and low position in the reptilian class of the Archegosauri. The species seems to have agreed with Amphinuma in the relative size of its branchial arches. There were large sculptured ossifications on the head and nape of the neck, and minute body scales which indicate it as a transitional form between the Batrachians and the ganoid fishes. The carboniferous rocks of Ohio afford a genus Raniceps, which seems to resemble the great Salamander of the

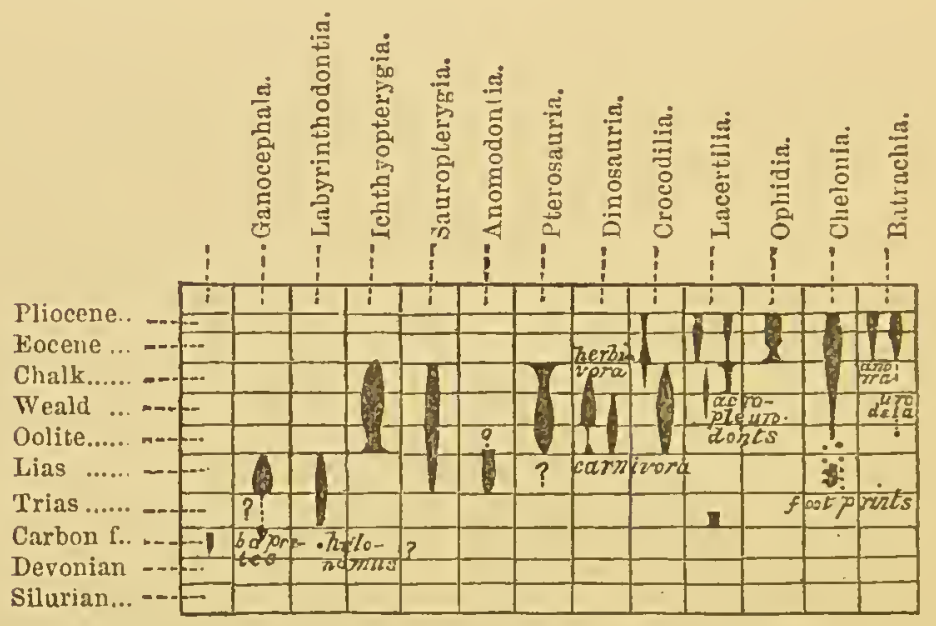

North German Coalfields. In Nova Scotia an apparently batrachian or archegosaurian genus was found in the hollow of one of the fossil coal-trees (Sigitlaria), which has been termed Dendrerpeton. In the structure of the teeth, the sculpturing of the broad cranial plates, and the structure and proportions of the limb-bones, there was a great resemblance to Archegosaurus. Four other species of carboniferous Reptilia were found at a later period in these deposits. All illustrated a phase of life which has been extinct for myriads of years on this planet.

The student has observed with regard to the class 
Reptilia that it is now become less in number. The preceding diagram, partially from Owen, illustrates the history of the geological distribution of the reptilian class. It will be seen how great has been the number of the forms of extinct Reptilia; which now are merely known to the palæontologist, and which, if they were not described by us, would leave voids in the zoological description of the forms of life which would prevent us giving a complete series of animal species, whether living or extinct. 


\section{Class IV.-FISHES.}

THIS class exists and breathes in water. A few retain the primitive vermiform condition and develop no limbs; in the rest they are fins of simple form, moving by one joint upon the body, and rarely adapted for any other purpose than the impulse or guidance of the body through the water. They may be

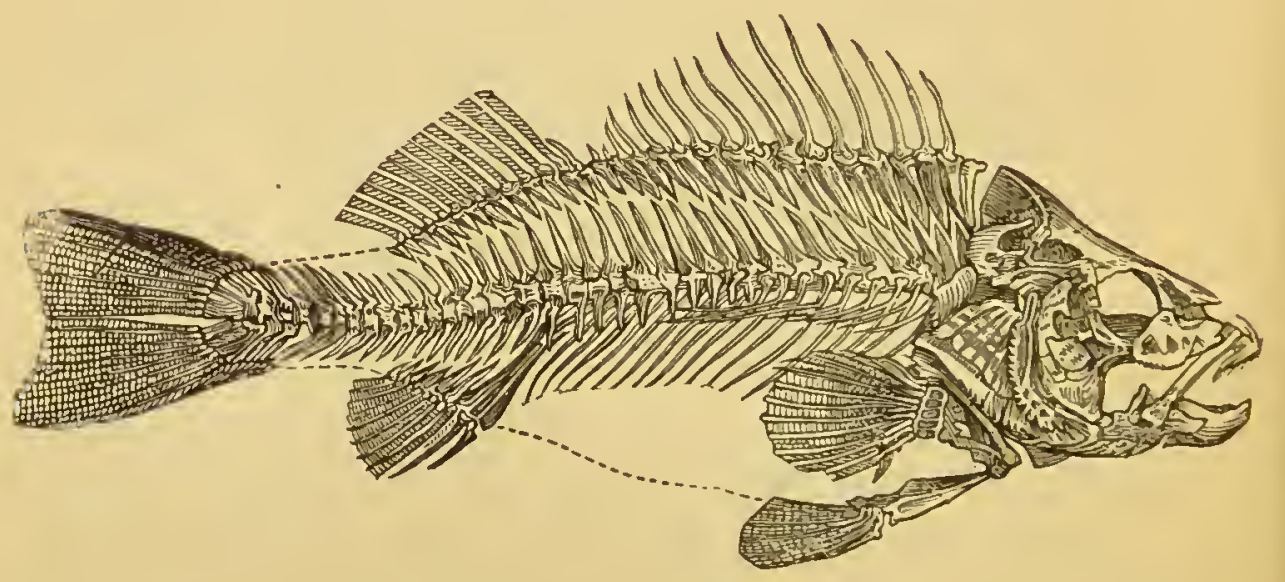

Skeleton of Perch.

technically defined as vertebrated animals with red blood, breathing through the medium of water by means of branchiæ or gills. The four limbs are produced in lateral pairs, and in fishes the first pair are named pectoral fins, and the second pair, which are situated on the ventral aspect of the fish, are called ventral fins. In some fishes their relative position is 
in front of the pectorals, when they obtain technically the name of jugular fins.

The vertical fins of fishes are of a different nature, and the rays which support them, whether jointed and soft or hard and spinous, are not parts of the interior skeleton, but belong properly to the skin, or dermal skeleton. The first that rise vertically in the mesial plane of the back, whether one or more, are termed dorsal; those from the opposite ventral aspect, situated in all cases posterior to the vent, and therefore appertaining truly to the tail, are termed anals; and the solitary fin at the end of the tail is termed the caudal; the fish which have spiny rays on the back are named Acanthopterygians, and those which have only flexible and jointed rays Malacopterygians. In the great majority it lateral symmetry exists externally and in the skeleton; only one group, the Pleuronectidoe, or Flatfish, present a remarkable similarity on the two sides of the fish. The form in fishes varies extremely, passing from the common salmon-like form of the majority of fishes into thin vertical discs, as in Chotodon; ribbons, as in the Gymnetri; square boxlike forms like the Ostracions, or round bladder-shapes like the Diodons. The slender elongated cylindrical form is shown among the Syngnathide, or Pipe-fishes, Eels, Lampreys, and Sharks. A depressed discoid shape, with the appendage of a whip-like tail, is common among the Rays, and in the Pleuronectidce the same form is produced by compression, though attended with lateral dissimilarity.

The bones of fishes are primarily divisible into those of the neuroskeleton or vertebral series; of the Splanchnosieleton, for the special protection of certain organs; and of the derinoskeleton, parts of the cutaneous 
system, and analogous to the exterior skeletons of the lower divisions of animals. The shape of the body is usually such as is adapted for moving with least resistance through a liquid medium. The surface of the body is either smooth and shiny, or smoothly covered by overlapping scales. It is rarely defended by bony plates or roughened by tubercles, still more rarely armed with spines. The brain is small, and consists of a succession of simple ganglionic masses, most of which are appropriated to the function of a nerve of special sense. Touch is feebly exercised, and an organ for that sense rarely developed. There are only visible two external organs of sense, the orifices of the nostrils and the eyes; but the first may be simple, as in Rays and Sharks, or double, as in most osseous fishes, and they may be placed farther from or nearer to the eyes, the jaws, or the point of the snout; the eyes vary exceedingly in size according to the species, and may be altogether concealed beneath the skin. They may be directed laterally, elevated, or be turned altogether towards the sky. One family of fishes, the Chondropterygii, has the external border of the branchix fixed to their skin, and as many openings for the escape of the water as there are intervals between the branchiæ. All other fish have these branchix free on their external edge, and the water which has entered the mouth is ejected by a single opening, or gill, on each side; the gills are of different sizes, and open more or less remotely. Herrings have them large, and nearly encircling the head; in Eels they are small, and placed far back; there are even some species of this family which have only a single aperture for both gills. The operculum, or gill-plate, whose pulsations serve in respiration, may vary in form and size; the termination 
of the membrane beneath may be united totally or in part with that from the other side, or with the part next the shoulder. The number of rays supporting it may be more or less considerable. Sometimes, as in Diodon, a great part of this organ may be concealed by the skin, or altogether wanting, as in all the fish provided with several orifices. The jaws may have teeth of every kind, and these may be found in all parts of the mouth, and even in the throat. The lips may be furnished with barbels or beards of different substances, numbers, and lengths. There may be fleshy filaments hanging from the skin, as in Scorpcena; some rays of fins may be separated, and susceptible of independent motion, either from the ventral fins, as in Lophius, or from the pectorals, as the Gurnard.

The nature of the integuments on the body, head, and fins may vary. A fish may be naked, scaly, spinous, or plated in all or in several of its parts; the scales or plates may offer endless differences in size, order, shape, and inequalities of surface. The same differences may occur in the skin of the head. The line which is marked on the sides of fish, consisting of a succession of pores, or of small tubes in the scales, may be more or less prominent, and even rugose or plated; it may be also nearer the back, more or less arched, straight, or interrupted. Four types of scales have been described by Professor Agassiz as characteristic of fishes. He considered the form of the scales to bear so close a relation to the rest of the ichthyic structure and the gerieral economy of a fish, that he founded his primary division of the class upon the form of the scales. 'The fish of the Cycloid order have scales composed of concentric layers of horn or bone, without spinous margins, and not covered with enamel. Most 
commonly the cycloid scales are imbricated; occasionally they are placed side by side, in contact, but not overlapping; sometimes they are more remote; and in Anguilla the narrow, oblong cycloid scales are in groups, lying at right angles to each other, so as to produce a kind of lattice-work under the cuticle. Some genera of fish with smooth, scaleless skins come into this order.

The Ctenoid order of fish have horny or unenamelled bony scales, with spinous teeth on the posterior edges of the layers like a comb. As the scales grow their spinules wear off, and in some species we observe no more than a single series on the posterior edge of the last-formed layer of the scales; in others, the teeth are more persistent. There are some scaleless groups associated with Ctenoids. The ctenoid scales are mostly imbricated. In ganoid fishes, the plates or scales are covered by a thick coat of enamel, and are sometimes of considerable dimensions; and in many of the extinct species, which compose the bulk of this order, the enamelled plate is rhomboidal, with a hook at its anterior angle, which assists in retaining it in its place.

The recent species included by Agassiz in this order do not form a natural group. Fishes of the Placoid order have the skin covered with irregular plates of hard bone, varying greatly in shape and size. In the Rays and Monk-fishes they form large, rough, or spinous tubercles, and in the Dog-fish fine grained shagreen. As formed by Agassiz, the order corresponds with the Cartilagenii or Chondropterygii of authors, and includes species with smooth skins. The head of the Sturgeon is protected by large dermal plates, closely arranged, and the rows continued along the trunk of the fish are examples of the placoid scales of Agassiz. The sternum, as it has been called, of the Herring is 
formed of a series of acutely bent dermal bones, and the Dory has two rows of plates along the belly. In the Ostracionidice and Syngnathida the fish is wholly or completely encased in scales, so connected as to admit of few motions of the body; and in the Gurnards and many other Sclerogenidce, some genera of Siluridce, the great Suclis among the Clupeidce, and Polypterus among the Ganoids, the cranial and humeral bones of the exoskeleton present hard, rough, shagreened surfaces exteriorly, in which the soft epidermis is not perceptible, and the resemblance to the dermal plates of the Sturgeon is close. In many other fishes the cranial bones emit processes from their surfaces which serve as canals for the mucoducts.

The spinal column, composed of numerous articulations united by cartilages which permit of certain movements, curves with great facility from side to side; but the vertical motion is much more restricted, chiefly in consequence of the projection of the upper and under spinous processes of the vertebræ mucoducts.

The great organ of movement in all fishes is the tail. The muscles by which it is brought into play extend in lengthened masses on either side of the vertebral column. The body, being rendered specifically lighter by the distension of the swim-bladder when that exists, is impelled forward by the rapid flexure of the tail acting laterally upon the water. The head of fishes exercises but slight movement independent of the rest of the body; but the tympano-mandibular arch of the maxillary and premaxillaries, the hyoid and branchial apparatus, and occasionally the scapular arch, have more or less motion. The finsy terminations of the last-named appendage, and of the pelvic bones, as well as the vertical fins, are seldom at rest. 
The position, direction, and dimensions of the eyes of fishes vary greatly. In some they have an upward aspect, and are often very close upon each other; in others they are lateral, and so wide apart as to be even directed slightly downwards. Fishes possess the faculty of perceiving odours; various scents attract or repel them; and there is no reason to doubt that the seat of that perception lies in the nostrils. The sense of taste is not highly developed, as, with few exceptions, they swallow their food rapidly and without mastication. The tongue is almost immovable, often entirely. osseous, or beset with teeth or dental plates. The sense of touch is deadened over the whole of the body by the coating of scales, and is chiefly confined to the lips. Even these parts are in many species as hard and insensible as bone. The appendages termed barbels, which are possessed by the Cod and Roach, are supposed to aid as organs of touch, as well as the delicate rays which the Gurnard develops from its pectoral fin. The skin secretes a shiny matter which bestows much brilliancy on the class, and is also found in the thickness of the peritoneum and in the swimming-bladder. The structure of the organ of hearing is specially adapted for the sensation of the sonorous undulations of water.

The teeth of fishes are more variable in form, structure, number, and position than those of any other class of animals. In some forms, as Iryliobates, Scarus, or Myletes, they are.depressed prisms of three, four, five, or six sides. More generally they are round and tapering, varying in length and thickness from short, obtuse cones to such forms as may be deemed ciliiform. These points may be curved, reflexed, or bent at right angles, and their bases may be fixed or movable. When acicular or ciliiform teeth are arranged so closely 
as to resemble the pile of velvet, they are said to be villiform ; and when coarser and straight, or with their points bent back, they are cardlike or cardiform. In Sharks the teeth have a variety of forms, from the long triedral dagger or spikenail of Oxyrhina and Odontaspis, to the serrated or lobed cutting teeth of Galeocerdo, Carcharodon, and Carcharias, in which the teeth, set in a row, make a most powerful sectorial instrument, down to the pavement-like or tesselated teeth of the Dog-fish, used for crushing. In Myliobates, AEtobates, Rhinopterc, the pavement formed by the broad teeth is of the most regular and beautiful kind. In Plagiostomi the teeth are limited to the maxillary and mandibular bones, while in Cyprinus they are wanting in the jaws, while grinding teeth exist on the pharyngeals.

In fishes the branchial circulation alone is provided at its base with a muscular apparatus, or heart, corresponding to the right auricle and ventricle of the higher classes, while nothing of the kind exists at the base of the circulating system of the body; in other words, the left auricle and ventricle are entirely wanting, the branchial veins changing into arteries without any muscular envelope. The muscular apparatus of their circulation is composed of the auricle, the ventricle, and the bulb of the pulmonary artery, and the auricle itself is preceded by a large sinus in which all the veins of the body terminate; thus these are in a single series, from cavities separated by constrictions, into which the blood must flow in its progress from the body to the branchiæ. Their size is small in proportion to the dimensions of the body, and does not increase in the same ratio with the growth of the individual. Three of these receptacles - the auricle, the heart, and the 
bulb-are lodged in a pericardium, which is itself placed beneath the pharyngeal bones, between the inferior parts of the branchial arches, and for the most part protected externally by the scapular arch. It is by an infinite subdivision of the vessels over the surface of the branchix, or gills, that the blood of fishes becomes subjected to the influence of the surrounding water, which is made to flow incessantly between the gills by the movement of the jaws, and by the opercular and hyoidan apparatus. If the air is expelled by ebullition from the water fishes cannot live, and many species are obliged to rise frequently to the surface for the purpose of breathing atmospheric air. All can be suffocated when held under water enclosed in a glass net. When fishes are deprived of water they perish, not so much for want of oxygen as because their branchiæ become dry and unable to perform their functions duly. Hence those species of which the branchial orifice is small, as the Eel, or those which possess receptacles for moisture, like Anabas and Ophicephalus, long survive exposure, while such as have their gills greatly cleft and open, as the Herring, expire almost instantly when withdrawn from their moist abode. In two genera of fishes (Amphipnous cuchia and Saccobranchus singio) there is a lunglike sac for supplying air to the gills. This does not, however, represent the lungs in the higher Vertebrata, which finds its homolngical representative in the air-bladder. This in many genera has no opening or external communication, so that the air which it contains must be the result of secretion. This air consists, in particular fishes, of nitrogen, with a very small quantity of oxygen, and a trace of carbonic acid; but in the air-bladder of sea-fishes living at great depths oxygen predominates. Amongst the 
abdominal fishes it communicates by a tube with the intestinal canal, either directly, as in Cyprinus, into the œsophagus, or into the base of the stomach, as in the Herring. In some fishes the air-bladder is no bigger than a pea, and in some (Pleuronectes) it is entirely wanting, the species in such cases generally remaining at the bottom, and, swimming obliquely on one side, propel themselves forward by a nearly vertical movement of the tail. In some cartilaginous fishes, as the Skates and Rays, the absence of the swimming-bladder seems compensated by the enormous size of the pectoral fins, which of all the external organs are probably the most efficient in raising the body, as the caudal extremity is the power chiefly employed during an onward course. The Lamprey has neither swimming-bladder nor pectoral fins, and dwells in the mud. Flat fishes, being unprovided with swimming-bladders, are supposed for that reason to raise themselves with diffculty to the surface, and they do not appear to strike the water laterally, like other fishes, but swim rather after the manner of the Cetacea, by a motion alternately up or down. The tail is always vertical, unlike that of the Whale, as a true fish, possessing the power of extracting air from water by means of its gills, does not, except at rare intervals, require to mount to the surface for the performance of the vital act of respiration; for all cetaceous animals, being furnished with lungs which cannot perform their functions except through an immediate communication with the atmosphere, require their bodies to be terminated by a horizontal expansion, the action of which is the most efficient for an ascending course. Richardson, however, points out that it is difficult to account for the reason why the swim-bladder should have been denied 
to so many species, not only of the more indolent Dermopteri, Plagiostomi, and Pleuronectide, but to many others which yield to none in the ease and velocity of their movements. In the rapid-swimming Mackerel, the air-bladder is wanting, while it is present in a closely allied species, the Scomber pleumatophorus. Many fishes, as the electric Eel (Gymnotus) and the Torpedo, possess the power of giving electric shocks. In Torpedoes the apparatus consists of two organs, built up of membranous tubes filled with mucous matter, divided by transverse chambers closely set together, like the cells of honeycomb, and disposed in two groups placed on each side of the head. In the Gymnotus the electric organs are four, and occupy the under surface of the body throughout its entire extent to a considerable thickness. The shape of the caudal fin varies much in fishes, according to the kind and degree of motion required; in the imprisoned embryo, the Eel and the Lepidosiren, the vertebræ continue to the end of the body in a straight line, distinct, and decreasing to a point. Such form of development is called symmetrical. In another type, exhibited by the Sturgeons, Chimæras, and Sharks of the present day, and the majority of Mesozoic fishes, the upper lobe of the tail becomes largely developed, whilst the tail becomes bifurcate but unsymmetrical. This is the heterocercal type of tail. In some Oolitic fishes is observed such a lengthening of the dermoneurals of the tail, with such a shortening and ruming together of the terminal vertebræ, and such a proportion of the dermohæmals, as leads to an equal-lobed caudal fin, which has been termed by Agassiz homocercal; but as it is only symmetrical in contour, and remains more or less unsymmetrical in its framework, Owen has termed 
it homocercoid. Most fishes pass through in their development these changes. Salmons, most Malacopteri, and many Acanthopteri, pass from the heterocercal to the homocercoid form. Anacanthini and Scomberoids go a step further, and reach the truly symmetrical homocercal form, the latest and highest grade of piscine development. The heterocercal tail helps the fish to vary its onward course, as in the Sharks and Sturgeons, which twist round as they swim. The homocercal tail is more adapted for direct, straightforward progression.

\section{Order 1.-Protopteri.}

The endoskeleton in this order is notochordal, partly cartilaginous, partly osseous; there is no occipital condyle; the vomer is undivided; the temporal foss roofed over by bone; the ribs short, with free extremi-

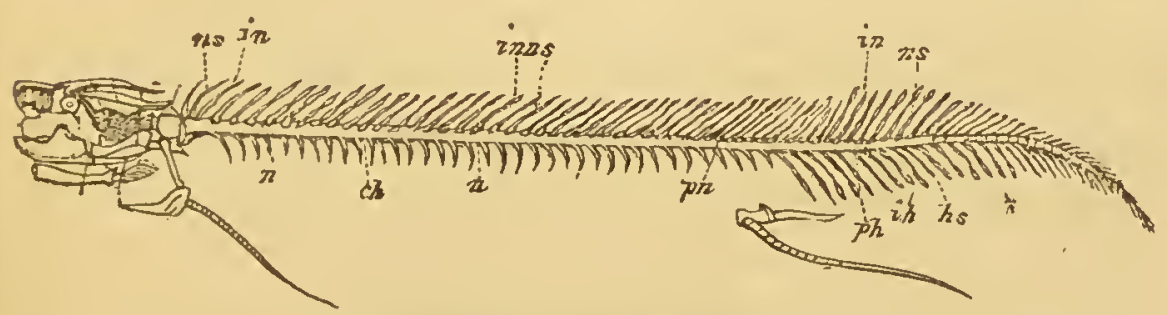

Skeleton of Lepidosiren.

ties; the exoskeleton has subcuticular cycloid scales; the scapular arch is attached to the occiput; the proximal ends of the hyoidean and tympano-mandibular arches are distinct; the vertical fin is a continuous border to the compressed tail; the pectoral and ventral fins are subulate, many-jointed-the former are fringed beneath, the latter pelvic in position; the pelvis is unattached to the spine; the gills are fila- 
mentous and free in a branchial chamber with a single vertical outlet; the branchial arches are unconnected with the hyoid; the air-bladder is double, lung-like, with air-duct, glottis, and pulmonary vein; the prosencephalon is predominant in the brain; the nasal sacs are sublabial, with two remote extra-buccal apertures; the auditory labyrinth is in a distinct chamber; the bulbus arteriosus long, with two longitudinal valves; the intestine has a spiral valve, the vent is anterior to the urethra; and the ovaria are distinct from the oviducts. The order is transitional between the reptiles and the fishes, with both of which it has been classed. Two distinct species of this order are known-one an inhabitant of the river Amazon ( $L$. paradoxa), and another ( $L$. annectens) from the Gambia. The latter river in the rainy season floods extensive tracts of country. On the waters retiring after the rains have ceased to fall, the Lepidosirens that are left burrow into the mud, which a tropical sun soon converts into a hard cake. An aperture is left that admits air, and the fish remains in its chamber torpid and clothed in a thick secretion of mucus, till the water again verflowing the muddy banks enables them to swim out of the mud again. They have been brought to England imbedded in clay round the roots of plants imported from the Gambia, and their presence only became known after the plants were placed in the stove and well watered. It is by a modification of the airbladder rendering it analogous in function to the lungs of an amphibian, and also by a peculiarity in the gills, that the Lepidosiren is adapted to the alternate conditions of an active, tadpole-like fish, or an airbreathing dweller on the dry land. As a general rule, all fishes more highly organised than the Dermopteri 
have, in their embryonic stage, five branchial arches and five branchial arteries. In osseous fishes the anterior or hyoid arterial arch develops either a gill or a single layer only, or a rudimentary consisting of a network of vessels, or both, or neither. Two of the arterial arches, which in other fishes supply a pair of branchix, remain undivided in Lepidosiven, and in their primitive condition of vascular hoops, which end directly in arterial trunks going to the air-bladders and ramified over their cellular surface. Owen considers that the gelatinous chorda dorsalis, the inferior transverse vertebral processes, the normal attachment of the scapula to the occiput, the branchiostegal covering of the permanent gills, the opercular bones, the absence of a pancreas, the presence of a spiral intestinal valve, the relative position of the anus, the extraoral nasal sacs, the scaly integuments, the mucous tubes and pores on the head, the lateral line, and the totality of the organisation of the Lepidosiren, will be sufficient to prove its ichthyic nature. The optic nerves do not cross each other, but are parallel, as in Polypterus, the Sturgeons, and Plagiostomi. In ordinary fishes the nerves cross, but without an intermixture of nervous fibrils. The Brazilian species of Lepidosiren is three feet long; the Gambian one foot. It is said that the African species is found also on the eastern coast, near Quilimane. Small external gill-leaflets were observed by Van der Hoeven in the African species. They live on vegetable matters. The vein of the swim-bladderthe pulmonary vein-enters the auricle of the heart separately, at a distance from the vence cavce. In L. paradoxa the auricle is double; the partition, however, is not a continuous membrane, but a retiform tissue, everywhere perforated. The urinary bladder is 
situated behind the rectum. The stomach is a little wider than the œsophagus, which passes into it without any definite boundary. At the pylarus there is an annular membranous valve, near which the gall-duct opens. The anus is not situated in the middle, but sometimes more to the right, sometimes more to the left.

\section{Order 2.-Plagiostomi.}

Endoskeleton cartilaginous or partially ossified; vertebræ biconcave; exoskeleton as placoid granules or tubercles, spiny in some; mouth transverse on the lower surface of the head; optic nerves commissurally united, not decussating; valves of bulbus arteriosus multiserial; gills attached to the skin by the outer margin, with intervening gill-apertures, five or more in number, on each side; no operculum.

Three great divisions of plagiostomous fishes exist, respectively typified by the Cestracion, the Sharks, and the Skates. In the Cestraphori there is a spine in each dorsal fin, and the back teeth are obtuse. In the Selachii, or true Sharks, the branchial apertures are lateral, and in the Prastides, or Rays, they are beneath. The first sub-order is chiefly restricted to a fossil state, where the large offensive and defensive spines of fish are often found, and are termed "ichthyodorulites." The Squali have free supplementary eyelids, an incomplete scapular arch, and no pectoral cartilage. The Scyllido, or Dog-fishes, have the anal fin situated either before, beneath, or behind the second dorsal, and are mostly spotted or coloured with lively tints. These miniature Sharks are common on the English coasts, 
and graduate in size up to the large Stergostoma, which reaches a length of fourteen to fifteen feet. The Carcharicle, or white Sharks, are the most dangerous and most gigantic of the order, the weight of some reaching as much as 1,500 lbs. Oxyrhina, Selache, and Odontaspis are amongst the largest Sharks known. Some of the Nictitantes, or Topes, have flat, pavement-like teeth, which indicate crustaceans as their chief food. The Lamnidce, or Porbeagles, the Alopecide, or Fox-sharks, are well-known English forms. In the latter, the upper lobe of the tail is greater in length than the body of the fish. It is said, on dubious authority, to congregate in large numbers'and attack the Whale by striking it violent blows with its tail. The spined Dog-fish (Acanthus mulgaris) is a Shark of enormous geographical distribution, the same species being found nearly all over the world. The hammer-headed Sharks (Zygcenidce) are very common on the African coast, and are also of wide geographical distribution. The basking Shark (Selache maxima) is another characteristic English form, growing often to the length of thirty-six feet, indolent, and not very sensible to slight wounds; it is often seen lying on the surface of the water, with its dorsal fin raised in the air, whence it has obtained the name of basking Shark. Many of the Sharks bring forth their young alive, and are truly viviparous; others deposit them in horny cases-cases with two hornlike or ciliated prolongations at each end. In the very young Shark branchial filaments project externally from the branchial apertures. These appendages are only temporary, and the blood of the fish is afterwards wrated by the true gills. In all Selacia the females are larger than the males, as amongst the predaceous birds. They are very tenacious of life, and their skins, 
of variable degrees of roughness, are used as shagreen. The teeth are developed from within.

In the Rays the body is excessively depressed, and the pectoral fins are laterally expanded, so as to form a discoid or subrhomboid body with an appended tail, which in the Rhinobatidce is fleshy and tapering, but in the Raiidce, Trygonidce, and some other groups is cartilaginous, slender, and sometimes elongated like the thong of a whip. The Sting-ray (Trygon pastinaca) has a narrow lancet-shaped spine placed erect on the dorsal surface of this whip-like tail, with its cutting edges turned sideways, forming a dangerous offensive weapon, which the fish can use with great effect. The Thornback (Raia clavata), the true Skate (Raia batis), and the Homelyn (Raia miratehus) are of common consumption in England. They are often oviparous. Many species have spines or tubercles on the back, or the fins, and the tail, which varies in development according to the age and difference of sex. In Cephaloptera an enormous size is frequently reached; one taken off Messina weighed 1,250 pounds. The males are usually smaller. The Raia Banksii of Lacépède, of Barbadoes, required seven yoke of oxen to draw it along; another species is said to be twenty-five feet in length. In Myliobates (the Eagle Ray), the pectoral fins are broad, acuminate towards the apex, interrupted at the sides of the head, surrounding the head anteriorly. The teeth are large, composed of vertical fibres or cylinders, forming transverse laminæ, covering each jaw with mosaic work. The tail is flagelliform, very long, armed with a serrated spur behind the dorsal fin.

The Torpedoes have the body covered with naked unarmed skin, disciform and rounded. The tail is pinnate at the point; the dorsal fin is above the tail, 
and is generally double. The teeth are conical, acuminate, and crowded. These fishes were known to the ancients on account of their wonderful property of giving painful and paralysing shocks. The electric organ of the Torpedo is situated on each side of the body, and consists of a multitude of hexagonal prisms or membranous tubes, arranged side by side, perpendicular to the ventral and dorsal surfaces, which present numerous transverse partitions of microscopic delicacy, in which the finest nervous filaments are spread, and between which a fluid is contained. The filaments arise from thick branches of the nervous fibre and the fifth pair, which run to the electric apparatus. Hunter counted four hundred and seventy prisms in each battery of the Torpedo galvani, and demonstrated the enormous supply of nervous matter which they receive. The fish gives the electric shock voluntarily, when excited to do so in

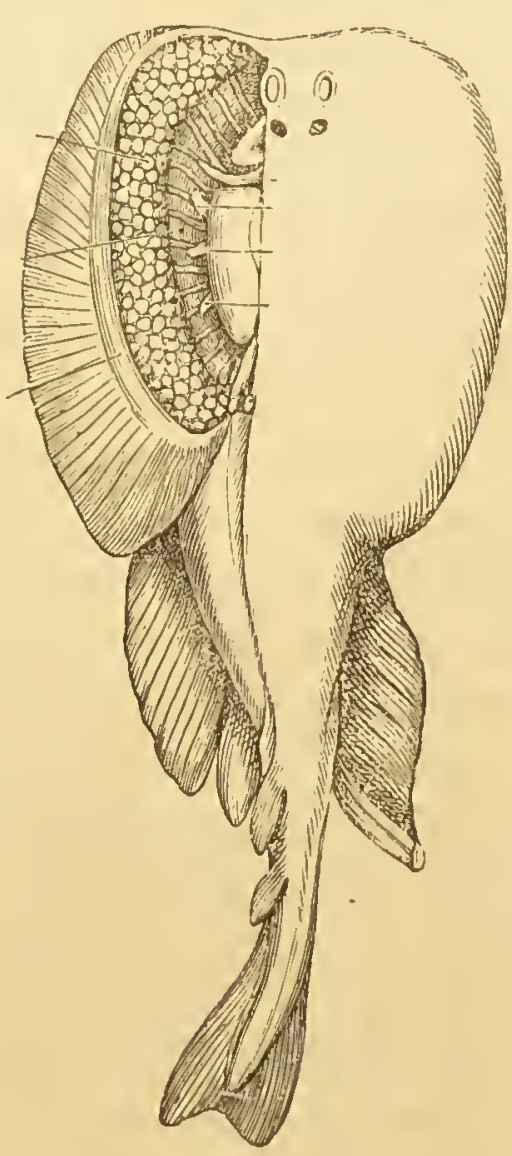

Elcctric Apparatus of Torpedo. self-defence or when roused to kill its prey, but to receive the shock the object must complete the galvanic circuit by communicating with the Torpedo at two distinct points, either directly or through the medium of some conducting bodies. In the Sawfishes (Pristis) the body is elongate, depressed anteriorly, covered with small flat 
scales. The pectoral fins are distant from the head, and not produced to the ventrals. The tail has two dorsal and a caudal fin. The teeth are small and crowded into a plane. The head is produced anteriorly into a depressed ensiform process of the premaxillary, armed with teeth at the margin on each side. This often measures one-third of the length of the body.

\section{Order 3.-Holocephali.}

Endoskeleton cartilaginous, subnotochordal ; cranial wall complete; tympanic pedicle confluent therewith; exoskeleton asplacoid granules; anterior dorsal fin with a strong spine; mouth terminal, beak-shaped; dental plates and columns fused with the jaws.; optic nerves not decussating; valves of bulbus arteriosus multiserial; gills laminar, with a small proportion of the border free; a single external gill-aperture on each side; opercular and branchiostegal rays. Oviparous; ova few and large. Two genera alone are known of this singular and aberrant order. They all have interiorly five gill-apertures, which communicate with a single common passage, having only one external opening. The rudimentary operculum is concealed beneath the skin. The upper jaw is represented by the vomer, the palatines, and the tympanals, rudimentary on the sides of the mouth. Hard bony plates supply the place of teeth in the jaws, four above, two below. The snout projects, with regular rows of pores; there is a fleshy, club-shaped process, with a spiny point, between the eyes. The first dorsal is armed by a strong spine placed over the pectorals. The claspers of the male are trifid; the eggs are large and leathery, with flat velvety borders. The cranium is fibrocarti- 
laginous, continuous, produced below into an articular process for the lower jaw. The operculum is small, adhering to the hyoid arch, sustaining rays posteriorly. The rays of the branchiostegous membrane are flat, concrete at the base, conjoined with the rays of the operculum, and contiguous to them. There are no temporal foramina; the notochord presents numerous small cartilaginous rays in its sheath, and cartilaginous laminæ, much less numerous than these rings, form the arches of the vertebral column. The anterior part of this, with which the skull is connected by articulations, is flatter, and formed of a single piece; above this is a perpendicular cartilaginous laminæ, to which the large spine, situated in front of the first dorsal fin, is affixed. In the lips and at the side of the mouth there are special cartilages, which correspond to the cartilaginous parts of the oral ring in Petromyzon. They are closely allied to the Sharks in their general form, and in the position of their fins, but all their branchix open externally by a single apparent hole on each side. Hard and indivisible plates supply the place of teeth, four on the upper jaw and two on the lower. The two genera are distributed at the opposite poles of the globe. In the true Chimoera the snout is simply conical; the second dorsal commences immediately behind the first, and extends to the tips of the tail, which is drawn out in a long filament, and is furnished beneath with another fin similar to the caudal of a Shark. It is two or three feet long, of a silver colour, spotted with brown; it inhabits our seas, and is caught generally in the wake of the Herrings. In the Callorhynchus of the South Seas, the snout is terminated by a fleshy appendage, resembling a hoe in form. The second dorsal commences over the ventrals and terminates opposite the beginning 
of the fin attached to the under part of the tail. But one species is known. Another family of fishes allied to Chimora, and termed Edaphodonts, was found in the Mesozoic and Cænozoic periods. The only parts of chimæroid fishes likely to be fossilised are the jaws and spines. The body and dental substances are so combined in the more or less beak-shaped jaws, that they characterise the order, and are never found separate. It is chiefly on such fossil mandibles, and portions of them, that the evidence of the Holocephali in former geological periods rests. These singular fishes ranged, under different genera and specific modifications, from the bottom of the Oolitic series to the present period. The Edaphodus, Ischiodus, Elasmodus are examples, which have been described by Sir P. Egerton. The order Holocephali seems to have been distributed in Europe over a larger space than at present its two scattered existing species.

\section{Order 4.-GANoIDEI.}

Endoskeleton cartilaginous, partly bony, or ossified; in a few recent and in most Palæozoic extinct forms, notochordal; exoskeleton as ganoid plates or scales; fins usually with the first ray a strong spine; caudal fin unsymmetrical in most; a swim-bladder, often cellular, and with an air-duct; intestine in many with a spiral valve. The scales are bony, generally of a rhombic or quadrangular form, seldom rounded in outline or imbricated in position, and their surface is always smooth and coated with a layer of enamel. They are generally arranged in oblique rows, those in each row being usually united to one another by a hinge-like pro- 
longation of the anterior angle. The ganoid scales are imbedded like ordinary scales in depressions of the skin, but the epidermis is excessively thin and adheres closely, so as to appear wanting. This is the case in Polypterus, but in Lepidosteus the epidermal covering is more evident. The living Ganoids have completely bony skeletons, but the fossil ones may have had skeletons soft and cartilaginous like those of the Sturgeons. The fins are frequently, but not always, covered on their anterior border with a single or double row of spring-plates, or lamince; their caudal fin sometimes involves in its upper fold the extremity of the vertebral column, which may continue to the end of that fold; their nasal apertures double; their gills are free, and lie in an operculated cavity, as in the osseous fishes. Several have an accessory organ in the form of an opercular gill, which is different from a pseudobranchium, and may occur at the same time with it; many have also blowing-holes like the Plagiostomi. They have several holes in the arterial trunk, like the latter; their ova are conveyed from the abdominal cavity by tubes; their optic nerves do not decussate, but merely cohere laterally; their intestine often contains a spiral valve, like the Plagiostomi. They have a swimming-bladder with an air-tube, like many osseous fishes; their skeleton is either bony or partly cartilaginous; and their ventral fins are abdominal. If, however, reference be made to the absolute characters only which are never absent, the Ganoids are fishes with numerous valves in the arterial trunk, no decussation of the optic nerves, free gills and opercula, and with abdominal ventral fins.

The Ganoids further resemble the Sharks in the possession of a gland, considered by Carus to be a thymus, 
which in Polypterus and Lepidosteus is found, and also in the Sturgeons. Two great divisions of ganoid fishes exist-those which have been termed Lepidoganoidei, and those called Placoganoidei. The former sub-order is represented alone by the bony Pikes (Lepidosteus and Polypterus) among existing forms, but comprised the whole group of ganoid fishes whose remains are found fossil. The second sub-order comprises the Sturgeons and some of the older Devonian fossil forms.

The Lepidostei, or bony Pikes, are by no means rare in the North American waters, it being the opinion of Agassiz that each separate river, basin, or watershed has its separate species of Lepidosteus. They frequent shallow, reedy, or grassy places. One of the species reaches the length of seven feet. It is covered with hard, bony, rhombic scales, which are arranged in oblique rows backwards from the back towards the belly. The branchiostegal membrane has three rays. The dorsal fin is small, remote towards the tail, placed behind the anal. The first ray of dorsal fin, of the anal, and of the pectoral and ventral fins, and the rays of the caudal fin, are covered with aculeate, imbricate; and serrate scales.

Polypterus is an allied African genus. Three species are known, two in the Nile and one in the Senegal. They attain a size of about two feet. The gland, which has been termed (contrary to the opinion of Mr. John Simon) a thymus gland, is double in Polypterus; and the spiral intestine valve, which in Lepidosteus is but slightly developed, attains its maximum size in this genus. Another remarkable form is the Mudfish (Amia), from the fresh-water streams and lakes of the southern United States. In habit it resembles the osseous fishes rather than the Ganoids. Cuvier com- 
pared the air-bladder of Amia to the lung of a reptile, on account of its great cellular subdivisions. As in Polypterus, there is no gill on the gill-cover. The fossil forms of ganoid fishes can only here be indicated. The Pycnodus, Dapedius, Leptolepis, Ocanthodes, Dipterus, Colacanthus, Holoptychius, are well-known types.

The placoganoid sub-order have the skeleton cartilaginous and the tail asymmetrical, with a fin adhering beneath the spine of the back. There are no rays to the branchiostegal membrane. In the Sturgeons, the body has an armour of osseous scutes, disposed in five longitudinous rows. The head is produced beyond the mouth into a triangular apex, flat below. The cirri in front of the mouth are inferior and edentulous.

The Sturgeons live in the seas of the Northern Hemisphere, and from thence ascend different rivers. They are very abundant in the rivers of Siberia, which flow to the southwards, and also on both sides of North America. They ascend the muddy rivers in vast numbers, and avoid clear cold water. Caviare is prepared from the roe of the Sturgeon, and isinglass from the swimming-bladder. In the Spatularia, a closely allied genus, the skin is naked and destitute of bony shields; the snout is expanded into an enormous leaf-like prolongation. The gill-openings are larger than in the Sturgeons, and the membranous tip of the gill-flap reaches the middle of the body. The mouth is very wide, with a multitude of little teeth. There is a gelatinous chord in the spine like that of the Lamprey-a special intestine valve. The pancreas is partially divided into cæca and an air-bladder, which communicates with the csophagus by a large hole. 


\section{Order 5.-LophoBrancini.}

The endoskeleton is partially ossified, without ribs; the exoskeleton is ganoid; the gills tufted; the opercular aperture small; the swim-bladder without air-duct. The males are marsupial. The branchial laminæ are broad, club-shaped, not numerous, arranged in a double row along the branchial arches, folded transversely. The branchial aperture is small, superior, with a large operculum fixed to the skin throughout nearly its entire circumference. The rays of the branchiostegal membrane are small and very thin. All the species belonging to this order are of small size; only a few go to the length of a foot. In the Sea-horse (Syngnathus), a species of this order, hibernation has been observed, during which respiration has been diminished. The eggs are carried under the abdomen or at the base of the tail, mostly two longitudinal folds of skin which close like folding-doors in the male, to whose protection the female consigns them, and with whom the young ones when born continue to live for a time. In Solenostromus the ventral fins form a sac, which serves a similar purpose. Some have prehensile tails, like those of an American platyrrhine Monkey, whereby they suspend themselves to vegetable matter in the sea. They resemble the Chameleon in being able to direct one eye backwards and the other forwards ; and Professor Lichtenstein observed a circular movement in the water near their gill-openings; on the right side the whirl revolved to the left, and on the left side to the right, the rotation being symmetrical and constant like that of a Rotifer. The Irippocampi inhabit all parts of the ocean. Many of the order are remarkable by the sin- 


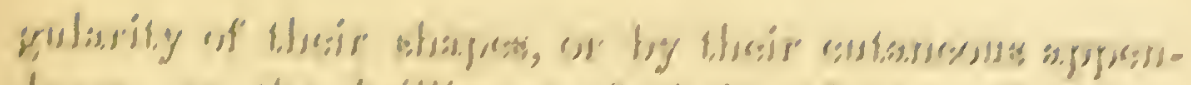

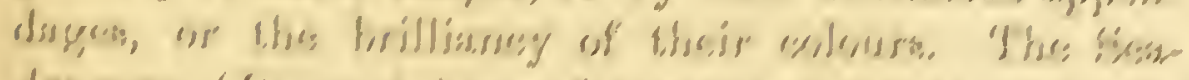

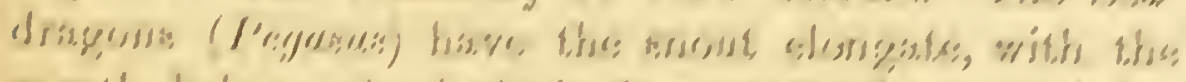

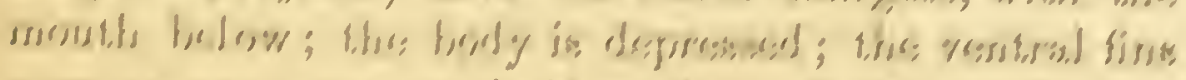

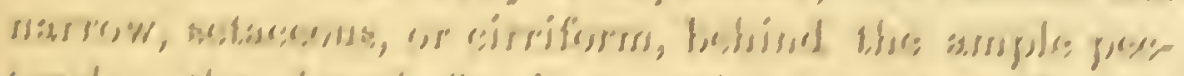

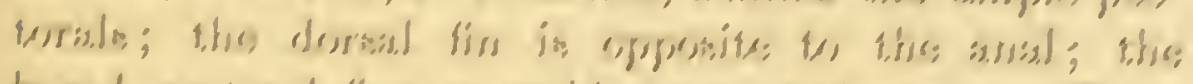

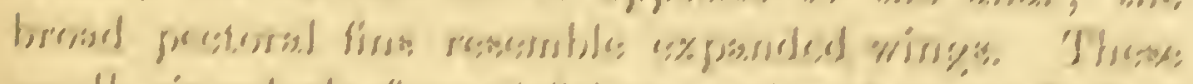

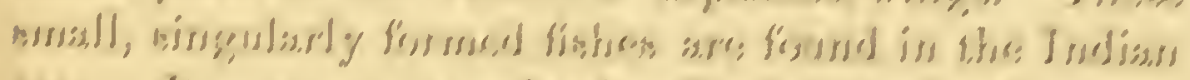

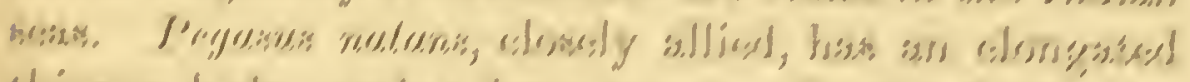

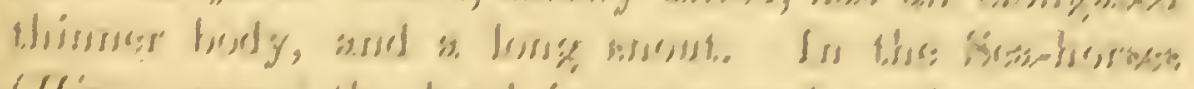

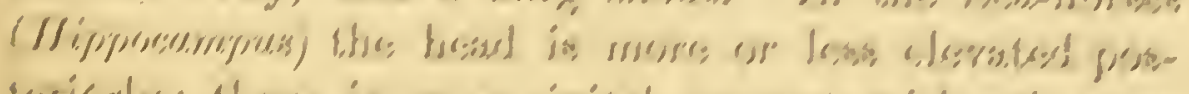

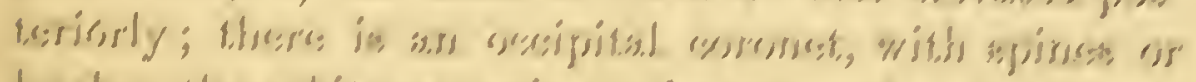

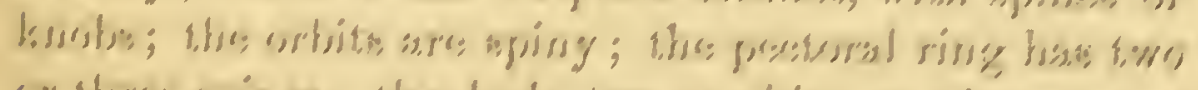

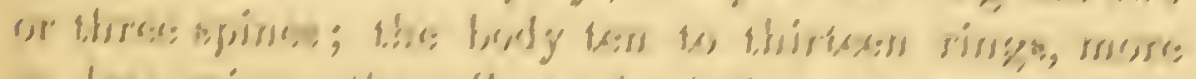

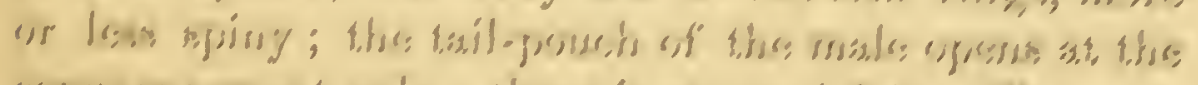

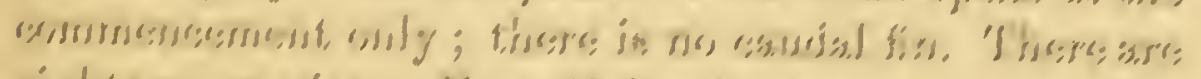

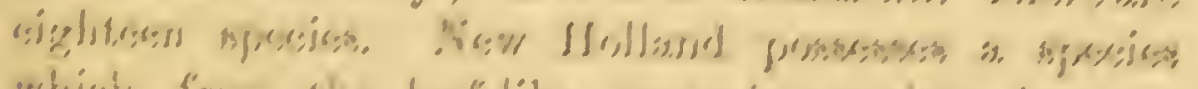

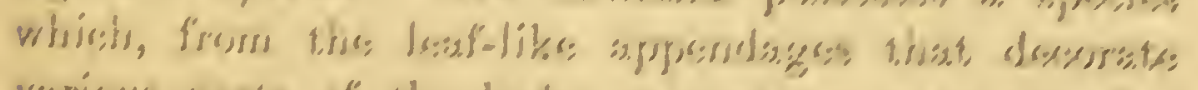

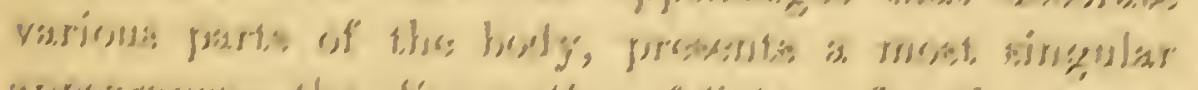

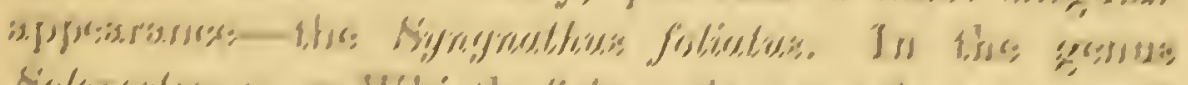

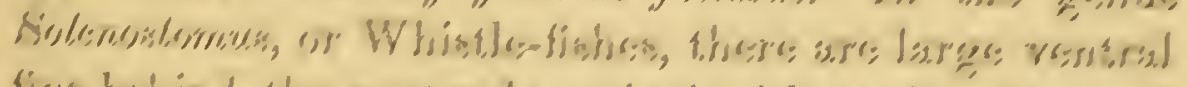

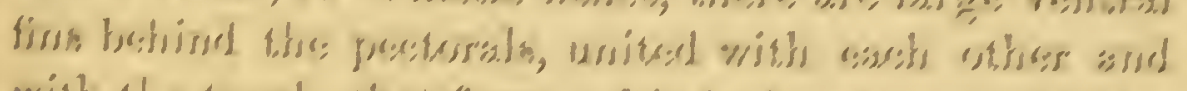

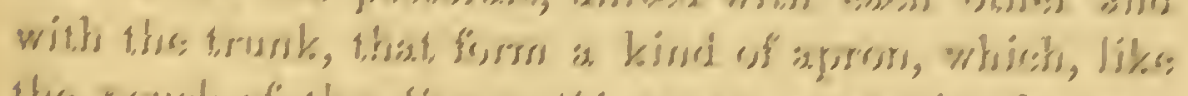

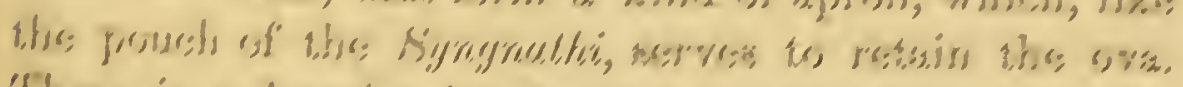

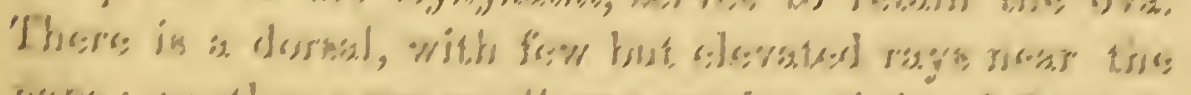

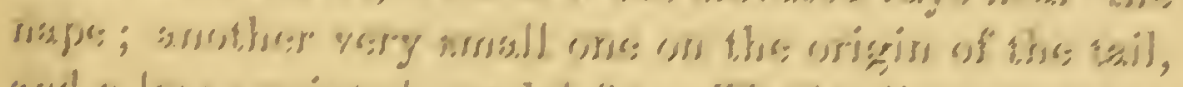

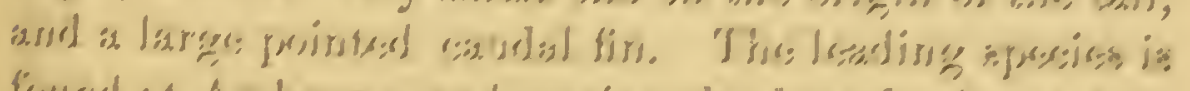

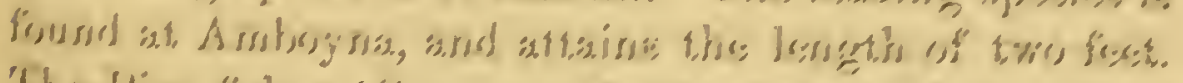

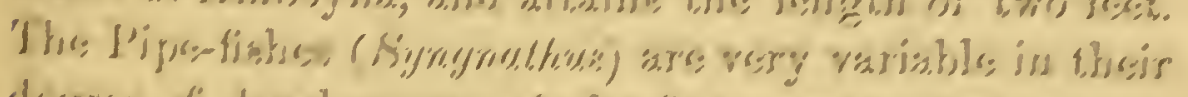

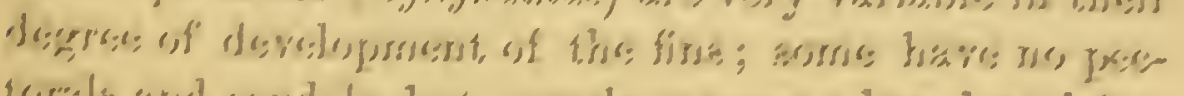

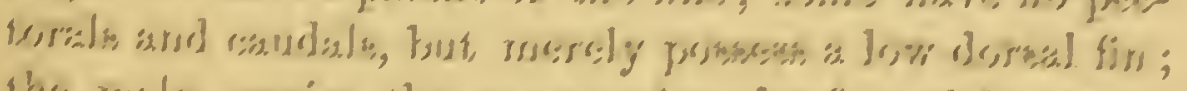

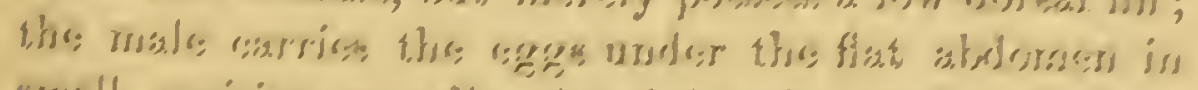

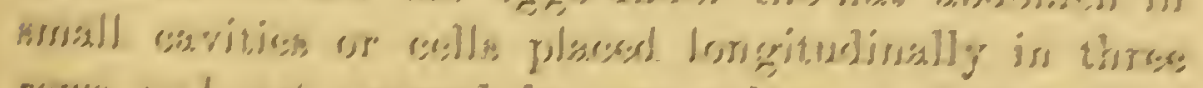

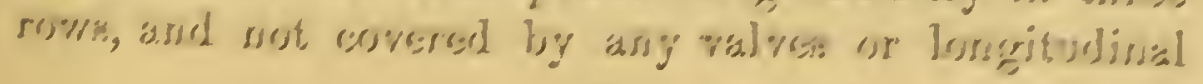


appendages of skin; they feed principally on small crustaceans ; the scutellated plates of mail which cover their body almost always render it angular; they are small, and nearly without flesh; their intestine is equal without cæca.

\section{Order 6.-Plectognathi.}

The branchiæ are pectinate, with the lamellæ narrow and numerous; the upper jaw bones are united to the sides of the intermaxillary bones by an immovable connection; the palatine arch is immovable; the body covered either with multangular scutes or with spines and rough scales; the swimming-bladder is large in most, and always destitute of a duct; there are opercula; and the rays of the branchiostegal membrane are covered with a dense skin.

Three great groups exist, represented by the Balistidoe, the Ostracionidoe, and the Diodontidoe. In the Balistidoe, or File-fishes, the snout is conical or pyramidal; the mouth is anterior and furnished with teeth; the body is covered with hard scales, sometimes very small, or with a coat of mail, composed of angular areola. Although no ventral fins are present, there is a pelvis in all, of which the two bones have coalesced. In many the scales are very small, and their place is supplied by spine-like inequalities on the skin. In others, very large rhomboidal scales are present; ofteu there are found behind the branchial aperture some larger scales or pentagonal horny plates. Many species have three or more parallel rows of horny spines on each side of the tail, and in some species of Monocanthus, the tail has a quantity of hard bristles on 
each sides. The snout is conical, the mouth small and terminal, and the teeth distinct but not numerous.

In Balistes the first dorsal spine is articulated by ring and bolt to the broad interneural osseous plate. When the spine is raised, a depression at the back part of its base receives a corresponding projection from the contiguous base of the second ray, which fixes it like the hammer of a gun-lock at full cock, and it cannot be let down until the small spine has been depressed as by pulling at the trigger ; it is then received into a groove on the supporting plate, and offers no impediment to the progress of the fish through the water. This trigger-like fixing of the spine takes place also in the dead fish. The teeth consist of true dentine, with a thick layer of dense tissue that differs little from enamel. In the Gymnodonts the jaws are at the anterior part projecting from the mouth, and covered with an ivory substance made up of very small concrete teeth. In these fishes the three anterior branchial arches alone carry gills, the fourth does not. In the Sun-fish (Orthragoriscus mola) there is no swimmingbladder. Behind the smooth margin of the jaws, which is invested with dental substance, are some small conical teeth, arranged laterally. The body, compressed and spineless, is not susceptible of inflation, and the tail is so short and high that the fish resembles one whose posterior portion has been truncated, producing a singular appearance which is amply sufficient to distinguish it. The dorsal and anal, both high and pointed, are united to the caudal; the stomach is small. The weight of the Sun-fishes is often upwards of three hundred pounds.

In the Urchin-fishes (Triodon) the upper jaw is divided into two, and the lower is entire. The body is 
covered with short spines. There is a pendulous sac beneath the body. Diodon is able to inflate itself by taking air into its spacious stomach and then swimming belly upwards. Tetrodon, which is also spinous, exhibits in some of the species the olfactory organs as fissured appendages in front of and above the eyes. The Nile during its inundations casts thousands of them on the shore, where they serve as playthings for children.

All these genera agree in one striking character-the faculty of swelling themselves up like a balloon by filling their stomach or crop with air. When thus inflated they roll over, and float on the surface, with the abdomen upwards, unable to direct their course; but they are extremely well defended while in this position by the erection of the spines with which their skin is everywhere furnished. When captured, a whistling noise is produced by the air which rushes out of their stomachs.

\section{Order 7.-ACANTHOPTERI.}

The endoskeleton is ossified, and the exoskeleton appears as ctenoid scales; the fins have one or more of the first rays, unjointed or inflexible spines; the ventrals are in most beneath, or in advance of the pectorals; the swimming-bladder has no air-duct; the branchiæ are pectinate with narrow lacinix; the supermaxillary bones are not connate with the intermaxillaries; the rays supporting the anterior part of the dorsal and anal fins are inarticulate-mostly hard, strong, acuminate at the apex. This order of fishes is the most numerous of all. The scales are mostly furnished 
with fine spines or points at the posterior margin. The ventral fins have commonly a hard-pointed ray like the first ray of the dorsal and anal fins; they are placed in almost all under or in front of the pectorals and only in few behind these. Many families of acanthopterous fish exist, only a few of which need be mentioned as illustrative examples in this place. The Uranoscopidce, or Star-gazers, have the power of raising their eyeballs out of their sockets, and of retracting them again within the level of the orbits. They frequent the bottom of the sea, and have barbels developed as in many other species of ground-fish. The Perches (Percidce) are, perhaps, almost the most characteristic and typical examples of acanthopterous fishes. In them the body is oblong, covered with rough scales; the præperculum and the operculum are rough with teeth or spines; there are teeth in the jaws and vomer, often also in the palate-bones; the branchiostegal membrane has mostly seven rays; the ventral fins are thoracic in most. In the section of perch-like fishes which were called Mullus by the Romans, there are no teeth in the upper jaw, whilst the lower jaw and vomer are crowded. The Perches (Percini) have no cirri in the lower jaw. The rays of the branchiostegous membrane are more than four. The common Perch (Perca fluviatilis) is well known. The female deposits her ova in lengthener strings, the number of the eggs sometimes amounting to nearly a million. The Bass, or sea Perch (Labrax lupus), is common in the Mediterranean, where it was highly favoured by the Romans. The sea Perches (Serrani) are distinct from the Basses, and are frequent in the Mediterranean. The Theraponidce and Polynemidee may be passed over, but the Mullide, or Surmullets, which 
are also frequent in the Mediterranean, form a perfectly natural family, distinctly allied to the Penoids, but readily distinguishable from other Acanthopterygia by the two dorsals widely separated from each other, by the large and easily detached scales of the head and body, and by the pair of symphysial barbules of the mandible, which retire between the limbs of that bone when not in use. The body is oblong, little compressed. The fins are of moderate spread. The Holocentridce have an unusual number of rays in the ventrals, and are fishes remarkable for the brilliancy of their colours, the neatness of their forms, and their very ctenoid scales. The Sclerogenidce, or Mailed-cheeks, are composed of thethree Linnæan genera Trigla, Cottus, and Scorpcena, which are remarkable for presenting an enormous variety of external form, some being beautiful, splendid, elegant, or graceful, and some being remarkably ugly, and having loose disgusting skins. The Gurnards (Trigla) give a good idea of the general form of one of the leading tribes of the family; the Flying-fish (Dactylopterus) is extremely common in the Mediterranean, while it represents the Exocietus of the Atlantic. By the extension of the pectoral rays and membrane, this fish is enabled to raise itself from its proper element to the regions of the air, though this is by no means a continual flight, for the utmost it can do is to describe an arc over the surface of the water, extending to a distance of about one hundred and twenty feet, and sufficiently elevated for the fish sometimes to fall on the deck of a large vessel. This power of flight or momentary suspension would be much greater if the pectoral membrane could preserve its humidity longer, but it is soon evaporated in the heat of the tropics, and the membrane as it becomes 
dry loses its buoyant power, and the fish falls. They are sometimes so numerous as to afford much pleasure to the spectators by their repeated flights; and at particular times, especially on the approach of rough weather, in the night numbers of them may be seen by the phosphoric light they emit, marking their arched passage in apparent streams of fire. The Cotti, or Bullheads, are frequent in the northern continents.

The Synanceia bracheio of the Isle of France appears like a mass of corrupted jelly, its whole body being like an ulcer ready to burst, with parts of the skin wrinkled like those of a leper. The Gasterostei, or Sticklebacks, are the most common form of Acanthoptera near English towns.

The Sciænoids are said to utter at times a low bellowing sound, which has gained for some of the species the vulgar name of "Drums" or "Grunts." Some of them (Pogonias) grow to a great size, and occasionally weigh above a hundred pounds.

The Sparoids, which are, like the Perches, more frequent in the Mediterranean than here, are well exemplified by the Sargus Rondcletii and by the Sargus ovis of America, vulgarly called the "Sheepshead," which is one of the most delicious fishes. The Mrnoids have greater protractility of the mouth, and a greater thickness of the face and of the body generally, than the Sparoids. The Labyrinthibranch family of Acanthopteri comprises such forms as the Anabas scandens, which have a peculiar structure of their pharyngeals, by which a quantity of water can be retained in their complicated folds. Some of these fishes rise to a height of five feet above the water, climbing up by means of the preopercular and anal spines. Another of the family (Macropodus pugnax) is trained by the Siamese 
to combat with members of its own species. Great tenacity of life is manifested by other members (Ophicephalus) of this family. The Mrugitide, or Mullets, which it is hardly necessary to distinguish from the Surmullets (INullidce), are of great dietetic value; the Atherines are frequent on the south coast of England; and the Notocanths have many isolated dorsal spines, and the coracoid bones are suspended to the vertebral column, and not to the head. The scomberoid fishes form a natural group. The Tunny is one of the largest known fishes in the sea, the larger individuals frequently weighing a thousand pounds. The Bonito of the Atlantic and the Pilot-fish (Naucrates ductor) have afforded subjects for the inventive faculties of sailors during the last two hundred years. All the vulgar narratives about the affection and relations between the Pilot-fish and the Shark are entirely imaginary. The Compphona Hipprurus is the Dolphin or Dorado of poets and sailors, and is celebrated for the beauty of its versatile tints. The Sword-fish (Xiphias) has an enormous prolongation of the premaxillary bones, which are firmly united with the maxillaries. The sword is of great length, and capable of being driven through a plank of immense thickness.

The family Squammipennes or Chætodonts have the softer and frequently also the spinous portions of the dorsal and anal fins covered with scales, which, as it were, encrust them and render their discrimination from the rest of the body by no means easy. This is the most obvious character of these fishes, of which the form in general is much compressed. The intestines are rather long, and the cxca numerous. The teeth are long, slender, and hairlike, and the species in general are alike remarkable for their singular forms and splendid 
colours. 'In some forms (Chelmon) the mouth is prolonged into a tubular snout. In the Dories (Zeidce) the fish have all protractile mouths. The form is compressed, and the body high in all the species. The Tæniodii or Ribbon-fishes, form a natural family, nearly allied to the Scomberoids. Species exist which are nine or ten feet long, yet not six inches high, and scarcely an inch thick. The texture of the bones is very delicate; the skin naked and silvery; the long dorsal often joined to the caudal ; the anal, when it exists, is similarly connected; the articulated fins for the most part simple; and soft rays of the ventral never exceed five, sometimes reduced to one or two, attached to the throat. The Teuthyoids are confined to the Indian and Pacific oceans. The Flute-mouths (Fistularia) have the nasal vomer, preopercula, interopercula, pterygoids, and tympanics in a long tube, with the mouth at the extremity, formed as usual of the premaxillaries, maxillaries, palatines, and mandible. The ribs are either short or wholly absent.

The Gobiioids are divided into two subordinate groups, the Gobies and the Blennies. Many of these are viviparous. In one species, the Lump-fish (Cyclopterus lumpus), the body is short and thick as well as high. The Blennies occur in almost the whole of the Northern Hemisphere, and occasionally on the shores of Australia and New Zealand. The Wolf-fish (Anarrhichas lupus) is of frequent occurrence in the northern seas; its ordinary length is from three to four feet; but examples sometimes occur of nearly double that size. The fore-teeth project considerably, and diverge a little from each other, forming a powerful weapon moved by jaws of such strength that a fish has been known to imprint the marks of its teeth upon a bar of iron. The 
Icelanders eat its disgustingly-tasted flesh, dry and salted.

The Anglers (Lophii) are the last family of acanthopterous fishes. The skeleton, though not hard, is fibrous. Scales are almost generally absent. In some genera bony tubercles, and in others small grains with spikes, exist. The ulna and radius are elongated into a kind of arm, whose fingers are represented by the rays of the pectoral. The head is excessively large in proportion to the rest of the body, very broad and depressed, and spinous in many places; the mouth deeply cleft, and armed with pointed teeth; the lower jaw furnished with numerous cirri; there are but three branchiæ on each side. It is asserted that these fishes live in the mud, where, by agitating the rays of their head, they attract smaller ones, who take the enlarged and fleshy extremities of those rays for worms, and thus become their victims. At the end of these rays is found the structure which answers to the nostrils in other fishes. This organ is supported on a membranous stalk, and when its summit is opened it spreads out like the cup of a flower. The bottom of this cup is divided into projecting leaflets, on which the olfactory nerve is distributed, after traversing the axis of the footstalk. The fish erects these stilted nostrils, and turns them towards any object whose odour it wishes to ascertain, much as a slug elongates its horns. Cheironectes is a closely allied fish, which possesses the faculty of distending its large membranous stomach with air, and swelling out the body like the Diodon. 


\section{Order 8.-ANACANTHINI.}

The endoskeleton is ossified; the exoskeleton in some has cycloid and in others ctenoid scales; the fins are supported by flexible many-jointed rays; the ventrals are beneath or in advance of the pectorals, or wanting; the swim-bladder when present is without a duct. There are three great families-the Ophididce, the Cods (Gadidre), and the Flatfish (Pleuronectidee). The Gadidee are a most important family, as the fish which is comprised within their limits are perhaps those which are largest consumed as food. The body is moderately elongated; the scales are small and soft; the head naked; there are no spines in the fins; the jaws and front of the vomer have pointed teeth of unequal height, producing cardlike or raduliform patches ; the branchiostegals are seven; there are one or more dorsal fins; the stomach is capacious and cæcal; the pancreatic cæca are numerous. There is a large air-bladder with strong walls, often denticulated at the sides; a large branch of the cæliac artery perforates the fibrous coat of the air-bladder, and divides itself into a dense vasoganglionic network. The common Cod (Gadus morrhua) is from two to three feet long, and occurs in vast profusion in the Northern Ocean. It feeds on smaller fishes, such as Herrings, Mollusca, Worms, and Crustacea. One female is said to contain from four to nine millions of eggs. The Haddock (Gadus crglefinus), the Whiting ( $G$. merlangus), the Hake ( $G$. merlucius), the Ling (G. molva), the Torsk (G. brosme), are common articles of diet in the British Isles. The gadoid family is scarcely known near the Equator, but reappears in the higher southern latitudes in the same generic forms, 
though differing in species from the Gadidx of the Northern Hemisphere.

The Echeneidae, or Remoras, have a flat head, occupied on the dorsal aspect by a laminated disk that forms an adhesive sucker, by which the Echeneis can attach itself to ships or to other fishes, most cornmonly to the large Sharks. The body is elongated, tapering much towards the tail, scaly; the mouth is small and horizontal. The most absurd legends have been written respecting the alleged power which the Remora possesses of staying the progress of a ship through the waves. The Pleuronectidce, or Flatfish, form another frequent and singularly formed type of anacanthine fish. They present a character which is perfectly unique amongst vertebrated animals; it is the total want of symmetry in the head, where both eyes are on one side, which always remains uppermost while the animal is swimming, and which is always deeply coloured, while that on which the eyes are wanting is always whitish. The remainder of the body, though, generally speaking, formed as usual, participates a little in this irregularity. Thus the two sides of the mouth are not equal, and the two pectorals are rarely so. The body is strongly compressed and vertically elevated; the dorsal extends along the whole back; the anal occupies the under part of the body, and almost seems to be continued forwards by the ventrals which are frequently united to it. There are six rays in the branchiæ. The abdominal cavity is small, but prolonged by a sinus which penetrates into the thickness of both sides of the tail, for the purpose of lodging a portion of the viscera. The natatory bladder is wanting, and they seldom quit the bottom. The cranium has both the orbits on one side; all the bones, how- 
ever, common to other fishes are found in it, but unequally proportioned. The asymmetry is reversible: thus individuals are now and then found whose eyes are placed on the side opposite to that in which they are generally seen. The Plaices (Platessa) have a range of obtuse teeth in each jaw, and generally teeth as if paved in the pharyngeals; the dorsal extends no farther than to above the upper eye; the form of these fishes is rhomboidal, and most of them have their eyes on the right side. The Plaice ( $P$. platess $)$, the Flounder ( $P$. Alesus), the Dab (P. limanda), are examples. The

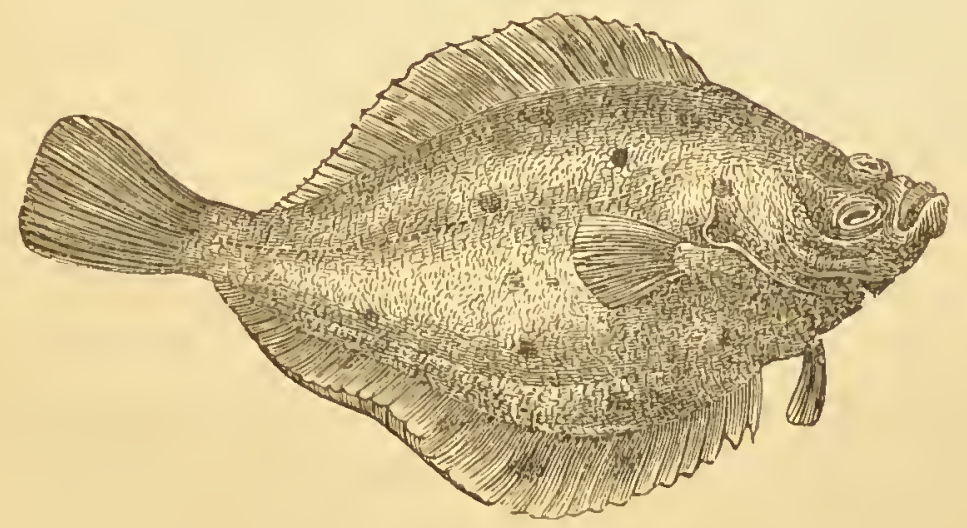

Holibut (Hippoglossus) have the shape and fins of a Plaice, with the jaws and pharynx armed with teeth, which are most commonly strong and pointed; the form is oblong. The Holibut attains a length of six or seven feet, and weighs from three to four hundred pounds. It is salted, dried, and sold in slices throughout the whole of the North. In the Turbots (Rhombus) the teeth are small and crowded, or like those of a card on the jaws and pharynx, as in Hippoglossus. The eyes of most are on the left side. In the Turbot (Rhombus maximus) the body is rhomboidal, and almost as high 
as it is long, the brown side studded with small tubercles. The Brill (Rhombus vulgaris) has the body more oval and without tubercles; it is distinguished by the first rays of the dorsal fin, which are half free, and split into thongs at the extremity. In the Soles, the mouth is twisted to the side opposite the eyes, and on that side only furnished with very minute and crowded teeth, the opposite one being toothless; the form is oblong; the snout rounded, and generally projecting beyond the mouth; the dorsal commencing at the mouth, and extending, as well as the anal, to the caudal; the lateral line is straight.

The Sole (Solea vulgaris), the lemon Sole (Solea pegusa), and many other species, are found principally in the Mediterranean.

\section{Order 9.-MaLacopteri.}

The skin in most has cycloid and in a few ganoid plates; it is rarely naked. The fins are supported by rays, all of which, save the first, in the dorsal and pectoral, in some are soft, or many-jointed; there is a swim-bladder and air-duct; peritoneal outlets in many. Such well-known types of fishes as the Eel, Herring, Salmon, Pike, and Carp are comprised in the order, which is divided into three minor groups- the Apodes, Pharynognathi, and Abdominales. The first vr Apodal order includes the Cuchia (Symbranchus), the Eel (Murcena), the Gymnotus. In this order the forms of the teeth vary greatly. In a few species they are mere grinding machines; in the majority long and slender and sharp for the retention of their prey; in others they are variously lobed, fine-edged cutting instru- 
ments. On these different kinds of dentition the genera and minor groups are formed. They have a thick and soft skin, which almost renders the scales invisible, and but few bones. They have no cæca, but nearly all of them possess natatory bladders, which frequently assume the most singular shapes.

The Murcena helena was a fish formerly very common in the Mediterranean, and much prized by the ancients, who fed it in ponds expressly constructed for that purpose. The true Eels (Anguilla), unlike the Mrurcena, have pectoral fins. There are three species known in England. In the Congers the dorsal begins close to the pectoral fin. The Conger is found in all the seas of Europe; it attains the length of five or six feet, and the thickness of a man's leg. It is not in much request for the table. The Gymnotidae differ from the. Eels in many essential points of their organisation. They have no scales, and are confined to South America. The most highly celebrated species is the Gymnotus electricus, which has been called the electrical Eel. It is from five to six feet long. The electric shocks given by it are subject to the will of the animal. By repetition of them the fish loses for a time the electric power; hence, in order to capture them more easily, wild horses are sometimes driven into the water and exposed to their first attacks.

The Clupeida, or Herrings, are so numerous, and many of them are so alike, that great confusion has existed amongst the species. The Herrings are recognised by having no adipose fin; the upper jaw is formed, as in the Trouts, by intermaxillaries without pedicles in the middle, and by the maxillaries on the sides; the body is always covered with numerous scales, and in the greater number we find a natatory 
bladder and many cæca. A part only of the family ascend rivers.

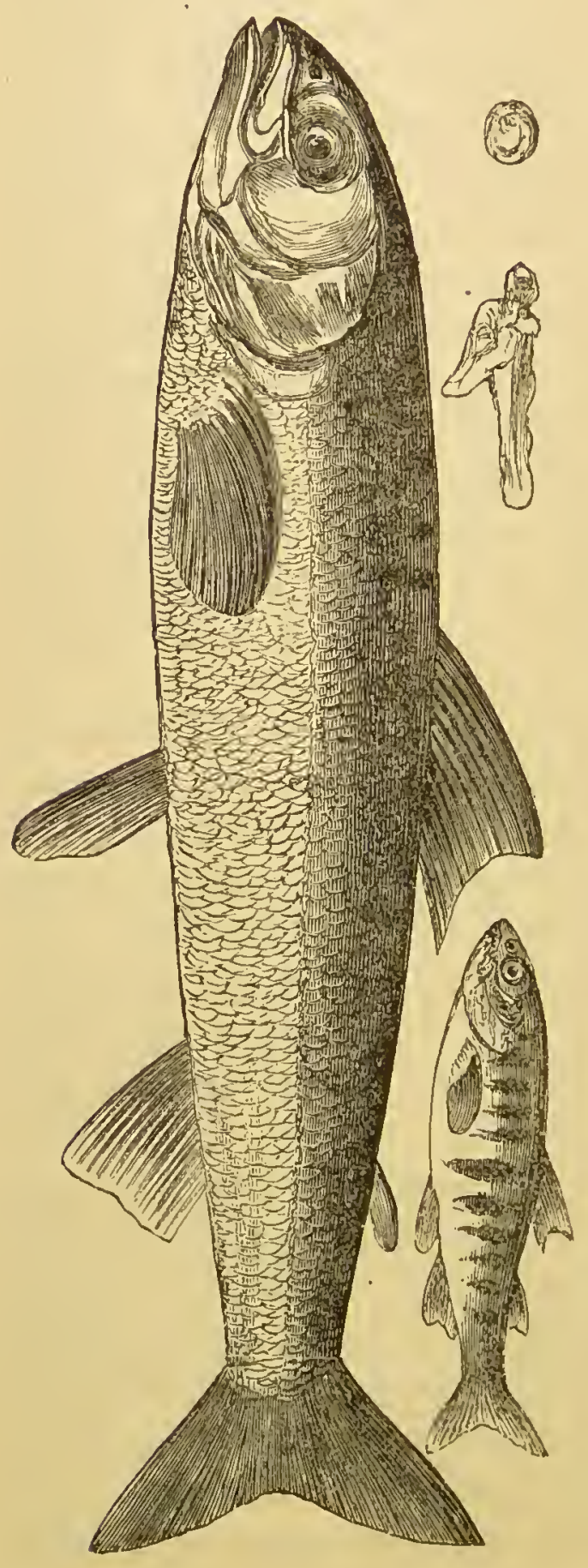

The Clupea barengus, or common Herring, the C. sprattus (Sprat), the C.latulus (Whitebait), the $C$. pilchardus (Pilchard), and the C. Sardina (Sardine) are familiar examples. The Shads $(A \operatorname{los} a)$ are distinguished by an emargination of the upper jaw. All the other characters are those of the Pilchard and Sardine. The Anchovies (Engraulis encrasicholus) are very plentiful in the Mediterranean, and are found on the coasts of Greenland, Jutland, and the Baltic ; they are occasionally caught in the Irish Channel.

The Salmons (Salmonida) form a separate and distinct family; very distinctly characterised by a scaly body, and a 
first dorsal with soft rays, followed by a second one small and adipose, that is to say, formed of skin filled with fat, and unsupported by rays. Nearly all of them ascend rivers. They are naturally voracious: the structure and armature of the jaws are singularly various. The S. salar (Salmon), S. trutta (Salmon Trout), S. fario (common Trout), S. salvelinus (Char), S. umbla (Ombre), are examples of the common English types of the family. The Smelt (Osmerus eperlanus), the Capeling (Mallotus villosus), and the Grayling (Thymallus vulgaris) are allied genera.

The Pikes (Esox), like the Carps, are destitute of the adipose fin; the edge of the upper jaw is formed by the intermaxillary, or at least when it is not quite so formed the maxillary is destitute of teeth, and concealed in the thickness of the lips. They are voracious; many of them ascend rivers; and their intestine is short and without cæca; they all have a natatory bladder. With the exception of the Microstomes, all those that are known have the dorsal opposite the anal. The common Pike (Esox lucius) is one of the most voracious and destructive of all fishes. The Garpikes (Belone) are remarkable for their colour, which is a beautiful green. The whole edge of the upper jaw as well as the lower one is extended into a long snout, formed by the intermaxillaries, both furnished with small teeth; wo others in the mouth. Another and very characteristic family of Malacopteri is that which comprises the Carps (Cyprinidx); these are recognised by the slightly cleft mouth, the weak jaws generally without teeth, and whose border is formed by the intermaxillaries; by the pharyngeals, which are supplied with strong teeth, and which compensate for the trifling armature of the jaws, and the small number of branchial rays. The body is 
scaly, the stomach and pylorus have no cæcum. Of all fishes they are the least carnivorous, and they are entirely restricted to fresh water. The common Carp (Cyprinus carpio) is of an olive green colour, and was introduced into England in 1614. In the ovaria of the Carp as many as seven hundred thousand eggs have been found.

The Gold-fish (Cyprinus auratus), the Barbel ( $C$. barbus), (xudgeon (C.gobus), Tench (C. tinca), Bream (C. abramis), Dace (C. leuciscus), Minnow (C. phoximus), Roach (C. rutilus), Bleak (C. alburnus), Loach (C. cobitis), form frequent English examples of one of the cummonest orders of Malacopteri.

\section{Order 10.-Cxclostomi.}

The body is cylindrical; the heart distinct; the branchial cavity has no bulb; the branchiæ are sacciform, with external spiracles, six or seven on each side, blood red; the mouth is subcircular, suctorial, but longitudinal when closed; the olfactory sac communicates with or is produced into a canal. The species best known (Myxine glutinosa, or glutinous Hag) was classed by Linnæus among the Vermes. The mouth is a membranous ring, with a single tooth on its superior part; while the strong teeth of the tongue are arranged in two rows on each side, so as to give to these animals the appearance of having lateral jaws like insects. Their tongue performs the office of a piston in exhausting the mouth, so as to enable them to adhere to other bodies, like the Lamprey; the lips are furnished with eight cirri, and above is a spout-hole communicating with the mouth: the body is nearly cylindrical, and terminates in a fin which surrounds the 
tail; the intestine is simple and straight as viewed externally, but plaited within; the liver has two lobes; the eggs grow to a considerable size. So large an amount of mucus is contained in the lateral pores of the animal, that when taken and confined in a glass jar the poured-out substance gives the water the appearance of jelly. The Sandlaunce (Ammocretes) has the body cylindrical, with numerous annular lines about it, that give it much the appearance of a worm. It lives in the mud of rivers. The mouth is incapable of adhering by suction to other bodies; the fins are very shallow, and the tail sharp at the tip. The $A$. branchialis grows to six or eight inches long, and is as thick as a goosequill. The Lampreys (Petromyzon) have tongues which act llike pistons in the circular mouth, and are capable of ivigorous motion, being the mechanism by which the fish is enabled to attach itself more firmly to stones or t to fasten itself to the other fishes. The maxillary ring is armed with strong teeth, and the interior disk of the 1 lip, which is very circular, is furnished with an extremely thard shell, and similar ito teeth. This ring is suspended under a transverse plate which appears to supply the want of intermaxillaries, and on the sides of which vesiges of maxillaries may

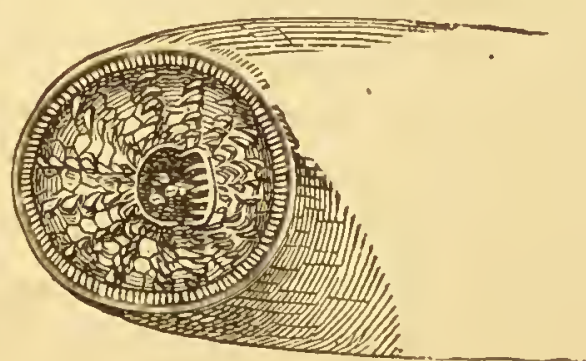

Mouth of Lamprey. ve observed. There are two longitudinal rows of mall teeth on the tongue, which moves backwards and forwards like a piston; by this the suction is mroduced which distinguishes the animal. Water eaches the branchia from the mouth by a particular nembranous canal, placed under the œsophagus, and 
perforated with holes that may be compared to a trachia. The Lampreys habitually fix themselves by suction to stones and other solid bodies; they attack the largest fishes in the same way, and are finally able to pierce and devour them. The Lampreys, or Lamperus, ascend the mouths of rivers in the spring, and are highly esteemed. The greater Lamprey grows to the length of more than three feet. It is common in the Severn, and has been alleged to be hermaphrodite. The P. fuviatilis, or Lampern, is in length from twelve to eighteen inches; olive back, silvery below; the first dorsal is distinct from the second. There are two thick teeth separate in the top of the maxillary ring. It is very tenacious of life, and will live many days out of water. The gills of Lampreys and Myxines are little bags, each of which has its proper artery and its proper orifice in the pharynx, through which the water flows in to pass out on the dermal side by another hole. These purse-shaped bags are called fixed lungs, in contradistinction to the gills of osseous fishes, whose exterior edges are free and pectinated; but Professor Owen has observed that if one of the sacs were adherent to the adjacent side of another, and then each ray slit open and detached from the outer integument, a gill would be formed receiving its blood from two arterial branches, and resembling were it pectinated the gill of an osseous fish. Seven genera of fish allied to the Lampreys are known.

\section{Order 11.-Cirrostomi.}

The body is compressed; the mouth is a longitudinal figure with subrigid cirri on each side; there are 
pulsating vessels or sinuses in place of a heart; the blood is pale; there are free pharyngeal branchial filaments and a branchial dilatation of the cesophagus; the respiratory processes project from above the pharynx into the large cavity of the mouth. Only one genus is known, the Branchiostoma, or Amphioxus. Pallas described this as a Limax or Slug, but its structure was shown by $\mathrm{O}$ wen and others to be truly piscine. The longitudinal slit forming the orifice of the mouth resembles that of the Lamprey, the labial feelers appearing like movable teeth.. It is a thin transparent creature, about an inch and a half long, not possessing jaws, but having a large buccal cavity into which the short vascular processes that perform the function of gills project freely without cartilaginous supports or lateral attachments. The buccal cavity communicates by a small pharyngeal opening with a wide barrelshaped œsophagus, which occupies more than a fourth of the whole length of the fish, and whose under surface is ciliated throughout, and organised to assist in respiration. Vessels that ramify over its vertical ciliated bands communicate with the dorsal and ventral portions of the vascular trunk that carries on the circulation, without the intervention of a central propelling organ. There is behind the posterior end of the expanded œsophagus a small widening of the circumferential vessel, which pulsates rhythmically, and which Professor Owen considers to be a rudimental representative of the branchial heart of the Myxinoids, the next order of fishes in organisation. The Lancelot has no ganglionic brain, and consequently the protecting integuments which cover the head and the cavities which make sense capsules in the higher vertebrates are not developed. The only cartilaginous part of the 
fish is a jointed hæmal arch, which extends from the anterior end of the spinal chord on the ventral aspect to the orifice of the pharynx, and serves to support the oral filaments. This represents the labial arch of the higher Myxinoids. The intestine proceeding from the esophagual bag is slender, almost straight, and terminates at the anus. There are four species, at least, known from Europe to West Indies, Peru, and Borneo. 


\section{Sub-Kingdom-MOLLUSCA.}

THE name Mollusca was applied by Cuvier to the 1 great primary division of the animal kingdom which includes all species having a gangliated nervous system, with the ganglions or medullary masses disposed more or less irregularly in different parts of the body, which is soft and inarticulate. The pulmonary or branchial circulation is separate and distinct, but it is aided by the direct propulsion of a heart in one class only. There is always a heart for the systemic circulation,
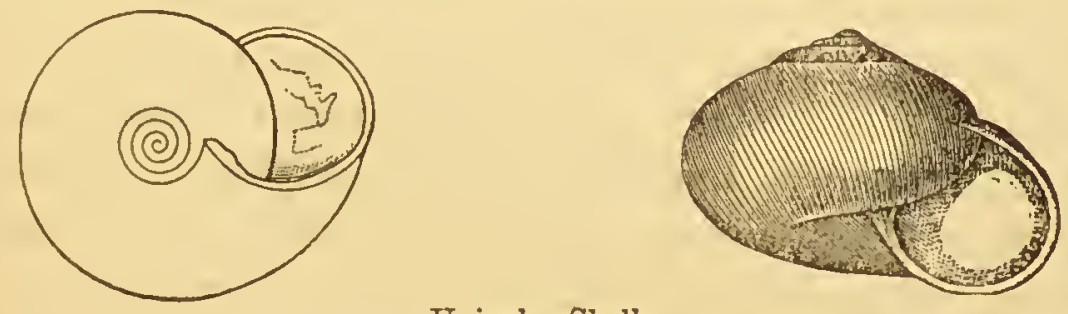

Univalve Shell.

and it mostly consists of one ventricle and one auricle. Some of the molluses breathe air, but the greater part respire through the medium of salt or fresh water. The blood is white or bluish. In one class only is there a rudiment of an internal skeleton, giving attachment to a part of the muscular system; in the rest it is absent, and the muscles are attached to various points of the skin. The contractions produce inflexions and extensions of their different parts, and alternating with relaxations enable the species to creep, climb, 
swim, burrow, and seize upon various objects as the form of those parts may permit; but, as the locomotive organs are not supported by articulated and solid limbs, the molluscs cannot leap or advance rapidly on dry land. Many of the aquatic species are encumbered with a heavy shell. Nearly all the molluscs have an extensive fold of skin reflected over their body, which it covers like a mantle; it is sometimes produced into a breathing-pipe, or extended and divided in the form of fins. When the mantle is simply membranous or fleshy, and when a horny or testaceous rudiment of a shell is developed, but remains concealed in the substance of the mantle, the mollusc is said to be naked. When the shell is so much enlarged that the contracted animal finds shelter beneath or within it, the animal is said to be testaceous. The masticatory or oral organs present all the various modifications for predatory, omnivorous, or herbivorous habits; and the stomach may be simple, multiple, or complicated with a peculiar armature. Some are unisexual, others androgynous, a few dioecious. The science which describes the animals which belong to the sub-kingdom Mollusca is termed Malacology, and that which gives an account of the external or internal shells, Conchology. The definitions of the latter science were fixed by Linnæus, and have been continued by succeeding authors with more or less degree of complication. The development, structure, configuration, and physiological subserviences of shells demand careful consideration. The formation of a shell commences with the exudation of layers of albumen from the outer service of the mantle or skin of the embryo mollusc, which is generally followed by the admixture of particles of carbonate of lime. This firstformed shell of the embryo constitutes the nucleus of 
the shell of the naked mollusc. This is developed in most cases before the embryo quits the egg-covering, but is never coeval with the first formation of the animal; it is preceded by several distinct stages in the development of the embryo. The subsequent growth of the shell depends upon the deposition of fresh layers to the inner surface of the circumference of those previously formed, beyond which the new-formed layers extend in proportions which determine the figure of the future shell. Sometimes the calcifying margin of the mantle extends outwards at an obtuse or right angle to the last-formed margin of the shell, and after having deposited a calcareous plate in this position is retracted and absorbed, to be again similarly produced and extended after ordinary growth has proceeded to a certain extent. It is to this periodical growth of the mantle, and the plethoric condition of the calcifying vessels, that the ridges on the exterior of the shell in the Venus plicata among bivalves, and in the Scalaria pretiosa among univalves, are due. Should the mantle, instead of being uniformly extended, send outwards a number of detached tentaculiform calcifying processes, these will form a row of spines corresponding in length and thickness to the soft parts on which they are moulded; and as the calcifying processes continue to deposit shelly material during the progress of their absorption, the spines, which were at first hollow, thus become solidified, and are soldered to the margin of the shell. This development of calcifying processes or filaments of the mantle and spines may likewise alternate with periods of the ordinary formation of the shell; and thus the exterior of the shell may become bristled with rows of spines, as in some species of Spondylus, and in the Mruex crassispina. 
The most simple form of shell is the cone, which may be much depressed, as in the genus Umbrella, or extremely elevated or contracted, as in the Dentalium, or of more ordinary proportions, as in the Limpets. The apex of the cone is oblique and excentric, direeted towards the head in the Limpets, the Argonaut, and the Nautilus, but in most other molluses towards the other extremity of the body. A shell may consist of one piece, as in the inopercular univalves; or of two pieces, as in the opercular univalves and most bivalves; or of three pieces, as in Terebratula; or of four or more pieces, as in some of the Pholades and the multivalves proper, or Chitons. With respect to the operculum, this part is sometimes calcareous, but it consists frequently of albuminous membrane only, or is horny, thus presenting the condition which the univalve shell itself presents in certain genera, as Aplysia, Loligo, \&c.

The conical univalve shell is generally spirally convoluted, sometimes, as in the Nautilus, in the same plane, more usually in an oblique direction. As a general rule, the spiral univalve, if viewed in the position in which its inhabitant would carry it if it were moving forwards from the observer, is twisted from the apex downward from left to right, the spire being directed obliquely towards the right. In certain genera, as Clausitia, Physa, the shell is twisted in the opposite direction; such shells are called perverse, or sinistral. Some species of Butimus, Partula, and Pupa are sinistral, and a few marine shells, as Fusus reversus, also exhibit the reverse of the ordinary disposition of the spire. The part around which the spiral cone is wound is termed the columella. This is sometimes simple, sometimes plicated, as in the Voluta musica; it is also sometimes solid, sometimes hollow; when the 
latter its aperture is termed the umbilicus. The opening forming the base of the spiral univalve is bounded by an inner lip and an outer lip; the inner lip offers a smooth convex surface, over which the foot or locomotive disc of the mollusc glides to reach the ground. In many univalves the aperture of the shell is entire; in others it is broken by a notch or perforated by one or more holes, or a portion of it is produced into a canal or siphon, or it may present a pallial notch opposite to the siphon. These modifications are important on account of the constancy of their relations to certain conditions of the respiratory organs; thus the conchologist, in grouping together all the spiral univalve shells, of which a part of the margin was either notched or produced into a grooved siphon, would really indicate a very natural tribe of Mollusca, every species of which, he might be assured, was aquatic and marine, and breathed by means of two gills having a pectinated structure, to which the water is conducted by a fleshy tube. Were a like correlation between the shell and its inhabitant to hold good in other families of Mollusca, the classification of shells would then be a subject of much importance, and worthy the attention of the scientific naturalist. Unfortunately the reverse of this is frequently the case. The part called the operculim, which is present in certain univalve molluscs, is a plate consisting of layers of sometimes calcified, sometimes uncalcified albumen, attached to a disc at the back part of the foot, and forming, when this is retracted, a more or less perfect defence to the outlet of the shell. Some opercula increase by the addition of matter to their entire circumference, and these are either concentric, as in Bithynia and Paludina, or excentric, as in Ampullaria and most of the pectinibranchiate molluscs; 
other opercula grow by the addition of matter to part of their circumference, and these are either spiral or imbricated, in the latter the layers of growth succeed each other in a linear series. No operculum presents an annular form. As the operculum sometimes varies in structure in species of the same genus, as e.g. of Vermetus; as, moreover, this part is inconstant even as to its presence in species of the same genus, as in the Volutes, Cones, Mitres, and Olives; and as some genera in a natural family, as Harpa and Dolium among the Buccinoids, are without an operculum, while the other genera of the same family possess that appendage;-it obviously affords characters of very secondary importance in a scientific classification of the univalve Mollusca. Much confusion, indeed, might have been introduced into the science of Malacology if the opinions of those conchologists who have proposed to classify shells from the modifications of the operculum had been much respected by naturalists. True bivalve shells are peculiar to the acephalous Mollusca, and their presence is constant, although they are in a few instances too small to cover the whole of the body, and in the Ship-borers exist only as small instruments, limited to the function of excavating the burrows inhabited by these molluses. But all the species in which the bivalve shell is inadequate to the protection of the whole body derive extensive defence by burrowing in sand, or stone, or wood; and they also commonly line their burrows with a layer of smooth and compact calcareous matter, forming a tube. This calcareous tube, in some cases, is of considerable size and thickness, as in the Teredo gigantea or Septaria of Lamarck. In the Clavagella one valve, and in the Aspergillum both valves, are soldered to this tube, which in the 
latter presents a peculiar modification of its exposed extremity, which resembles the end of the spout of a watering-pot. No two shells can present a greater contrast than do those of the Placuna and Aspergillum, yet the organisation of their respective constructors is essentially the same. In a classification of shells, the calcareous tubes of the Dentalium, Serpula, Aspergillum, Vermetus, \&c., would be associated in the same general group; but we need only to observe how these products of animals, belonging not only to different classes but to distinct primary divisions of the animal kingdom, are arranged in the cabinets of collectors, to be convinced that Conchology as a classificatory science apart from Malacology no longer exists. With regard to the structure and physiological relations of bivalve shells, it may be observed, first, that in all acephalous Mollusca which breathe by distinctly developed lamellated gills, one valve corresponds to the left, the other to the right side of the animal; but in the brachiopodous bivalves, one valve is applied to the ventral and the other to the dorsal aspect of the animal.

In all the lamellibranchiate bivalves which are free, the two valves are symmetrical, and the shell is termed equivalve; in all those which adhere by one of their valves to foreign bodies-this valve is deeper and larger than the unattached valve-such shells are termed inequivalve. Of those Acephalans which are attached to foreign bodies by means of a byssus, some, as Tridacna, Saxicava, and Byssoarca, are equivalve, and both valves are notched, to form the hole for the passage of the byssus; while others, as the Pectines, Aviculce, and Peda, are inequivalve, the byssus passing. through a groove in the right valve.

Linnæus, who first introduced precision into the 
description of shells, defined several points requisite to be noticed in the outer and inner surface of a bivalve shell; but the epithets which his comparison of the bivalve selected for illustration induced him to attach to those parts have been abandoned and changed. If the shell of the common cockle be examined, each valve will be seen to be produced into a conical prominence bent towards and nearly meeting at that part by which the valves are joined together. These prominences are termed the umbones. The apex or beak of the umbo corresponds to the apex of the univalve shell, and is the point at which the development of the apex commences. When the apex is directed in the transverse plane of the shell, and so placed that a bisection of the shell in that plane through the apices shall divide the valve into two equal parts, the shell is termed equilateral; of this form the common scallop is an example. When, upon a similar division, a slight difference is observed in the two valves, the shell is termed subequilateral; but where the difference is well marked, it is an inequilateral bivalve. When the apex is bent, as is commonly the case, out of the transverse plane, it is always directed more or less towards the anterior part of the shell. If such a bivalve shell as a Cytherea or Isocardia be held before the observer, with the umbones directed forwards and the hinge above-in the position, in fact, in which the living animal would place itself if it were creeping forwards from the observerthe right valve will of course correspond with the right hand of the observer, and the left with the left.

Now, if a bivalve in which the apices hare a spiral twist, as an Isocardia or Diceras, be placed in the above position, and compared with the univalve shell of a Concholepas or Purpura, it will be seen that the left 
valve corresponds with the ordinary or dextral spiral univalve, and the right valve to the perverse or sinistral univalve. Instances, however, have been met with where the characters of the valves of the bivalve were reversed, like the occasional exceptions in the perverse sinistral univalve before mentioned. When the circumference or margin of one valve fits exactly at every part to that of its fellow, it is said to be regular or entire; but if it be notched at any part so as not to come into contact with the corresponding part of the opposite valve, it is irregular or emarginate. With respect to the outer surface of a bivalve, the parts called umbones and apices have already been defined, and the upper or dorsal and anterior margins of the valve determined. If we continue our examination of the exterior surface of the bivalve, we shall find in most cases anterior to the apices a depression of variable extent and depth. This is the lunule; it may be cordiform or crescentic, lanceolate, oval, oblong, deep, superficial, \&c. Behind the apices is another depression, longer and narrower than the lunule, and which is called the fissure, and its margins lips. Behind the fissure there is sometimes a small depression, called the suture. The general more or less corrvex surface of each valve is called the venter, or belly, which terminates in the limb, circumference, or margin.

The most important part of the margin is that which is medified to form the joint or hinge upon which the two valves open and shut. This part is called the cardinal edge, and generally presents certain prominences and depressions, the projections of one valve interlocking with the depressions of the other. The projections or teeth, together with the cavities or cardinal pits, are very regular in their formation in each 
genus and species of bivalve. What is of more importance is, that every modification in the structure of the hinge is generally found to coincide with some recognisable and more or less important difference in the organization of the soft parts; so that conchologists have justly attached great value to the characters derivable from the hinge, especially for the purpose of generic distinctions. When the teeth are situated be. neath the apex, or centre of the hinge, they are called cardinal; when they are removed from the centre of the hinge, they are named lateral teeth; when two only are present, one is called anterior, the other posterior; when there are three, they are distinguished respectively as the anterior, medium, and posterior teeth; but when the hinge is composed of a great number of teeth, it is said to be serial, as in Arca. The direct medium of union of the two valves is a dense fasciculus of elastic albuminous fibres, generally of a brown colour, called the ligament, or elastic ligament. The fibres of this part are attached by their extremities to the two valves, which in most cases present a particular surface for their reception. The ligament is always so long as to prevent the actual closing of the valves, except when its elasticity is overcome by a certain force, as by that of the contraction of the adductor muscle or muscles. Thus the inorganic power of elasticity is made the direct antagonist of a vital and muscular contraction, and as the patent condition of the bivalve shell is that which the exigences of the animal most constantly require, it is assigned to a force which can act without ever causing fatigue, while the occasional or protective action of forcibly closing the valves is due to an action under the immediate control of the will or instinctive sensation. The modifications 
of the internal surface of a bivalve shell are, perhaps, the most interesting and important, as they relate immediately to the structure of the soft parts, and bespeak the general nature of the organization of the animal. Hence they afford the characters by which the habits and structure of an extinct genus may be, to a great extent, determined. The adductor muscles leave wellmarked impressions on the inner surface. If there be but one muscular impression on a valve, then it belongs to monomyary or unimuscular bivalve; and if neither valve of a fossil shell presenting this character has been immediately attached to foreign bodies, then the laws of coexistence warrant the inference that the constructor of such a bivalve possessed a byssus and the muscular organ called the foot, but that the foot was developed only to the extent adapted to serve as an instrument for moulding the soft fibres and regulating the attachment of the byssus. If each valve of a bivalve shell exhibit two muscular impressions, it proves the species to be dimyary or bimuscular; if, moreover, there be a thin, small muscular depression beneath the cardinal hinge, we have then an indication that the animal possessed a large foot, organized to serve as a locomotive or burrowing fleshy organ, the retractive muscle of which was inserted in the above depression. The line continued between the impressions of the two adductors indicates by its depth and breadth the development of the muscular margin of the mantle, and is called the pallial impression. If this line be continued uninterruptedly parallel with the margin of the ivalve, we may be assured that the animal was either' without siphons or had them of very small size; but if the pallial line be broken by an angular notch continued inwards before its junction with the posterior 
muscular impression, then it may be certainly inferred that the animal had well-developed muscular tubes, or siphons, for respiration, with all the concomitant powers and habits. Thus the general organization of the soft and perishable fabricator of a bivalve shell may be as certainly determined by the evidence of its fossilized enduring case, as that of a vertebrate species by the structure of its skeleton. The more immediate affinities of the bivalve are revealed by the modifications of the hinge.

It sometimes happens, however, that the whole of the internal or nacreous stratum of a fossil bivalve shell is destroyed, especially if it have been embedded in porous chalk; and as the muscular impressions and the articular structure of the hinge are composed exclusively of the inner stratum of the shell, the means of determining the nature and affinities of the animal in that case are lost; and unless the observer were acquainted with the texture and structure of the bivalve shell, he would run the risk of mistaking the part of a decomposed bivalve for the whole of some nondescript acardian species, as those bivalves are termed in which the hinge is naturally wanting.

The classification of Mollusca adopted by Professor Owen and other writers is into the following six orders: Cephalopoda, Gasteropoda, Pteropoda, Lamellibranchiata, Brachiopoda, and Tunicata. For detailed reference to the minute anatomy of these orders, reference must be made to Dr. S. P. Woodward's "Manual of Mollusca." The position of the Tunicata in the molluscan series has been much controverted. They are, however, retained in this place, whilst the Bryozoa or Polyzoa are associated with the Radiate sub-kingdom, in conformity with the practice of the elder school of zoologists. 


\section{Crass I.-CEPHALOPODA.}

\section{FNCEPHALOUS molluscs, with locomotive and pre- hensile organs radiating from the head; diœcious}

and ametabolian. The animal is chiefly divided into a somatal and a pallial portion. The former is chiefly muscular. It contains the organs of sense, mastication, and digestion, and supports the organs of prehension and the chief powers of locomotion. It is called the head. The pallial division, termed trunk or abdomen, consists of a more or less muscular sac or mantle, with a transverse anterior process, from which an expiratory sac or funnel projects, and it contains the respiratory, generative, and digestive organs. The branchiæ are pinnatified and concealed; the sexes distinct. All Cephalopods are oriparous. As far as observation has extended, a part only of the yolk has assim:lated into a germ mass; and development is progressive, without metamorphosis, to the completion of the minute Cephalopod in the egg. Two orders of Cephalopoda exist, one with four and one with two pairs of gills.

In the Tetrabranchiata the branchiæ are in two pairs, without branchial hearts; the funnel is formed by a convolute muscular plate; the mantle is thin and feebly muscular; there is no ink-bag; the arms are very numerous, hollow, and with retractile tentacula; the mandibles have calcareous tips; the eyes are pedunculate; the bead retractile, within a shell which is ex- 
ternal, many-chambered, siphunculate, the outer layers porcellaneous, the inner layers and partitions nacreous. The Nautilus may be taken as a type of this order. The shell is divided into tubes and chambers by a series of partitions (septa), or by a tube or siphuncle. The last chamber only is occupied by the animal; the others are probably occupied in succession. They are empty during life; but in fossil specimens they are often filled with spar. In the recent Nautili the shell is smooth; but in many fossil species it is corrugated, like the patent iron roofing so remarkable for its strength and lightness. There are three or four species known to exist, and about one hundred and eighty-eight species fossil. The fossil Lituites and Orthoceras were often of extremely large size, and were characteristic of the Silurian and Lower Silurian deposits. In the Ammonites, the body chamber of the shell was elongated, the aperture was guarded by processes, and closed by an operculum; the sutnres are elongated or lobed and foliated; and the siphuncle was external, dorsal as regards the shell. More than eight hundred species of Ammonites are known, ranging from the Trias to the Chalk inclusive, and with many allied genera. The shell has an external porcellaneous layer, formed by the collar of the mantle only, and of an internal nacreous lining, deposited by the whole extent of its visceral surface. They vary from the size of a bean to that of a coach-wheel. Their name is derived from their resemblance to the horns upon the statue of Jupiter Ammon. They are called Cormu Ammonis and, vulgarly, Snakestones.

In the dibranchiate Cephalopods, the animal is swimming, naked, the head distinct, the eyes sepile and prominent, the mandible horny ; the arms eight or ten: 
provided with suckers; the body round or elongated, usually with a pair of fins; there are two branchiæ, furnished with muscular ventricles; the ink-gland is always present, and the funnel is a complete tube; the shell is internal, except in Argonauta, horny or shelly, with or without air-chambers. The shell of the Argonaut does not correspond with the ordinary shell of molluscs. Besides the two gills, this order has other modes of defence than an external shell would have afforded, viz. powerful arms furnished with suckers, the secretion of an inky fluid with which to cloud the water and conceal retreat, more perfect organs of vision, and superadded branchial hearts, which render the circulation more vigorous. The suckers are in a single or double series on the inner surface of the arms. From the margin of each cup the muscular fibres converge to the centre, where they leave a circular cavity, occupied by a soft caruncle rising from it like the piston of a syringe, and capable of retraction when the sucker is applied to any surface. So perfect is this mechanism for effecting adhesion, that while the muscular fibres continue retracted it is easier to tear away the limb than to detach it from its hold. The ink-bag is tough and fibrous; the ink was formerly used for writing, and in the preparation of the genuine sepia. From its indestructible character it is often found in a fossil state. The skin of the naked Cephalopoda has variously coloured vesicles or pigment-cells, which contract or expand, by which the colouring matter is condensed, dispersed, or driven into the deeper part of the skin. The colour accumulates like a blush when the skin is irritated, even some hours after separation from the body. During life these changes are under the control of the animal. 
The sole locomotive organs in the ordinary octopod, and the sole prehensile organs in all the Dibrancliata, are the appendages termed arms, feet, and tentacles. They have no true homology with the locomotive members of the Vertebrata, but are analogous to them, inasmuch as they relate to the locomotive and prehensile faculties of the animal. The mantle is usually connected at the back of the head by a broad "nuchal" muscular band; but its margin is sometimes free all round, and it is supported only by cartilaginous ridges, fitting into corresponding grooves, and allowing considerable freedom of motion. The Cuttle-fishes are generally nocturnal or crepuscular animals, concealing themselves during the day or returning to a lower region of the water. They inhabit every zone, and are met with near the shore, as well as in the open sea, hundreds of miles from land. They attain occasionally a greater size than any other Mollusca. MM. Quoy and Gaimard found a dead Cuttle-fish in the Atlantic, under the equator, which must have weighed two hundredweights when perfect; it was floating on the surface, and partially devoured by birds. Banks and Solander also met with one in the Pacific, which was stated to have been six feet in length. The arms of the octopods are sometimes two feet long. It is difficult to capture some species alive, but they are frequently found in an uninjured state in the stomach of Dolphins. The most peculiar structure in the Cuttle-fishes is what has been termed the hectocotylus, which is a peculiar appearance and enlargement of one of the eight arms in the male, fitting it for the purpose of helping forward the reproduction of the species. In many cases it is so altered as to be incapable of being used as a locomotive organ. This detached arm was 
formerly mistaken for a parasitic worm; it is now regarded as the spermatophore of the male animal, presenting an analogous phenomenon to what occurs in some species of Spiders, in which certain parts of the palpi of the males are developed into spoon-shaped organs which perform the same office as the hectocotylus. There are two sections of dibranchiate Cephalopods; one, those with eight feet (Octopoda), and one with ten feet (Decapoda). The former comprises the ordinary Poulpes and Argonauts; the latter the other varieties of Cuttle-fish. In the Argonauts or Paper-sailor's, the dorsal arms of the female are webbed at the extremity, secreting a symmetrical involuted shell. The third left arm in the male is hectocotylized, colourless, developed in a sac. The female is polyandrous, and the mantle is supported in front by a single ridge as a funnel. The Nautilus of the Greeks, it is now hardly necessary to say, does not use its arms as suils, but sometimes as oars, when it wishes to progress slowly while floating on the surface of the water. Four species of Argonaut are known. They inhabit the open sea throughout the warmer parts of the world, and are most active during the night.

In the Octopodidoe the arms are similarly, elongated, united at the base by a web, while the shell is represented by two short styles encysted in the substance of the mantle. These are the "polypi" of the Greek zoologists. They are solitary animals, frequenting rocky shores, and are very active and voracious; the females lay their eggs on seaweeds or in the cavities of empty shells. They are universally known on the coasts of the temperate and tropical zones, and vary in length from one inch to two feet.

The Decapoda have eight true arms, and two elon- 


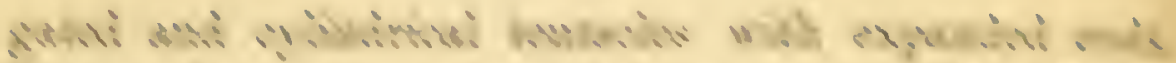

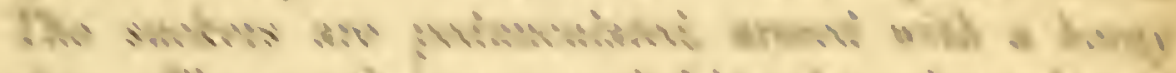

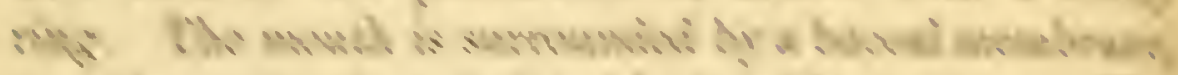

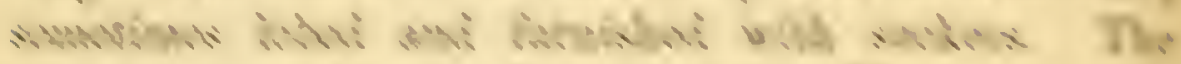

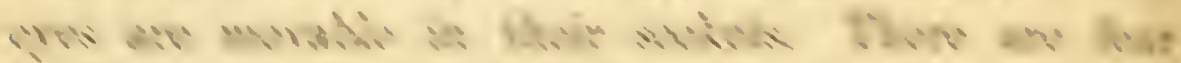

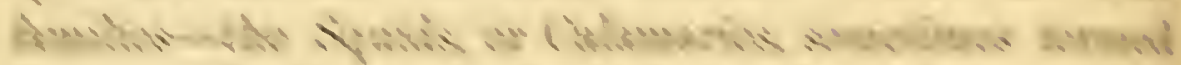

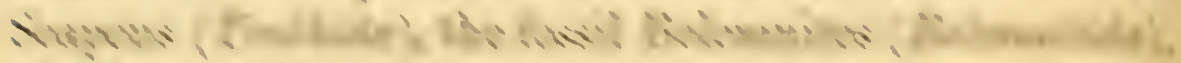

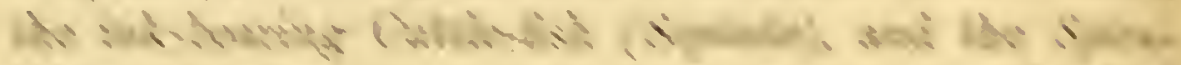

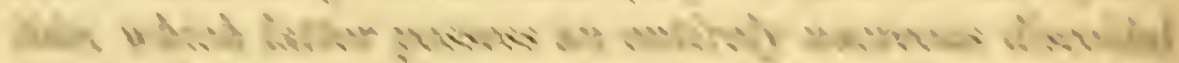

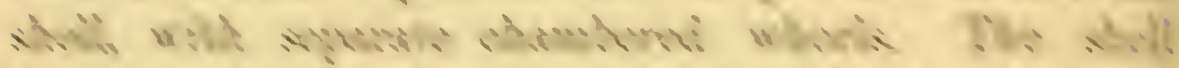

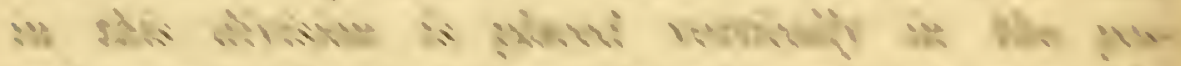

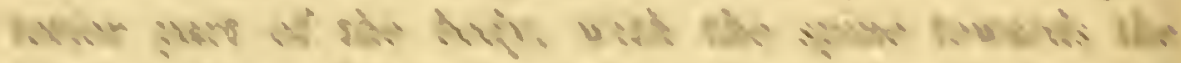

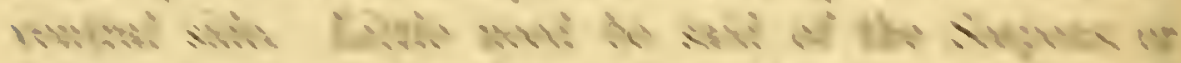

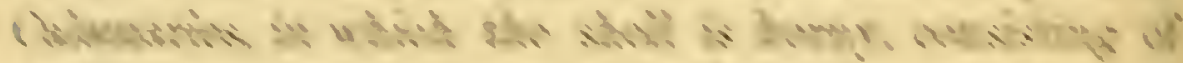

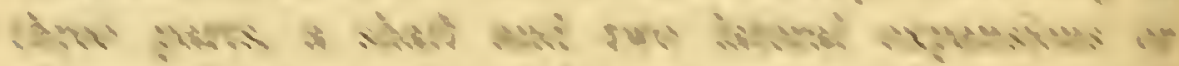
why

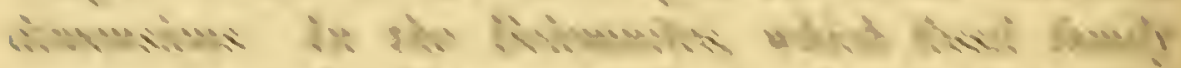

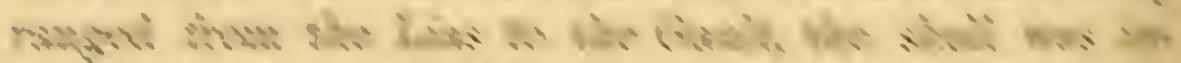

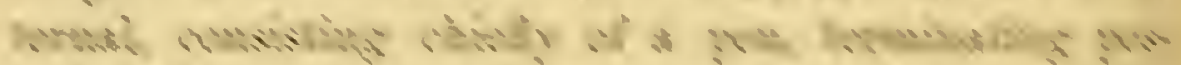

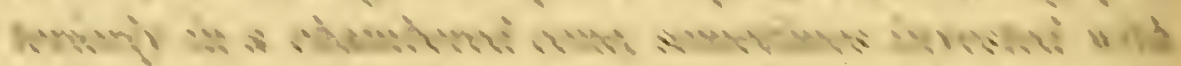

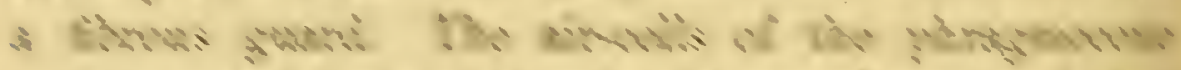

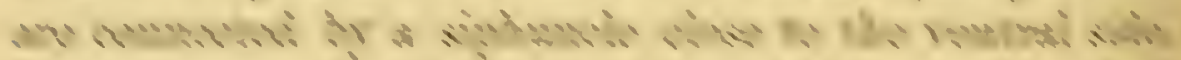

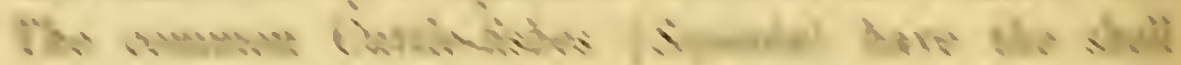

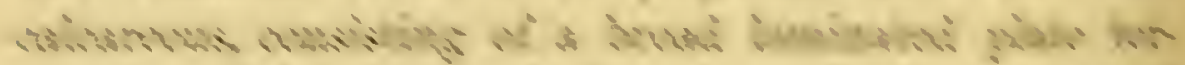

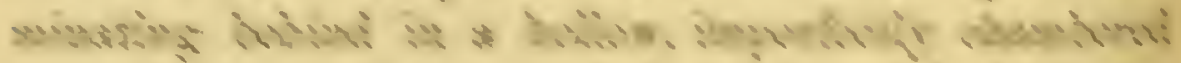

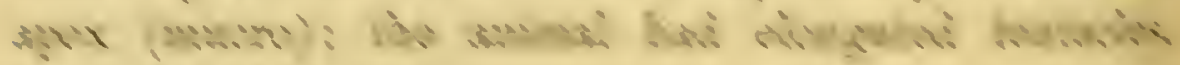

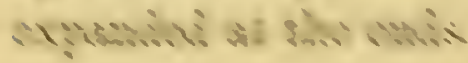




\section{Class II.-GASTEROPODA.}

THIS class comprehends those which have a ventral 1 muscular disc of greater or less extent adapted for creeping. The class is divided into several orders, according to the various constitutions of the branchial organs. The orders Pectinibranchiata, Scutibranchiata, Pulmonifera, Tectibranchiata, and Nucleobranchiata, are here included. Most Gasteropods are marine; some inhabit fresh waters; a few are terrestrial; a few species are ovoviviparous; most Gasteropods are oviparous. The young of the water-breathing Pulmonifera are excluded with a protecting operculated shell, which in the naked species is either shed or concealed by a fold of the mantle. They swim by means of a pair of ciliated fins attached to the sides of the head, and thus move far away from their parents. The shell is produced from the metamorphosis and calcification of cells deposited in layers beneath the epidermis, in the situation of the rete mucosum in the human integument. The order Pectinibranchiata have the abdomen well developed and protected by a shell, into which the whole animal can usually retire. The mantle forms a vaulted chamber over the back of the head, in which the excretory orifices are placed, and in which the branchir are almost always lodged. The branchiæ are pectinated or plumlike, situated in advance of the heart. This order includes two broad divisions, the Siphonostoma (Zoophaga) and the Holostomata (Phytophaga). 
The Siphonostomata, or carnivorous Gasteropods, have the shell spiral, usually imperforate, the aperture is notched or produced into a canal in front. The operculum is horny and lamellar. Most of the section are canivorous. The margin of the mantle is produced into a siphon, by which water is conveyed into the branchial chamber. The Strombidce form an important family, in which the animal has large eyes, placed on thick pedicles; the tentacles are slender, and rise from the middle of the eye pedicles; the foot is narrow, ill-

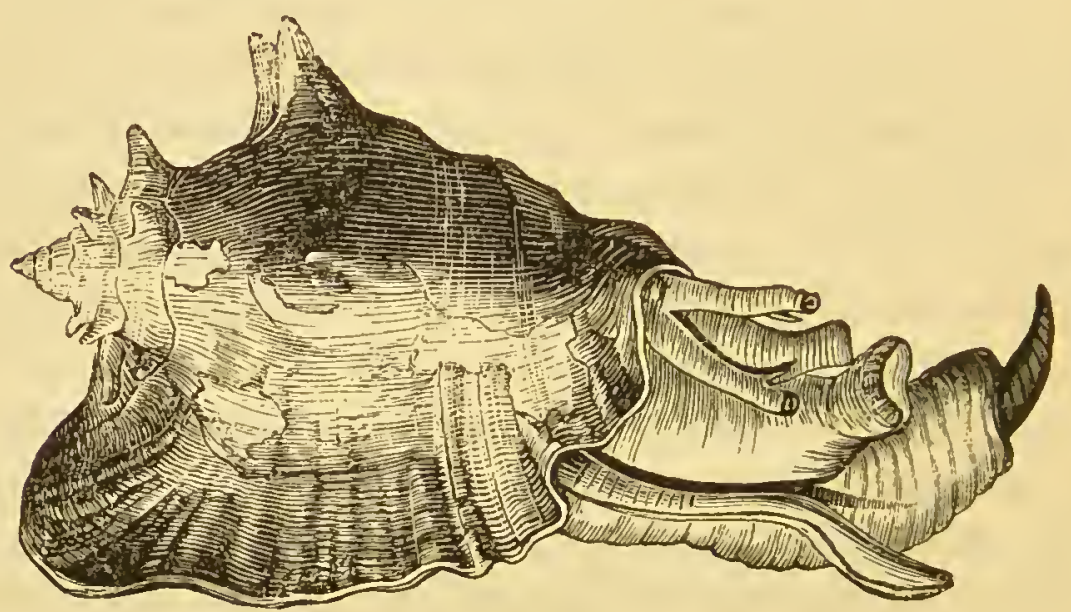

Strombus.

adapted for creeping; the operculum is small, narrow, pointed or serrated on the outer edge; the shell has an expanded lip, deeply notched near the canal. Some of the species of Strombus weigh sometimes four or five pounds; the apex and spines of the Strombus gigas become solidified by calcareous deposits with age. They are extensively used in the manufacture of cameos. In Pteroceras, the shell, when young, is like that of Strombus ; but the outer lip of the adult is produced into several long claws, one of them close to the spire, and forming a posterior canal.

The Muricidce have a broad foot, much expanded in 
some; the eyes are sessile on the tentacles at or near their base; there are two branchix; the shell has a straight anterior canal, and the aperture is entire behind. The genus Murex is the most typical form. The Murices appear, according to Woodward, to form only one-third of a whorl annually, ending in a varix; some species form intermediate varices of less extent. MI. erinaceus is termed by fishermen the Sting-winkle, and it is said that it makes round holes in the other shell-fish with its beak. The ancients obtained their purple dye from a species of Murex; the small shells were bruised in mortars, the animals of the larger ones taken out. Heaps of broken shells of the $M$. trunculus, and caldron-shaped holes in the rocks, may be seen on the Tyrian shore. On the coast of the Morea, the analogous species, Murex brandaris, appears to have been used. The genera Typhis, Pisania, Turbinella, Cancellaria, Trophon, Pymla, and Fasciolaria, are other leading types of Muricidce.

Fusus (the spindle-shell), called the red Whelk on the coasts of the Channel, and "Buckie" in Scotland, is extensively dredged for the markets, being more esteemed than the Buccinum. In the Shetland Isles it is suspended horizontally and used for a lamp, the cavity containing the oil and the canal the wick. The reverse variety is found in the Mediterranean and on the coast of Spain.

The Buccinicle form a Linnæan genus of Vermes testacea, characterized by having a shell with a smooth non-plicated columella, and with a fissure or short respiratory canal inflected towards the left. These forms, which comprise those usually termed "Whelks," have been subdivided into the following sub-genera: Buccinum proper, Brug., of which the Whelk (Bucc. 
undatum) is an example; Nassa, Lam. ; Eburna, Lam. ; Ancillaria, Lam. ; Dolium, Lam. ; Perdix, Marl. ; Harpa, Lam.; Purpura, Brug.; Monoceros, Lam.; Ricinula, Lam.; Concholepas, Lam.; Cassis, Brug.; MLorio, Montf. ; Terebra, Brug.

In the Conidae the shell is characterized by its conical form, the base of which is formed by the spire, which is accordingly flat, or very slightly projecting; the aperture is narrow and rectilinear, or nearly so, without any enlargement, or plication. The Linnæan genus is retained without subdivision, and forms with Pleurotoma, Lachesis, and Terebra the family Conidce.

The Volutida have a univalve spiral shell, with an aperture without a beak, and somewhat effuse, and a columella twisted or plaited, generally without lips or perforation. They are distributed in the following sub-genera: Oliva, Brug.; Volvaria, Lam.; Voluta proper; Cymbium, Montf.; Marginella, Lam.; Columbella, Lam.; Nitra, Lam; Cancellaria, Lam. They are perhaps the most characteristically carnivorous among the siphon-bearing Mollusca.

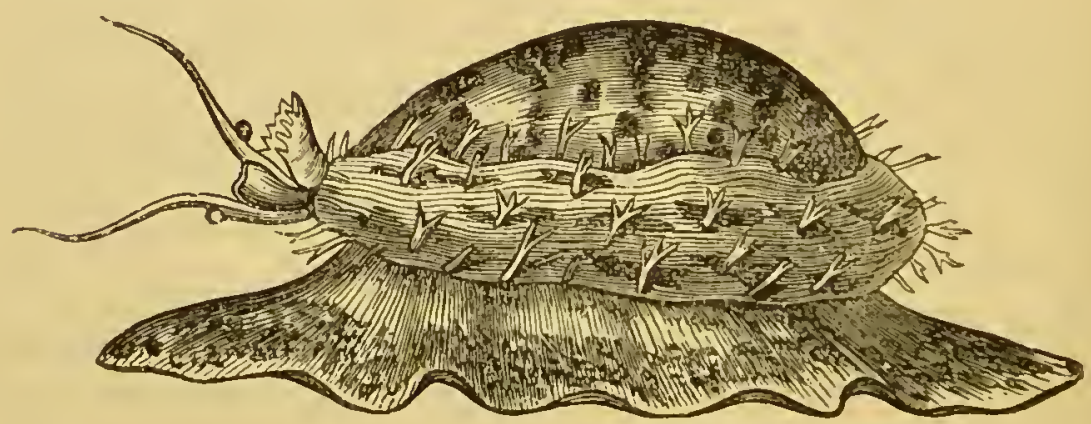

Cowrie (Cypraa).

The Cyprocidce have a subovate smooth shell, with a linear aperture extending from one end of the shell to the other, and transversely furrowed or dentated in 
the mature state. The genus is retained without subdivision, and forms part of the buecinoid family of the pectinibranchiate order of Gasteropods of the system of Cuvier. This genus is remarkable for the difference of form which exists in the young and old states of the shell; in the former the lip is thin and the aperture wide, but the mantle is progressively developed until its lobes extend over the columella on one side and the lip on the opposite of the aperture, covering them with successive layers of nacreous shell, and at length diminishing the aperture to a narrow linear form.

The first family among the Holostomata deserving investigation is the Turbinidce. They are characterized by a subconical spiral shell, with the margin entire, without a fissure or canal for the siphon of the mantle, the animal not possessing any respiratory tube. The mouth of the shell is closed by an operculum, or some analogous part. The Trochide include the following genera: Turbo, Phasianella, Imperator, Trochus, Elenchus, Rotella, Monodonta, Delphinula, Cyclostrema, Euomphalus, Ophileta, Phanerotinus, Stomatella, Gena, Broderipia. The Gasteropod called Turbo pica by Linnæus, having been ascertained to have a trochoid operculum, is now referred to the genus Trochus.

In the Naticidce the animal has a long retractile proboscis; the tentacles are often connate, with an expansion of the head; the foot large; the mantle lobes reflected over more or less of the shell; the shell is globular, and with few whorles. The spire is short and obtuse; the aperture is semilunar. The coloured markings of the Natica are indestructible, and are frequently discovered on fossils. The Natica frequent sandy and gravelly bottoms, ranging from low water to sometimes ninety fathoms. They are carbon- 
iferous, and feed on the smaller bivalves, and are themselves devoured by the Cod and Haddock. Their eggs are agglutinated into a broad and short spiral band, very slightly attached, and resting free on the sands. In the Pyramidellidae the shell is spiral and turreted; the nucleus minute, sinistral; the aperture is small; the columella sometimes has one or more prominent plates; the operculum is horny. Many fossil forms belong to this family. The Solariida comprise many shells, which are of the greatest beauty. The Staircaseshell (Solarium perspectivum) has a spiral turriform operculum; the shell is orbicular, depressed; umbilicus wide and deep; aperture rhombic ; peristome thin ; the operculum horny and subspiral. The spiral edges of the whorls seen in the umbilicus have been fancifully compared to a winding staircase. The genus is confined to tropical seas. The Turret-shells (Turritella, Lam.); the Worm-shells (Vermetus and Magillus), and the Wentletraps are beautiful examples; they exude a purple fluid when molested. In the Vermetus of Adanson (the Serpula lumbricalis of Linnæus), the tubular shell is thin, divided by partitions, with the spire adhering at the apex; elsewhere it is loose; the aperture is obicular, with the margins connected; the head supports two tentacles, which are oculiferous externally at the base; the posterior appendage of the body is bent downwards, and is mostly furnished with an operculum; the branchiæ are arranged in a conical series at the left side of the respiratory cavity. The peculiar solidification of the elongated shell of the adult Magillus has already been mentioned. In both the above genera of tube or worm shells, the shell has the form of a regular spiral univalve when the animal is young. Magillus inbabits madreporic masses in the 
Red Sea; by its anatomy it is nearly allied to the Whelk family Buccinidae.

The Cerithicade are spiral, elongated, many-whorled, frequently varicose; the aperture is channeled in front with a less distinct posterior canal; the lip is generally expanded in the adult; the operculum is bony and spiral. The animal has a short non-retractile muzzle; the tentacles distant and slender; eyes on short pedicles, connate with the tentacles; mantle margin with a. rudimentary siphonal fold; tongue armed with a single series of median teeth, and three laterals or uncini.

About a hundred living species of Cerithice are known; they have a world-wide distribution, but flourish best in the tropics. They live in great part in the sea, partly in brackish water or at the mouths of rivers. The fossil species, which are still most numerous (upwards of four hundred have been described), are almost all limited to the Tertiary. The Cerithice live in brackish water, in mangrove swamps and the mouths of rivers. Sometimes they crawl on stones and leaves in the neighbourhood; and are sometimes found suspended by glutinous threads to boughs and the roots of the mangroves. A few other Mollusca exist, which have the power of emitting glutinous threads by which they are attached to floating seaweeds. The freshwater Cerithice are termed Potamides; they are abundant in a fossil state, but their shell has no varices. Terebratia, an allied genus, is so abundant near Calcutta that it is used for burning into lime; great heaps of it are first exposed to the sun to kill the animals. They have been brought alive to England. The Melaniacla have a spiral and tur'eted skull, with a thick, dark epidermis; the aperture is often channeled or notched in front; the operculum is houn and spiral. The 
spire is frequently extensively eroded by the acidity of the water in which the animals live. They are often viviparous, and inhabit fresh-water lakes and rivers throughout the warmer parts of the world. The colour in Melania is quite black; in the allied genus, Paludomus, it is olivaceous, with dark brown spiral lines.

The Gasteropods of the family Paludinidce inhabit fresh waters, and are of world-wide distribution. The females hatch the young alive, the ova coming to maturity in a long and wide oviduct. They are to be found in rivers, canals, and fresh waters, in the mud and under stones. The female lays from thirty to seventy eggs in a band of three rows, cleaning the surface as she proceeds; the young are hatched in tbree or four weeks, and attain their full growth in the second year.

The Litorinidie are a well-known family which comprises the common Periwinkles. These molluscs inhabit the lowest zones of seaweed between the tide marks; they are oviparous, and used for food. The Periwinkles are found on the seashore in all parts of the world. In the Baltic they are frequently distorted. The Bonnet-limpets (Calyptrceidce) are found adhering to stones and shells; most of them appear never to quit the spot on which they first settle, the margins of their shells becoming adapted to the surface beneath. Some wear away the space beneath their foot, and other's secrete a shelly base. Both their form and colour depend on the situation in which they grow; those found in the cavities of dead shells feed on the seaweed growing around them, or on animalcules: In one group the shell is elongated, and the inner process is a partition covering the hinder half of the cavity like a slipper, whence the name Crcpidula has been given. 
The number of species of Crepidula has been much increased by the changes of appearance which the shell presents according to the body to which it happens to be fixed. The late lamented observer, Dr. Gray, pointed out that if attached to a broad stone or other body the shell is smooth, circular or ovate, and moderately convex; if fixed to a small round stone, and the shells are obliged to group themselves on one another, it is then narrow, very convex. When in deep water, and fixed between the roots of sea plants, it becomes irregular, thick, and of a uniform colour; if it happens to be fixed on the inside of a dead spiral shell, especially if that shell is inhabited by a Soldier-crab, it becomes flat or even concave externally, and is of a white colour.

The Haliotidce, or Ear-shells, are those in which the shell is ear-shaped, spiral, or trochiform. The aperture is large and covered with nacre or mother-of-pearl. The formation of this nacre is due to alternate layers of very thin membrane and carbonate of lime, but the pearly lustre depends upon minute undulations of the layers. This structure has been adapted by the manufacturers of artificial mother-of-pearl buttons from engraved steel. The Hatiotis abounds on the shores of the Channel Islands, where it is called the Ormer. It is also eaten in Japan. It adheres with its large foot like the Limpet. The shell is much employed in manufacture. Several forms of trochiform shells, amongst which may be noticed Scissurella and Pleurotomaria, must be here noticed. Fossil forms of the latter formed prominent species in the Lower Silurian and carboniferous ages.

The Janthinidoe are beautiful, delicate, thin, translucent, and trochiform shells, the base of which is deep violet, and the spire nearly white. They are gregarious 
in the open sea, where they are found in myriads, and are said to feed on the small blue Velellce. They are frequently drifted to the southern and western shores of England, especially when the wind continues long from the south-west. When handled, they exude a violet fluid from beneath the margin of the mantle. In rough weather they are driven about, and the float which is secreted in the female is detached. This float consists of a series of albuminous air-vesicles, to the under surface of which the ovarian capsules are attached. The capsules beneath the farther end of the raft have been observed to be empty at a time when those in the middle contained young with fully-formed shells, and those near the animal were filled with eggs. They have no power of sinking or rising in the water. The raft, which is much too large to be withdrawn into the shell, is generally thought to be an extreme modification of the operculum; but M. Lacaze Duthiers is of opinion that it is built up of glutinous matter secreted by the foot. The family Fissurellidoe have a conical and limpet-shaped shell, the apex being perforated at the branchial opening. They are usually termed Keyhole Limpets.

The Neritidae are closely allied, and inhabit nearly all warm climates, the genus Nerita being confined to the sea, and that of Neritina chiefly to the fresh and brackish waters. They are usually small globular shells, : ornamented with a great variety of black or purple bands and spots, covered with a polished horny epidermis.

The Scutibranchiata or cyclobranchiate order of gasteropodous Mollusca comprises species wherein the branchix are a series of lamellæ surrounding the body between the foot and the mantle, and sometimes are 
two symmetrical formed, placed behind the heart. Three families exist-the Patellidce, or Limpets; the Dentalüda, or Tooth-shells, so named from their fancied resemblance to the tooth of an Elephant; and the Chitons. The Limpets live on rocky coasts between tide marks, and are consequently left dry twice a day; they adhere very firmly. On soft rocks, as those of the chalk formation, they live in pits half an inch deep, formed by the carbonic acid disengaged in respiration.

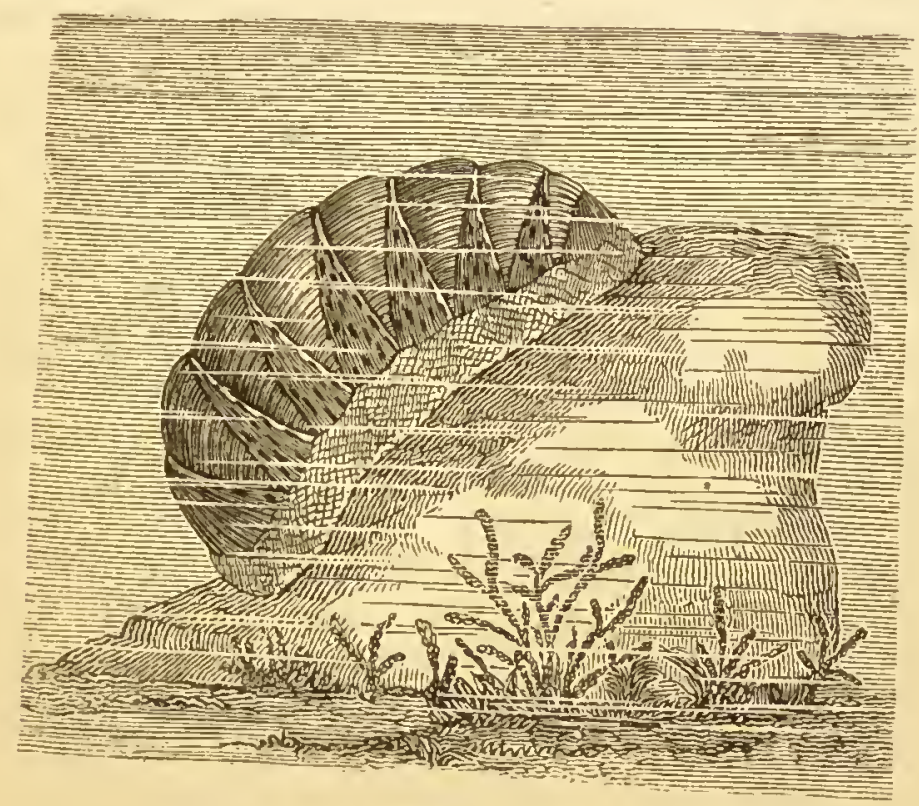

Chiton.

Some species of Limpet obtain enormous dimensions. The shape of some species of Limpet is believed to vary with the nature of the surface on which they habitually live. Limpets are found in every quarter of the globe. The position of the allied genus Siphonaria is exceedingly doubtful, Dr. Gray placing them with the pulmoniferous molluses. The Chitons have the shell composed of eight transverse plates which are lodged in a coriaceous mantle, which forms an expanded margin 
round the body. The border of the mantle is either bare or covered with minute plates, hairs, or spines. More than two hundred and fifty species of Chiton are known. Dr. T. Williams has in two brief sentences summed up the chief characters of this extraordinary genus: "A Chiton has a carapace like an isopod Crustacean, a dorsal vessel like an Annelid, bilateral, symmetrical, reproductive viscera like an acephalous mollusc, and head and foot like a patelloid Gastropod, a posterior anus like the Fissurellidæ, and branchiæ like those of the brachyurous Crustacea. Such manifold affinities at once unite and sever this odd group from several most dissimilar classes."

The pulmoniferous molluscs have part of the mantle cavity forming a vascular air-sac, or lung. Most Pulmonata are terrestrial; those which are aquatic rise to the surface of the water to breathe. A few are naked; most are testaceous; and the latter are distinguished as having or wanting the operculum. Two great divisions of pulmoniferous Mollusca exist-the operculate and the inoperculate forms. Both are normal Gasteropods, having a broad foot, and usually a large spiral shell. The inoperculate Pulmonifera are divided into three groups-the Slugs (Limacida), Pondsnails (Limnaida), and Ear-shells (Auriculidce). In the Snails the shell is external, usually well developed, and closed by a layer of hardened mucus during hibernation. They are of world-wide distribution, ranging northwards as far as the limit of trees, and southwards to Tierra del Fuego. In bathymetrical distribution they have been observed at various elevations. M. d'Orbigny observed six species at elevations exceeding eleven thousand feet in South America; and Layard found $H$. gardeneri at the height of eight 
thousand feet. The Tree-snails (Bulimus) and the

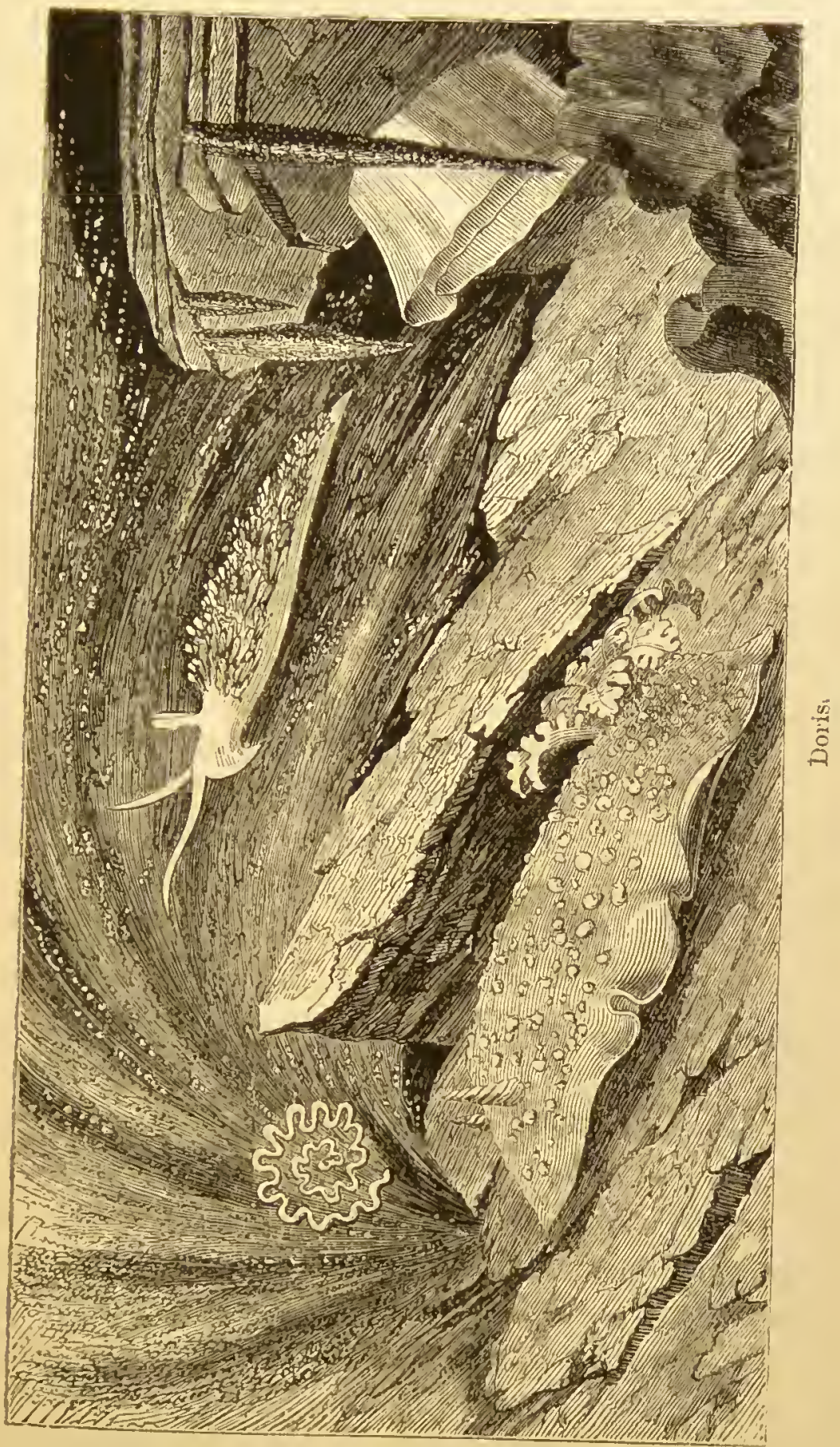

Agate-shells (Achatina) are also found in tropical 
climates. There are more than twelve hundred species of these land shells known, while more than seventeen hundred species of Helix are known to exist. In the Slugs (Limacidce) the shell is rudimental and internal, or else partially concealed by the mantle and placed over the respiratory cavity. They often climb trees in quest of the decaying vegetable matter on which they feed; and they lower themselves to the ground by means of threads. In the genus Oncidium, which forms an aberrant type of Limacidce, there is no shell, and the animal is covered with a coriaceous mantle alone. The Pond-snails (Limneidee) inhabit fresh waters in all parts of the world; they feed chiefly on decaying leaves, and deposit their spawn as oblong transparent masses on aquatic plants and stones. They frequently glide beneath the surface of the water, shell downwards, and hibernate in the mud; they can lower themselves from aquatic plants by a mucous thread, and reascend by the same. The Auriculidice have a broad and short muzzle with two tentacles, the eyes sessile behind them; some are found in salt water; some are amphibious. Auricula and Melampus live in damp situations near the sea, and on the muddy banks of rivers. Polydonta inhabits moist situations in woods near the sea, but is wholly of terrestrial habits, living on decayed matter, and crawling about actively after showers of rain. Alexic and Carychium abound in salt-water marshes. The operculated Land-snails, which resemble Periwinkles in outward form, differ from them in the situations they inhabit, being purely terrestrial. There are three families-the Cyclostomidre, the Helicino, and the Aciculido. These make a general transition to the heteropodous or nudibranchiate forms of Gasteropoda.

The Tectibranchata have branchiæ resembling pinna- 
tified leaves restricted to one side, and covered by the mantle and a small shell, which is sometimes exposed. Most are phytophagous; all have a complex gizzard. Four families are known-the Tornatellida, Bullida, Aplysiadce, and Pleurobranchidce.

The naked nudibranchiate molluscs, in which the branchix extend more or less freely from various parts of the body, may be referred to this division. There are five families-Doride, Tritoniado, Atolidee, Phyllivhoidce, Elysiadce. The nudibranchiate Gasteropods have a locomotive organ, compressed, and resembling a fin, but single and ventral in position. The branchiæ, when distinct, pectinate and pinnate packed in a small compass, with the heart in a dorsal sac or in a symmetrical shell. The sexes are distinct. These molluses all live in the sea, and usually swim with the fin-shaped foot upwards and downwards. They progress rapidly by the vigorous movements of their compressed tails, or by a fan-shaped ventral fin, and adhere to seaweed by a small sucker placed on the margin of the latter. There are two leading families-the Firolide, which have large bodies and small or no shells, and the Atlantido, which can retire into their shells and close them with an operculum. Both animal and shell are symmetrical, or nearly so. The Carinaria is an example of this order. It has fully-formed branchiæ; in Atlanta they are sometimes distinct, and wanting in others; in Firoloides they are only indicated by a ciliated, subspiral band. The larvæ are furnished with a shell and with ciliated vela; they are diccious. In Firola the animal is elongated, cylindrical, translucent, furnished with a ventral fin, and a tail fin used in swimming; the gill is exposed on a posterior part of the back in this genus, covered by a small hyaline shell in Carinaria. 


\section{ClasS III.-PTEROPODA.}

THE mantle in these is closed; appendages of the 1 head either wanting or extremely reduced. The

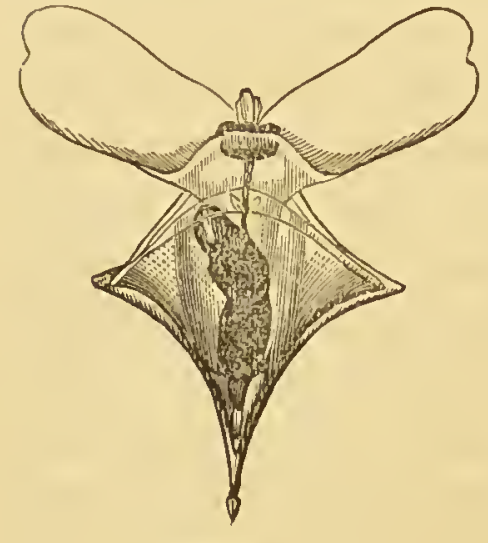

Hyalca. principal organs of locomotion are two membranous fins, like wings, situated on the sides of the neck. The head is small, sometimes marked off from the body by a welldefined neck (Clio), and sometimes not (Cleodora); the fins spring from the sides of the neck, or of the head if the neck be absent. The mantle is in some little developed (Clio), in others it forms a large cavity on the inferior aspect of the body (Cleodora). The shell is present or absent (Gymnosomata, Clio; Thecosomata, Hyalcea); if present, it is very delicate and transparent. Its form may be a simple cone, a bent one, or a spiral ; the simple cone may be partially divided into dorsal and ventral plates by a transverse slit (Hyalcea). The head supports around the mouth tentacles, varying in number, and armed with retractile suckers; on the upper aspect are also retractile tentacles, like those of Gasteropoda. On the inferior surface, behind the mouth, are organs which appear to be homologues of the second and third parts of the foot of Gasteropoda. Digestion: an odontophore; a gizzard 
and the first bend of the intestine ventral. Respiration: the branchial organs are slightly developed, having sometimes ciliate and sometimes folded surfaces; they are sometimes absent. The heart is opisthobranchiate. The renal organ is connected with the pericardial sinus, and opening externally. Nervous system is much as in Gasteropoda, but the supra-œsophageal ganglia are less developed. Eyes are tentacular in some and absent in others. Auditory sac is connected with the pedal ganglion, which also supplies the epipodia; they are all hermaphrodite (Ord). The Pteropoda are so called on account of the resemblance of their principal organs of motion to a pair of wings, both as to form and in their mode of action on the surrounding medium. They are small marine floating species, and might leave evidence of their existence in deposits of the deepest ocean. The greatest extremes of form are presented in this order, some species of Hyaloea being almost globular, others, as certain Cleodorce, being very long and slender. The shell is always characterized by the delicacy and transparency of its texture; it deviates least from the ordinary form of the spiral univalve in Spirialis and some allied fossils. In Limacina, the turns of the shell are reduced to one whorl and a half; in Hyalcea, the shell resembles a bivalve, in which the two valves have been cemented together along the hinge, leaving a narrow fissure in front and at the sides. The ventral valve is most convex, the dorsal one most produced, overhanging the fissure-like opening through which the head and swimming lobes are protruded. In Cleodora, the shell is narrowed and lengthened out, the two plates being united together along the sides so as to leave only an interior aperture. 


\section{CI.ASS IV.-LAMELLIBRANCHIATA.}

IN this class the body is compressed, covered on both I sides with a lamina of the mantle. The branchiæ are at the sides of the body, placed under each lobe of the mantle, mostly lamellose, two on each side, more rarely pectinate, comprised of thin fimbriæ or laciniæ, crowded together. There are four lamelli that form tentacles,

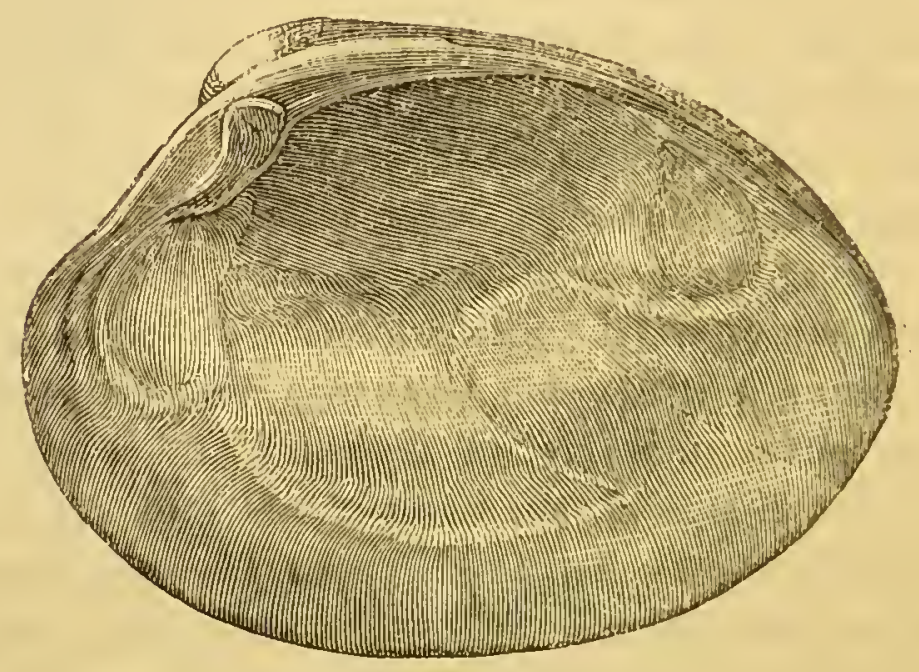

Internal aspect of Bivalve Shell.

in by far the most oval or triangular, placed in pairs at the sides of the mouth. The two shells are lateral, and are incumbent on the mantle, conjoined by an elastic ligament at the back. This position of the valves is the reverse of that in the Brachiopoda, under the names of Oysters, Scallops, Mussels, and Cockles. 
They are all aquatic, and, except a few widely dispersed and prolific genera, are all inhabitants of the sea. They are found on every coast and in every climate, ranging from low-water mark to a depth of wore than two hundred fathoms. They lie on one side in their native element, and the lower valve is deeper and more capacious than the upper'; in these the foot is wanting, or else small and not used for locomotion. Many other bivalves live in an erect position, resting on the edges of their sheils, which are of equal size. Most are free and locomotive; the instrument with which they nove being a single symmetrical muscular organ developed from the ventral surface of the visceral mass. They are, as a rule, diccious and ovoviviparous. The ligament of the conchifera forms a substitute for the muscles by which the valves of the Brachiopoda are opened. It consists of two parts, the ligament properly so called, and the cartilage. They exist either combined or distinct, and sometimes one is dereloped and not the other. The external ligament is a borny substance, similar to the epidermis, which covers the valves; it is usually attached to ridges on the posterior hinge margins, behind the umbones, and is consequently stretched by the closing of the valves. The internal ligament or cartilage is lodged in furrows formed by the ligamented plates, or in pits along the hinge line; in Mya and Nucula it is contained in a spoon-shaped process of one or both valves. Three great sections of Lamellibranchiata or bivalve Mollusca exist. The A. Siphonida, in which the animal is unprovided with the respiratory siphons. The mandible lobes are free, or united only at one point, which divides the brachial chamber from the exhalent chamber (cloaca); the pallial impression is simple. The shell is usually pearly or sub-nacreous 
inside, and cellular externally; the pallial line is simple or obsolete. In the Siphonida the animal has respiratory siphons; the mantle lobes are more or less united. This is divided into two groups, one in which the siphons are short and the pallial line is simple (Integropallialia), and one in which the respiratory siphons are long and the pallial line sinuated which are termed Sinupallialia. The Oysters (Ostreadce) have the shell inequivalve, also slightly inequivalve; it is free or adherent, and resting on one valve; the beaks are central and straight; the ligament is internal; the epidermis is thin; the adductor impression is single, and is situated behind the centre; the pallial line is obscure; and the hinge is usually edentulous. The animal is marine; its mantle is quite open, and it is very slightly adherent to the edge of the shell; the foot is small and byssiferous or obsolete; the quills are crescent-shaped, and there are two on each side; the adductor muscle is composed of two elements, but representing only the posterior shell muscle of other bivalves.

The Aviculide, a family closely allied, contain the genera from which the mother-of-pearl is chietly derived (Meleagrina). The value of pearls has declined in modern times. The "nacre," or "mother-of-pearl," is the iridescent pearl-like inner layer of the shell. For this substance, which is used largely in ornamental manufactures, immense numbers of the "pearl oyster" are annually imported-the "silver-lipped" variety from the Society Islands, the "black-lipped" from the Philippines, and a smaller kind from Panama. These fetch from $£ 2$ to $£ 4$ per ton. The Pinnce also belong to this division of Iamellibranchiates. In these the shell is fragile, thin, and often imbricate, or squamose, large, triangular, thin, and very small at the point. 
The animal penetrates the sand with the point of its shell, and fastens itself above by the byssus to other objects.

The Mytitidce, or Mussels. There is a small anterior adductor; the mantle lobes are united between the branchix and slits; the foot is cylindrical, grooved, and byssiferous. The shell is equivalve, and the hinge is edentulous.

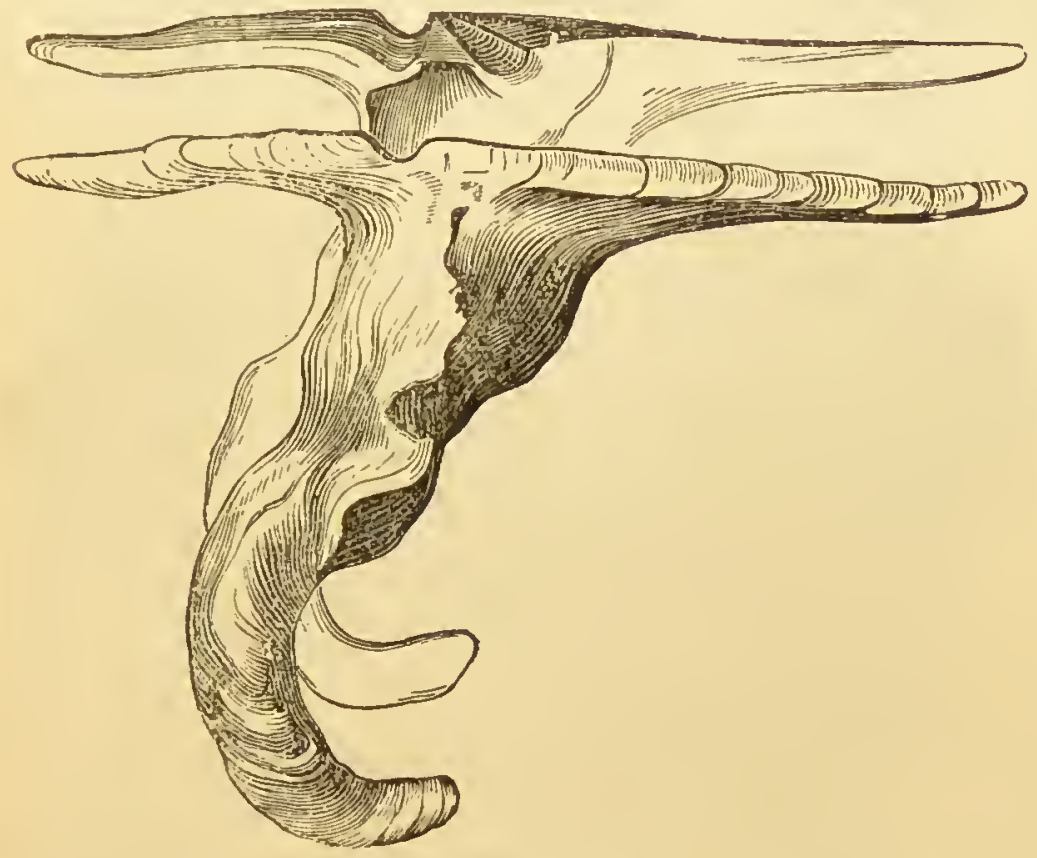

Hammer-oyster (Malleus).

The Ark-shells (Arcada) differ widely from the true Mussels, as the foot is large in some, serving for creeping, in others furnished with a horny and lamellose byssus, not divided into filaments. The Trigonida, which are closely allied to the Ark-shells (Arcadce), have the mantle cloven anteriorly, and no trachea. The foot is not byssiferous, and serves for creeping. Many species of Trigonia existed in the middle secondary periods. 
The Unionidae or fresh-water Mussels are composed of various species to which North American zoologists have assigned distinctness. Professor Lea has especially signalised himself by the formation of an enormous number of species from every rill, brook, and rivulet in the United States. The allied genera Anodon and Iridina are also common river Mussels.

Amongst the integropallate Siphonida, the Clamshells (Chamidce), which present an irregular form, deserve especial notice, as they afford a link to an extinct family of molluscs, the Hippurites, which were

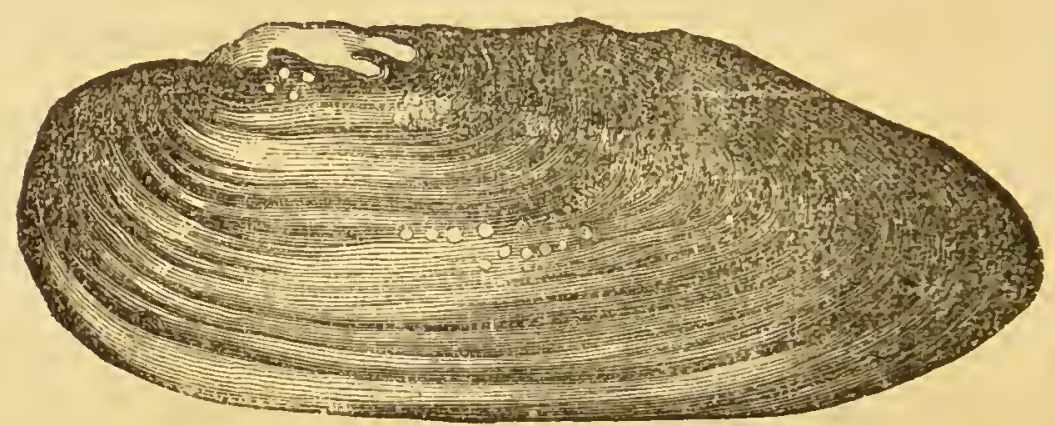

Unio.

excessively frequent in the Cretaceous strata in a fossil state.

The Tridacnidoe have been frequently confounded with the Clam-shells, but they comprise a far fewer number of species. In this family the lamellibranchiate type of organisation is shown under its largest size. The valves of Tridacna gigas are used for ornamental purposes in gardens, and as holy water stoups in Romanist churches. Two large valves employed for this purpose in the church of St. Sulpice, Paris, measure each two feet in breadth. They are also used as basins for fountains. Linnæus records a shell in the "Museum Ludovicæ Ulricæ" which weighed 
five hundred and thirty-two pounds. Hippopus mence-

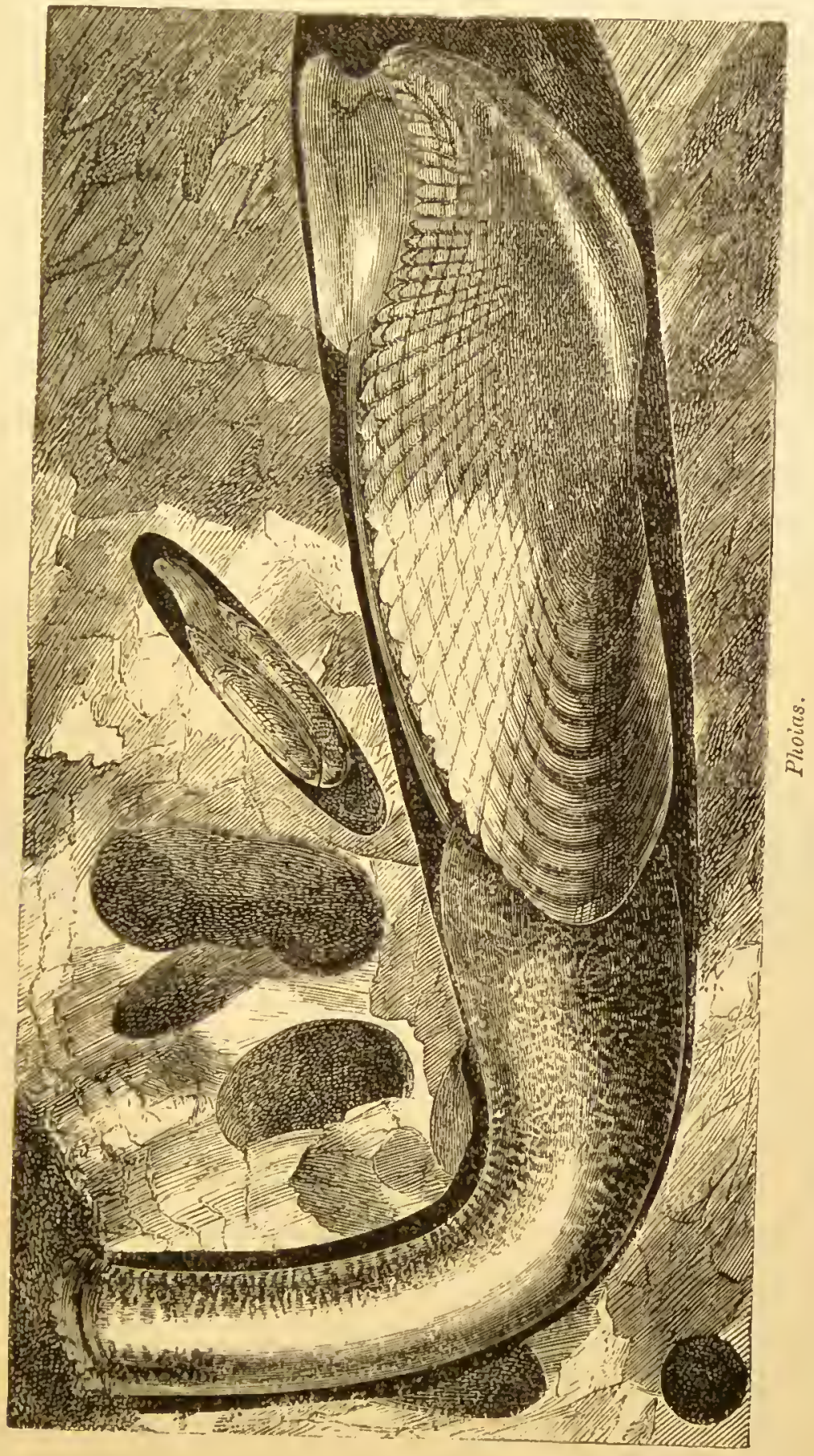

latus, or the "Bear's-paw clam " of dealers, is one of the 
most beautiful bivalves, and is nearly unequalled in form, texture, and colour.

The Cockles (Cardiadex) are a common and welldistributed family, which is found in a fossil state. The Sucinida, Cycladida, Cyprinida, form also familiar examples of the Integropalliata division of the class.

The division Sinupalliata comprehends those molluscs which are most frequently known for the beauty of their forms. There is, however, a certain sameness and resemblance of the characters of the Veneridce, MFactridce Tellinida, Solenida, Myacidae, Anatinida, Gastrochonidae, and Pholadidce, which renders little more than the mention of their names here necessary. All bivalve Mollusca are richly prolific. 


\section{CIASS V.-BRACHIOPODA.}

THE molluscs of this class are so called because the chief moving prehensile parts resemble the "arms" of some polypes. They are specially disposed, fringed, and ciliated, and may answer to those of the Bryozoa, or ciliobranchiate polypes. The soft parts are protected by a shell consisting of two valves, one applied to the dorsal the other to the ventral surface. The latter has a prominent notched or perforated beak,

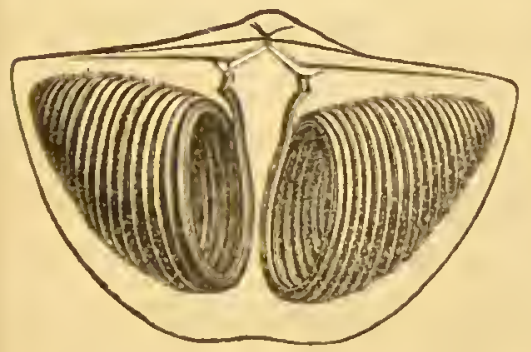

Brachiopodat.

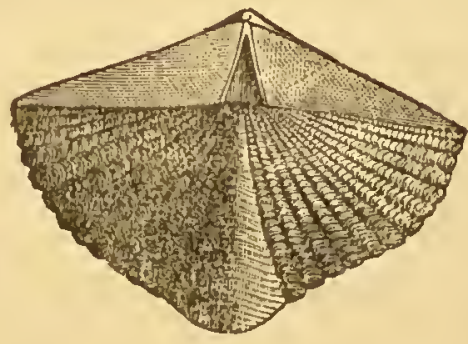

through which, in most, a pedicle passes to attach the animal to some foreign body. There are several pairs of muscles for opening and shutting the shell. The valves of the Brachiopoda are respectively dorsal and ventral; the largest is the ventral valve, which has a prominent beak, by which it is attached, or through which the organ of adhesion passes. It is sometimes perforated, as in Terebratulide. The smaller (dorsal) valve is always free and imperforate. The valves are articulated by two curved teeth, developed from the 
margin of the ventral valve, and received by sockets in the other: this hinge is so complete that the valves cannot be separated without injury. A few genera have no hinge. In Crania and Discina, the lower valve is flat, the upper like a Limpet. The valves of Lingula are nearly equal, and have been compared by Petiver to a Duck's bill. This and several other points of distinction seem to show the correctness of Deshayes' classification of Brachiopods into two groups, the one with articulated the other with non-articulated valves. In the first or articulated group, the valves are opened by muscles acting on the cardinal process of the dorsal valve; while in the latter or non-articulated group the valves are opened by the pressure of fluid in the perivisceral cavity. There is also a striking difference in the arrangement of the muscles. And while the articulated group possess an anal aperture, the non-articulate possess none whatever.

Little is known respecting the development of the Brachiopoda, but there can be no doubt that in their first stage they are free and able to swim about until they meet with a spot whereon to affix themselves. It is probable that in the second stage they all adhere by a byssus, which in some instances becomes consolidated, and forms a permanent organ of attachment. Some of the extinct genera appear to have been free. All the species are marine. They are found hanging from the branches of corals, the under sides of shelving rocks, and the cavities of other shells. Some attain their full growth in a single season, and all probably live many years after becoming adults. The Brachiopoda, above all other shell-fish, enjoy the greatest range of climate, depth, and time; they are found in tropical and polar seas, in pools left by the ebbing tide, and at the 
greatest depths hitherto explored by the dredge. While the class was of enormous distribution during palæontological time, it is restricted at the present time to less than a hundred species. The chief families are Terebratulidce, Spiriferidce, Rhynchonellide, Orthidee, Productide, Craniader, Discinider, and Lingutides. 


\section{Class VI.-TUNICATA.}

THE Tunicates have been described by Van der Hoeven as acephalous molluscs without shells. The external covering is perforated by two openings in other respects like a sac, and entirely closed, of rarious thickness and hardness, gelatinous in some, in others leathery. The large solitary Tunicates are termed Ascidians, from their resemblance to a water-skin or small leathern bottle. They become several inches long, and affixed to rocks or stones or searreed, but sometimes so slightly that they are brought up detached and yet uninjured by the dredge. Their appearance is sufficiently unpromising, and their surface is often rugged or concealed by adhering sand and fragments of shell. Seaweeds grow upon them, and small bivalves burrow in their tunics. They are hollow and elastic, and have two orifices from which (especially the terminal opening) they squirt water, as the bivalve shellfish do when molested. Male and female organs are united in the same individual. The respiratory organs are gills which differ much from those of the bivalve molluscs. The position of these animals in the molluscan sub-kingdom has been considered doubtful by many zoologists, who have laid stress upon their affinity with the Bryozoa or Polyzoa. It has been well pleaded by M. Milne Edwards that the Ascidians bave less intimate analogies with the Mollusca, properly so called, than is usually believed. They resemble, it is 
true, these animals in the arrangement of their digestive apparatus and some peculiarities of the respiratory system, but they depart from the molluscan type in their mode of circulation, in the metamorphosis which the fry undergo, and above all in the power which most of them possess of multiplying by gemmation. In these important physiological characters they approach the Polypi. As the position both of the Tunicata and the Bryozoa have been much disputed, and it has been even proposed to join them together and elevate them into a group termed Molluscoidea, the following words by Professor Owen will sufficiently justify the retention of Tunicates among Molluscs, and Bryozoa among Radiates. "The metamorphoses which the Bryozoa undergo are like those of the lower Polypi. The Bryozoa are allied to the compound Ascidir; but not one of the ascidian Molluscoids quits the ovum as a gemmule, swimming by means of cilia; and no Bryozoan quits the ovum in the guise of a Cercarian or Tadpole, to swim abroad by the alternate inflections of a caudal appendage. In a progressive and continuous series of teachings by pen or word of mouth, the place of an osculant or transitional group is governed by convenience, by considerations of how best to teach by comparison and easy gradation. The real merits of the man who would make scientific capital by changing the position of such group, and by imputing error or ignorance to the author from whom he may differ in this respect, are easily weighed and soon understood." 


\section{Sub-Kingdom-ARTICULATA.}

THIS primary division of the animal kingdom has the brain in the form of a ring, embracing the gullet; there is a double ganglion above the tube, which supplies the organs of sense; from the subœsophageal ganglia two chords are extended along the ventral surface of the abdomen, and are in most species united at certain distances by double ganglions, which give origin to the nerves of the body segments and their appendages. As the nervous centres are symmetrically disposed, this kingdom has been called by Owen Homoganglionata. The body is correspondingly symmetrical; the skeleton is external, and consists of articulated segments of frequently an annular form; the articulated limbs in those species which possess them have a similar condition of the hard parts in the form of a sheath, which encloses the muscles. The respiratory organs commonly open upon the sides of the body, rarely near the anus, and never communicate with the oral aperture, or mouth. When the jaws are present, they are lateral, and move from side to side. The heart is situated in the back, and is often vasiform, and the veins are frequently in the form of large irregular sinuses. There is always a circulation. In one of the classes, Annelida, the blood is red. Most Articulates are diœcious, a few are hermaphrodites, still fewer are parthenogenetic. There are six primary divisions 
or classes of the Articulata sub-kingdom, to which the names have been respectively given of the Insecta, Arachnida, Crustacea, Cirripedia, Annelida, and Entozoa. Of the position of the last class in the articulate subkingdom there exists much doubt. 


\section{ClaAss I.-INSECTA.}

THE head is distinct from the trunk, to which two 1 antennæe are attached. The respiration is by means of air-canals distributed internally throughout the body, and generally divided into very fine branches. The first character separates Insects from Arachnidæ, in which the head and thorax form a single piece, and which have no antennce; the second distinguishes them from the Crustaceans, whose respiratory organs are gills, or other external appendages. The body of the six-footed insects is separated into three parts--head, trunk, and abdomen. On the head are distinguished the antennee and the eyes. The former are composed of a series of movable jointed threads, which, unconnected with the oral organs, are attached to the head. The number of joints and the relative size is very different. Sometimes they exceed the size of the body, in others they are very short and almost concealed beneath the eyes. When they are thin, and of the same thickness throughout, they are termed filiform; when, as in Butterflies, they have a knob at the end formed of thicker joints, they are termed clavate. The eyes are either simple or compound. The compound eyes are composed of numerous hexagonal facets, in some instances of enormous number, there being eight thousand in the eye of a Fly, and eight thousand eight hundred in that of a Cockchafer. 
The oral apparatus is formed of six principal parts, of which four form the laterally moving jaws, and two face each other above and below. The two last are called labrum and labium respectively. Both the other two parts, which are termed mandibulce and maxilla, move laterally from within outwards, and from the jaws.

The number of segments or "somites" in the body of insects never exceeds twenty. In the adult condition the integument is more or less hardened by the deposition of chitine. The thorax supports all the locomotive members : both the first pair, which may be compared with the pectoral extremities of the vertebrate animals, and the last pair, which are analogous to the pelvic members, as well as the middle pair, to which there is no correlative in the vertebrate series. The abdomen in insects is normally composed of nine "somites." There is no regular plan of the course of the circulation in insects. The tracheæ serve as the organs of respiration. Insects have been divided into three sections, which have been termed Ametabola, Hemimetabola, and Holometabola. The first division do not pass through any metamorphosis, and are destitute of wings in the adult condition. In the hemimetabolic insects there is a metamorphosis, which consists of three stages, forming an incomplete gradation, the pupa being converted into the perfect insect, or imago, by the liberation of the wings, no other change being required. The larva and pupa are closely alike. In the third or bolometabolic sub-class, the insect passes through three stages, which differ greatly from each other in appearance. The metamorphosed animal passes through the respective changes of caterpillar, pupa or chrysalis, and imago or perfect animal. There are no 
hermaphrodite insects. The following diagram will assist the student in the classification of insects.

\begin{tabular}{|c|c|}
\hline Ametabola. & Lice. \\
\hline Hemimetabola. & $\begin{array}{l}\text { Aptera (part). } \\
\text { Hemiptera. }\end{array}$ \\
\hline & $\begin{array}{l}\text { Orthoptera. } \\
\text { Neuroptera. } \\
\text { Thysanoptera. }\end{array}$ \\
\hline Holometabola. & $\begin{array}{l}\text { Aptera (Fleas) } \\
\text { Diptera. } \\
\text { Lepidoptera. } \\
\text { Hymenoptera. } \\
\text { Coleoptera. }\end{array}$ \\
\hline
\end{tabular}

The above classification is not followed precisely in the present work, which unites the anoplurous Aptera, or Lice, with the aphanipterous Aptera, or Fleas.

\section{Order 1.-Aptera (Fleas and Lice).}

The insects of this order have no wings. Some zoologists have classified the Fleas amongst the Diptera

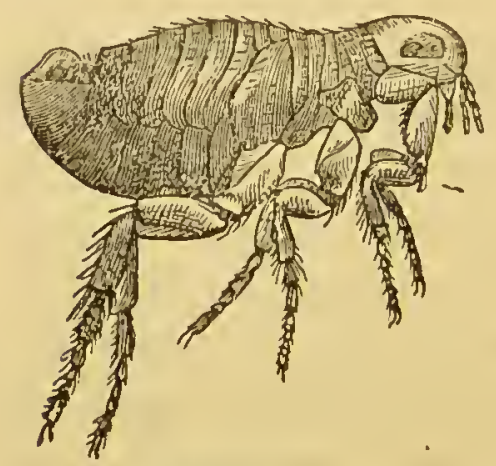

Flea (Pulex). and the Lice among the Hemiptera. The Fleas are abundant in Europe and the north of Africa. In the hot parts of America they are associated with a smaller species (Pulex penetrans), which attacks the feet of man by silently inserting its body under the skin, where the female lays eggs in a sac as large as a pea, which contains matter, and festers under the skin, unless it is extracted by the careful insertion of a needle. The Lice are divided into Head-lice and Body-lice, and 
the latter being frequently developed in the disease termed phthiriasis, in which insects are produced in such extraordinary numbers that they have been supposed to originate by spontaneous generation. Two other groups are known-the Mallophaga, or Birdlice, which do not appear to live upon the juices of the animal upon which they are parasitic, but on the texture of the feathers; and the Thysanuridee, Podurce, or Springtails, in which a forked caudal appendage exists, which aids the animal to make enormous leaps. The body in Thysanuridce is often covered with minute hairs or scales.

\section{Order 2.-Diptera (Gnats, Flies).}

All suctorial insects which in the perfect state possess only two membranous wings are called Diptera. The second pair of wings common to other insects is absent, and is replaced by two appendages, which have received the name of balancers, because they serve to regulate the action of flight. The mouth is suited for suction only, and is in the form of a trunk, composed of a sheath, a sucker, and two palpi. The antennæ are usually three-jointed. They have been divided into two principal groups. One, formed of at least six joints, and the palpi of four or five; these are called $N^{N}$ emocera. In the other the antennæ consist only of three joints, and the palpi of one or two, and are termed Brachycera. The Nemocerce are usually light and elegant in shape, and are divisible into two families, of which the Gnats (Culicidce) and the Craneflies, vulgarly called "Daddy-long-legs" (Tipulidce), are examples. The brachycerous Dipterans comprise such well-known 
types as the Gadflies (Tabanidce), Houseflies (Muscidce), and an enormous number of species which are more or less carnivorous, and which annoy domestic animals by their parasitic habits. The bite of some of these species, e.g. the Tsetse, has been alleged to produce the destruction of flocks and herds to an enormous extent in South Africa. It is said not to be dangerous to Man, to any wild animals, the Pig, Zebra, Ass, or Goat, but to mortally sting the Ox, Horse, Sheep, and Dog, which have been introduced in Central Africa. Owing to the contradictory accounts of travellers, precise knowledge of the habits of this extraordinary species is much to be desired.

\section{Order 3.- Hemiptera (Bugs).}

These Insects have the mouth suctorial and beakshaped, consisting of a jointed rostrum composed of the

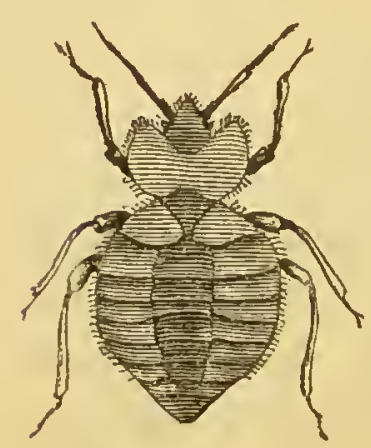

Bug (Cimex).

elongated labium; the eyes are compound, and there are two pairs of wings. They are divided into two sections-the Heteroptera, or true Bugs, and the Homoptera, which includes the Cicadee, the Aphidae or Plant-louse, and the Coccidar. Bugs were unknown in England until the beginning of the sixteenth century, though they have been erroneously supposed to have been brought from America. The so-called Waterscorpions and the Spume-insect, or Cuckoo-spit (Aphrophora fumaria), the Lantern-flies (Fulgora), all belong to the homopterous division. The Cochineal-insect is common on the cactus plants of South America, where it serves as a beautiful dye. 


\section{Order 4.-Lepidoptera (Moths, Butterflies).}

They have been so called because their wings are covered with minute scales. They are almost universally distributed, either under the form of Butterflies, in which the antennæ are clubbed at the tip, or as Moths, in which they are filiform or pointed. The group which is usually termed Diurnal Lepidoptera, or true Butterflies, is the most beautiful, and comprises hundreds of species of gaily-painted summer insects. The larræ, or "Caterpillars," are vermiform in shape,

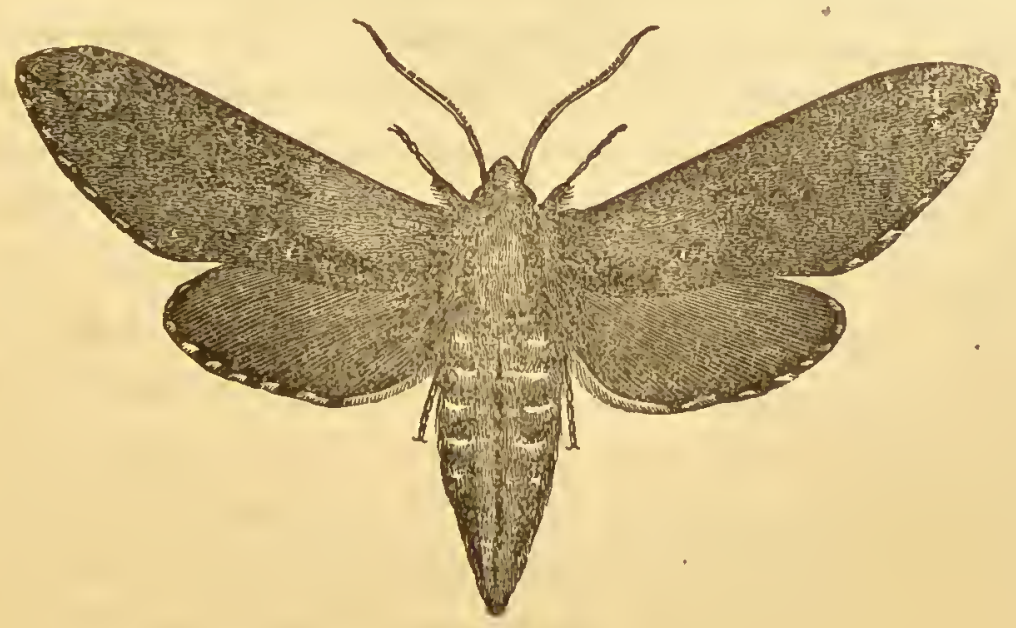

Hawk Moth.

normally composed of thirteen segments, the anterior portion forming a distinct and horny head, with antennæ, jaws, and simple eyes. The mouth of the Caterpillar, unlike that of the perfect insect, is formed for mastication. The labium also supports a little elongated tubular organ, pierced with a microscopic aperture, which is the spinning apparatus which the animal uses in fabricating the threads. The Hawk Moths, amongst which the Privet-hawk Moth (Sphinx ligustri), and the Death's-head Moth (Acherontia atropos) are well 
known as forming examples of a type which oscillates between the Butterflies and the true Moths. Amongst the semi-nocturnal forms the Silkworm Moth (Bombyx mori) should especially be noticed. It has short plumose antennæ, a thick short body, stout legs, and white wings, with two or three dark lines stretching across them parallel to the margin. It lays its eggs, which are of a greyish tint, on the leaves of the mulberrytree (Morus alba), upon which the larva feeds. These larvæ form the cocoons from which the silk is procured. The eggs may be preserved a long time without deteriorating provided they are kept free from damp, and not too many in the same packet. The eggs in this state are called by the cultivators seed. The larvæ, when first hatched, are a quarter of an inch long, and of a dark colour, and the first care after their birth is to separate them from their shells, and place them in hurdles where they may find appropriate food. For this purpose a paper perforated with holes, and covered with mulberry-leaves, is spread over the basket in which the larvæ are placed, and in passing through the holes to get at the mulberry-leaves they free themselves from their shells. The Silkworm lives in a larval state from six to eight weeks, during which time it moults or changes its skin four times, increasing in size and voracity with every moult, and when fully grown is about three inches in length. The Caterpillar now stops eating, betakes itself to some convenient spot where, after spinning a fer threads in various directions, it suspends itself in the midst of them, and by continually twisting its body it gradually envelops itself in a thick, silken, oval-shaped cocoon. The silk is a secretion of a pair of tubes called sericteria, which terminate in a pore or spinneret on the under-lip of the 
Caterpillar. The two fine filaments from the sericteria are glued together by another secretion from a small gland, so that the apparently single silk thread proceeding from the Caterpillar is in reality double. Whilst spinning the cocoon, which is usually completed in five days, the larva decreases in bulk, casts its skin, becomes torpid, and ultimately assumes the chrysalis form in the interior of the cocoon. The cocoons when completed are thrown into warm water, which dissolves the glutinous matter that causes the threads to adhere, and separates them. The end of the thread is then found and placed upon a reel ; the silk is wound off the cocoon, and formed into what are called hanks. The Tineince are a form which may be divided into three groups-1st, the species hurtful to our stuffs and furs; 2nd, the species which destroy our corn crops; 3rd, the species which feed on plants.

\section{Order 5.-ORthoptera (Grasshoppers, Crickets).}

Some of the largest known forms of insects are found in this order, and particularly those which are of extraordinary shapes, as the Mantes or Praying-insects. The mouth is masticatory; there are four wings; the anterior parts are smaller than the posterior; they are coriaceous, or leathery, and form elytra; the posterior part of the wings is membranous and longitudinally folded, the under wings being folded over the upper. The Earwigs (Forficula), the Praying-insect, with its stretched-out legs (MIantis), the Walking-sticks and Leaves, the Field-crickets (Gryllus campestris), and the Mole-crickets (Gryllotalpa vulgaris), and, above all, the 
Locusts, whose predatory attacks on all surrounding vegetation (Acridium migratorium) have been so often described, serve as familiar examples of the Orthopterous order of insects.

\section{Order 6.-Hymenoptera (Bees, Wasps).}

These have all four membranous wings lying in repose longitudinally upon the body, and intersected by a network of nerves. The mouth is composed of two horny mandibles, jaws and lips adapted for suction.

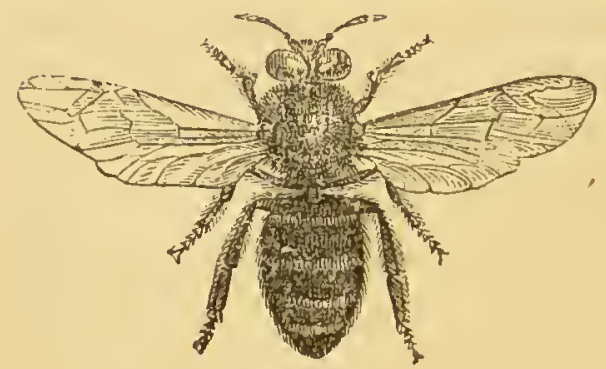

Drone.

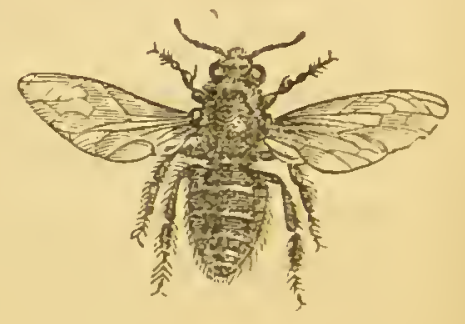

Worker.

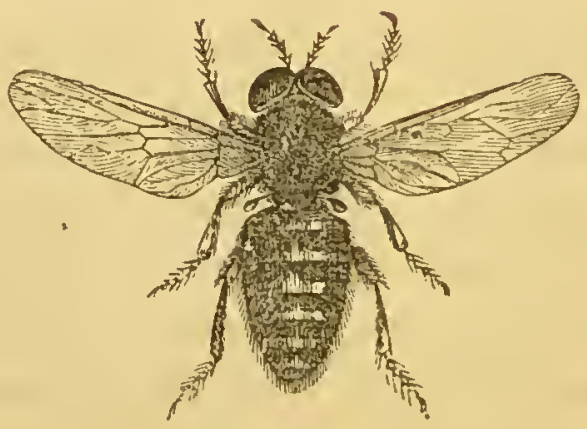

Queen Bee.

Sometimes the wings are absent. The muth is always provided with biting jaws, or mandibles; the maxilla and labium often converted into a suctorial organ. The females have the extremity of the abdomen mostly furnished with an oripositor, or sting. Four leading 
families of Hymenoptera exist- the Apiarice, containing the Honey-bees, the Melipodce, the Bumblebees; the Vespiarice, or Wasps; the Formicarice, or Ants; and the Gallicolce, or Gall-insects. Nearly all of these are gregarious in their habits, and all undergo complete metamorphosis. Social communities exist among these insects, which consist usually of three classes of individuals, the "males," "females," and "neuters," or workers. Large constructions are made by the collective labour of myriads of Ants, which display an enormous social combination of the separate labours of all individuals to one common end.

\section{Order 7.-Thysanoptera (Thrips).}

This order has been separated from the Orthoptera. They all possess very narrow membranous wings, without any folds or network upon them, but furnished and decorated with beautiful fringes upon the edges. The Thysunoptera have filiform antennæ and very large eyes. The different species of the genus Thrips have a great diversity of wing-fringing. The structure of the wings is somewhat analngous to that observed in the Lepidoptera. The metamorphoses of Thysanoptera are incomplete. The chrysalis condition is not observed, and the larvæ are born from the egg, greatly resembling those of adults. The larva moults several times.

\section{Order 8.-Neuroptera (Dragon-flies, May-flies).}

These have four membranous wings, generally rather broad, provided with transverse delicately reticulated 
nervures, which give them the appearance of lace. One section undergoes incomplete metamorphosis. The Libellula, Ephemera, and Termites belong to this category. The insects belonging to the other section, in which are classed the Phryganidce, or Caddis-flies, the Panorpato, and the Myrmeliones, or Ant-lions, undergo complete metamorphosis. The Caddis-flies have even been separated by Kirby into a separate order, named Trichoptera. The White Ants of Africa and the Dragon-Aies form the types of the order. The Ant-lion constructs for itself a kind of funnel in the sand by describing back-

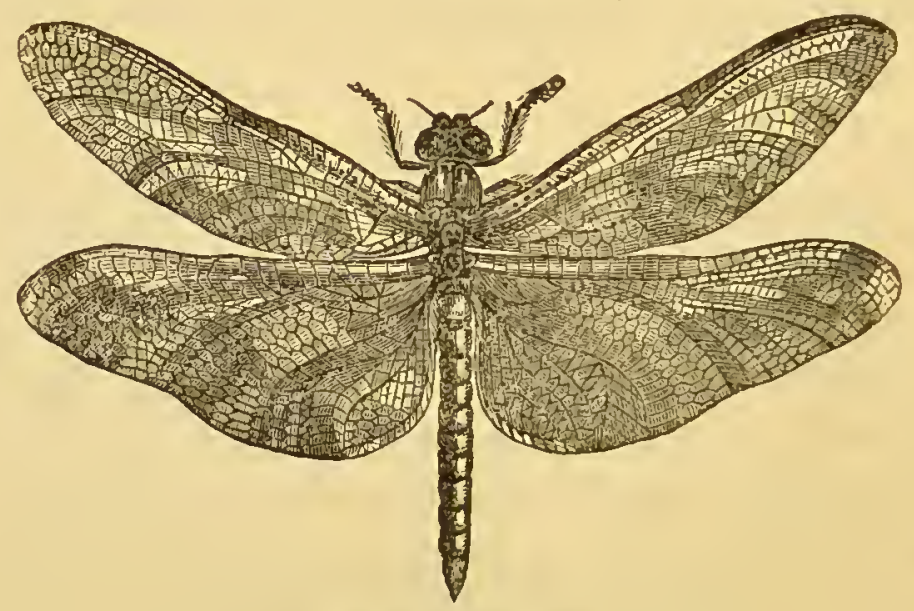

Neuropterous Insect.

wards the turns of a spiral, whose diameter gradually diminishes, and throwing the sand away with its strong square head. It then hides at the bottom of the hole, and when the victim arrives at the borders of the funnel throws at it a shower of dust to alarm it and force it to drop to the bottom of the cavity, where its blood is slowly sucked. The Dragon-flies (Libellula) pass through a series of changes which are of extremely short duration, and in the Ephemerce reach their minimum of brevity. The larva of the Libellula is more compressed than the adult. In both conditions the Dragon-flies are essentially carnivorous. 


\section{Order 9.-Coleoptera.}

The enormous number of species of this common order of insects leads to an apparent disproportion between its numerical superiority to other orders, and its absolute value as equivalent to them in the process of subordination of characters. The mouth is masticatory, furnished with mandibles and maxillæ. The wings are four, which are rarely absent, but the anterior part of wings, which are termed elytra, are hard and horny, forming protective cases for the large membranous posterior wings. The elytra are sometimes varied with bright colours, but never cross over each other. Complete metamorphosis exists in the Coleoptera, the larva resembling a worm with a horny head, the remainder of the body being soft, its mouth being formed like that of the insect in its perfect state. Each of the three wings succeeding the head has generally a pair of limbs, usually short; in many there is found a pair of false limbs, which are attached to the end of the abdomen. The nymph takes no food, and is not active; a membranous skin, which is applied exactly over the neighbouring parts, permits them to be visible. The hardness of the integuments and the brilliancy of their colours make the greater number of these insects remarkable, such as the gilded Carabus, for example, so frequently found in sandy parts. Some are carnivorous, others living on vegetable matter. We are already acquainted with a hundred and fifty thousand species. We, however, shall only mention the Scarabcei, to some of which the Egyptians paid so much respect; the Cantharides, or Spanish Flies, which live on the lilac and ash trees in Southern France and Spain, 
and furnish us with a strong blistering substance; the grain-devouring Weevils; the Woodpiercers and the Wimble, which perforate old furniture and timber; the Dermestes, who devour the cast-off skins of other animals, and thus commit immense injury in furs and collections of zoology; and lastly, the Ladybird, the Cicindela, and Carabus. When the larva of this insect is perfect it excavates in the earth an oval cell, where it changes into an inactive pupa, which is generally of a white colour, the wings and legs being folded on the breast. These insects, both in their habitation and mode of living, vary considerably in their mature as well as imperfect condition. The affinities of the Coleoptera to the Orthoptera are more manifest in their nature than those between the Coleoptera and any other order of the mandibulate insects. The intervening link is found in the Forficula. This genus, placed by Linnæus at the end of the Coleoptera, and afterwards referred by Latreille to the order Orthoptera, now constitutes the type of an order apart and intermediate between these two. The want in some Ants of the wings, sting, and ocelli has induced Mr. Macleay to believe that the Hymenoptera make an approach to the Coleoptera. Mr. Kirby would place the Strepsiptera in juxtaposition with the Coleoptera. He observes that the metamorphosis in the former, "being different from that of Orthoptera and Hemiptera, and nearer to that of the Coleoptera, this seems its most natural station, considered as an elytrophorous order." 


\section{$\mathrm{C}_{\text {IASS }}$ II.-ARACHNIDA.}

THE wingless insects which undergo no transformation, and breathe by air-slits, and were separated by Lamarck from the rest of the Insecta under the name Arachnida, or Spiders, are a well-defined and natural division of the animal kingdom. They are articulate animals, with articulate feet and legs. The head is joined to the thorax so as to form a single piece, to which Latreille gave the name cephalothorax. To this piece alone are the feet attached. They are not subject to metamorphosis, or even require new kinds of organs. The respiration is tracheal or branchial, and there are stigmatiform openings for the entrance and transmission of the air. In the greater proportion of species there is a rudimentary heart and circulation. 'The greater proportion of the Arachnida have more than six feet. Though certain of them possess organs adapted to a circulating system, they are entirely distinct from the class Crustacea. The feet and legs of Arachnides are not on the same type as those of insects. They usually consist of seven joints, and are not thinner towards the extremity, so that the tarsi differ less from the other parts than in insects. If we suppose that the two last joints belong to the tarsus, then the tibia consists of two joints, of which the first is in some the longest and in others the second. The structure of the eyes is another peculiar character in the Arachnida. 
All true insects have two eyes, with plane facets, presenting the appearance of a very delicate network; but in Arachnida the eyes are smooth, whether isolated, as among the greater number, or grouped, as in Spiders, and form a small mass, of which the surface is granular or subgranular, and not in facets. The greater proportion of Arachnides dwell on the land, a few inhabit the waters, and a certain number are parasitical on the bodies of other animals, of which they suck the juices. In general they are carnivorous, and live either on blood or on animal substances, a very small number existing on vegetable matter. Many are furnished with mandibles, which perform the functions of a trunk or sucker; and others are provided with an isolated or separate trunk, frequently accompanied both by mandibles and palpi. They are mostly solitary animals. Although possessing no evident organ of hearing, they have a perception of sound, and touch is acutely performed by their extremely sensible tarsi or palpi. The Scorpions are viviparous, but most of the species lay eggs. They are met with in every quarter of the globe; and there are no families or groups which, as in the case of other classes, belong exclusively to the Eastern or Western Hemisphere. The large Arachnida inhabit warm regions, especially the genera Scorpio Mygale, Telephonus, and Phrynus. By far the greater number of this class live on land, a lesser number in fresh water, and a very few in the sea, being precisely the converse rule to that which prevails among the Crustaceans. The Lamarckian system of Arachnida, which, in spite of its antiquity, is the most natural, united the thysanurous insects, the Bee, and the Myriapoda, or Centipedes, in one common order of antennated tracheal Arachnides. Two of these groups 
have been already mentioned among the insects, but the position of the Myriapoda is still extremely doubtful. They have no separation between the thorax and the abdomen, but the whole body is parted with rings. The oral organs consist in most of two mandibles, which are toothed at their broad extremity, and of a fourlobed underlip whose two lateral lobes represent the two lower jaws. In some the second pair of feet forms, by coalescence of their basal pieces, a sort of second underlip, which cover's the oral organs and the first pair of feet from underneath. They live in obscure places, under the bark of trees, and on the ground, under fallen leaves, stones, \&c.

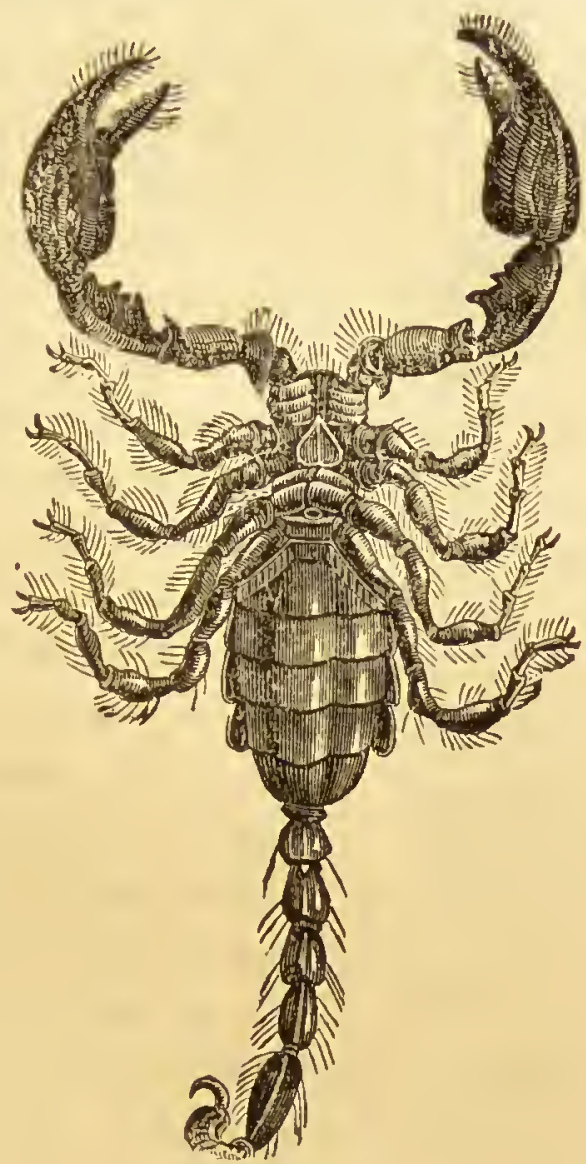

Scorpion.

In the Julidce, or Chilognatha, the two mandibles are without palpi, divided into two portions, with imbricated teeth ; they are covered by a lower lip, composed of the confluent maxillæ. They live principally on vegetable substances, some also eat dead earthworms and small molluscs. They diffuse, like many other dead animals of this family, an unpleasant smell, which in some species is very powerful; it is caused by an unctuous fluid which is secreted in small sacs or 
vesicles, which have erroneously been supposed to be respiratory organs. These animals roll themselves up spirally, with the head in the middle, in which posture they pass the winter. The second family, Scolopendride, or Chilopoda, have two mandibles with small palps, a

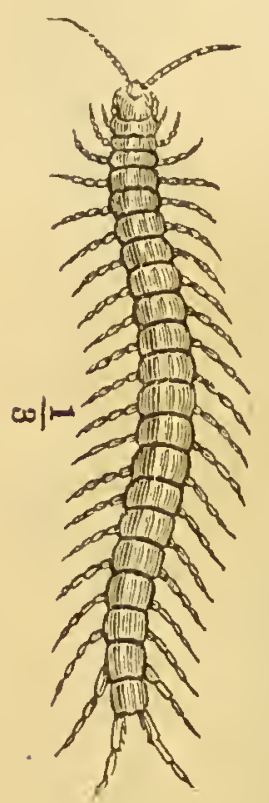

Centipede. quadrified lip, followed by two pairs of foot-jaws, the second dilated, terminated by a strong hook, perforated for the discharge of a poisonous liquid.' These live on animal food, insects, \&c. The bite of the larger species, or Centipedes, causes great pain in man and severe inflammation or swelling. Some species diffuse a phosphorescent light. In the typical Arachnida there are no antennæ. The trachea for respiration branched, but not ganglionized. There are two or four smooth eyes. In some the feet are elongate, of the length of the body, or longer than the body. The first segment of the body is tubular, exserted, perforated at the apex by the mouth. The ocelli are four, arranged in a tubercle behind the tube at the middle part of the second segment. The abdomen is small and conical. The Pycnognonida, which have been arranged by many able naturalists with the Crustaceans, do not, as they have been alleged, live parasitically on Whales and other marine creatures. The Colopoda are almost microscopic animals, which live in mosses, canals, and sluices, amongst confervæ, and in rain-water in spouts. The feet are very short, truncated, conical, indistinctly triarticulate, armed with four or three little clars, of which the posterior are placed at the extremity of the 
body. The abdomen is not distinct from the trunk. There are two oculiform points in most, and the mouth has two distinct exsertile calcareous styles. In the Acarina the cephalothorax is conjoined with the abdomen, and not divided into segments. The mouth in many is in the form of a rotellum. Some of the mites have only six feet. The Acarus domesticus, or Cheese Mite, the Sarcoptes scabiei, or Itch Insect, the Demodex folliculorum, which inhabits the sebaceous follicles of the skin of the human face, the Ticks (Ixodes), the Water Spiders (Phalangium), form a common type of this order. They run very quickly, lurk in chinks of walls, live in the ground between stones or trunks of trees, \&c. The long, thin legs, after their separation from the body,

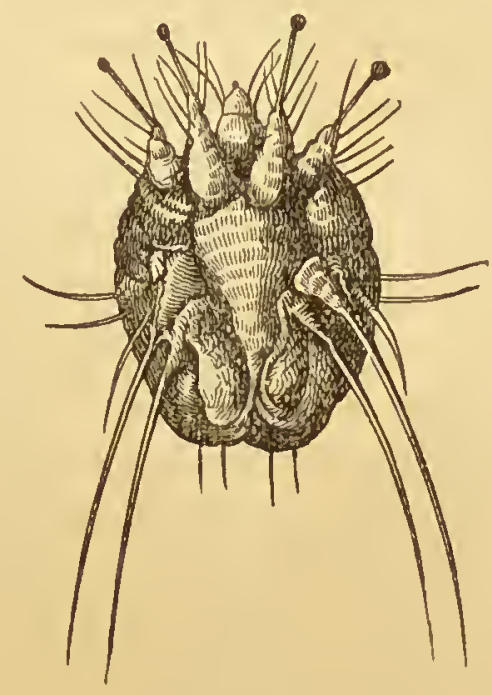

Mite. present for a long time indications of remaining irritability. The Pseudoscorpiones have the cephalothorex joined with the abdomen, which is annulate. The palps are large, terminated by a didactylous hand, or chela. In the small Book Scorpion (Chelifer), the shearshaped palps are twice as long as the body, which without the palp is scarcely one line in length. The Solifugce bave the cephalothorex distinct from the abdomen, which is annulate, and the palps are filiform and porrect, of the length of feet. Galeodes, of which the bite is alleged to be dangerous, is the best known form of the Solifugce. It inhabits southern Russia and Africa. The Pedipalpi 
have large palps resembling feet, and chelate at the apex; the abdomen is divided by segments; the pulmonary sacs have no tracheæ; there are eight or four stigmata. This order is composed of the Phrynida and the Scorpiones. The last live in the warm regions of the temperate zone and in tropical countries. In the last joint of the abdomen is a poison gland, which renders the wound of the Scorpion dangerous. Moreover, these animals are distinguished by two combshaped appendages at the back of the abdomen, which consist of a flat pedicle that runs transversely outwards and becomes thinner towards the apex; this on its inferior margin bears parallel lancet-shaped leaflets standing perpendicular to its axis. Scorpions generally inhabit dark places, under stones, among old ruins, or deserted dwelling-houses. In running, they usually carry their tails curved forward over their backs, and they possess the power of moving them in all directions, either as offensive or defensive weapons. The young are produced alive, nearly a hundred being extractable from the body of some of the Central American Scorpionidce. These were suspended or connected by a lengthened thread, each being enclosed in what may be termed a placental membrane. The female, as in the Opossums, carries her young for several days on her back, and watches over and defends them for about a month. The Scorpions are divisible into two divisions, one of which has eight and the other six eyes. The Araneida comprise the true Spiders. In these the palps are subfiliform, with the last joint in the male supplied with various appendages. The abdomen is covered with a continuous and mostly soft skin, constricted at the base, or joined to the cephalothorex by means of a petiole. The stigmata are never more than 
four, and mostly only two. The respiration in all is pulmonary, and in some is tracheal at the same time. All the Spiders form from a silky substance certain filaments with which they cover their eggs. Many also form webs and nets in which they capture their prey. At the hind part of the body four, or in most species eight, spinnerets are found, beset with fine tubercles through which the silky matter escapes. The secretion is effected in the form of an adhesive fluid, by. means of glands or

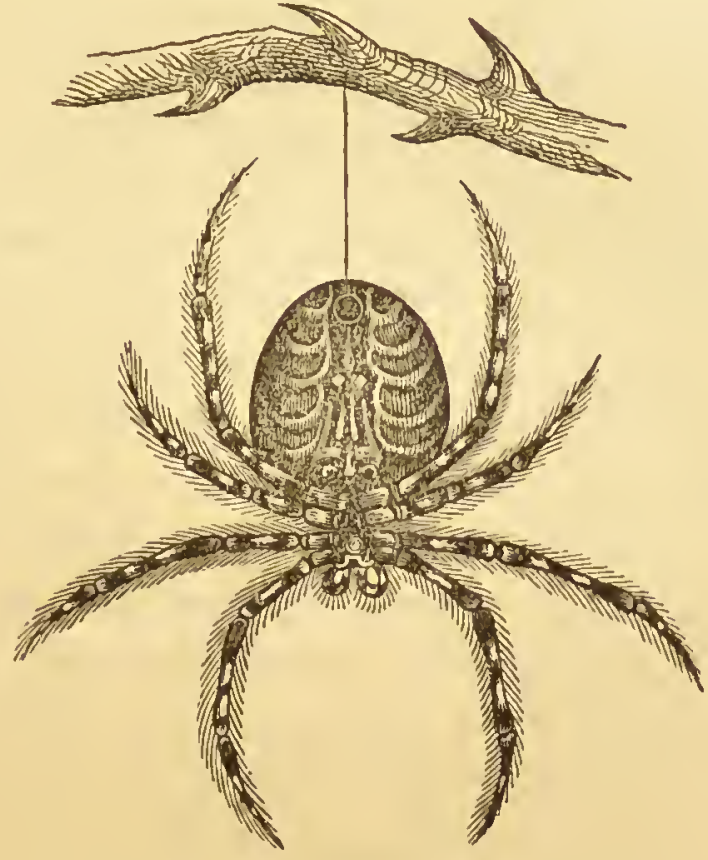

Spider. tubes of very different form-pearshaped, glandular sacs united in groups, blind tubes converted and ramified. The genus Mygale has been alleged to seize on small living birds, whence the name, but there is no evidence of any other fact than that it preys on the flesh of birds. An enormous number of genera and species of Spiders exist, some of which (Argyroneta) live in fresh water and spin a bell-shaped waterproof web, filled with air, and open below, which it attaches to water-plants by threads. The domestic Spiders (Aranea) weave close, adhesive, nearly horizontal webs in the corners of walls, in chamber windows, \&c., and a tube close by the net is a lurkingplace in which they wait for their prey. Some of the 
Spiders of Italy, e.g. the Ragno malmignato (Latrodectus malmignatus), are poisonous, and cause strong convulsions in Man. Another family of Spiders, termed Citigrada by Latreille, are erratic, not constructing webs or nets to capture prey, but pursuing their prey by running. The females of many species sit upon the web of eggs to guard them, or bear their eggs about with them in a round sac. They also, as in the Scorpions, protect their newly hatched young for some time. The Tarantella (Lycosa tarantula) is an example of the group. The Saltigrade family are erratic, do not form nets, and pursue their prey by running and rushing upon it with a leap. The Arachnida vary in their instincts as remarkably as the insects, and we may feel inclined to allow them to possess still higher faculties; they are capable of a kind of education, and show signs of a sort of intelligence. To secure their prey, many of them use different devices, whilst in the construction of their habitation they evince a singular industry. The nest of the Mygale and the webs of the Garden Spiders are equally curious. The silk used for their webs and retreats is secreted by an apparatus lodged in the posterior part of the abdomen. This apparatus, which is situated under the anus, consists of several packets of vessels, turned on themselves, and ending in pieces pierced at the summit of four or six mamelons called winders. The gluey matter expelled through these pores acquires consistence by the contact of the air, and forms threads of extreme tenuity and of immense length. The animal by the aid of its limbs reunites a multitude of these threads into a single cord, and every time the animal balances itself the winders touch the body on which it rests, and they attach the extremity of one of these threads to it; the 
opposite end being still enclosed in the secretory apparatus, of course it can augment the length at pleasure. There is much difference in the colour and diameter of the thread; a Mexican Spider constructs a web interlaced with wonderful ingenuity by red, yellow, and black threads. It has been calculated that ten thousand threads as they come from the winders of our common spiders are not equal in thickness to one of our hairs ; there are other species, found in hot countries, which form nets so strong that they can arrest the flight of small birds, and it is difficult for Man himself to get through them without a strong effort. The ways in which the Spiders arrange their silk is no less curioussome confine themselves to stretching irregular threads, while others weave webs of extraordinary regularity. Occasionally we find them motionless in the middle of their webs, waiting for their prey; at other times they hide themselves in a retreat which they have constructed close at hand, and which resembles a silky tube, or a small cup or cupola. The pulmonary pouches are bags containing laminx; these latter are very closely packed together, in a manner resembling the leaves of a book, the admitted by stigmata comes in contact with their surfaces.

The Crustaceans uniformly breathe by means of gills. There are no air-passages or stigmata present as in insects. They are distinguished from the preceding class by the presence of abdominal feet. The Myriapoda agree with Crustacea in this respect. The breathing organs in all the species are arranged for aquatic respiration. The sexes are distinct. The external integument is composed of chitine hardened by the addition of earthy particles. This crust is coloured by a pigmental substance, diffused more or less 
irregularly through its outer surface, the basis being a vascularly organised membrane or corium. The erust is minutely tabular, covered by a thin chitonous layer composed of hexagonal cells, and lined by a thin membrane which plays an important part in the moulting process. In some smaller Crustacea, the integument is translucent and of a parchment nature. The external integument, or skeleton, is always disposed in a series of segments, either actually separate and movable on each other, or confluent to a variable extent. The segments are variously proportioned and combined; but the entire body can be divided into three parts, the head, the thorax, and the abdomen, Most of the Crustacea manifest their distinction of form by different combinations and proportions of the same number of primary rings or segments. Each ring consists of certain elementary parts, which by varying their proportions contribute to the particular form of the region of the body to which they appertain. The Crustacea which have seven thoracic and seven abdominal segments form the sub-class Malacostraca. A fer large species and a number of the smaller members of the class have the thorax and the abdomen composed of respectively a greater or less number of constituent segments than seven, and are termed Entomostraca. In many Crustacea the head is not distinct from the thorax, and its place is solely indicated by the position of the eyes, the attachment of the antennæ, and the presence of the mouth; it is most completely connected and fused with a large part of the body in which the principal viscera are contained, and which may be compared, not with the thorax of insects, but also with the anterior part of their abdomen. To this part of the body another succeeds, commonly called the tail. This includes the 
posterior portion of the intestinal canal and of the nervous system. In other instances the hindmost portion is less obviously separated from the trunk, and the body is in rings or segments. In the Xiphosura the divisions are not recognisable on the dorsal surface, for the body is parted into shields alone. The antennæ, eyes, and oral organs are attached to the anterior portion of the cephalothorax, or to the head itself. The external antennæ consist commonly of three or four large and thicker joints at the base, and a filiform part terminating finely, and composed of numerous joints. Sometimes the antennæ terminate in filaments.

In Palinurus they exceed twice the length of the body. Limulus has no antennæ at all. There are commonly two compound eyes, or two groups of simple eyes. The coexistence of compound and simple eyes as in many insects is rare in Crustacea. The body is almost always divided beneath by transverse indentations into sections, but its upper part in the decapod Crustaceans is covered by a continuous shield, termed the testa or carapace. In the short-tailed Crustaceans the pectoral shield is much developed, and covers the body beneath as the shell does above. The intestinal canal is short and straight, and thus agrees with the nature of their food, which is animal. The respiratory organs consist of gills, with a few exceptions, in which the skin itself appears to be the only organ of respiration. The eggs of Crustacea, after they have been laid, often continue attached to different parts of the parent's body, and these advance to further development.

In Daphia, the eggs remain for some time in a cavity beneath the shell or the back. In Cyclops, they are carried about in two bunches by the female at the base of the abdomen. The same is observed in many 
parasitic Crustaceans. In others, they are attached to

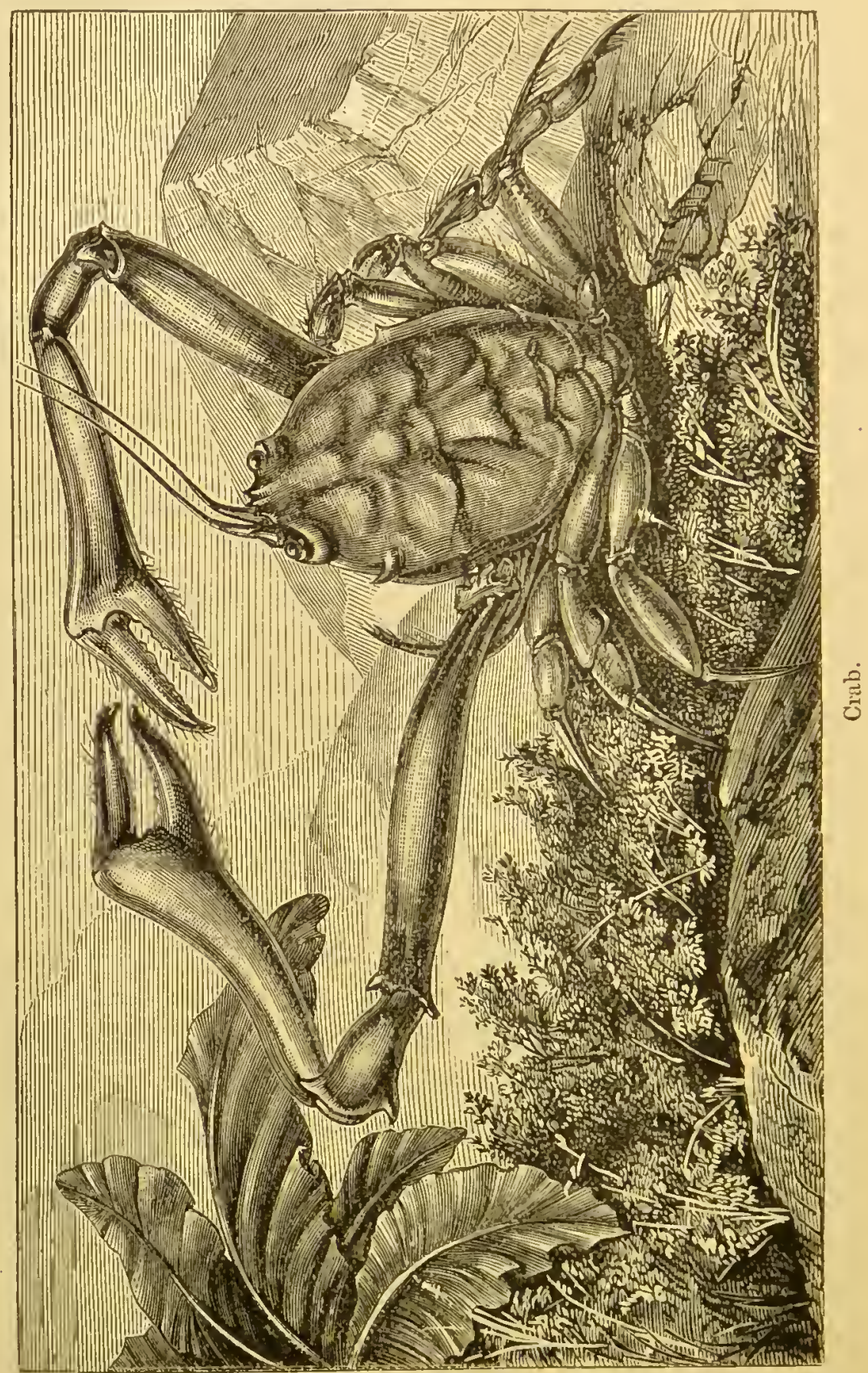

the feet by an adhesive fluid hardened into threads; 
in the ten-footed Crustaceans to the feet of the abdomen, or of the so-called tail. Other Crustaceans divest themselves of their eggs without bearing them about on their body, and attach them to other objects. Many remarkable metamorphoses are known in the earlier periods of the life of Crustacea. The Crustaceans cast their shell several times. As long as the new shell is thin and flexible, the Crayfish and Crabs are very sensitive. They then conceal themselves in holes until the new shell has attained sufficient hardness, for which a few days only are requisite. The power of restoration or reproduction is very great in this class, so that even feet amputated or broken off are replaced by new ones.

Eurypterus, Himantopterus, and Pterygotus, from the Upper Silurian and Old Red Sandstone, are the most extraordinary of the Palæozoic Crustacea. Some of these far surpassed in size the largest living Lobster or Crab. They have been considered as the representatives of the larval condition of the stalk-eyed Mralacostraca, but an affinity to the Ostracoda is shown in the following structures. The body segments are elewen or twelve in number without appendages, and terminated by a pointed or bilobed tail; their carapace is comparatively small, with compound eyes on the antero-lateral margin. Himantopterus and Pterygotus have three pairs of limbs, viz. the chelate antennæ, the foot-jaws, and the natatory feet, with their fin-like palettes which spring from the under side of their cephalothorax. Eurypterus has eight feet.

Agassiz at one time regarded them as fishes, because the surface of the body and limbs often presents a peculiar imbricated sculpture. Some of them were a yard long, and the Pterygotus is supposed to have attained the length of seven feet. It is possible that 
certain tracks formed on the sea-bed may have been made by Crustacea of this magnitude, like those of the Potsdam Sandstone of America, called Protichnites. None of the great family of Trilobites are found in the Upper Coal-measures, but are entirely confined to the Palæozoic system. Of those described and grouped in genera, amounting to upwards of four hundred, fortysix are Silurian, twenty-two Devonian, and four Carboniferous; but according to Brown, thirteen genera are peculiarly Lower Silurian, three Upper Silurian, one Devonian, and three Carboniferous. The skeleton of the Trilobite consists of a variable number of trunkrings or segments, a cephalic shield, and the pygidium or tail, composed of a number of joints, more or less anchylosed. A labium or hypostome has been discovered in some species. No indications of antennæ or limbs have ever been found, but such locomotive power as even the Chiton and Limpet exhibit when requisite there can be no doubt they enjoyed. Indications of the difference of sex have been considered to be shown in the variations of the length of the cephalic and caudal spines, and in the prominence of the head-lobes. The minute Agnostus is one of the oldest and simplest forms; only the cephalic shield is preserved; it is usually found in large shoals, as if it were the larval form of some large Trilobite. M. Barrande observes that the Sao, being first a simple disc, passes through twenty stages of growth, ultimately having serenteen thoracic segments, and two caudal joints; between the thorax and abdomen the additional segments are developed. The Trinucleus, with its ornamental border, and the Illomus, in which we find the trilobation less conspicuous than in most genera, are characteristic of the Lower Silurian strata. Calymene, or the Dudley 
Trilobite, which is so compactly rolled up, and Asaphus candatus, in which the lenses of the large eyes are frequently well preserved, and visible without a glass, are much celebrated, and are from the Wenlock Limestone. Each of the eyes has been computed to possess at least four hundred facets, and in the great Asaphus tyrannus six hundred have been supposed to have existed. The eyes are supported on pedicles in one species, the Asaphus Kowatewskii. Asaphus gigas is the largest Trilobite; some of these indicate the animal to have been eighteen inches in length. The xiphosourous order of entomostracan Crustacea have twelve pairs of feet, six attached to the cephalothorax and six to the abdomen. There is an appendage, elongate, acuminate, curvate, or gibbous above, plane beneath, adhering by articulation to the posterior part of the abdominal shield, covered with very hard skin. The Molucca Crab (Limulus Mroluccames) is found on the shores of the islands of Sunda and Molucca; its Malay name is Mimie. The Limuli live constantly in pairs, and can exist more than a day out of the water. In the order Ichthyophthira the mouth is suctorial, the rostrum tubular, including two mandibles, which are setaceous and acuminate, formed of labium and labrum conjoined, sometimes concealed, or a tubercle instead of a haustellum. The anterior feet have hooks or acetabula for fixing the body. The animalcules in an adult state adhere parasitically to fishes, and are often deformed and soft, with obsolete segments. The females are supplied with oviferous appendages and external ovaries. The Lerncea, Gillworm, or Fish-louse, is an example of this order. In the Copepoda (Cyclops), the body is oval, attenuated posteriorly, terminated by two appendages, as if by a forked tail. The maxillæ 
and foot-jaws are various in number, lamellose, and setigerous. The antennæ are either two or four. The natatory feet, mostly eight, are cloven into two oars.

The Cyclops is very common in almost all fresh water, may be frozen in the water, and after continuing motionless for days can be restored when the water is thawed, after some hours, from their torpor to their former activity. They are usually thickly beset with Vorticellce. The Ostracoda have the body compressed with indistinct segments included in a bivalve shell, with dorsal hinge. The anterior antennæ are setaceous, the posterior are geniculate and pediform. There are two pairs of maxillæ, the second pair, or foot-jaws, having a pectinate or flabelliform appendage at the base. The feet are undivided and acuminate towards the extremity - there are four or six-and slender.

The Phyllopoda have the feet lamellose, branchial, in eight pairs or more; in some other, natatory feet are inserted behind the former. There are two compound eyes. The Branchipus stagnalis and the Sand Crab, Artemia salina, form examples of this family.

Apus is another genus which has oral organs formed on the type of insects. The isopod Crustacea have the head distinct from the segment bearing the first pair of feet; the trunk is divided into seven rings, sustaining seven pairs of feet; the feet of the trunk are all undivided; the tail has segments different in number up to seven, and is supplied beneath with branchial foliaceous feet; the mandibles and maxillix are mostly distinct; the antennæ are four, and the eyes two. This order comprehends many parasitic forms, which, as 
well as the Wood-lice, were formerly employed in medicine, and possess the power of rolling themselves up into a ball. They live under stones or moss, in moist meadows, decaying wood, \&c. The Amphipods have the eyes sessile; there are four antennæ, the two middle inserted above the lateral; the mandibles are mostly furnished with palps; there are two pairs of maxillæ, and one pair of foot-jaws; the trunk is mostly divided. into seven distinct segments, bearing seven pairs of feet, not cloven into two oars; the membranous vesicles for respiration adhere to the base of some of the feet. They are divisible into two divisions - the genuine Amphipoda, and the group which has tiwo feet under the head, whence the name Lremodipoda has been applied to them. They do not swim, but creep on marine plants and animals in search of food. The posterior part of the body is little developed. The Lcemodipoda are parasitic on some Whales. The amphipodous Crustaceans have Talitrus (the Sandhopper) and Gammarus (the Pond Shrimp) among their typical genera. The stomatopod Crustacea comprise such forms as Squilla Phyllosoma and Mysis. The decapod Crustacea are the most numerous, and the most important to Man, on account of the quantity of edible species. They are divided into Macroura and Brachyura, respectively typified by the Lobsters and Crabs. In the first section the post abdomen is large, often longer than the cephalothorax; the penultimate segment has lateral appendages, which form with the last segment a terminal pinna of the tail; the shell is less hard and not so thick as in Brachyura. The Prawns (Palcemon squilla), Shrimps (Crangon vulgaris), Lobsters (Astacus maintimus), form examples of this family. The Brachyura have the tail or posterior part of the abdomen small, 
reflected forwards, almost always received in a furrow

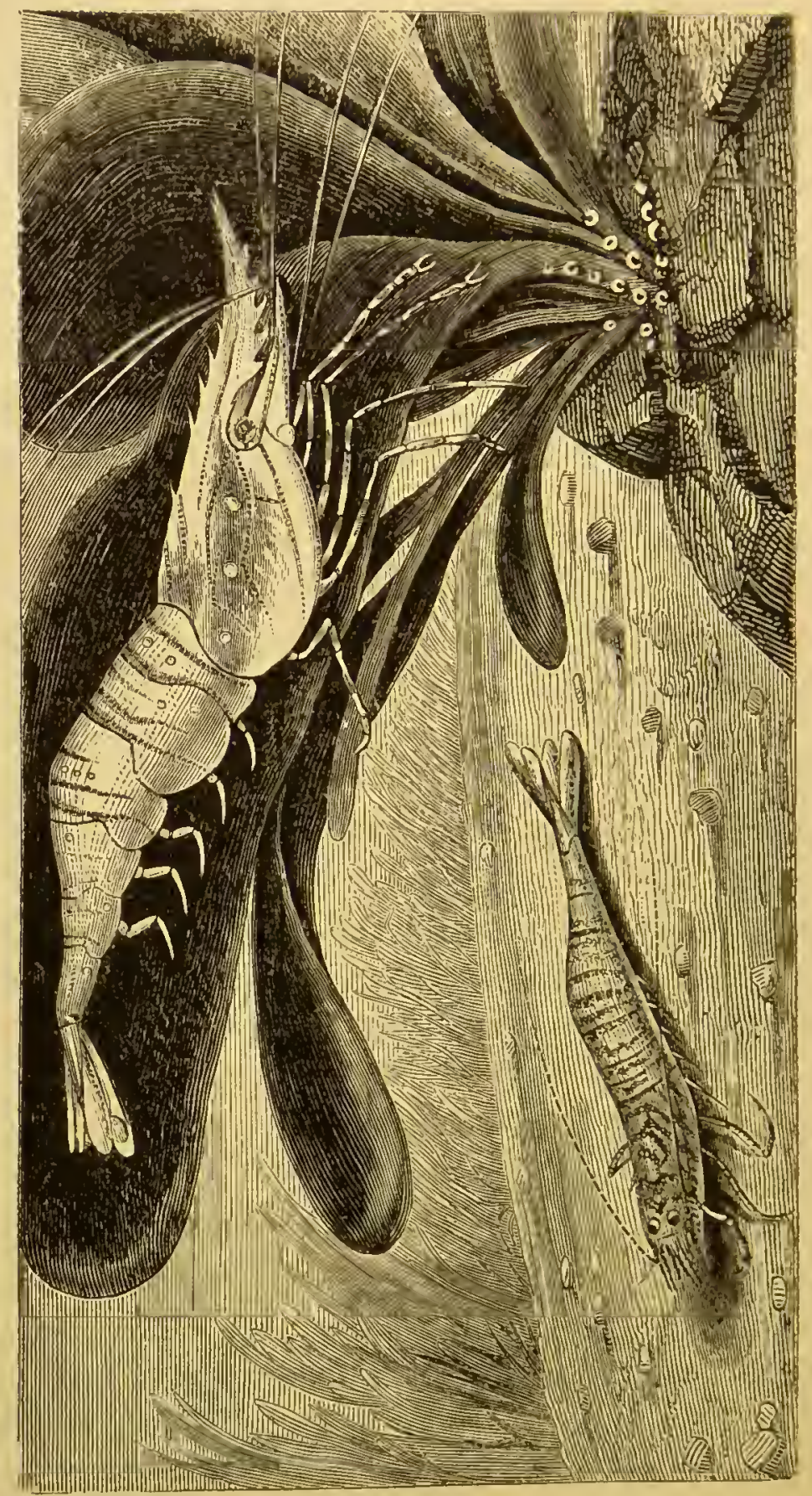

兽

of the sternum, not terminated by a pinna, with the 
appendages filiform, in the females oviferous. The antennæ are short. The genera of Crabs, of which the common Shore Crab (Cancer monas) may be taken as an example, amount to over forty in number. Nearly all are edible. 


\section{CLASS III.-CIRRIPEDIA.}

THESE are Crustaceans which are affixed in the adult 1 period, included in a multivalve shell or coriaceous covering, furnished with calcareous points, as though rudiments of shell. The eyes in the adults are none. There are six pairs of feet, with short fleshy peduncles, and two multiarticulate and horny cirri. The mouth has the mandibles and maxillæ membranous and horny. The tail is round, acuminate, and reflected between the feet towards the vertebral surface of the animal. The shells differ much in different species. Some of these animals are pedunculate; others, not the Cirripeds, however, are definitely classed in one general class. In the adult state the body of these animals is inarticulate, though on the dorsal surface, between the different pairs of feet, a separation into segments is indicated. It terminates backwards in a thin tail, which earlier writers improperly called the proboscis. Along the ventral surface there are six pairs of arms, each of which bears, on a short pedicle, two long filaments turned inwards, that consist of numerous joints, and are beset with hairs. The animals extend these filaments constantly during life from the opening of the shell, and draw them into it again, by which they introduce between the shell the water for respiration, and with it their nutriment. The nervous system consists of six ganglia, or properly pairs of ganglia, connected by two 
nervous cords. Cirripeds are found in the seas of every region of the world. They attach themselves to rocks, to marine animals (as Shell-fish, Whales, and Turtles), to different Polyparies, marine plants, the hulls of ships, the floating wreck of vessels that have been lost, as fragments of wood, bottles, \&c. There are two families. One the Balanoidea, in which the shell is sessile, truncato-conical or tabular, calcareous, open at the apex; there are calcareous valves at the aperture. The animal is conical and sometimes depressed. These are frequently called Sea Acorns, or Sea Tulips. The pieces of shell which form the calcareous tube shut upon each other with teeth. In some the base is closed by a calcareous plate, in which hollow tubes run from the base to the margin, which communicate with other tubes in the length of the shell. In the genus Coromula, the operculum is not articulated together, but is composed of two or four calcareous pieces united by membrane. In the true Acorn Shell (Balanus) the shell is conical, and composed of six laminæ or valves. The operculum is articulated, subvertical, and consisting of four valves.

The pedunculated Cirripeds, or Lepadidce, have the animal suspended by a cylindrical and inflexible peduncle. The shell is mostly compressed, or the involucrum coriaceous.

In Tetralasmis the peduncle is short and hirsute. The shell has four valves. In Anatifa (the Goose Muscle or Barnacle) the peduncle is smooth and elongate in some. The Anatifa lavis has been connected by vulgar tradition with the Barnacle Goose (Anas bernicla), of which it was alleged to be the egg, by the predecessors of modern researches into the Cirripedia. The fossil Cirripedes consist of the ordinary forms of the still- 
existing Balanidce; they belong chiefly to the sessile division. In the Eocene Tertiary they are rare, but are found more abundantly afterwards. In the shelly beds of the northern drift the Balanus porcatus attains a great size; it is a puzzling fossil, and its large basal plate when detached has caused some mistakes. In the middle division of the Crag a Coronula has been found; the Crag has afforded many cetaceous bones. In older deposits remains of pedunculated Cirripedes occur, but they are generally scarce and fragmentary. A species of Pollicipes is found in the Lias, adhering to driftwood perforated by bivalves. Another occurs in the Oxford Clay attached to the shells of Ammonites, which probably floated in the sea after death; they are also attached to groups of seaweed. The Turrilepas is found in the Wenlock. The Chalk affords a species of the anomalous genus Verruca, many species of Pollicipes and Scalpellum, and the only extinct genus of Cirripedes-Loricula. This remarkable fossil exhibits, in all the examples hitherto found, only one side, and is found attached to Ammonites. In the imbrication of its valves and this unsymmetrical development it resembles Verruca znore than any other Cirriped. At the present day the Philippine Archipelago, which is the richest marine province, affords only five species during the deposition of the great cretaceous system-the Lepadidee arrived at their culminant point; there were then three genera, and at least thirty-two species. 


\section{CLASS IV.-ANNELIDA.}

THE name of this class should, perhaps, on account of the derivation from the Latin anellus, an earlier form than annelus, be written Anellata or Anellides. They are a class of articulate animals with a long cylindrical body, divided into ring-like segments, having red blood and respiratory organs, but no jointed extremities. They are classified as follows:-
Abranchia.
Suctoria.
Leeches.
Terricola.
Earthworms and Naiads.
Dorsibranchiata.
Errantia.
Nereids and Centipedes,
Cephalobranchiata. Tubicola. Lug Worms and Sea Mice.
Serpulans.

The body of ringed Worms is generally much elongated and cylindrical; in some instances it is broader and oval. It is divided by transverse folds into rings or girdles, which in most species are very numerous, and in one and the same species may vary greatly in number, at least when the number is very great. The common Leech has about a hundred such; Emina gigantea, above four hundred; in the Phyllocloce laminosa there are nearly five hundred rings; while in other individuals of the same species there were sometimes only three hundred. The integument is always soft, and never horny; but some live in sheaths or shells, occasionally comparted with bits of shell or grains of sand into a mosaic work of considerable strength, and sometimes, as in Serpula, consisting of calcareous matter. 
In some, the head is not distinct from the succeeding rings of the body; in other's, it is distinguished from the trunk by its different form. On the rings of the body spines or hairs'are usually set, which, however, may be entirely wanting, as in the Leech. In most, the hairs or spines are placed upon minute lateral tubercles, which may be considered as rudiments of feet. These feet are never jointed as in insects, and are usually divided into two parts, which may be named oars or fins, one on the dorsal surface, another on the ventral surface. On each of these two projections a bundle of hairs or setæ are set. In the Dorsibranchiates there are found in addition, on the dorsal surface towards the sides, and near the oars, or upon them, the external respiratory organs-gills of various forms, sometimes divided like a comb or branched like a tree, sometimes composed of simple filiform appendages resembling the cirri of the oars. In other ringed Worms the gills are situated at the most anterior part of the body. In the Leech, the Earthworm, and allied genera no respiratory organs are visible externally. The nervous system of the Annulata consists of a double median central chord or chain of small ganglia, extending from one end of the body to the other; the two chords diverge anteriorly to allow the passage of the œsophagus, and again unite above that tube to form a distinct, though small, bilobed cephalic ganglion or brain. All have organs of respiration, adapted in a few species for extracting oxygen directly from the atmosphere, and in the rest of the class through the medium of water; in these the gills are usually external, vary considerably in form and position, and form the only part of the external surface which retains the ciliated epithelium. The suctorial Annulata comprises the Leeches, which 
are provided with a suctorial disc at each extremity of the body, and have neither bristles nor tuberculate feet. The second is the Annulata terricola, which includes the Earthworms; these have neither tubercular feet, nor external gills, nor suckers, but are provided with short stiff bristles fulfilling the functions of feet, and which are, in fact, rudiments. The tubicole Annelida have bristle-bearing feet, and the respiratory organs at the anterior extremity of the body. These Annelides can scarcely be said to have a distinct head. The integument is naked, soft, and vascular in the whole class. It consists of a delicate epidermis and a firm corion. In some Earthworms the skin is red; in Leeches it is variegated by a layer of pigment cells. In most Annulata the epidermis reflects iridescent tints produced by the multitude of small strice on the surface. In some of the Errantia the skin develops threadlike and platelike processes, which in some species of Aphrodite are so large and numerous as to overlap one another like scales. The reproductive power is in some animals of the class very great, and in others small. Worms which have been cut through transversely continue to live for a long time. Many species shed a phosphorescent light. Annulata are universally distributed in all seas and countries, though few marine Annelida comparatively have been described. In the suctorial order, the animal is able to convert the anterior extremity of the body into a suctorial cavity. They creep along the ground by affixing this suctorial apparatus, and by contracting and extending the body alternately. They swim with great rapidity by bending the body with a serpentine and sinuous motion. The genera Clepsine, Hirudo (Leech), and Homocharis form leading types. The common Leech (Hirudo medi- 
cinalis) is found almost everywhere in Europe in fresh water, especially in ponds, marshes, and canals. In winter it rolls up annularly, and conceals itself in the mud. It lives exclusively on blood. It is hermaphrodite. The anterior sucker has its upper lip composed of many segments; its opening is transverse, and it contains three armed jaws, each having on its edge two ranges of very fine teeth, which permit them to perforate the skin without making a dangerous wound. They assemble their egg's in cocoons, which are surrounded with a fibrous excretion.

The setigerous order are divisible into those which have no external organs of respiration (Abranchia), and those in which the gills are external. The common Earthworms (Lumbricus) are examples of the first group. The body is provided with setæ without rudiments of feet, is cylindrical, attenuated at both extremities, obtuse posteriorly. The mouth is subterminal under the projecting upper lip. They are oviparous; but the method of propagation has not been satisfactorily shown. The body is composed of upwards of a hundred and twenty rings. It traverses the soil in every direction, swallowing a quantity of sand. In the allied genus, Nais, the body is elongated, but the rings are less distinct than in the Lumbrici. They inhabit boles in the mud, from which one half of the body projects, and is constantly in motion. The order Errantia comprises the most brilliant and highly organised individuals of the class.

In Arenicola, there are branchiæ resembling small trees on the rings of the middle part of the body only ; neither teeth, tentacula, nor eyes are visible.

The Lobworm (Arenicoln piscatorum) is very common in the sand on the seashore, where it is disinterred 
by the fishermen, who use it as a bait. It is about a foot long, of a reddish colour, and diffuses an abundant yellowish liquid when touched.

Amphinome is one of the most beautiful of animals, it having long bundles of lemon-coloured setre, and beautiful purple plumes on the branchiæ.

Eunice gigantea is the largest known Annelide, being

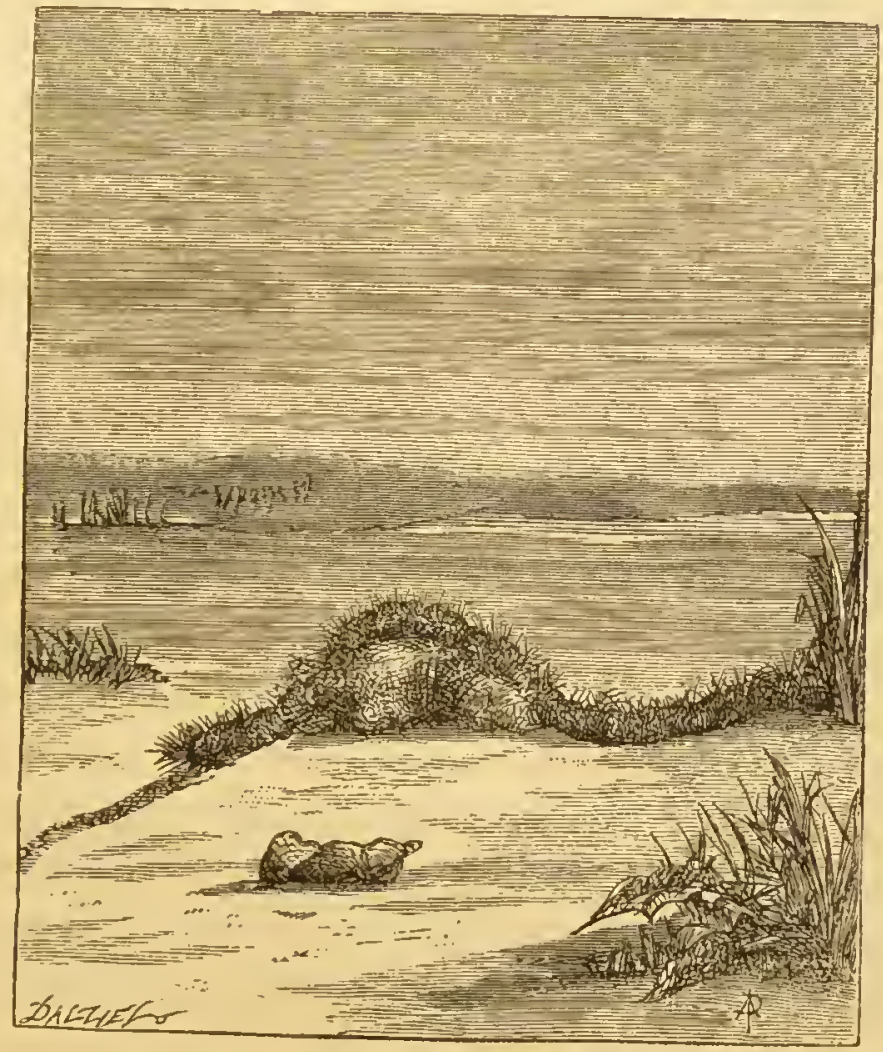

Arenicola.

four feet in length. It is comparatively common in the West Indian seas. The true Nereids or Seaworms have an even number of tentacula attached to the sides of the base of the head, and a little farther forward two others which are biarticulate, between which are two simple ones.

The Aphrodite aculeata, or Sea-mouse, is one of the 
most beautiful marine objects on the British shore. It is ordinarily five or six inches long and an inch and a half broad. The hairs on the two sides of the body are glistening green and red, or playing with all the colours of the rainbow; the back is clothed with a folty covering which consists of interwoven hairs. When this covering is opened, five nearly circular plates are seen on each side which partially cover each other, and of which the middlemost are the largest shown. If two consecutive plates be separated, there are seen on the ring that lies between them small longitudinal nodes which are parted by a pit, and are provided outwards and backwards with pectinated appendages, as though torn at the margin.

The tubicolous order are divisible into many genera. Some of them form a calcareous homogeneous tube like the shell of the Mollusca; others construct one by agglutinating grains of sand and particles of mud and fragments of shells by means of a membrane. The tube of others is merely horny or membranous.

The Serpula, so common an object on our seashore, may be taken as the type of the first division. The calcareous tubes of the Serpulce twine round and cover stones, shells, and all submarine bodies. The section of these tubes is sometimes round and sometimes angular. The mouth is situated between the branchiæ, not tentaculate, and transverse. The branchiæ are two large, pectinate, flabellate, with bearded laciniæ and a cylindrical filament at the base of different length in each branchiæ, the longer sustaining an orbicular disc or infundibuliforum operculum. The calcareous tube is procumbent, twisted, or convoluted into a spire, including the animal. In an allied genus (Hcrmella amphitrite) the first segment of the body is supplied on 
both sides with a triple series of very glittering tufts. The rudiments of the feet, in addition to setæ, are supplied with an elongate cirrus, which performs the office of branchiæ. The animals live gregariously, included in tubules made of sand and fragments of shells, conjoined to form a common honeycombed mass. The sub-division of Amphitrite, which is termed Amphictene, has numerous tentacles covered with villæ denticulate. The setæ glisten with gold, and are in a double row in the anterior segment of the body. The worm whose tube is termed sandquiver is frequently met with on the European coast.

Terebella, an allied genus, inhabits an artificial tube, composed of grains of sand and fragments of shells. The body has fewer rings; the mouth is bilabiate and transverse; the upper lip is produced, surrounded by numerous long tentacles; there are rudiments of feet, with a double row of uncinate setæ at most of the ventral pinnæ. In Sabella the tube is composed of pieces of clay or mud, and is rarely calcareous. The species are large. Their face-formed branchiæ are especially beautiful. Some have a membranous disc on the anterior part of the back, through which pass the first pairs of the bundles of setæ; their pectiniform branches are spirally contorted, and their tentacula reduced to slight folds. 


\section{Class V.-ENTOZOA.}

THIS name is given to an extensive series of inver1 tebrate, low-organized, and generally vermiform animals. Most of them are parasitic on the internal organs of other animals. Their blood is colourless, which in the higher organised species is circulated in a closed system of vessels, having neither auricle nor ventricle. They have no organs of sense, no

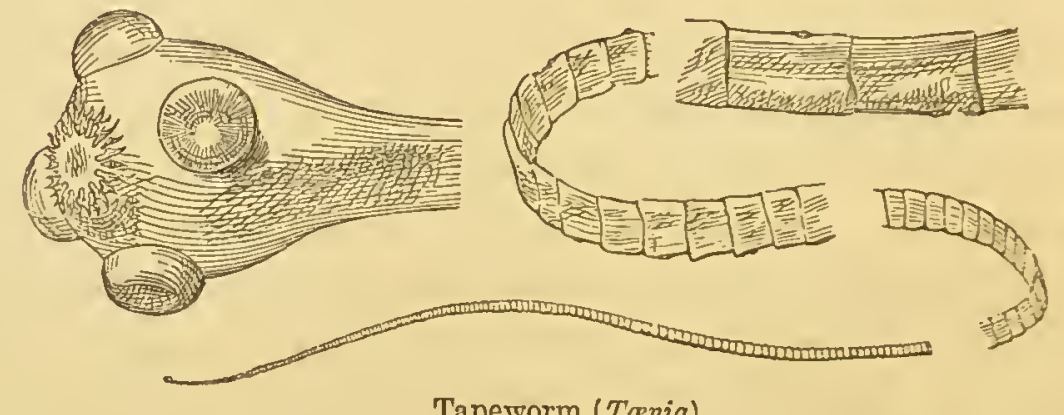

Tapeworm (Tania).

respiratory organs, and no articulated members for locomotion. The digestive system consists of either a tube with both oral and anal orifices freely suspended in an abdominal cavity, or of tubes or cavities excavated in the parenchymatous texture of the body. and without an anal outlet. In the higher organised Entozoa a filamentary nervous system has been recognised, complicated with a ganglion near the mouth. The generative system is hermaphrodite, unisexual, or diocious. The principal species of Entozoa known to infest the human body are the following: Ascaris vermicularis, Ascaris humbricoides, Trichocephalus dispar. 
Bothriocephalus latus, Toenia solium, in the alimentary canal; Distoma hepaticum, in the gall-bladder; Acephalocystes endogena, Echinococcus hominis, in the substance of the liver, in the omentum and cavity of the abdomen; Filaria bronchialis, in the bronchial glands; Strongylus gigas, in the kidney; Spiropterc hominis and Strongylus spiniger, in the urinary bladder; Polystoma pinguicola, in the ovarium ; Trichina spiralis, in the voluntary muscles; Cysticercus cellulosce, Filaria medinensis, and Filaria oculi in the cellular tissue. This list is not of course complete, as the recent labours of Spencer, Cobbold, and other helminthologists have greatly increased our knowledge of the parasites affecting man. Rudolphi distributes the intestinal worms into five orders, which are characterised as follows :-

Order 1. Nematuidea (Round Worms).-Elongated; rounded and elastic body; a separate mouth and vent; an intestinal canal; distinct sexes.

Order 2. Acanthocephala (Hooked Worms).-Head with a retractile proboscis; body roundish; utricular elastic bead, armed with hooks or recurved spines; sexes distinct.

Order 3. Trematoda (Flukeworms). - Body soft, rounded or flattened; suctorial pores; male and female organs in the same individual.

Order 4. Cestoidea (Tapeworms).-Body elongated, flattened, soft, continuous, or articulated; head either simply labiated, or provided with pits (bothria), or suctorious; orifices either two or four in number; male and female organs in the same individual.

Order 5. Cystica (Hydatids).—Body flattened or rounded, continued posteriorly into a cyst, which is sometimes common to many individuals; head provided 
with two or four pits, or with four suckers, and with a cluster of hooklets, or with four unarmed tentacles; sexual organs hitherto indiscernible.

The Entozoa are included in the last four orders of Rudolphi. They have no distinct intestinal canal; and Cuvier considered the presence of this structure in the Nematoidea of sufficient importance to form the character of a primary group, which was equivalent to all the remaining orders combined. He observes that the orders thus distinguished might form two classes. The first order is termed by Cuvier, Cavitaires, and in it he includes the genus Pentastoma of Rudolphi and the Epizoa, or Vers rigidules, of Lamarck, as well as the nematoid Entozoa.

The organisation of the Pentastomata, which were defined by Froelich prior to Rudolphi under the name of Linguatula, entitles them to rank with the highest organized Entozoa ; but as regards the Epizoa, or the external lernean parasites of fishes, although they agree with the Nematoidea and all other Entozoa by having no distinct respiratory organs, the ciliated natatory extremities which they exhibit in the roung, and the external ovarian appendages of the adult, are characters which indicate their intimate relationship with the siphonostomous Crustaceans, and raise them above the Entozoa. Professor Oren has combined the Nematoidea of Rudolphi with the genera Porocephalus, Linguatula, Syngamus, \&c., all of which, under the habit of cestoid or trematode worms, form a class named Cœlelmintha. The types of three different orders are already embraced in this class; the Nematoidea of Rudolphi forms one, and a second for the Linguatula has been established by Diesing; this, with 
other congeneric species, has been called Acanthotheca. The type of a third order of Cœlelmintha is clearly indicated by the remarkable organisation of the genus Syngamus, as described by Siebold.

The four orders of intestinal worms in which the digestive function is carried on in blind canals excavated in the parenchymatous substance of the body, but which have no distinct intestine, have been combined by Cuvier into a group which he names Vers intestinaux parenchymateux. Professor $\mathrm{O}$ wen has proposed for them the name of Sterelmintha. This group has been subdivided by Cuvier into three families or orders; the first corresponds to the Acanthocephala of Rudolphi, the second to the Trematoda, and the third is equivalent to the Cestoidea and Cystica. Cuvier makes a fourth order of the genus Ligula of Bloch, restricting to it the application of Cestoidea. It must be objected to this distinction that the passage from the Tania to the Ligulce is rendered very gradual by the traces of bothria and of generative organs; these are found in the higher organised Ligulce which infest the intestines of some aquatic birds. With respect to these, Rudolphi hazarded the hypothesis that these species are the more simple Ligulce of fishes, which are developed into a higher grade of civilisation by means of the abundant nutriment and warmth which they enjoy in the intestines of the birds which have swallowed the fishes so infested. These migrations have since been experimentally proved in respect to several Intestinalia, particularly as regards the Cystica, Rud. ; these when introduced into other animals become Cesroidea, as from the flesh of prey into the gut of the devourer. The Cystica are in short incompletely developed Cestoidea. The intestinal worms, as at present 
known, form two classes, each of which is divided into three orders.

\section{Class 1.-Coelelmintha.}

Order 1. Nematoidea.-Ex., Filaria medinensis., Fil. oculi, Fil. bronchialis, Ascaris lumbricoides, Asc. vermicularis, Trichocephalus dispar, Spiroptera hominis, Strongylus gigas, Strongylus spiniger. The Trichina spiralis is a larval Nematoid, which acquires fully developed sexual organs when received into the intestinal canal, whence their progeny migrate to the muscular tissue.

Order 2. Acanthotheca.-Ex., Linguatula toenioides.

Order 3. Syngamoidea.-Ex., Syngamus trachealis.

\section{Class 2.-Sterelmintha.}

Order 1. Acanthocephala. - Ex., Echinorhynchus gigas.

Order 2. Trematoda.—Ex., Distoma hepaticum, Polystoma pinguicola, Planaria.

Order 3. Tænioidea. - Ex., Bothriocephalous latus, Trenia solium: the Cysticercus cellulosce and Echinococcus hominis are larval states.

The examples quoted are species which infest Man, with the exception of Planaria and allied Turbellavia, and of the orders Acanthotheca, Syngamoidea, and Acanthocephala, which have no representatives among the human internal parasites. The Bothriocephalus latus is the typical species of Tapeworm in Russia and Switzerland, and occurs less frequently in Germany and Holland. It is distinguished from the Tonia 
solium not by the head alone, but by the greater or less breadth of the body. In Trenia solium, the middlemost joints are longer than they are broad. In Bothriocephalus latus the joints throughout the entire body have more breadth than length, and in the middle of each joint are two apertures, of which the anterior is the larger and more readily perceptible, from it the penis occasionally hangs everted. In Trenia solium, the apertures are at the edge of the joints, and alternate irregularly, i.e. they are situated sometimes on the left, sometimes on the right, without determinate order of succession. The Cysticercus is a solitary form of worm, with depressed and rounded body passing into a caudal vesicle. This is the scolex, from whence spring the long flattened tape-like worms. The cystic worm undergoes a series of changes, by which the whitish and rounded scolez becomes attached to the walls of the duodenum to await its subsequent growth, when its transverse wrinkles are multiplied, and in the course of a few days the body becomes divided into segments, which, at first very short, elongate and soon present the marginal generative pores. Küchenmeister, by feeding a Dog with flesh in which were concealed portions of a Ccenurus, formed after some time a Tania in its intestine, which until then had been met with only in the Wolf; and giving segments of this Tania to Sheep, they became in due time victims to Cænurus, numbers of which were found in their brains, presenting different degrees of development. The name Echinococcus is given to the hydatid cyst filled with the larvæ of tænioid worms. It occurs in the liver, abdomen, heart, voluntary muscles, and ventricles of the brain of Man, and in the liver, lungs, \&c., of the Ox, Sheep, Goat, Ape, Pig, \&c. 


\section{Sub-Kingdom-RADIATA.}

YUVIER included in his Radiata a larger group of mammals than we shall include under this head. They are divided into two great divisions, the Radiata proper, under which we shall place the Echinodermata and the Colenterata. The latter have been well defined as animals whose alimentary canal communicates freely with the general or "somatic" cavity of the body. The body is generally composed of two layers or membranes - an outer layer, or "ectoderm," and an inner layer, or "endoderm." No circulatory organs exist, and in most there are no traces of a nervous system. Peculiar stinging organs or thread-cells are usually if not always present, and in most cases there is a radiate or starlike arrangement of the organs, which is especially pereeptible in the tentacles, which are, in most cases, placed round the mouth. There are distinct reproductive organs in all. The establishment of Colenterata as a separate sub-kingdom was advocated by Frey and Leuckart, but has not received general assent amongst the majority of English zoologists. As a group, however, its adoption is eminently convenient.

The Radiata may be grouped as follows :-

$\begin{array}{lll}\text { Bryozoa, } & \text { Acalephø. } & \text { Echinodermata. } \\ \text { or } & \text { Anthozoa. } & \\ \text { Polyzoa. } & \text { Hydrozca. } & \end{array}$

We shall first consider the Bryozoa, or Polyzoa, which 
Cuvier included with Polypi, Gegenbaur with Vermes, and some have grouped with the ascidian tunicary Mollusca that were last described. All of them fundamentally differ from the Cœlenterata in the superior development of their alimentary canal. They are all minute and aquatic, and form composite structures which are almost always fixed. Plumatella being taken as a type, is found to be of a composite structure, consisting of a number of individuals joined into a common mass. This mass is termed by Allman a polypary or conoecium, and the individual is termed a Polypide. The mass branches in a tree-like shape, whence the name Bryozoa has been given to the group. Each Polypide is retracted within a cell, formed by the wall of its proximal cavity, and hardened with horny matter; each is a tube, which is attached by its base to the rest of the polypary, the mouth opening at the free distal extremity, which is crowned with a circlet of tentacles supported by a disc (lophophore). The freshwater forms have the disc horseshoe shaped, and supporting a double row of tentacles; the marine, with a few exceptions, have the lophophore circular, and the row of tentacles is single. The larger including mass or cœnocium is composed of two membranes. The outer, or ectocyst, is tough, brown, horny, and often strengthened by silicious or earthy particles. The external membrane is the endocyst which lines the ectocyst; it is soft, transparent, and contractile, and projects beyond the ectocyst, to form the evertible part of the body.

Digestive system: The mouth is a slit, which is guarded by a valve (epistome) on the anal aspect. This is peculiar to fresh-water forms; hence it is called phylactolœmatous, as opposed to marine gymnolœma- 
tous. The tentacles are hollow, as well as the crescentic lophophore and the epistome. Their cavities communicate with the perivisceral cavity. Both of the surfaces are ciliated. The crescent of the tentacles is surrounded in the lower kind by a delicate cup of membrane attached to the back of each tentacle (calyx). This is peculiar to the fresh-water form.

The osophagus is ciliated internally; the stomach is not ciliated, and is cæcal, the œsophageal and intestinal openings being placed close to each other. In marine forms there is a distinct gizzard. The intestine leads without further bend to the anus, and is placed at a point just below the tentacular ring, and opposite the concave side of the lophophore. There are brown cells, possibly hepatic, in the walls of the stomach.

There is no heart or vessels ; the fluid of the perivisceral cavity must represent the blood; it is colourless, and crowded with irregularly shaped particles; it does not stagnate, but is constantly redistributed by the cilia lining the endocyst, and also by changes in the position of the body-wall.

Respiration: This is partly by tentacles, partly by the surface of the endocyst, and partly, in some cases, by the regular sucking in and throwing out of water by the œsophagus.

The nervous system consists of one ganglion, which is placed between the commencement of the œsophagus and the rectum; it is therefore subœsophageal, giving off branches to all the surrounding parts.

Reproduction is by eggs and by gemmation. They are all hermaphrodite. The ovary is roundish, and is fixed to the endocyst a little below the lophophore. The testis is irregular, lobed, and formed upon a flexible cord, attached by one end to the stomach and by the 
other to the floor of the cell. The spermatozoa are formed in "vesicles of evolution." The ova after fertilization undergo much of their development within the body of the parent; the mode of escape is by rent, not by duct.

In the genus Eschara, the polypary of the aggregate cells are sub-stony, foliaceous, ramose; both surfaces of the polypary are covered with opposed cells. In Retepora the polypary is reticulo-ramose, or perforated reticularly and calcareous. The cells of the Polypus are situated on one side only of the polypary. Adeona has the polypary frondescent or fan-shaped, on both sides celluliferous and calcareous, supported by a stem sub-articulate and not polypiferous. In some of the species the stem bears a flattened expansion, perforated like a sieve or net, from coalescence of the branches and permanence of the intervening spaces. In Flustra, which is one of the commonest and most characteristic Bryozoa, the polypary has aggregate cells, membranaceous frondescent, lobate, or expanded into a crust on one or both sides. The cells are often aculeate on the anterior margin; their opening is transverse, semicircular, or lunate. All the above bryozoan forms have the posterior harder portion of the animal covered by a movable operculum; the tentacles are sixteen or more. In the next section of Bryozoa, the posterior harder part of the animal is without operculum; there is a setose collar or a crown of setæ in the anterior part of the body in many, or a muscular ring in others, in place of an operculum. In Tubulipora the polypary is calcareous, made up of crowded tubular cells, which are either parasitic or incrusting; the aperture of the cells is orbicular; there are twelve tentacles. In Cellularia the polypary is ramose, composed of cells, 
arranged in a single or double row or verticillate, tubular, calcareous, with orbicular aperture. On the polypary of this and some other genera are developed organs which have some resemblance to a bird's head. They have joints which admit of motion like the jointed feet of Articulata, which motions persist even when the animal has been for some time dead.

These bird's-head processes, or avicularia, are scattered over the whole surface of the body. Each of them is like the head of a bird, with an upper and lower beak, and the whole is supported on a slender neck. The beak opens and shuts at intervals. In Serialaria the polpary is horny and ramose, composed of cylindrical and parallel cells, which cohere in rows. Anguinaria has the cells elongate, sub-clavate, perforated by a lateral aperture, set on a creeping fistulous stolon, erect and distant.

Bowerbankic has been selected by Farre and Rupert Jones as a typical example of the Bryozoon. During the expanded state of the animal the tentacula are kept quite straight and motionless. Each tentacle is provided upon the outer aspect with a series of stiff and immovable spines, probably serving to keep off any foreign bodies that by their proximity might interfere with the movements of the cilia. Besides the stiff spines, the tentacles are covered with an immense number of vibratile cilia, which at the will of the animal are thrown into most rapid movement, so as to produce strong and continuous currents in the surrounding fluid, whereby particles floating in the neighbourhood are hurried along with great velocity. From the direction of the streams produced by the cilia - namely, towards the mouth-it is seen that a succession of currents are produced which 
compensates to a great extent for the fixed condition of the Polyzoon. When animalculæ which float in the vicinity are forced towards the mouth by these currents, they are seized towards the centre of the tentacular zone, and being at once seized are immediately swallowed. The tentacula are highly irritable and sensible of the slightest contact. The mouth appears to be a simple orifice, incapable of much distention, through which the particles of food brought by the ciliary action pass into a capacious œsophagus, which gradually contracts its dimensions and forms a globular muscular gizzard, to which succeeds a stomach studded with brown specks, apparently of a glandular nature, and probably representing a biliary apparatus. The little animal is seen projecting from its cell, with the arms extended and the cilia in full operation, the upper part of the body being frequently turned from side to side over the edge of the cell, the extremity of which, from its peculiar flexibility, moves along with it. The food is retained for a considerable time in the stomach, and may be frequently seen to be regurgitated into the gizzard, whence, after having been again submitted to its operation, it is returned to the stomach. Here it is rolled about by the contraction of the parietes, and is submitted at its upper part to a rolling motion, whence, after a partial digestal in the stomach, it is rapidly pushed by the contraction of the intestine towards the anal orifice.

Halodactylus has the polypary fleshy, gelatinous, and pellucid. The polyp has twelve to sixteen tentacles, which are often longer on one side.

Another family of Polyzoa exists, in which the tentacles are set pectinately on two arms, and are numerous. 
In Cristatella the polypary is free, disciform, and polypiferous on the margin. In Plumatella it is affixed, tubular, with extremities of the tubules retractile and polypiferous, the stem being in the true Plumatellæ branched or lobate, and in the Alcyonelle incrusting, regular, and multiform, composed of aggregate and cylindrical tubules. 


\section{Class I.-ECHINODERMATA.}

THIS class comprises animals having a coriaceous 1 skin, without spines or quills or a shell-test. There is an intestinal canal, hanging free in the cavity of the body by single threads or membranes, usually long and tortuous, or provided with lateral appendages if it be short. There are blood-vessels and respiratory organs. When parts are multiple the number five

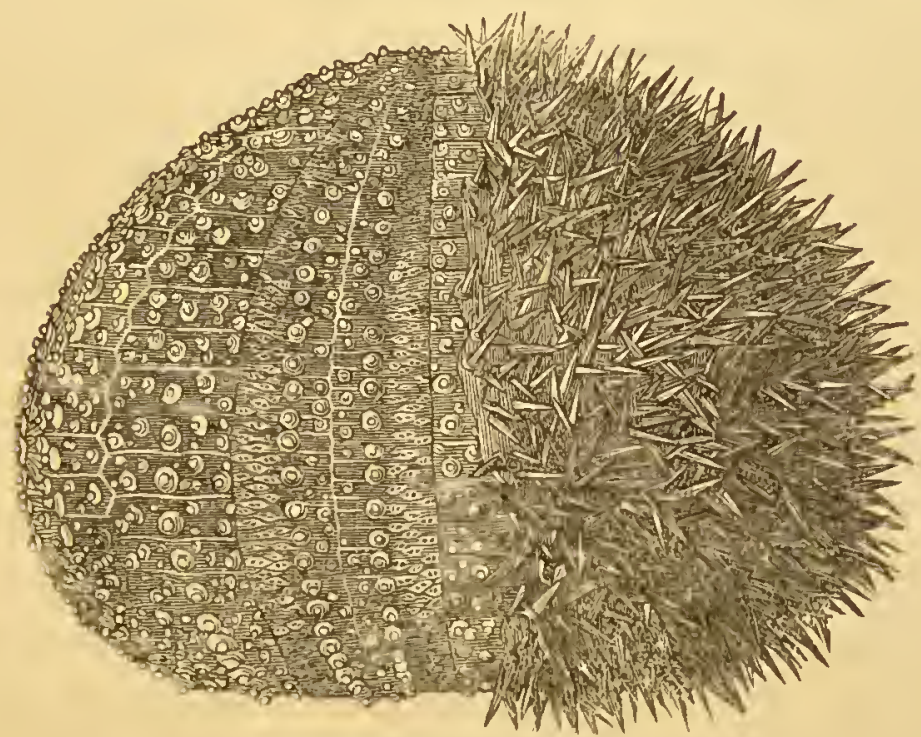

Sea-Urchin (Echinus).

prevails remarkably. In the Sea-urchins and the Star-fishes, the body has a quintuple arrangement, which in the Sea-urchins is round or somewhat pentagonal, flat and spread out in rays in the Starfishes, with the mouth on the inferior surface. In the Star-fishes, of which the body is flat, the mouth conducts 
to a wide stomach that fills the dise of the body. In Comatula, on the same side as the mouth, an anus exists, which in the true Asterice is opposite the mouth on the back of the disc. In the Ophiurce and in Euryale it is wanting. In the Asterice proper the intestinal canal has cæcal appendages which divide into branches, and fill the rays of the body; in those species whose intestinal canal is a blind sac, the appendages proceed directly from the stomach, at whose base, on the dorsal surface, there are usually two cæcal appendages in addition. In those Asterioe which have an anal opening, the stomach is divided by a circular fold from a compartment to which the blind appendages of the rays are attached. In the Sea-urchins (Echinus) the intestinal canal is very long. The œsophagus is tortuous, narrow, and beset with numerous follicles. When it passes into the intestinal canal there is a cæcal appendage; the walls of the canal are very thin. In Holothuria the intestinal canal is of nearly the same width throughout. It proceeds from the mouth along one side of the body to the lower extremity, then bends back to the anterior part, and finally descends along the other side to the cloaca, into which the respiratory organs also open. The sea-water penetrates into the somatic cavity in the majority of Echinodermata, and bathes the internal surface of the body and the outer surface of the intestines. Where no special respiratory organ exists, the function of such organ with regard to the change in the blood may be effected in the five vessels that run on the surface of the intestinal tube. In the Star-fishes the sea-water penetrates to the cavity of the body by means of five tubules in the integument, which are found in great numbers on the dorsal surface. In the Echina and Holothurice, it 
is not known in what way the water penetrates the cavity of the body. The power of reproduction in Echinoderms is very great. Star-fishes are frequently seen with one or more small arms, or rays, which have been formed anew in consequence of the loss of the parts. In Holothuria viscera may be lost and formed anew; and some species are propagated by spontaneous division. There are few special organs of sense. The nervous system in Echinus forms a ring which surrounds the mouth within the apparatus termed Aristotle's Lantern, and in Holothuria in the calcareous ring to which the longitudinal muscles are attached. All these animals inhabit the sea. They are found in all parts of the world, yet most of the species only in limited regions. There are two broad divisions of Echinodermata - those which are pediculate, and have numerous membranous contractile tentacles, terminated by a suctorial disc, issuing from minute apertures in the integument; and those which are apodal, in which the body is covered by a coriaceous, sometimes soft skin, destitute of ambulacreal feet. The former division is divided in to families - the Crinoidea, Asteridea, Echinidea, and Holothurida. The latter includes the Synaptine and Sipunculacea.

Family Crinoidea. The integument is calcareous and the skeleton external. The rays are articulate, supplied with a central canal which is absent in some. There are mostly two apertures of the nutrient canal. The names Sea-lilies, or Stone-lilies, have been often applied to this family, which in a fossil state was widely represented in the secondary period. Most of them are set upon a stem, those which are free, as Comatula, having been attached to a pedicle in the embryonic state. In Holopus, the calyx is affixed, 
hollow, and undivided, with scattered tubercles. There are four calcareous pentagonal plates at the upper margin of the calyx, sustaining four pairs of articulated and pinnate arms. The Carboniferous Limestone and Muschelkalk contain an enormous number of fossil genera which bear a general resemblance to Holopus. In Apiocrinites the column was thickened towards the calyx or cup, and became almost pear-shaped. In Encrinites it is round and not thickened at the top. In Pentacrinus the column is pentagonal, with joints having a five-leafed mark. The fossil species of this genus are found in the Oolitic Limestones; the living species exist in the Caribbean Sea. The stem of Pentacrinus has no muscles, but is merely passively motile or flexible by means of fibrous bundles and an elastic tissue between the joints. The body is composed of numerous calcareous pieces, varying in shape and arrangement, so as to become important guides to the identification of fossil species. From the central part arise large rays, each furnished with a double row of articulated appèndages, which, as well as the arms, are instruments for seizing prey and conveying it to the mouth. The part of the animal which is termed calyx, from its resemblance to a flower, has been commonly termed the lilystone. The body is supported upon a long pedicle divided into countless segments; and upon the sides of the stem similarly constructed filamentary branches are fixed at equal intervals.

Family Asteridce. These have the body depressed, not pediculate, but free, multangular or radiate, with integument coriaceous or calcareous. An internal calcareous row of joints runs along the middle of the rays, and takes its origin from the mouth, which is central and inferior; the arms 
dorsal or none. In the division marked Ophinure, the disc is distinct from the arms, which are not sulcate. In Euryale, termed by some Gorgonocephalus, the arms are prehensile, contortile towards the mouth, not scutate. The numerous jointed and flexible rays of Gorgonocephalus form so many legs, enabling the creature to drag itself along the bottom of the sea, or to entwine itself among submarine plants, as well as supplying the office of tentacula in securing food. In Ophiura the arms are five, undivided, serving for creeping; scutate, articulate ; the disc is plane; the name is given from the form of the arms, which resemble the tail of a serpent, and often exceed twenty times the diameter of the disc. Another division of Asteriada is that to which the more typical Star-fishes belong. In these the body is depressed, angulate, or stellate, the angles being produced with tentaculiferous or "ambulacral" furrows below extending as far as the point of the angles. The form is very various, as the arms are in some species (Ophidiaster) enormously developed, while in others it appears to consist only of a pentagonal disc. The Star-fishes bend their rays towards each other, which is serviceable in moving through narrow fissures and between stones. They do not swim, but creep by means of their tentacles, with the mouth downwards. They feed chiefly on Mollusca. The animal progresses by the protrusion of the numerous suckers, which fix and detach themselves alternately, some remaining firmly adherent, while others change their position, the whole animal thus progressing by an equable gliding movement.

The Echinidce, or Sea-urchins, form another singular family. In these the body is subglobose or depressed, without radiant lobes; the xnouth and arms are distinct; the mouth is inferior; the integument is cal- 
careous, beset with movable spines; the shell consists of an arrangement of plates, having a five or six sided form.

In Scutella the body is flat and shield-like, the whole circumference being almost circular. They bury themselves beneath the surface of the sand. The whole shell is entirely covered with minute appendages, resembling, when seen with the naked eye, delicate hairs, which, when examined under the microscope, are found to be

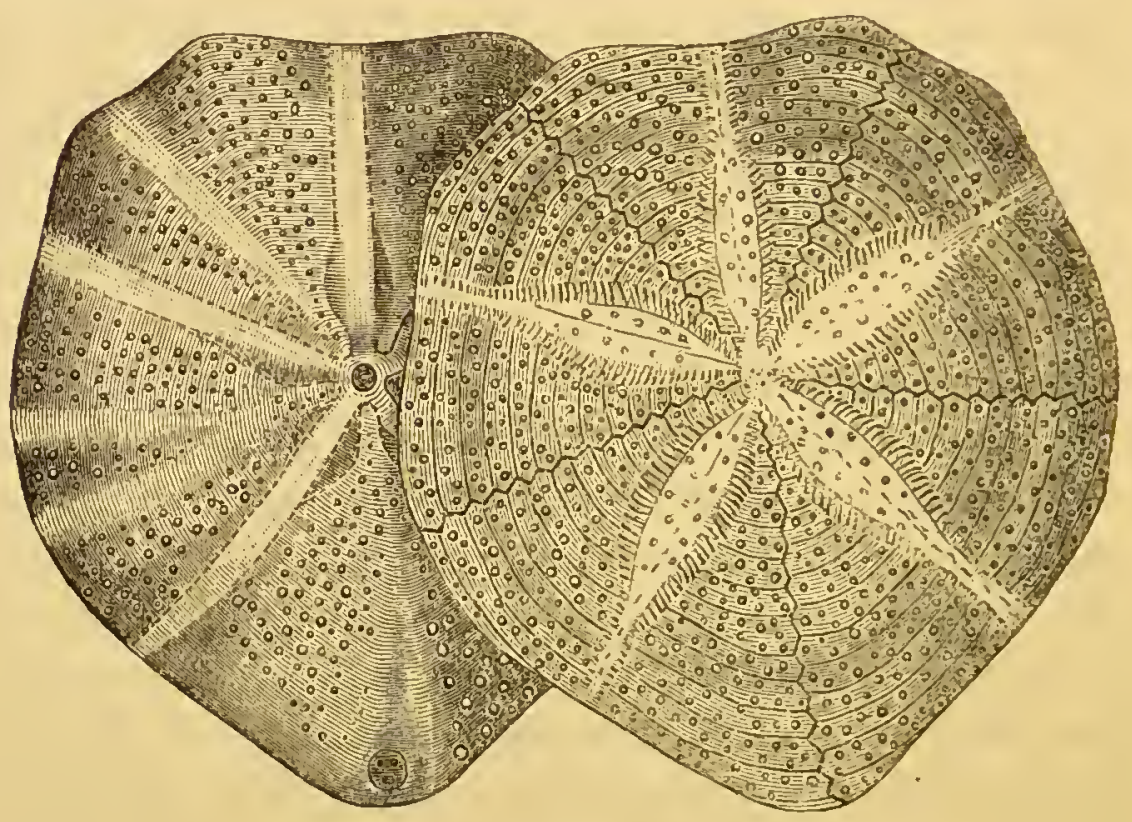

Scutella.

spines of the most elaborate structure, which articulate to the shell by a ball and socket joint, susceptible of being rooved in all directions. The flat Scutellee are connected by a series of intervening links with the globose Echidnce.

In the Holothurida the form of the animal is annulose or worm-like. Instead of being composed of hard calcareous pieces, the integuments of the body become 
soft and irritable; a few thin laminæ of earthy matter around the mouth are the only vestiges of the shell The suckers remain; and when protruded through innumerable apertures distributed over the surface of the body, they still form the principal instruments of progression. Holothurice feed upon Conchifera and other marine animals. Tiedemann frequently found shells entire and uninjured in the intestinal canal of Holothuria tabulosa, so that the molluses appeared to have been dissolved in the shell and digested. The Sea-slugs live on the coral reefs of the Molucca, Philippine, and Carolina Islands, and are fished up in large quantities under the name of Trepang, which is a delicate article of diet among Malays and Chinese.

In the order Apoda the body is covered with a coriaceous, sometimes soft skin, destitute of ambulacral feet or suckers. Radiating tentaculæ surround the mouth. There is much analogy with the annulose animals.

Synapta has a ring of pinnatifid tentacles round the mouth; there are no arborescent respiratory organs; the skin is very delicate, rough from extremely minute hooklets and calcareous Sipunculus. It has the body cylindrical and elongate; there is no calcareous ring round the cesuphagus. Its mouth is provided with a papillated retractile proboscis, with incised tentacular border or coronet of simple tentacles surrounding the mouth. The anus is a lateral aperture of the body, situated towards the anterior part. The animal can attain a length of more than one foot, exclusive of the proboscis, which is usually retracted. It is very contractile. Longitudinal and circular bundles of muscles are visible through the skin. There are two nervous rings around the œsophagus. 


\section{Class II.-ACALEPH AE.}

THE Sea-nettles are radiate animals of a gelatinous 1 transparent substance, which swim freely, and of which the organisation in parts that are frequently repeated usually indicates the number four, or its double. They have no intestinal canal, but ordinarily a blind

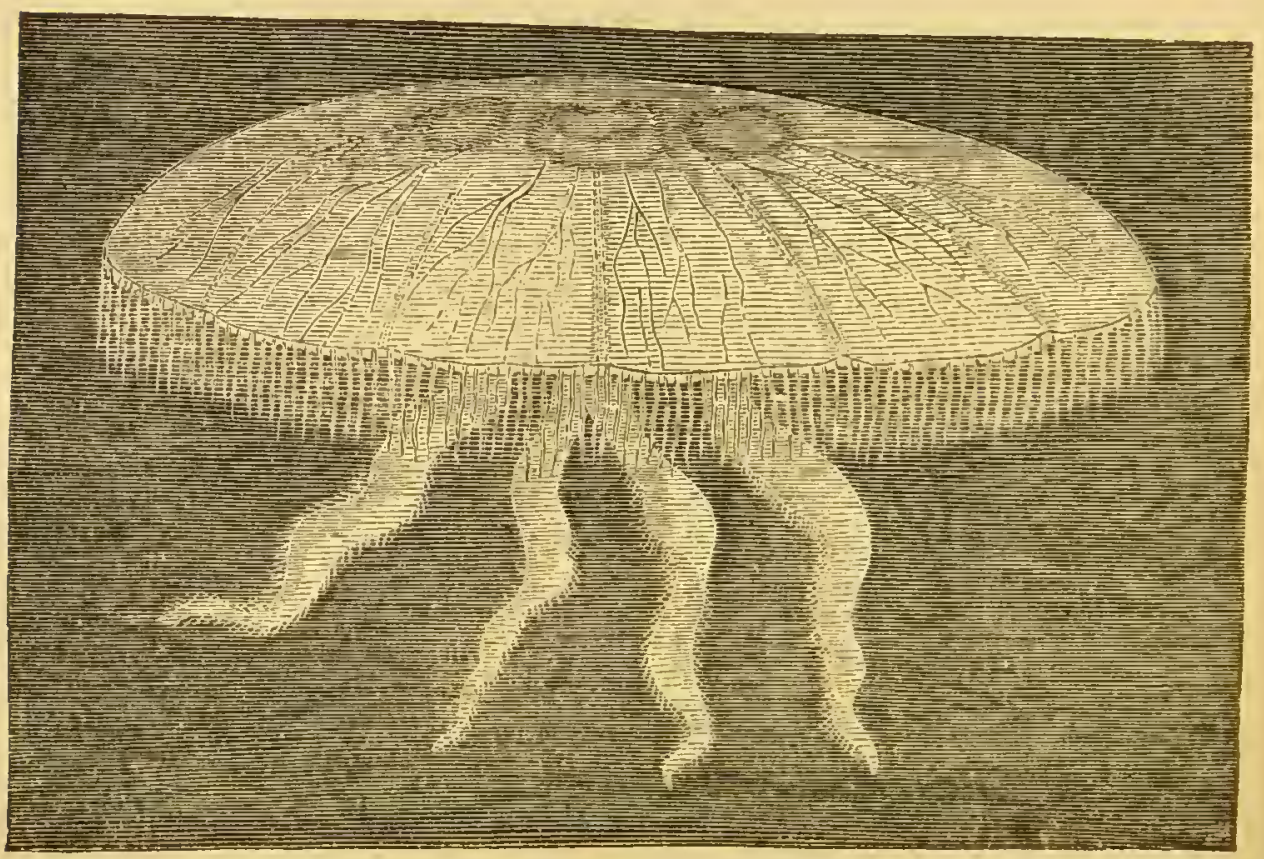

Medusa.

stomach, from which numerous tubes, mostly divided into branches, run like rays to the circumference of the body. The sexes are separate in some; in others they are bisexual. There are traces of a nervous system in all. They possess the faculty of stinging by the 
action of complicated structures called "thread-cells." On our own coast they are represented by numerous discoid and spheroid species, varying in size from an almost invisible speck to a yard in diameter, and which is usually termed Sea-blubber, or Sea-jelly. There are four great divisions. The Pulmograda, or Medusce, in which the body is discoid with a marginal velum, and a central iuferior mouth usually prolonged into a more or less complex proboscis. The locomotion is by rhythmical contraction of the disc. The sexes are distinct. In the Ciliograda, the body is spheroidal, oblong, or lobated, rarely tumelliform. Locomotion is by longitudinal bands of cilia. The sexes in some are combined. In the Physograda, the body is floated by aircells. Locomotion is by the parts exposed to and acted upon by the winds, and nutrition is by numerous suctorial tubes.

In Medusce the body is in the form of a gelatinous disc, more or less concave above, called the umbel, from the centre of which and from the margin there depend in most of the species processes or filaments more or less numerous and more or less elongated. The Medusce are commonly known by the name of Sea-blubber, Jelly-fish, \&c. They have a stomach or digestive cavity excavated in the centre of the disc, and opening externally either by a central and inferior crucial mouth, or continued into branched appendages, and receiving the nutriment by innumerable minute pores, analogous to the stomata of plants or those rootlike appendages. The digested fluid is conveyed by vessels from the stomach to an exquisite network or plexus situated on the under surface of the border of the disc, where it receives the influence of the atmosphere, and is fitted for assimilation. Some species, as 
the Medusa curitu, have also intestinal canals leading from the stomach to separate anal outlets. Traces of a nervous system and rudimental organs of vision have been discerned in some of the Medusce. They swim by muscular contraction of the margins of the disc. They are of distinct sexes, which congregate together chiefly in the autumnal months. The male and female organs much resemble each other, and are situated in both sexes in corresponding cavities, generally four in number, on the under surface of the disc. The ova are received when impregnated in marsupial sacs appended to the arms (in Medusa aurita), whence they escape in the form of ciliated ova, afterwards assume the structure of eight-armed polypes, pass the winter in this state, and undergo their final transformation in spring. Notwithstanding the complication of the organic machinery, functions, and generative economy of the Medusce, their solids form so small a portion of their frame that of a Medusa of ten pounds' weight, what remains upon the filter through which its fluid parts (chiefly sea-water) have escaped does not exceed two drachms. A great number of the Meclusce are phosphorescent, shining in the night like globes of fire; but the nature and the agents of this wonderful property remain to be discovered. Most of the Medusce at certain seasons sting and inflame the hand that touches them, but the cause of this property is equally unknown. Several of the animals belonging to this class are phosphorescent. According to Ehrenberg, the Arabians on the Red Sea name the entire family of the Medusæ Sea Candles. Not Medusce alone but other Acalephæ possess this property, which is a vital phenomenon, and ceases on the death of the animals. Some of them are luminous after death, as are all animal organic substances; but that 
light is of a different nature to phosphorescence during life. Beroe refescens emitted a light after death which differed by its bluish green colour from the yellowish red irradiations of the living animal. Dead Acalephæ or mucus arising from decaying animal matter can contribute little or nothing to the illumination of the sea, the chief cause of the brilliant sparks residing in minute marine animals, especially Medusce. The Acalephæ are in all seas. A large number of species occur in the Mediterranean; in the seas of the cold and temperate zones hardly any Siphonophora are found, excepting the chance individuals of the genera Velella, Porpita, and Dephys, which are thrown on the British coasts. No specific distinction appears to exist between the species found in the Red Sea and those of the North and the Baltic. Medusce exist in such enormous quantities at certain places that they form, as it were, banks in the sea, which it requires days to sail through. In fine calm weather they come to the surface; during storms they seek the quieter waters of the depths. The ordinary examples of Medusce met with in the British seas appear like mushroom-shaped gelatinous discs, from the under surface of which variously shaped appendages hang freely, floating in the water, some serving as tentacula, others for the prehension of food. The body of these Acalephs or Medusce is specifically heavier than the water of the ocean, and would consequently sink without some effort on the part of the animal. The agent employed to sustain it on the surface, and to a certain extent to row it from place to place, is an umbrella-shaped expansion or disc, which is seen continually to perform motions of contraction and dilatation repeated at regular intervals. By these constant movements of the disc the Medusce can strike 
with sufficient force to insure its progression in a certain direction when swimming in smooth water, but these efforts are perfectly useless against rapid and violent wave-currents. The tentacular appendages,

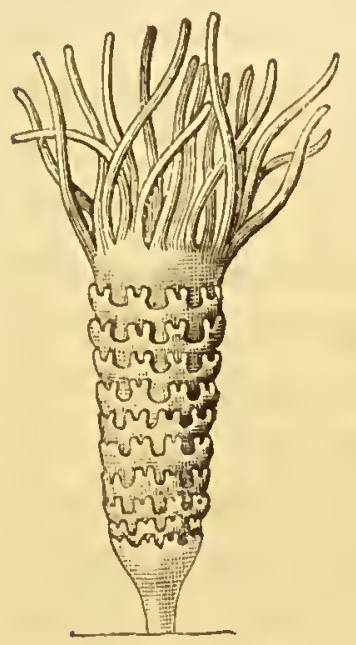

Strobila of Medusa.

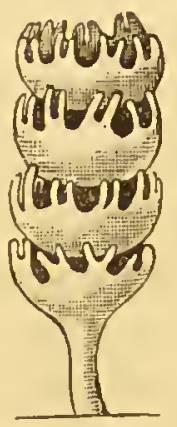
situated round the margin of the disc in such species as are provided with these organs are likewise capable of contractile efforts, and may, in some slight degree, assist as agents of impulsion, although they are destined to the exercise of other functions. The disc when cut into seems perfectly homogeneous in it texture,

and does not contain any fibrous substances; but in a few large Mlechusce its inferior surface becomes corrugated into minute radiating folds, which seem to contract more energetically than the other portions. The substance of the body is generally entirely soft and gelatinous, emulating the structure of the vitreous humour of the eye, its entire organisation consisting of an aqueous fluid contained in innumerable polyhedral hyaline cells. The process of change in the larval Medusce indicates a succession of steps in which the individual changes from the infusorial to the polype type, and finally, after various changes, to the splitting up into a pile of Medusce. Sars describes the manner in which a gelatinous polypoid animal with its thick body deeply annulated, and the rings of which develop bifid processes, underdoes its charge. He termed this creature 
Strobila, from its resemblance to an artichoke, and finally saw the rings or segments separate from one another, and swim off as little Mredusce.

The genus Medusa comprises those which have a mouth under the centre of the lower surface, either opening simply upwards or prolonged into a pedicle.

In Equorea are comprised those which have the mouth simple, and neither prolonged nor furnished with arms when no tentacles can be found except the umbella. It is the Phoncynia of Lamarck. When the umbella is surrounded with tentacula, it is known as the Equorea of Péron, which in the seas of hot climates is one of the most numerous of the subgenera. Certain species are remarkable for the laminæ which cover their inferior surface. Others are remarkable for having small cavities encrusted round the umbella. There may be united under the name of Pelagia, such as have the mouth prolonged into a pedicle or separated into arms. In all these subgenera there are no lateral cavities, but in the most numerous of them, simple-mouthed Medusce, there are four organs formed of a folded membrane, which at times are filled with an opaque substance and which appear to be ovaries. They are generally placed in many cavities, opening to the inferior surface or on the sides of the pedicle. These are sometimes taken for mouths, because little animals are sometimes caught in them. Some have supposed them to be respiratory organs, but this function is probably carried on by the edges of the umbella. The tentacula, both round the umbella and the mouth, do not vary according to the species, but according to the age of the animal. All the MIedusce with a mouth in the centre and four lateral ovaries are classed under Cyance, one of the most largely- 
spread species, which, when old, has four large arms. The edge of the umbella is finely ciliated throughout; reddish branching vessels proceed from the stomach to the circumference. Another species has the edges furnished with long tentacula, or fulvous or brown lines or spots arranged in radii on its convex side. This species is very common, and shows great variety in the spots.

The term Rhizostoma is applied to that portion of the great genus Medusa which comprises those species which have no mouth opening in the centre, and which appear to live by the suction of their pedicles or tentacula. These have four or more ovaries.

Rhizostoma, properly so called, includes those which, according to the species, have the central pedicle more or less ramified. The vessels arising from the small ramifications of the pedicles unite in a cavity at its base, from which branches proceed to all parts of the umbella. The most common of this species is the blue Rhizostoma, which is found along the French coast at low water, and its umbella is sometimes as much as two feet wide. Its pedicle is divided into four pairs of minutely forked and dentated arms; each one has at its base two dentated auricles; the umbella is surrounded in the thickness of its margin with a fine network of vessels. Messrs. Audouin and Milne Edwards have observed that these Menusce live together in groups; at least they are always found swimming in numbers in the same direction, with their body obliquely inclined. The Cephece of Péron are distinguished from other Rhisostomas by having the dentitions of the pedicle intermixed with filaments. The Cassiopece have no real pedicle; their arms, which are generally eight in number, are sometimes ramose, arising from the inferior surface. 
In other species without a central mouth we find none of those numerous ramifications in the pedicle nor open cavities for lodging the ovaries. These can be classed under the name of Astoina. Some, however, such as Lymnorea and Favonia of Péron, have a large pedicle, furnished on each side with filaments, which may act as suckers; others are even destitute of these filaments, but have an infundibuliform membrane at the extremity of the pedicle, from the bottom of which vessels seem to arise that ascend into the pedicle, and spread out through the umbella. Such, for example, is the Medusa proboscidalis found in the Mediterranean. In the Orythyia that membrane is wanting. In Berenix there is no pedicle at all, but the inferior surface is provided with small suckers along the track of the vessels. In Endora no suckers are visible, but the two surfaces are smooth, and without any apparent organs. One species is found in the Mediterranean. When these simple animals become more concave, their inferior surface becomes an interior surface, and may be considered as a true stomach. Such are the Carybdea, in which no traces of internal organs can be perceived, and which only differ from the Hydra in size.

The Beroë have an oval or globular body, furnished with salient ribs, covered with filaments of a sort of lace, extending from one pole to the other, and in which ramifications of vessels are perceptible, and a kind of motion resembling that of a fluid. The mouth is at one extremity; in those which have been examined, it leads into a stomach that occupies the axis of the body, and on the sides of which are two organs, probably the same as those which in Medusa have been termed ovaries. Such is the Beroe pileus, the body of which is spherical, and has eight ribs; there are also 
two ciliated tentacula, susceptible of great elongation, issuing from its inferior extremity. It is very common in the northern seas, and even in the British Channel. Whales are said to feed on it. Writers have referred to the same genus the species Idya, which is sacciform; it has ciliated ribs, and is open at both ends. Some species - such as Doliobrum, for example-are even destitute of ribs, their form resembling a bottomless barrel.

The Callianirce appear only to differ from Beroë by having the ribs more projecting, and also having them united in pairs, forming two species of wings. Much is not yet known of their internal organisation.

The Tamirce appear to closely resemble the Callianira, but they differ by having three long ciliated ribs on each side, and two long ramose filaments.

In the Alcinoes the body is of a cylindrical form, open at one extremity, and furnished at the other with two large wings, which, when folded over, completely envelop it. Its cylindrical portion is flanked with four projecting ribs ending in a point, and it has on it lines of cilia.

The Ocyroes have a similar body, with four lines of cilia, but without ribs; it has similar wings, each furnished at the base with two ciliated points.

Cestum closely follow the Beroës. They are distinguished by a very long gelatinous ribbon; the margin of one side is furnished with a double row of cilia, the other edge has it also, but in an inferior degree; the mouth is in the centre of the inferior margin, which is a wide aperture, and opens into a stomach, which is terminated by a very minute anus; from the anal extremity vessels commence which traverse both extremities of the ribbou; two sacs, probably ovaries, open on the sides of the moutb. This 
animal much resembles the Callianira with two ribs and

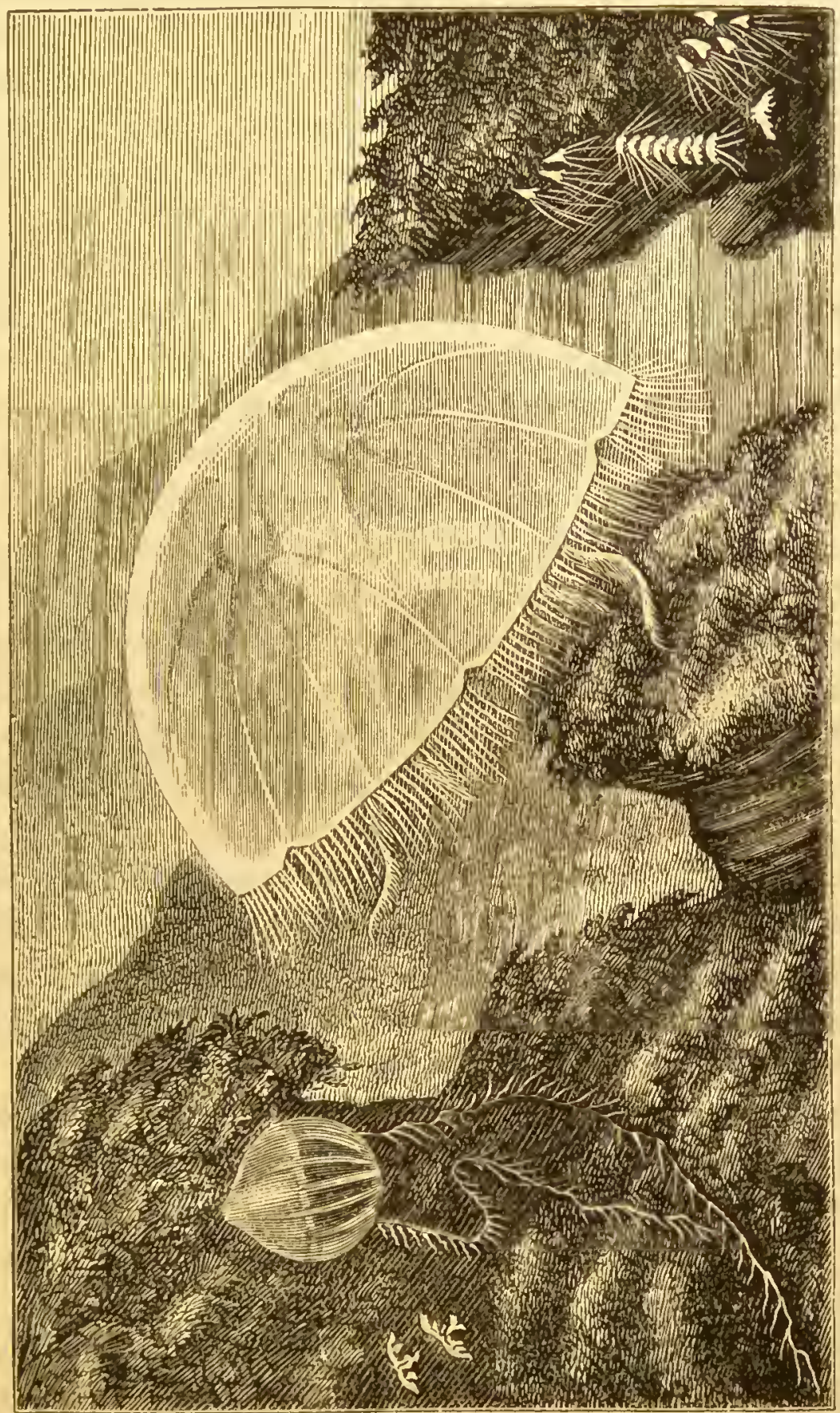

very elongated wings. The only species yet discovered 
is the Cestum Veneris, which is over five feet in width, and is only two inches in breadth. It is very difficult to preserve an entire specimen. The two following genera were once classed with Medusce, but now form a separate family in this order, on account of their internal cartilage which supports the gelatinous substance of the body.

In the Porpita this cartilage is circular, and its surface is marked with concentric striæ, which are crossed by radiating striæ. The upper surface is only covered with numerous tentaculæ, the exterior of which are the longest, and supplied with small cilia, each of which ends in a globule. Air sometimes exists in the cilia; those in the centre are the shortest, simplest, and most fleshy. The mouth is in the middle of all these tentacula; it is a little salient proboscis; it leads to a simple stomach, which is surrounded by a sort of glandular substance. One species, which is found in the Mediterranean and other seas of hot climates, is of a beautiful blue colour.

In Velella, as in Porpita, the mouth, which is in the form of a proboscis, is on the lower surface surrounded by innumerable tentaculæ, the exterior of which is the longest, but it differs from Porpita by not being ciliated; and a still more important character is that the cartilage, which is oval, has on its superior surface a vertical and tolerably elevated crest. This cartilage is diaphanous, and is merely marked with concentric striæ. One species of this genus is known, and is found in the same seas as the Porpita.

The hydrostatic Acalepha are distinguished by having one or more bladders usually filled with air, by means of which they suspend themselves in the water. Their appendages are particularly uumerous and variously 
shaped; some probably serve as suckers and others as ovaries, while some longer than the rest as tentacula are attached to these vesicles and compose the whole apparent organisation of these animals. There is no visible mouth. The Physalice resemble an extremely large oblong bladder, elevated on the upper surface into an oblique and wrinkled crest, and furnished near one of its extremities beneath with numerous cylindrical fleshy productions variously terminated that communicate with the bladder. Those in the centre produce, more or less, numerous groups of small filaments; the lateral ones are merely divided into two threads, one of which is frequently very long. There appears to be an extremely small orifice in one of the extremities of the bladder, but internally no other intestine is found, but another bladder with thinner parietes and cæca that partly extend into the cavities of the chest. There is no nervous, circulating, nor glandular system. The animal swims on the surface of the sea when it is calm, employing its crest as a sail. When living it is also furnished with extremely long filaments, more slender than the others, which are sprinkled as it were with pearls or drops. When touched it stings. They are found in the seas of hot climates.

The Physsophorea arc eviclently allied to the Physalice, but their bladder is proportionally much smaller. It has no crest, and is frequently accompanied by lateral bladders. Their tentacula, which are both various and numerous, are suspended vertically under the bladder like a garland or cluster. In Physsophora properly so called, between the upper bladder and the tentacula, are other bladders, placed either side by side or one on another, sometimes of an irregular figure, and sometimes polyhydric, forming by their union prisms or 
cylinders. The teniacula, partly conical, partly cylindrical, and partly formed by groups of threads or globules, and partly filiform and capable of considerable elongation, form a group at the inferior extremity.

In Hippopus there are merely lateral vesicles, almost semicircular, or shaped like a horse's foot, and compressed into two ranges, thus forming a sort of spike like certain grasses, from which hangs a sort of ring that crosses the preceding parts. The united contraction of these vesicles enables the animal to move rapidly.

In Cerpuleta the vesicles are regularly attached on both sides of an axis, which is often very long. In Racemida all the vesicles are globular and small; each one has a minute membrane, and they are united in an oval mass, which moves by their joint contractions. In Rhizophy $a$ there are no lateral vesicles, but merely an * upper bladder and a lengthy stem, along which the tentaculæ are suspended, some conical and the others filiform. The Stephanomia appears to be a third combination, where the lateral bladders, which in Physsophora properly so called adhere to the end of the stem above the tentaculæ, extend along its length, and intermingle with tentaculæ of various forms.

Next to these hydrostatic Acalepha come the Diphyes, which is a very simple genus; two different individuals in this class are always found together, one encased in a cavity of the other, but they can be separated without killing either. They are gelatinous, diaphanous, and move like a Medusa. The receiver produces from the bottom of its cavity a chaplet which traverses a semicanal in the received, and appears to be composed of ovaries, tentaculx, and suckers, like those of the preceding genus. 
In Diphyes, properly so called, the two individuals are almost alike and pyramidal, with some points round their aperture, which is at the base of the pyramid. In Calpes the received is still pyramidal, but the receiver is very small and square. In Abyles the received is oblong or oval, \&c. ; the receiver somewhat small and bell-shaped. In Cuboides the received is small and bell-shaped; the receiver much larger and square. In Navicula the received is bell-shaped; the receiver is large, but is shaped like a wooden shoe. There are several combinations besides these.

The Calynimidre, Cesticle, Calliancridce, Pleurobraclide, and Beroiclce have been separated from the rest of the Acalephce by Greene and many modern writers, and placed amongst the Actinozoa. 


\section{ClASS III.-ANTHOZOA.}

THESE are gelatinous oblong or conical animals, with a contractile body, an intestinal cavity, and an oral aperture which is surrounded by arms and tentacles. Besides these arms there are no special organs of sense, though the majority of polyps appear to be very sensible of the light. Propagation is partially by eggs, partially by germs or buds; in many instances the latter are not detached from the parent stem, and thus compound animals arise. The corals were often conconsidered to belong to the vegetable kingdom. The Actinia, or Sea Anemone, may be taken as the type of the class Actinozoa. The body is soft, fleshy, or coriaceous; much variable in form and size; cylindrical in figure, and attached by one of its flattened ends, which is termed the base, a mouth being placed in the centre of the disc or opposite end. The outer margin of the disc is surrounded by numerous tentacles, disposed in alternate series; between the disc and the mouth there is a region destitute of any appendages, and which is termed the peristomial space. The mouth is slightly elliptical in form, a pair of tubercles with a groove between them existing at each opposite point of its circumference. The stomach or digestive fac into which the mouth leads is a short distensible tube open, at both ends, and extending about balf way towards the base of the animal. In diameter it scarcely 
exceeds the mouth, with which its form, when viewed on its upper surface, is seen to correspond. The folds or grooves between the oral tubercles are continued in the form of semi-canals along the inner surface of this stomach, till they reach the wide aperture which communicates with the somatic cavity. The tissues consist of two layers, the ectoderm and the endoderm. The Actinozoa, however, show a greater tendency to divide these layers into more complex structures, in some of which muscular fibres are present. There are often cilia, especially in the internal or somatic cavity, where they serve to promote a circulation of the internal digestive fluids. Thread-cells almost universally exist, but there are no traces of a nervous or vascular system. There are distinct internal reproductive organs. Sexual reproduction exists in all Anthozoa. Some, as Actinia, are simple, while some are composite. Most of the Actinozoa are permanently fixed; a few have slight locomotion. Some of the Actinozoa are unprovided with any central support, but a large number secrete a calcareous or horny framework, which is called the corallum.

The following classification of Anthozoa is now generally adopted, the position of the Ctenophora, which we have left with the Acalephæ, being doubtful.

\section{Class Anthozod.}

Order 1.-Zoantharia.

Z. malacodermata

Fam. Actinidx

Ilyanthidx

Zoanthidæ 
Z. sclerobasica

Antipathidx

Hyasonemidæ

Corals-Z. sclerodermata.

Fabulata

Perforata

Aphorosa

Tubulosa

Order 2.-Alctonaria.

Alcyonidx

Tubiporidæ

Pennatulidæ

Order 3.-Rugosa.

In the first order, Zoantharia, the soft parts are disposed in multiples of five or six, and the tentacles are simple and usually numerous. The corallum is usually absent, the septa of each corallite following the numerical rule of the soft parts. The body has been compared to a tunicated cone or short cylinder, implanted on a flat plain base, while the opposite end has the oral aperture depressed in the centre, and furnished with variously figured tentaculæ. In a state of contraction the mouth is closed, the tentaculæ shortened, and the whole concealed by this border being like a curtain over them, leaving a mere depression on the top. There is no intestine, nor any other visible exit from the stomach than the mouth, by which the undigested remains of the food are ejected, always wrapped in a large quantity of clear glairy fluid. In a state of expansion and hunger many kinds of Helianthoidea can protrude the stomach beyond the lip, in the form of 
large bladder-like lobes, which often hang over the sides and almost conceal the rest of the body. Amongst these, there are frequently extruded at the same time some white filaments, like bundles of ravelled thread, which have escaped through a circular opening in the bottom of the stomachic membrane. The space between the walls of this organ and the outer envelope is divided into numerous narrow compartments by parallel and perpendicular lamellæ of a musculotendinous character, which extend from the mouth to the base, and radiate to the centre like the gills of a mushroom to the stalk. When a helianthoid polyp is at rest and unalarmed, it can dilate the body to fully twice its ordinary bulk by imbibing water through the mouth or tentaculæ, the bases of which open in the spaces between the perpendicular lamellæ. These spaces being filled, the water is then made to permeate the rim of the oral disc, which is full of cavities and cells for its reception, and the tentaculæ are distended, the water being forced into them while the little opening on the tips is held close. The reproductive organs are in the form of reddish bands, which contain ova and spermatozoa, and are situated on the faces of the mesenteries. Most of the Actiniæ are diœcious, i.e. male and female. Sexes are not developed in the same individual. No traces of a nervous system exist. The embryo is free, swimming; ciliated, and rounded. They are all animal feeders, and the principal use of the tentaculæ seems to be to catch the errant prey and convey it to the mouth. To disable the animal and render its struggles for escape unavailing, the class is furnished with poison-vesicles and spicula, similar to those in the tentaculæ of the Hydra. The Sea Anemones live on Crustacea, Conchifera, \&c., swallow even occasionally large bivalves, reject the shell when the fleshy 
part has been extracted and consumed by the mouth, and evert for this purpose their body, which they also do whenever they feel hunger. Their reproductive power is almost as great as that of Hydra; if they are divided transversely new tentacles after a few weeks are seen on the inferior portion, and each half becomes a perfect creature. They may thus be propagated by fission, but propagation by spontaneous fission does not appear to occur naturally amongst Actinix; it is usually effected by ova which get into the stomach from the ovaries, and are there developed. When the young ones come out of the egg they are ejected by the mouth. The young have at first fewer arms or tentacles than are afterwards present.

In the family of Ilyanthidce there is no corallum, and the polypi are solitary or free, with a rounded or tapering basis. Whether it is an animal which in all stages of life is free or not, is doubtful. One of the genera, Arachnactis, is undoubtedly free. According to Professor Forbes, it can not only swim like a Medusa, but can convert its posterior extremity to a suctorial disc and fix itself to bodies in the manner of an Actinia. Ilyanthus Scoticus appears to be a free Actinia, with the tentaculæ simple, retractile, surrounding the mouth. It is about an inch and a half in length, the body being large above, but tapering at its posterior extremity into a point. The mouth is large and surrounded by a circle of numerous long filiform tentaculæ, which are nearly equal in thickness throughout their lengths. The body is of a pink colour, with regular distant longitudinal white stripes. The tentaculæ are greenish, with a dark line down the middle of each. The animal may fix itself in mud by means of its attenuated extremity, which may be regarded as analogous to the 
termination of Virgularia and Pennatula. The true Zoanthidce have the polypes attached, united by a cænosarc, and furnished with a spicular corallum. The animal is actiniaform, gregarious, and compound, arising from a common fleshy or coriaceous base, either rootlike and creeping or crustaceous. In Zoanthus the polypes are distant, and united by a creeping root-like fleshy band. The Zoanthus conchi is a very small species, composed of a number of Actiniæ united together at their bases by a thin encrusting fleshy band. When semi-expanded, which is its favourite state, it elevates itself to about twice its former height, and becomes contracted about the middle into an hour-glass form. The upper portion is lighter than the lower, and the superior or oral surface is marked by a central depression or mouth, and from it radiate to the circumference numerous rows of whitish glandular-looking bodies, which are the tentaculæ in a contracted state. When the creature is fully expanded, the tentaculæ become distended and elongated to about the length of the transverse diameter of the body; and they are generally darker at their extremities than towards the base. Like all Actiniæ, the present species possesses a power of considerably altering its shape; most frequently it is in the shape of an hour-glass, at others the oral surface is contracted to a mere point, and then occasionally is again enlarged to nearly twice the size of any other part; sometimes the mouth is depressed, and at others is elevated into an obtuse cone. This species, in addition to being rooted, is one of the most inactive of its order; for, whether in a state of contraction or expansion, it will remain so for many days, or even a week, without apparent change.

In the Zoantharia which have hard bases, the Antipa- 
thidce have the corallum sclerobasic, horny, smooth, or spinulous. The polypes have six tentacles. They have a certain resemblance to some of the Gorgonidce, but differ from them by reason that the number of their tentacles is a multiple of six, while in the Gorgonidce it is a multiple of four. The corallum in the Antipathidce is horny and sclerobasic, often branched or simple and covered with innumerable small polyps, each united by a cænosarc and possessing six tentacles. The Hyalonemiolce have been defined by Dr. Gray as social zoanthoid polypes, secreting a central siliceous, internal, axial coil for their support. The upper half of the coil is covered by a uniform cylindrical back, regularly studded with retractile polypes. The position of the Hyalonemidce, or glass zoophytes, in the series of Anthozoa is extremely doubtful.

The Sclerodeim zoantharia form such an important factor in the production of geographical variations in the Pacific, that we must give some space to the consideration of the functions they perform. Most of the soil at the bottom of the sea in Polynesia is formed by the labours of these small animals. The islands of Polynesia are often called atolls. During the gradual sinking of the land which forms the supporting base of the corals, the formation of an atoll by upward growth can be ascertained. The land is at first seen rising to the surface of the sea; as the land sinks down the coral rises to the surface, and is bathed by the surf on the margin of the reef. As the land becomes lower and smaller, so the living coral builds upwards to regain the surface; as the coral rises so the living portions come to the surface, and the under part remains dead coral. When the land is entirely covered the coral continues on its own base, being above the surface at 
each extremity, and the centre is formed into a smooth and tranquil lake. Thus, by the process of subsidence, the fringing reef is converted into the barrier reef, and the barrier reef is converted into the atoll. But, if the land should again arise, then would an island looking as if it were made exclusively of coral present itself. The little coral animals are vast in their work. In New Caledonia they have built a reef of four hundred miles; and again, along the coast of North-East Australia, one of a thousand miles. The atolls are built in the middle

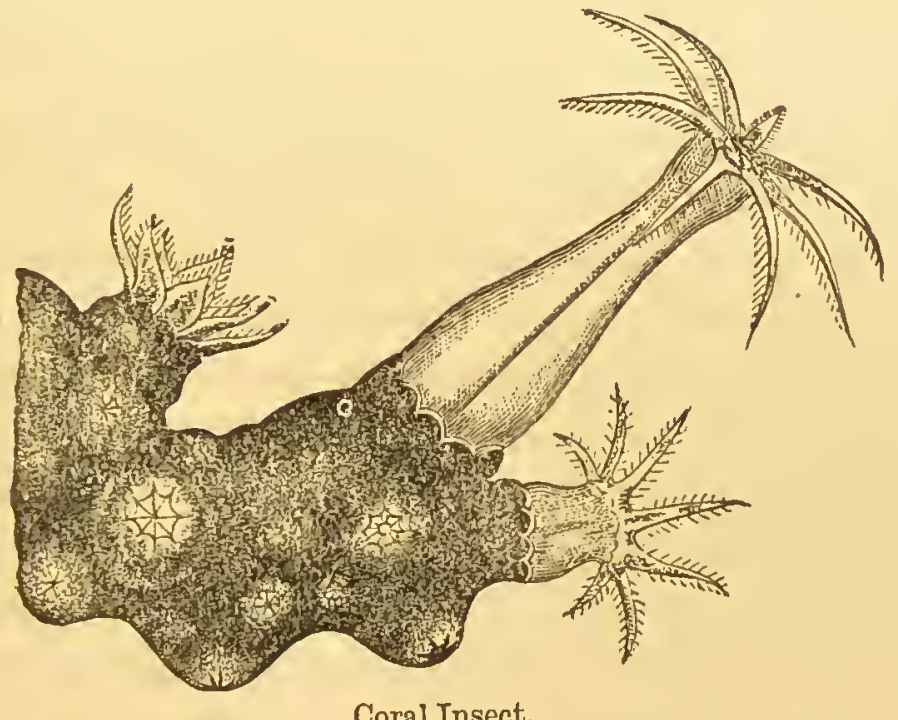

of the water, and in defiance of the sea. A small atoll may be fifty miles in length and twenty miles in breadth. If the ledge of reef of the coral rock were extended in one line it would be a hundred and twenty miles in length. Compared with the coral reefs, the Pyramids of Egypt are but as children's toys. As polypes have been superseded at the present time by the genera Porites, Millepore, Madrepore of calcareous Anthozoa, so will these have to give way to new forms of essentially analogous zoophytes, who will in time clothe with limestone future rising continents. The 
four groups, Tabulata, Perforata, Aporosa, and Tubulosa, have been formed of coral insects. In the Tabulata the septa, rudimentary or entirely, is absent; the tabulæ are well developed, and divide the visceral chamber into a series of stories. The perforate corals have the septa well developed; the dissepiments are rudimentary; and there are no tabulæ. The corallum is composed of porous sclerenchyma. The Aporosa have the septa well developed and lamellar; there are no tabulæ. The corallum is composed of compact imperforate sclerenchyma. In the tubulose corals, the septa are indicated by mere striæ.

In the second order, Alcyonaria, each polype has eight pinnately fringed tubercles. The somatic chambers are in number some multiple of four. The corallum never presents traces of septa. The Deadmen's Toes (Alcyonomium), Searods (Virgularica), and the Red Coral belong to this division of corals. All the polypes are furnished with fringed tentacles, and are composite, all the polypes being connected together with a cœnosarc. The Alcyonium forms spongy looking masses of a yellow or orange colour, and are covered with little star-shaped apertures, through which the delicate polypes can be protruded and retracted at will. The Searod (Virgularia) is occasionally found in the British seas. It is a long rod-shaped body of a light flesh colour, supported on a long calcareous rod, which is covered by a fleshy envelope, from which arise lateral processes, each of which bears numerous polypes. The Cockscomb (Pennatula) has the lower end of the fleshy envelope naked, and the fringes which bear the polypes are considerably longer, the whole animal bearing somewhat the appearance of a feather. Tubipora musica is a well-known example of organ-pipe corals. The sclero- 
dermic coral consists of many cylindrical tubes, which are connected by strong transverse plates, but not divided by vertical partitions (septa). The usual colour of the polypes is a bright green, while the coral is of a brilliant red.

The Seashrubs, Face Corals, and the Red Coral of commerce, belonging to the family Gorgonidce, are the best known. In all this family the structure is made up of numerous polypes, all of which are united by a common flesh or cœnosarc. A central branched axis or coral supports them. This coral is found to vary much in its composition; sometimes it is partly horny, and sometimes entirely so, at other times calcareous, as in Isis. The sclerodermic corallum differs altogether from the corallum ; it has been described as characteristic of the reef-building corals. The coral always forms an internal axis, covered by the cœnosarc, whence the polypes are produced. Being placed outside the polypes, it bears the same relation to the cœnosarc that the trunk of a tree bears to its bark. The polypes, having each eight tentacles, agree of course with their order, and it is this which distinguishes them from the Zoantharia, which possesses a sclerobasic coral.

The Corallium rubrum, or Red Coral, is the best known of the Gorgonidce. This is imported in large quantities from the Mediterranean. A bright red, finely grooved, calcareous sclerobasis is found in this species; it is generally more or less branched. A bright red cœnosarc or bark invests the corallum; it is all studded with numerous small apertures. The polypes are milk-white in colour, having eight fringed tentacles, and can be protruded at will from these openings. The cavities of the polypes are connected with a number of communicating canals into which the entire cœnosare is 
excavated. The entire system is filled with a nutritive fluid known as milk.

The Rugosa are extinct, and are only known to us by their hard parts or skeletons. Like the Zoantharia, they have a well-developed sclerodermic corallum; in them, however, the septa are always some multiple of four, and transverse plates or tabulæ are generally combined with the vertical plates or septa. They have their parts in multiples of four, and thus agree with the Alcyonaria; but they differ from them, as they have a well-developed sclerodermic corallum in which septa are found. 


\section{Class IV.-HYDROZOA.}

THESE are described as Colenterata. The walls of 1 the digestive sac are not separated from those of the general cavity of the body, but the two coincide with each other. The reproductive organs, which are in the form of outward processes of the body-wall, are external. They are all aquatic in their habits.

The sub-class Hydroida, known as hydroid zoophytes, comprises all the sea Firs and their allies, from their resemblance to the fresh-water polype, which is also a member of this division. They are

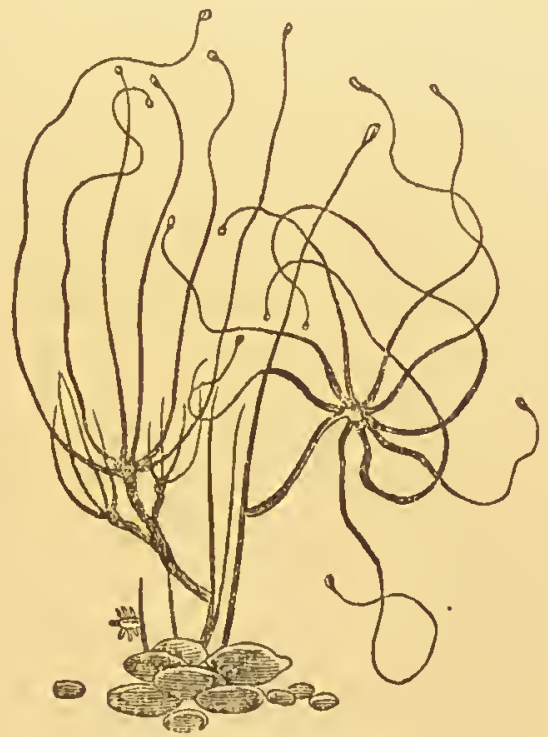

Freshwater Polype (Hyara). described as consisting of an alimentary region, or "polypite;" this at its distal end is furnished with a mouth and prehensile tentacles, and at its proximal extremity with an adherent disc, or "hydrorhiza." Sometimes the hydrosoma consists of only one polypite, as the Hydrida and some of the Corynida; but it is generally composed of a number of small polypites united by a cœnosarc, or common trunk, as in the majority of the Corynida, and Serlutarida, and Cam- 
panularida. In many cases, the Hydrosoma is fixed to some solid object by its proximal extremity. The hydroid zoophites exhibit three principal types of structure, which constitute so many orders.

In the first order, we have only the well fresh-water polypes, of which we may take the common green Hydra, as the type. It may be found in most of our streams and pools, and is visible to the naked eye, though it can only be satisfactorily examined by the aid of the microscope. When uncontracted, the body is in the form of a cylindrical tube, composed of two fundamental layers, the ectoderm and endoderm; the former contains many thread-cells, and is furnished with green granules identical with the green colouring matter of plants. At the base of the cylindrical body is a kind of disc-shaped sucker, with which the animal attaches itself to a foreign body. Its favourite position is that of hanging head downwards from the stem of a water-plant; it is not, howerer, permanently fixed, but is able to detach itself, and change its place at will. The aperture of the mouth is placed at the opposite extremity of the body; from five to fifteen small tubular filaments surround it, which are called " tentacles ;" each one consists of a tubular prolongation of the ectoderm and endoderm; it encloses a canal which at its base opens into the general cavity of the body. The ectoderm of the tentacles are well supplied with muscular fibres, and is richly furnished with thread-cells. They are retractile to such an extent, that they sometimes appear like small warts or tubercles, and can appear in some species several times larger than the body itself. They are the means whereby the Hydra obtains its food, which consists of minute aquatic organisms, such as small worms, insects, Crustacea, and Rotifera. They are drawn into 
the mouth, having been first seized by the tentacles. These seem to exercise an influence which is sometimes even fatal to the animals which they seize; this appears to be owing to the thread-cells. The mouth opens at once into a capacious cylindrical cavity, which is both the body-cavity and the stomach, and excavated along the entire length of the body. Water derived from the exterior and also the nutritive particles of the food fill this cavity. It is asserted that an anal aperture exists, but indigestible matters appear to be rejected by the mouth; there are no internal organs. The Hydra, therefore, presents little advance upon the higher Protozoa. It possesses, however, a permanent mouth, which is surrounded by special organs adapted to secure its food; there is besides a permanent cavity for the reception of the food, which is not shut off from the general cavity of the borly. These animals are not provided with any organ for the propulsion of the nutritive fluid through the body, and they do not possess any nervous system or organs of sense, and have no special respiratory or excretory organs. The essentially low position of the Hydra in the animal scale is shown in its great capacity of resisting mutilation or mechanical injury of any kind short of absolute annihilation. Trembley, of Geneva, discovered that the Hydra could be divided with a knife into fragments ; each and all of these possessed the power of developing themselves into a fresh and independent polype. Further, without any injury to the animal, it could be turned inside out, causing a transposition of the ectoderm and endoderm, and this without any apparent inconvenience or interference with its health.

Reproduction in the Hydra is effected non-sexually by gemmation, and sexually by the production of ovi and sperm-cells. Few individuals appear to survive 
the winter; the former process is followed in summer, and the latter in the autumn months. In the first case the Hydra throws out one or more buds, usually from the fixed end. These buds, which at first consist only of a tubular prolongation of the ectoderm and endoderm, enclose a cavity which communicates with the general cavity of the body. At the distal end of this bud a new mouth and tentacles are soon developed, and after a certain period is detached to lead an independent life. Reproduction is rapidly carried on, as each Hydra can produce many such buds during the summer season, and the liberated buds can also repeat the same process. In the second method of reproduction, towards the winter, ova and sperm cells are produced iu external processes of the body-wall. Near the bases of the tentacles the spermatozoa are found, developed in little conical elevations; near the fixed or proximal extremity of the animal there are some larger elevations, in which the ova are formed. When the ovum is mature, it is fertilized by the sperm-cells, and both by the rupture of the body-wall are set free into the water. When the embryo Hydra meets with a suitable locality, being covered with vibrating cilia, it fixes itself by one extremity, a mouth and tentacles develop themselves, and the cilia drop off.

In the second order of the hydroid zoophytes, Corynida, or Tubularia, there are many organisms closely related to the Hydra in their essential structure, although in the reproductive process there is a considerable difference. With the exception of the genus Cordylophora, which is found in fresh water, they are all marine. Some of the members consist of only a single polypite. The polypite is permanently fixed, without power to change its place; there is, however, 
a close approach to the structure of the common Hydra; there is considerable difference in the reproductive process. The hydrosoma is compound in the majority of the Corynida; it consists of a number of separate polypites, or zoöids, which all form parts of a root-like colony, and are connected with one another by a common flesh, or cœnosarc. In most cases the cœnosarc is protected by a horny-looking chitinous envelope, or polypary, but in some the polypites are naked. This horny covering, however, is in no case so prolonged as to form little cups, each containing a polypite. It is always found to stop at the bases of the polype, thus rendering it easy to distinguish the Corynida from the Sea Firs, to which they are closely allied. The common Pipe Coralline may be taken as a good example of the Corynida. Here we have a gregarious zoophyte inhabiting most of our British seas, consisting of numerous clustered horny tubes fired by their bases to shells or stones; the tubes are often considerably woven together, and usually branched; each gives exit at its distal extremity to a single polypite, and is filled with a soft, semi-fluid, reddish conosarc. The polypites are not retractile within their tubes, and are of a bright red colour; the horny polypary extends only to their bases; they are furnished with two sets of tentacles, the mouth being placed at the apex of the cone, and are somewhat conical in shape. One set of tentacles consists of numerous short ones, placed directly round the mouth; the other, which arises from the polypite about its middle or near its base; is composed of from thirty to forty tentaculæ of much greater length. At proper seasons the generative buds are produced near the insertion of the tentacles. The essential structure of 
the branched Pipe Coralline (Endendrium) is much the vame as I'ubularia; but the hydrosoma, which consists of a number of non-retractile reddish polypites, united by a cœnosarc which is furnished with a horny polypary, is truly compound. The whole colony now assumes a close resemblance to a plant.

We find in Cordylophora the only freshwater member of the order - a branched composite hydrosoma, carrying many polypites; a horny sheath defends the cœnosarc. We have a type of Corynida in Coryomorpha; here there is no polypary, and the hydrosoma consists of only a single polypite. It is fixed to the bottom of the sea by roots, which are filamentous, and is about four inches in length. It consists of a whitish pink striped, and terminates upwards in a pear-shaped head, having two sets of tentacles. When the animal is young the body is enclosed in a thin membranous tube; this appears to have no organic connection with the animal itself, and in some full-grown specimens is entirely wanting. It may be as well to consider the general phenomena of reproduction as carried on by all the hydroid zoophytes, the characters of the process in the Corynida being of a most remarkable nature. The individual in the case of the compound Hydrozoa consists of an aggregation, produced by gemmation or fission, of partially independent beings or zoöids, as in the case of composite animals, sponges, seamats, corals, and others; but in the case of the compound Hydrozoa the case is still more complicated, as in many of these organisms the zoöids differ much from each other in structure and function. The nutritive zoöids all resemble each other, or they are homomorphic, and the whole assemblage has been called "trophosome."

The third order, Sertularia, contains the Sea Firs 
and their allies. The polyparies are known to every visitor at the seaside, and are set down as seaweeds. The Sertularida are allied to the compound forms of the Corynida. As in the Tubularians, the whole cœnosare is enveloped in a horny polypary, which is well known to seaside observers. The Sertularida differ from the Corynida in two points. The Sertularida are simple, consisting of poly-

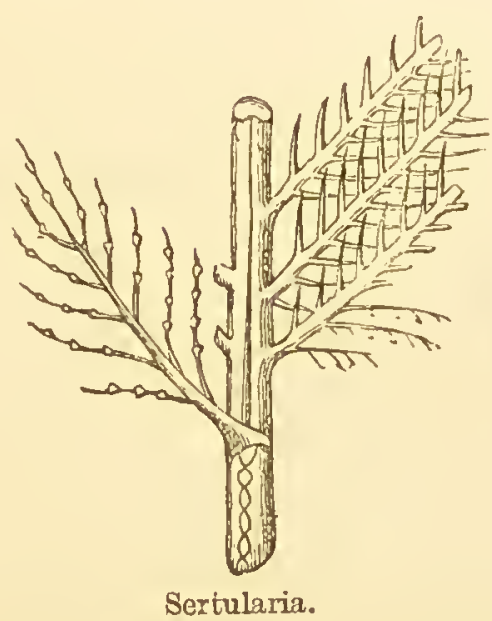
pites united by a branched cœnosarc, and the polypary differs in being prolonged to form a number of little cups, within which the polypites are lodged. Each polypite has its own hydrotheca, within which it can entirely withdraw and protrude its distal extremity. 


\section{Kingdom-ACRITA.}

TN this lowest division of the animal kingdom, or sepa1 rate kingdom, as Mr. Hogg and Professor Owen have classified it, the nervous system is not distinctly discernible, whence the name (from not discernible) is given. The alimentary canal is not separated from the parietes of the body, nor contained in a distinct abdominal cavity. It is divisible into the classes, Rhizopoda, Polycystina, Spongida, Thalissicolida, Gregarinide, and Infusoria.

The Acrita include a number of animals of simple organisation, many of which have until recently been associated with the lower members of the vegetable kingdom. In the substance of the bodies of most Acrita there is to be found a minute solid particle known as the nucleus, and certain clear spaces which have been termed contractile vesicles.

True sexual reproduction has not been proved to have taken place. In habits they are aquatic, and the greater part of the species are minute.

The Amoba may be taken as a type of Rhizopoda. It is a common animal, found in most ponds or infusions, looking like a globular mass of semi-transparent jelly destitute of any organisation. The helpless being soon commences to show signs of life by pushing out in various directions portions of the jelly-like substance of which its body is composed. It presents the 
simplest form of organic life, and is typically represented by a miscroscopic particle of sarcole, or mucogelatinous organic matter, possessing within itself the power of growth, of assimilation of extraneous circumstances, of movement by means of irregular and everchanging offshoots from itself, variable processes, and capable of multiplication by the severance of portions of itself, and probably of development by internal germs or gemmules. They present no definite constant figure, although it is possible to distinguish different $A$ mabce by the more frequent outline they present, and by the length or figure of the pseudopodia. The general opinion was that the sarcode of which they consist is naked and homogeneous; but Auerbach has alleged that they are all enclosed within an integument. A movement of granules is perceptible, especially along the margins of the variable processes. A nucleus with a nucleolus is believed to be generally present; vacuoles are almost always distinguishable, and one, two, or even more contractile vesicles have been seen in some specimens. There seems evidence of the process of encysting taking place under certain conditions. Ehrenberg described Amœbo as polygastric animalcules having a mouth but no alimentary canal, and moving by various processes produced from any part of the body indifferently. The power of. selection which the Amoba possesses is slight as regards food, as inorganic particles are frequently ingested with its more proper food. Sometimes the budy appears as a mere transparent film, investing the swallowed substance. Those portions of the food which are indigestible ure pushed out through some part of the gelatinous mass. Any part of the body is capable of performing the functions of locomotion, digestion, \&c. The running 
Rhizopods differ slightly from Amaba in structure. The body is composed of surcode, and movement is perforned by means of pseudopodia. The "Sun" animalcule is closely allied to Amoba; the form of its body is a depressed sphere, furnished with a number of filiform pseudopodia, radiating in all directions; these are usually longer than the diameter of the body, and less mutable than the same parts in Amœba. The Actinophrys, when magnified, is very curious, and the way it takes food is very peculiar. In this species of Rhizopoda the body is completely naked. The Rhizcpoda are divided into two classes, Amobea and Foraminifera. The first may be subdivided into Amobina, including naked-bodied Rhizopods, viz. Amoba, Actinophrys, Pamphagus, and Arcellina, of which Diffugia and Arcella are examples.

The Foraminifera differ from Amceba in being invested with a shell, which is

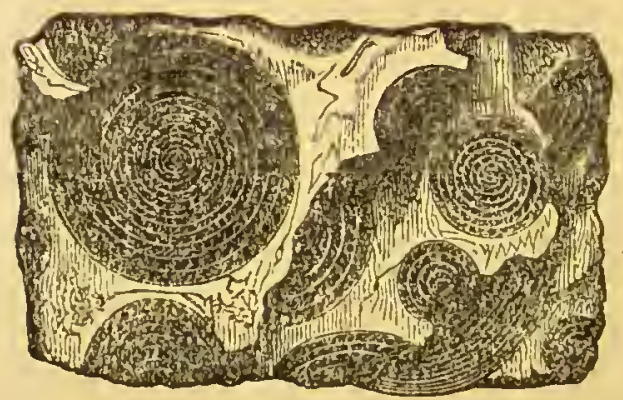

Nummulite. sometimes in one, but is generally united by minute apertures. In some the body is bright red.

The unilocular Foraminifera is an intermediate group between Polythatamia and Arcellina, the form Gromia scarcely differing in form from Difflugia or Arcella. Lagena is a good example of these Rhizopods, which may be known from its flesh-like shell.

Entosolenia is like Lagena, with the tubular neck inserted into the hollow interior of the shell.

Among the Polythalamia, the modifications of the shell are numerous. In Foraminifera, in addition to 
the terminal orifice, there is an external surface, perforated, through which parts of the body may be pro-, truded. In Gromia and a few other forms the shell is somervhat membranous, whilst in Proteonina it is aranaceous. These, however, are exceptional instances, since in the greater number of Foraminifera the shell

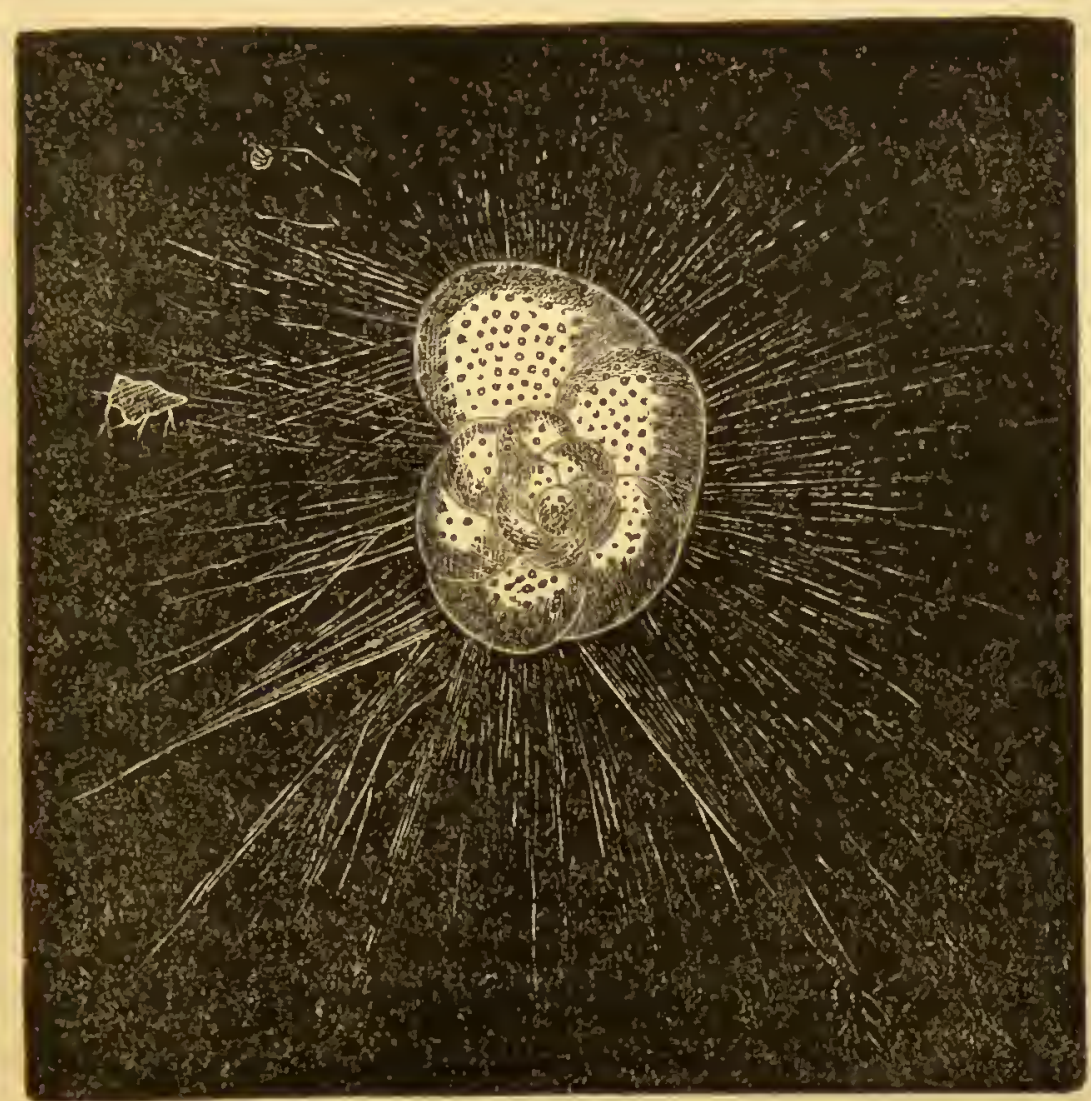

Foraminifer.

is evidently calcareous, presenting various degrees of consistence.

In Lagena it is hyaline, but in Miliolina and its allies it becomes unusually opaque, so as nearly to resemble white porcelain. In newly formed segments the shell is usually deficient in thickness. By far the greater number of Foraminifera are marine. They are found in 
all seas, proferring, however, those of southern or tropical climates.

The Spongidio are another and largo form of Acrita. Composed of horny elastic fibres, they have becn considered by many to be members of the vegetable kingdom. The dry spongo is, however, tho skeleton only of the fabric. In its original state cvery filament was conted with a thin film of glairy scmifluid mattcr, which constitntes the living part of the sponge, and secretcs the horny fibres which are imbedded in it. Some of the species have the skeleton strengthened by the addition of calcareous or siliceous spicula. The soft, gelatinous flesh is an agrregation of ammbiform bodies. The spicula have determinate forms, and all sponges of the same specics have spicule of the same shape, a character which leads to the identification of specics. Fossil flints are moroly petrificd sponges, as their microscopical examination roveals a variety of organisms which exhibit the unchanged spiculie of the original sponge. If a spongo be mechanically divided into severnl portions each becomes a distinct animal. The living substance of the sponge appears to be made up of agglomerations of amorphons Ameber, spread over the spicular or skeloton of the sponge. Each of these Amabe, or spongc-sholls, is about the thousandth part of an inch in diamotor. It is composed of a gelatinous cell-wall, having a number of granules fixed to its upper and inner surface, and with a few hyaline resiclcs perceptiblc towards the centre.

It has becn wcll said (Athenem, March 28, 1868): "Analogy of the phenomena of convertible modes of operation of the polar forco loads us to conclude that the difference between snot and sarcode, betwecn passive and active states of mucus, is due to a conversion of 
attractive or other mode of polar force into the mode called 'assimilative,' organic, or vital."

The Polycystina have a minute group of shell-bearing animals, apparently allied to the Foraminifera, from which they differ by their smaller size and the composition of their shelly coat, which is siliceous and not calcified. These shells are very beautiful, and in forms are various, but the spinous projections with which they are generally adorned give them a peculiar appearance. The animal itself consists of an olive-brown sarcode substance, capable of protruding pseudopodia through the numerous foramina perforated in the shell. The sarcode body is divided into four equal lobes, and does not fill the entire cavity of the shell, but would seem to be wholly confined to the upper portion of the shell.

Polycystina are widely distributed; their shells with others have been found to form part of the extensive organic deposit which is now being formed over a portion of the bed of North America. They are found in nearly every existing ocean. They appear, however, to have been more numerous than at present, as their remains have been discovered in both the Second and Tertiary formations. Nearly three hundred apparently distinct forms of these animals have been found in a Tertiary deposit in the island of Barbadoes.

The Thalassicolidæ are gelatinous bodies which are destitute of structure, have no determinate form, and are without the power of voluntary motion. They are usually found floating near the surface of the water. They vary in size from an inch: downwards. The Acanthometræ are closely allied to the Thalassicolidæ, but are of much smaller size. Some of the Thalassicolidæ have been considered to be referable to the dia- 
tomaceous group of vegetables. The Acanthometræ have siliceous radiating spines. Carpenter defines the sarcode substance as being composed of an albuminoid base with oil particles in a state of very fine division diffused through it ; it is tenacious, extensible, and contractile; it is diaphanous, reflecting light more than water, but less than oil ; and it is dissolved by alkalies, rendered transparent by acetic acid, and dyed brown by iodine. In the midst of this substance are usually to be seen vacuoles or cavities containing a thinner fluid, which is often coloured; these are extremely variable both in number and size, and their deficiency in any definite limiting walls is rendered obvious by their not unfrequent coalescence.

Under the order Gregarinæ a group of microscopic organisms have been placed, which are essentially diverse from all other acritan forms. They are only known as parasites within the bodies of other animals, especially amongst the Annulosa. Many Gregarinæ have a projecting process by which these animals are able to attach themselres more firmly to the surface of objects. The Gregarinæ are colourless. Their manner of propagation is remarkable. Two Gregarinæ come into contact, and a capsule forms around them both; next, certain globular vesicles are produced in the interior of the capsule, or cyst, and these after a time become separate bodies. The combination of two Gregarinæ is not, however, necessary, as the formation is sometimes found within the bodies of the single animals.

The Psorospermice are parasitic creatures which are found inside fishes; they are ovate in form, and have fish-like tails.

The class Infusoria are the most important amongst Acrita. If water in contact with organic matter is 
exposed to the atmosphere, it will be probably found to contain a considerable number and variety of living objects. These were divisible into two groups-one which exhibits great affinity to the Articulata subkingdom, and has been termed Rotifera; and one which was called Polyyastrica. But it has been demonstrated that the organisation of the Rotifera is of a far higher nature than had been suspected by Ehrenberg, and that the Polygastrica may be defined as a heterogeneous assemblage of minute, organised beings, chiefly consisting, according to Reay Greene, of Rbizopoda, unicellular and other Algce, embryonic forms, and true Infusoria. The class has been defined as animals belonging to the department of Acrita, provided with a mouth and rudimentary digestive apparatus. Their bodies usually consist of three distinct layers, the outer of which is in most cases furnished with a variable number of cilia. The well-known Vorticella is a campanulate Acrite furnished with a variable number of cilia, and with a flexible pedicle spirally contractile. It adheres to water-plants, insects, small crustacea, cyclopes, \&c. At a certain period they part from the stem, and then as freely moving forms are provided with cilia near the posterior extremity, by means of which they move forward, whilst the coronet of cilia at the edge of the opening is entirely retracted. By the rapid motion of its vibratile cilia, the Vorticella is enabled to create currents in the surrounding water, by the means of which any alimentary particles that may be floating therein are brought into the neighbourhood of the vestible. Some of these are rejected, whilst others are quickly propelled by the ciliuted cosopbagus into the pharynx, where they usually remain until a sufficient number become aggregated into a single lump. 'Though 
usually fixed, the Vorticella is sometimes observed to detach itself and swim slowly about in the surrounding water. It has the faculty, when alarmed, of contracting its stalk into a series of spiral folds, and of again causing it to resume its erect position, both of these movements being performed with great rapidity.

The Infusoria vary much in size, the greatest portion being microscopic. In all those forms of which the animal nature is beyond doubt, the mouth is universally present, though the position of this organ varies considerably among the different members of the group. The mouth is often surrounded by cilia. In some species urticating organs have been found. Propagation among the Infusoria is effected by fission, gemmation, encystation, or true reproduction. They are abundantly distributed over most parts of the globe, nor does there appear to be any remarkable difference between the Infusoria of temperate or tropical climes.

THE END. 


\section{SCIENTIFIC WORKS.}

\section{The Reign of Law.}

- By the Duke of Argyct. Crown 8vo, 6s. People's Edition (sixteenth). limp clorh, 2s. 6 d.

"There are few books in which a thoughtful reader will find more that he will desire to remember." 7 inles.

"Shows a breadth of thought, a freedom from prejudice, and a power of clear exposition rare in all ages and all countries. It is as unanswerable as it is attractive."Pall Mall Gazette.

"A masterly book. . . . Strong, sound, mature, able thought from its first page to its last."-Spectator.

\section{Primeval Man :}

An Examination of Some Recent Speculations. By the Duke of

ARGrul. Third Edition. Crown 8vo, 4s. 6d.

"This is perhaps the most clear, graceful, pointed, and precise piece of ethical reasoning published for a quarter of a century. Its great end is to show that it is impossible to pursue any investigation of man's history from the purely physical side. Its reasoning seems as absolutely conclusive against the upholders of the 'natural selection' theory. The book is worthy of a place in every libraly, as skilfully popularising science, and yet sacrificing nothing either of its dignity or of its usefuness." -Nonconformist.

\section{Climate and Time in their Geological Relations:}

A Theory of Secular Changes of the Earth's Climate. By Jusrs CroLt, of H.M. Geological Survey. With Illustrations. Demy ชro, 248.

"The most important work on geological events and changes which has appeared for many yeris." --Stanilarl.

"It will rank alongside 'Lyell's Principles,' and secure the reputation of its author." - Geographical Magazine.

"Sure to find a place in evers geologist's library."-Scotsman.

\section{Dictionary of Manufactures, Mining, Machinery,} and the Industrial Arts. By George Dodn, Author of "British Manuluctures." Post 8vo, 5s.

\section{The Seaside Naturalist :}

Outdoor Studies in Marine Zoology, Botany, and Maritime Geology. By the Rev. R. W. Fraser, M.A., Author of "Curiosities of the Seashore," \&c. With 60 Illustrations, by Wolf, Zwecker, G. H. Andrews, and others. Crown 8vo, 3s. 6d.

\section{The Great Ice Age, and its Relation to the An-} tiquity of Man. By Jam ES GEIKLe, F.R.S.E., of H.M. Geological Survey. With Maps, Charts, and numerous Illustrations. Demy 8vo, 24s.

"This book will mark an epoch in the scientific study of the Ice Age."-Saturday Review.

"We have indicated but imperfectly the philosophical spirit which marks every step of the inquiry, and we strongly recommend the volume to all." - Athenaum.

\section{Popular Lectures on Scientific Subjects.}

By the late sir Jorn F. W. Herochel, Bart. Eighth 'Thousand.

Crown 8ro, 6 s.

"A book of most profound and romantic scicutific charm."-Spectator. 


\section{SCIENTIFIC WORKS.}

\section{Geology for Students and General Readers.}

Timbodying the most Recent Theorics and Discoveric4. By A. IT.

Grens, M.A., Professor of Gcology and Mining in the Yorkshire

College of Sciencc.

In the press.

Part I.-The Elcments of Physical Geology, with upward of 100 Illustrations ly the Author. Demy 8 vo.

l'art II. -The Elements of Stratigraphical Geology, with upwards of 100 Illustrations by the Author. Demy 8 vo.

\section{Town Geology.}

By the Rev. Cinarles Kingsiey. Fourth Thousand. Crown 8vo, 53.

"A masterpiece of popular scientific exposition."-Fcho.

"The author here compresses within the briefest compass the results of many" ycars" thought and observation, and illustrates his facts and suggestions with singular felis't $y$ of languagc. Not ercn Professor Huxley could convey scientific information in a stylc more straightforward and transparent."-Pall Mall Gazette.

\section{God's Glory in the Heavens :}

A Survey of Recent Astronomical Dis:overy and Speculation in connection with the Religious Questions to which they give rise. By WrLi.IA Lritcir, D.D., late Principal of Queen's College, Canada. With numerous Illustrations. Fourth Edition. Crown 8ro, cloth extra, 4s. (id.

"We cannot conclude our notice of Dr. Leitch's book without dwelling upon the admirable manner in which the astronomical facts contrined in it are blended with practical observations and the higlest and most ennobling sentiments. It is thus that books on popular science should erer be written."-Reader.

\section{Optics.}

Light and Sight Theoretically and Practically Treated, with their application to Fine Art and Industrial Pursuits. By E. Nugext, C.E. New Edition, with a Chapter on Spectrum Analysis. With numerous Illustrations. Post 8ro, 5̄.

\section{Dictionary of Scientific Terms.}

By P. Austin Nuttall, LL.D. Post 8vo, 5 s.

"We do not know any other book that fills the place of the present one, and this dues its work well."-Euinburgh Daily Review.

\section{The Creation.}

'The Earth's Formation on Dynamical Principles, in accordance with the Mosaic Record and the latest Scientific Discoreries. By Archibald T. Ritchie. Demy 8vo, 18 .

\section{Our Inheritance in the Great Pyramid.}

By Professor C. Piazzi Smxти, Astronomer Royal for Scotland. New and Enlarged Edition, including all the most important Discorerics up to the Present 'I'ime. With 17 Explanatory Plates. Post Sro, 18s. 


s.:
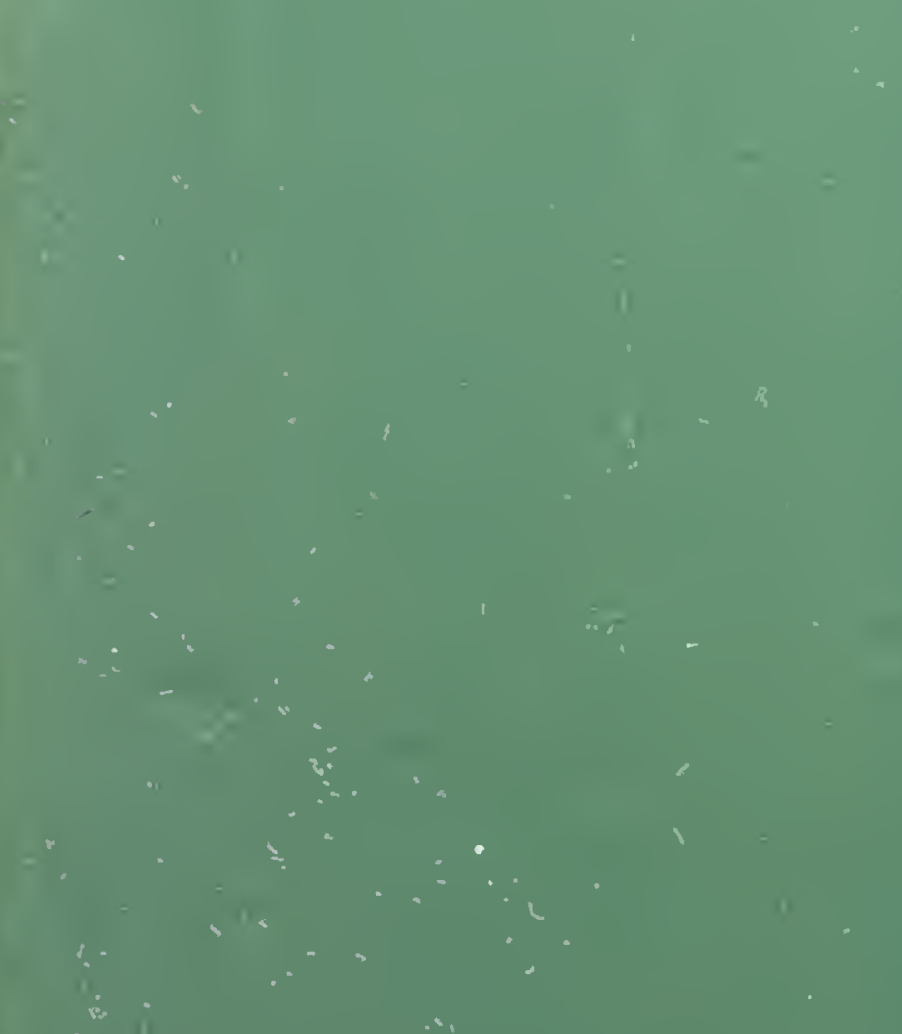

$-+$
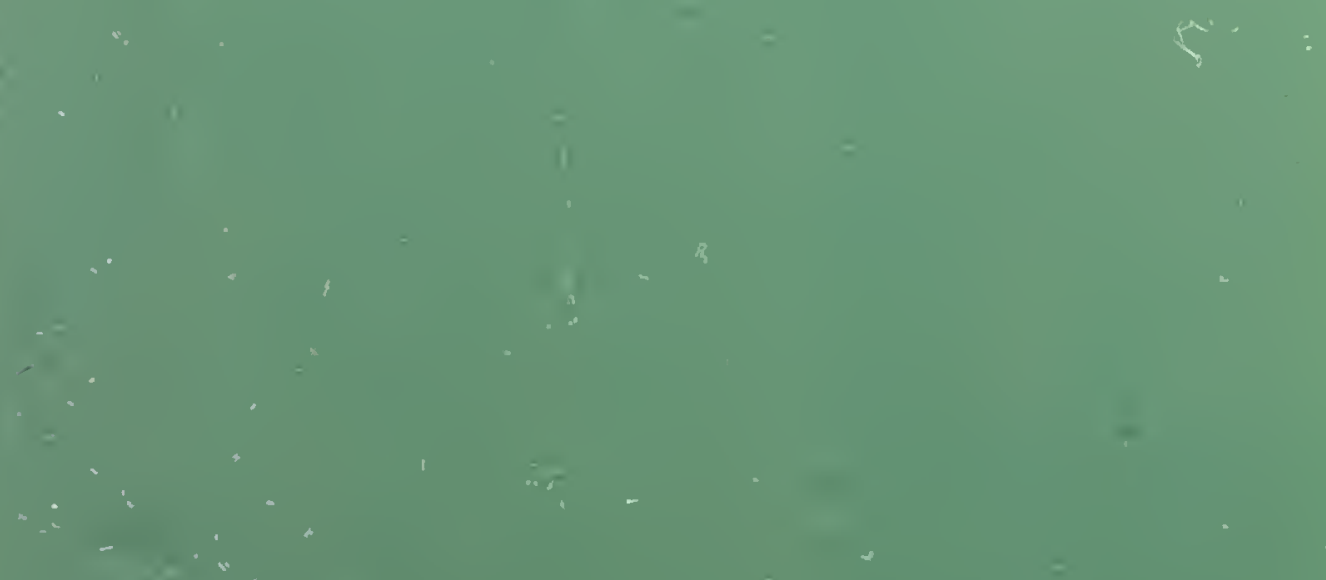

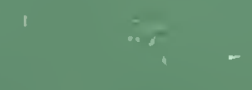

$\underset{\infty}{\infty}+4$

$\times 1$

$=+\cdots$

-

.

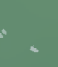

i)

$=$

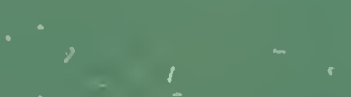

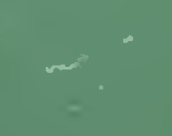

$\sim$

$+\ldots$,

$\cdot+\frac{1}{.+2}$

$=$
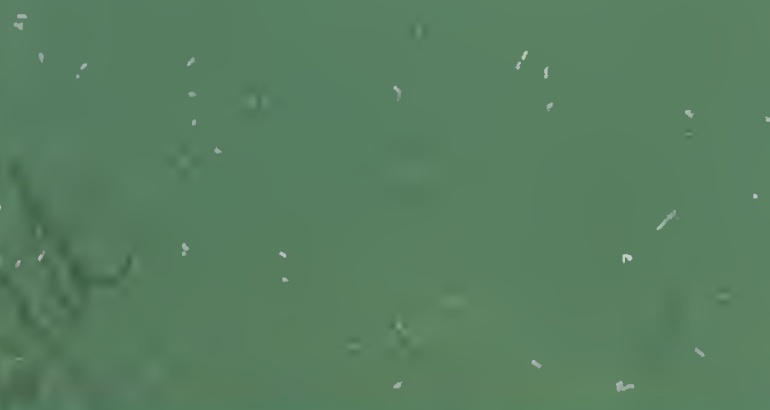

$\infty=$

$-\quad \therefore$

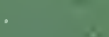

r 
